\title{
ONTARIO HIGH SCHOOL
}

BEGINNERS' ZOOLOGY

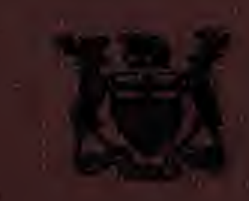

\section{AUTHORI2:D $\mathrm{gY}$}

TE MINISTER OE EDUCATHON

* FOR ONTMRIO

PRICE 75 CENTS

THE MACMILI.AN CO. OF CANADA HIMTED 
if

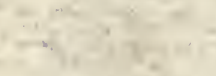

:
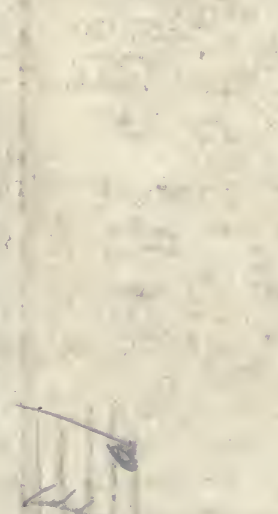

.

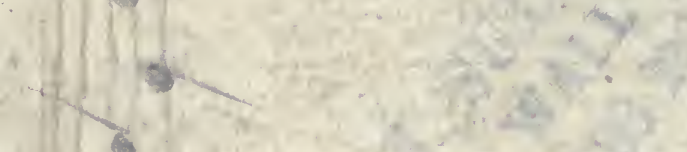

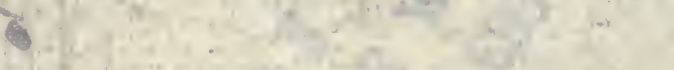

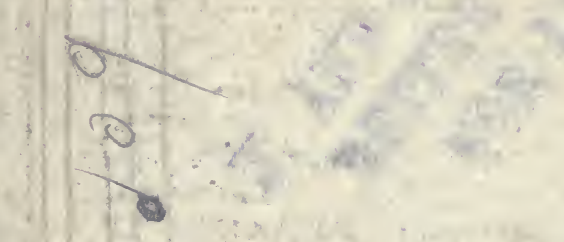

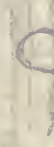

(1) 
Geo wochhart $2 C$. 



\section{BEGINNERS’ ZOOLOGY}

BY

WALTER M. COLEMAN

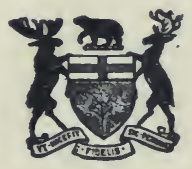

AUTHORIZED BY THE MINISTER OF EDUCATION FOR ONTARIO

TORONTO

THE MACMILLAN CO. OF CANADA, LIMITED 
Copyright, Canada, 1921

BY THE MACMILLAN COMPANY

OF CANADA, LIMITED 


\section{CONTENTS}

CHAPTER

PAGE

I. Introduction

II. Protozons . . . . . . . 10

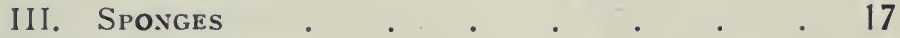

IV. Polips . . . . . . . . 22

V. EchINODERMS . . . . . 34

VI. WORMS . . . . . . . 42

Vil. Crustaceans . . . . . . 51

VIII. INSECTS . . . . . . . . 63

IX. Molluscs . . . . . . . 97

X. Fishes . . . . . . . 109

XI. Batrachians . . . . 126

XII. Reptiles . . . . . . . 139

XIII. BIRDS . . . . . . . . 150

XIV. Mammals . . . . . . . . 184 



\section{BEGINNERS'ZOOLOGY}

\section{CHAPTER I \\ THE PRINCIPLES OF BIOLOGY}

Biology (Greek, bios, life; logos, discourse) means the science of life. It treats of animals and plants. That branch of biology which treats of animals is called zoology (Gr. zoon, animal; logos, discourse). The biological science of botany (Gr. botane, plant or herb) treats of plants.

Living things are distinguished from the not living by a series of processes, or changes (feeding, growth, development, multiplication, etc.), which together constitute what is called life. These processes are called functions. Both plants and animals have certain parts called organs which iave each a definite work, or function; hence animals and plants are said to be organized. For example, men and most other animals have a certain organ (the mouth) for taking in nourishment; another (the food tube), for its digestion.

Because of its organization, each animal or plant is said to be an organism. Living things constitute the organic kingdom. Things without life and not formed by life constitute the inorganic, or mineral, kingdom. Mark I for inorganic and $\mathrm{O}$ for organic after the proper words in this list: granite, sugar, lumber, gold, shellac, sand, coal, paper, glass, starch, copper, gelatine, cloth, air, potatoes, alcohol, oil, clay. Which of these things are used for food by animals? Conclusion? 
Energy in the Organic World. - We see animals exerting energy; that is, we see them moving about and doing work. Plants are never seen acting that way; yet they need energy in order to form their tissues, grow, and raise themselves in the air.

Source of Plant Energy. - We notice that green plants thrive only in the light, while animal growth is largely independent of light. In fact, in the salt mines of Poland there are churches and villages below the ground, and children are born, become adults, and live all their lives below ground, without seeing the sun. '(That these people are not very strong is doubtless due more to want of fresh air and other causes than to want of sunlight.)
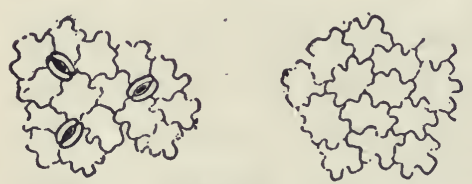

FIG. I. - SURFACES OF A LEAF, magnified.

The need of plants for sunlight. shows that they must obtain something from the sun. This has been found to be energy. This enables them to lift their stems in growth, and form the various structures called $t$ issues which make up their stems and leaves. It is noticed that they take in food and water from the soil through their roots. Experiments also show that green plants take in through pores (Fig. 1), on the surface of their leaves, a gas composed of carbon and oxygen, and called carbon dioxide. The energy in the sunlight enables the plant to separate out the carbon, of the carbon dioxide and to build mineral and water and carbon

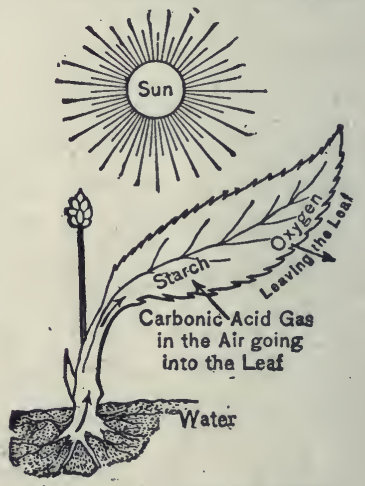

FIG. 2. - A LEAF STORING ENERGY IN SUNLIGHT. 
into organic substances. The oxygen of the carbon dioxide is set free and returns to the air (Fig. 2). Starch, sugar, oil, and woody fibre are examples of substances thus formed. Can you think of any fuel not due to plants?

How Animals obtain Energy. - You have noticed that starch, oil, etc., will bum, or oxidize, that is, unite with the oxygen of the air; thus the sun's energy, stored in these substances, is changed back to heat and motion. The oxidation of oil or sugar may occur in a furnace; it may also occur in the living substance of the active animal.

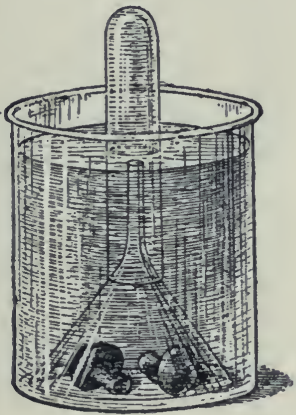

Fig. 3.-Colourless plants, as MushRooms, give off no oxygen.

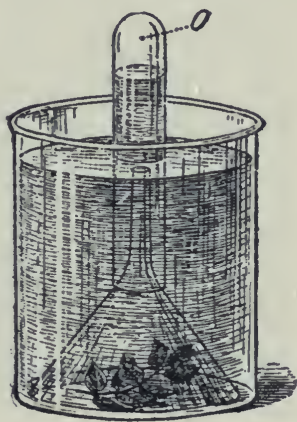

A GREEN I.EAF, even after it is cut, gives off oxygen $(O)$ if kept in the sun.

Fortunately for the animals, the plants oxidize very little of the substances built up by them, since they do not move about nor need to keep themselves warm. We notice that animals are constantly using plant substances for food, and constantly drawing the air into their bodies. If the sunlight had not enabled the green plant to store up these substances and to set free the oxygen (Fig. 3), animals would have no food to eat nor air to breathe; hence we may say that the sunlight is indirectly the source of the life and energy of animals. Mushrooms and other plants without green matter cannot set oxygen free (Fig. 3). 
Experiment to show the Cause of Burning, or Oxidation. - Obtain a large glass bottle (a pickle jar), a short candle, and some matches. Light the candle and put it on a table near the edge, and cover it with the glass jar. The flame slowly smothers and goes out. Why is this? Is the air now in the jar different from that which was in it before the candle was lighted? Some change must have taken place or the candle would continue to burn. To try whether the candle will burn again under the jar without changing the air, slide the jar to the edge of the table and let the candle drop out. Light the candle and slip it up into the jar again, the jar being held with its mouth a little over the edge of the table to receive the candle (Fig. 5). The flame goes out at once. Evidently the air in the jar is not the same as the air outside. Take up the jar and wave it to and fro a few times, so as to remove the old air and admit fresh air. The candle now burns in it with as bright a flame as at first. So we conclude that the candle will not continue to burn unless there is a constant supply of fresh air. The gas formed by the burning is carbon dioxide. It is the gas from which plants extract carbon.' (Beginners' Botany, Chap. XIII.) One test for the presence of this gas is that it forms a white, chalky cloud in lime water; another is that it smothers a fire.

Experiment to show that Animals give cff CarbonDioxiclc. - Place a cardboard over the mouth of a bottle containing pure air. Take a long straw, the hollow stem of a weed, a glass tube, or a sheet of stiff paper rolled into a tube, and pass the tube into the bottle through a hole in the cardboard. Without drawing in a deep breath, send one long breath into the bottle through the tube, emptying the lungs by the breath as nearly as possible (Fig. 4). Next, invert the bottle on the table as in the former experiment, 
afterward withdrawing the cardboard. Move the bottle to the edge of the table and pass the lighted candle up into it (Fig. 5). Does the flame go out as quickly as in the former experiment?

If you breathe through a tube into clear lime water, the water turns milky. The effect of the breath on the candle and on the lime water shows that carbon dioxide is continually leaving our bodies in the breath.

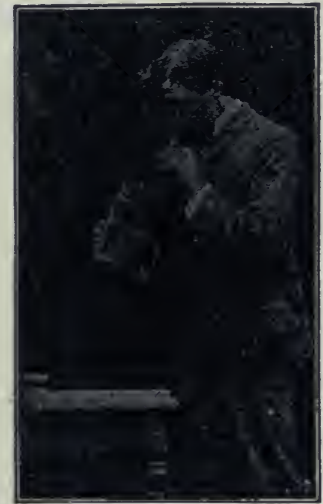

FIG. 4. - Breathing into a bottle.1

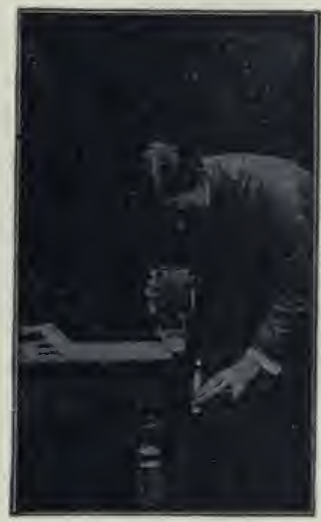

FIG. 5. - Testing the air in the bottle. 1

0xidation and Deoxidation. - The union of oxygen with carbon and other substances, which occurs in fires and in the bodies of animals, is called oxidation. The separa. tion of the oxygen from carbon such as occurs in the leaves of plants is called deoxidation. The first process sets energy free, the other process stores it up. Animals give off carbon dioxide from their lungs or gills, and plants give off oxygen from their leaves. But plants need some energy in growing, so oxidation also occurs in plants, but to a far less extent than in animals. At night, because of the absence of sunlight, no deoxidation is taking place 
in the plant, but oxidation and growth continue; so at night the plant actually breathes our some carbon dioxide. The deepest part of the lungs contains the most carbon dioxide. Why was it necessary to empty the lungs as nearly as possible in the experiment with the candle? Why would first drawing a deep breath interfere with the experiment? Why does closing the draught of a stove, thus shutting off part of the air, lessen the burning? Why does a "firefly" shine brighter at each breath? Why is the pulse and breathing faster in a fever?. Very slow in a trance?

The key for understanding any animal is to find how it gets food and oxygen, and how it uses the energy thus obtained to grow, move, avoid its enemies, and get more food. Because it moves, it needs senses to guide it.

The key for understanding a plant is to find how it gets food and sunlight for its growth. It makes little provision against enemies; its food is in reach, so it needs no senses to guide it. The plant is built on the plan of having the nutritive activities near the surface (e.g. absorption by roots; gas exchange in leaves). The animal is built on the plan of having its nutritive activities on the inside (e.g. digestion; breathing).

Cell and Protoplasm. - Both plants and animals are composed of small parts called cells. Cells are usually microscopic in size. They have various shapes, as spherical, flat, cylindrical, fibre-like, star-shaped. The living substance of cells is called protoplasm. It is a stiff, gluey fluid, albuminous in its nature. Every cell has a denser spot or kernel called a mucleus, and in the nucleus is a still smaller speck called a nucleolus. Most cells are denser and tougher on the outside, and are said to have a cell wall, but many cells are naked, or without a wall. Hence the indispensable part of a cell is not the wall but the nucleus, 
and a cell may be defined as a bit of protoplasm containing a mucleus. This definition includes naked cells as well as cells with walls.

One-celled Animals. - There are countless millions of animals and plants the existence of which was not suspected until the invention of the microscope several centuries ago. They are one-celled, and hence microscopic in size. It is believed that the large animals and plants are descended from one-celled animals and plants. In fact, each individual plant or animal begins life as a single cell, called an egg cell, and forms its

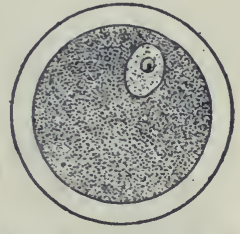

FIG. 6. - Egg cell of mammal with yolk. organs by the subdivision of the egg cell into many cells. An egg cell is shown in Fig. 6, and the first stages in the development of an egg cell are shown in Fig. 7.

The animals to be studied in the first chapter are onecelled animals. To understand them we must learn how
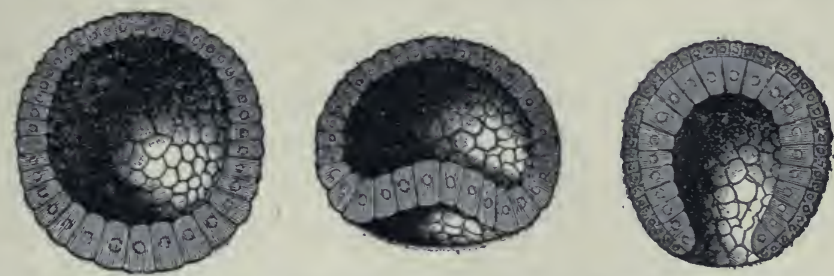

FIG. 7. - Egg cell subdivides into many cells forming a sphere (morula) containing a liquid. A dimple forms and deepens to form the next stage (gastrula).

they eat, breathe, feel, and move. They are called Protozoans (Greek protos, first, and zoon). All other animals are composed of many.cells and are called Metazoans (Greek meta, beyond or after). The cells composing the mucous membrane in man are shown in Fig. 8. The cellular structure of the leaf of a many-celled plant is illustrated in Fig. I. 
Method of Classifying Animals. - The various animals display differences more or less marked. The question arises, are not some of them more closely related than others? We conclude that they are, since the difference between some animals is very slight, while the difference between others is quite marked.

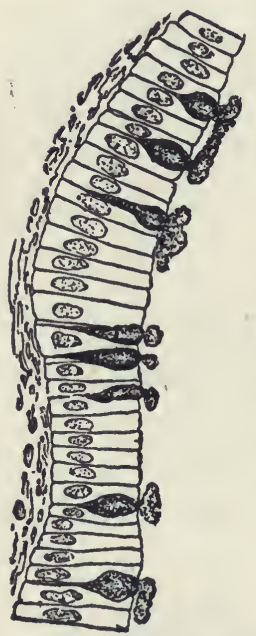

Fig. 8. - MUCóUs MEMBRANE formed of one layer of cells. A few cells secrete mucus.

To show the different steps in classifying an animal, we will take an example, - the cow. Even little children learn to recognize a cow, although individual cows differ somewhat in form, size, colour, etc. The varieties of cows, such as short-horn, Jersey, etc., all form one species of animals, having the scientific name taurus. Let us include in a larger group the animals closest akin to a cow. We see a cat, a bisor., and a dog; rejecting the cat and the dog, we see that the bison has horns, hoofs, and other similarities. We include it with the cow in a genus called Bos, calling the cow Bos taurus, and the bison, Bos bison. The sacred cow of India (Bos indicus) is so like the cow and the buffalo as also to belong to the genus Bos. Why is not the camel, which, like Bos bison, has a hump, placed in the genus Bos?

The Old World buffaloes, - most abundant in Africa and India, - the antelopes, sheep, goats, and several other genera are placed with the genus Bos in a family called the hollow-horned animals.

This family, because of its even number of toes and the habit of chewing the cud, resembles the camel family, 
the deer family, and several other families. These are all placed together in the next higher systematic unit called an order, in this case, the order of ruminants.

The ruminants, because they are covered with hair and nourish the young with milk, are in every essential respect related to the one-toed horses, the beasts of prey, the apes, etc. Hence they are all placed in a more inclusive division of animals, the class called mammals.

All mammals have the skeleton, or support of the body, on the inside, the axis of which is called the vertebral column. This feature also belongs to the classes of reptiles, amphibians, and fishes. It is therefore consistent to unite these classes by a general idea or conception into a great branch of animals called the vertebrates.

Returning from the general to the particular by successive steps, state the branch, class, order, family, genus, and species to which the cow belongs.

The Eight Branches or Sub-kingdoms. - The simplest classification divides the whole animal kingdom into eight branches, named and characterized as follows, beginning with the lowest: I. Protozonans. One-celled. II. Sponges. Many openings. III. Polyps. Circular; cup-like; having only one opening which is both mouth and vent. IV. Echinoderms. Circular; rough-skinned; two openings. V. Molluscs. No skeleton; usually with external shell. VI. Vermes. Elongate body, no jointed legs. VII. ARthropods. External jointed skeleton; jointed legs. VIII. Vertebrates. Internal jointed skeleton with axis or backbone. ${ }^{1}$

1 This is the briefest classification. Animals have also been divided into twelve branches. The naming of animals is somewhat chaotic at present, but an attempt to come to an agreement is now being made by zoölogists of all nations. 


\section{CHAPTER II}

\section{PROTOZOA (One-celled Animals)}

\section{The Амсва}

Suggestions. - Am œbas live in the slime found on submerged stems and leaves in standing water, or in the ooze at the bottom. Water plants may be crowded into a glass dish and allowed to decay, and after about two weeks the amœba may be found in the brown slime scraped from the plants. An amœba culture sometimes lasts only three days. The most abundant supply ever used by the writer was from a bottle of water where some oats were germinating. Use $\frac{1}{5}$ or $\frac{1}{6}$ inch objective, and cover with a thin cover glass. Teachers who object to the use of the compound microscope in a first course should require a most careful study of the figures.

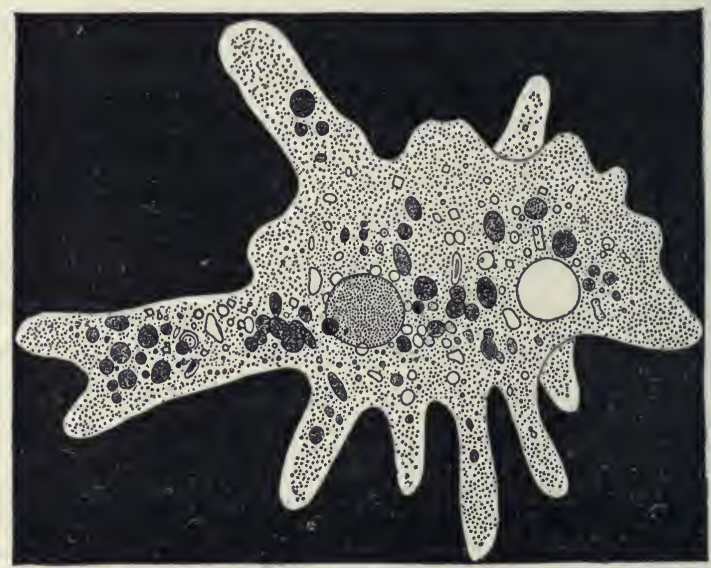

Fig. 9-Amcв BA Protens, much enlarged. 
Form and Structure. - The amoba looks so much like a clear drop of jelly that a beginner cannot be certain that he has found one until it moves. It is a speck of protoplasm (Fig. 9), with a clear outer layer, the ectoflasm; and a granular, internal part, the endop'asm. Is there a distinct line between them? (Fig. 10.)

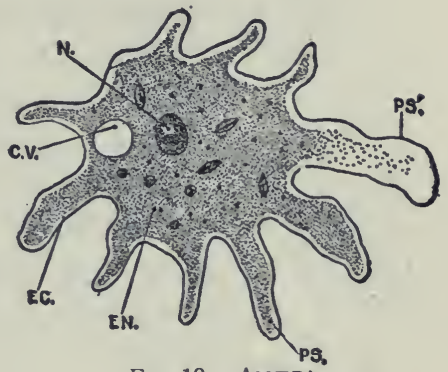

FIG. 10.-Амсв BA.

Note the central portion and the slender prolongations or pseudopods (Greek,

$c v$, contractile vacuole; $e c$, ectoplasm; $e n$, endoplasm; $n$, nucleus; $p s$, pseudopod; $p s$, pseudopod forming; ectoplasm protrudes and endoplasm flows into it. false feet). Does the endoplasm extend into the pseudopods? (Fig. 10.) Are the pseudopods arranged with any regularity?

Sometimes it is possible to see a denser appearing portion, called the nucleus; also a clear space, the contractile vacuole (Fig. IO).

Movements. - Sometimes while the pseudopods are being extended and contracted, the central portion remains
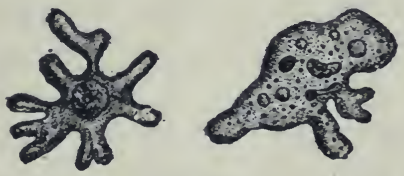

FIG. 11.-The same amœba seen at different times. in the same place (this is motion). Usually only one pseudopod is extended, and the body flows into it; this is locomotion (Fig. I I). There is a new foot made for each step.

Feeding.- If the amœba crawls near a food particle, the pseudopod is pressed against it, or a depression occurs (Fig. I2), and the particle is soon embedded in the endoplasm. Often a clear space called a food vacuole is noticed around the food particle. This is the water that is taken in with 


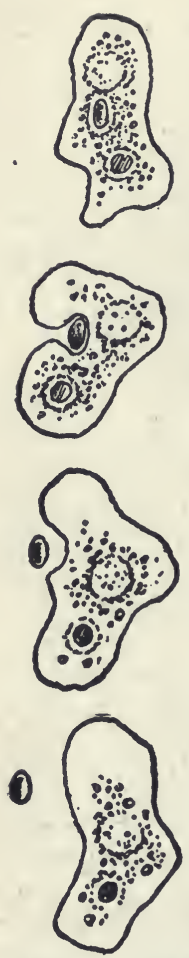

FIG. 12. - THE AMar BA taking food.

the particle (Fig. 12). The water and the particle are soon absorbed and assimilated by the endoplasm.

Excretion. - If a particle of sand or other indigestible matter is taken in, it is left behind as the amœba moves on. There is a clear space called the contractile vacuole, which slowly contracts and disappears, then reappears and expands (Figs. 9 and 10). This possibly aids in excreting oxidized or useless material.

Circulation in the amœba consists of the movement of its protoplasmic particles. It lacks special organs of circulation.

Feeling.-Jarring the glass slide seems to be felt, for it causes the activity of the amœba to vary. It does not take in for food every particle that it touches. This may be the beginning of taste, based upon mere chemical affinity. The pseudopods aid in feeling.

Reproduction. - Sometimes an amœba is seen dividing into two parts. A narrowing takes place in the middle; the nucleus also divides, a part going to each portion (Fig. 13). The mother amœba finally divides into two daughter amœbas. Sex is wanting.

Source of the Amoeba's Energy -We thus see that the amœba moves without feet, eats without a mouth, digests without a stomach, feels without nerves, and, it should also be stated, breathes without lungs, for oxygen is absorbed from the water by its whole

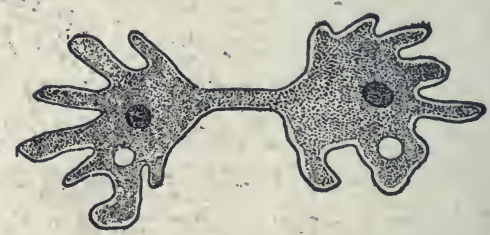

FIg. 13.-Амсва, Dividing. 
surface. Its movements require energy; this, as in all animals, is furnished by the uniting of oxygen with the food. Carbon dioxide and other waste products are formed by the union;these pass off at the surface of the amoba ard taint the water with impurities.

Questions.-Why will the amœba die in a very small quantity of water, even though the water contains enough food? Why will it die still quicker if air is excluded from contact with the drop of water?

The a mœba never dies of old age. Can it be said to beimmortal?

According to the definition of a cell (Chapter I), is the amoba a unicellular or multicellular animal?

Cysts. - If the water inhabited by a protozoan dries up, it encysts, that is, it forms a tough skin called a cyst. Upon return of better conditions it breaks the cyst and comes out. Encysted protozoans may be blown through the air: this explains their appearance in vessels of water containing suitable food but previously free from protozoans.

\section{The Slipper Animalcule or Paramecium}

SUgGestions.- Stagnant water often contains the paramecium as well as the amœba; or they may be found in a dish of water containing hay or finely cut clover, after the dish has been allowed to stand in the sun for several days. A white film forming on the surface is a sign of their presence. They may even be seen with the unaided eye as tiny white particles by looking through the side of the dish or jar. Use at first a $\frac{1}{3}$ or $\frac{1}{4}$ in. objective. Restrict their movements by placing cotton fibres beneath the cover glass; then examine with $\frac{1}{5}$ or $\frac{1}{6}$ objective. Otherwise, study figures.

Shape and Structure. - The paramecium's whole body, like the amoba's, is only one cell. It resembles a slipper in shape, but the pointed end is the hind end, the front end being rounded (Fig. I4). The paramecium is propelled by the rapid beating of numerous fine, threadlike append- 
ages on its surface, called cilia (Latin, eyelashes) (Figs.). The cilia, like the pseudopods of the amœba, are merely

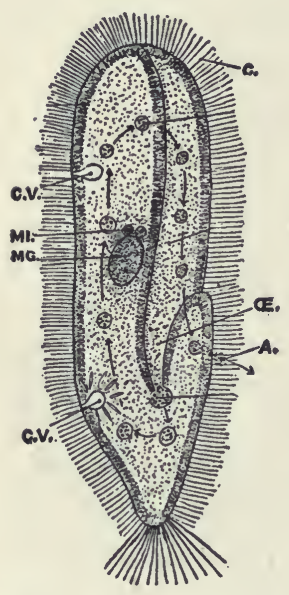

FIG. I4. - PARAMECIUM, showing cilia, $c$.

Two contractile vacuoles, $c v$; the macronucleus, $m g$ : two micronuclei, $m i$; the gullet $(E)$, a food ball forming and ten food balls in their course from gullet to vent, $a$. prolongations of the cell protoplasm, but they are permanent. The separation between the outer ectoplasm and the interior granular endoplasm is more marked than in the amœba (Fig. I4).

Nucleus and Vacuoles. $\rightarrow$ There is a large nucleus called the macronucleus, and beside it a smaller one called the micronucleus. They are hard to see. About one third of the way from each end is a clear, pulsating space (bb. Fig. I5) called the pulsating vacuole. These spaces contract until they disappear, and then reappear, gradually ex-

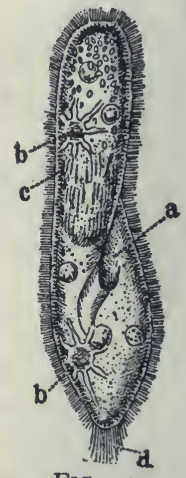

FIG. I5.

panding. Tubes lead from the vacuoles which probably serve to keep the contents of the cell in circulation.

Feeding. - A depression, or groove, is seen on one side; this serves as a mouth (Figs.). A tube which serves as a

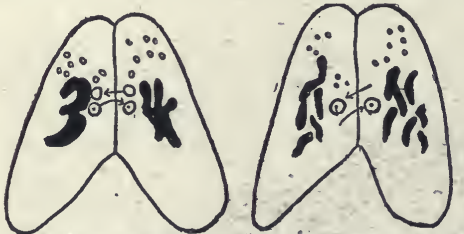

FIG. 16. - TWO.PARAMECIA exchanging parts of their nuclei. gullet leads from the mouth-groove to the interior of the cell. The mouth-groove is lined with cilia which sweep food particles inward. The particles accumulate 
in a mass at the inner end of the gullet, become separated from it as a food ball (Fig. I4), and sink into the soft protoplasm of the body. The food balls follow a circular course through the endoplasm, keeping near the ectoplasm.

Reproduction.-This, as in the amœba, is by division, the constriction being in the middle, and part of the nucleus going to each half. Sometimes two individ-

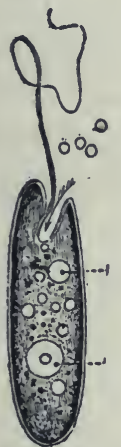
uals come together with their mouth-grooves touching and exchange parts of their nuclei (Fig. 16). They then separate and each divides to form two new individuals.

We thus see that the paramecium, though of only one

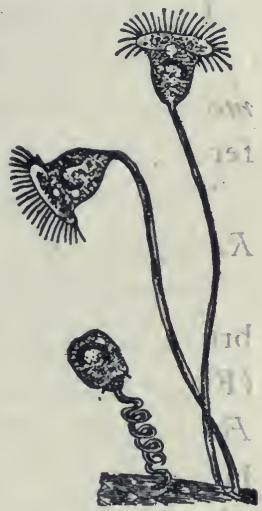

FIG. I7. - VORTICELla (or bell animalcule), two extended, one withdrawn. cell, is a much more complex and advanced animal than the amoba. The tiny paddles, Fig. 18. - or cilia, the mouth-groove, etc., have their Euglena. special duties similar to the specialized organs of the many-celled animals to be studied later.

If time and circumstances allow a prolonged study, several additional facts may be observed by the pupil, e.g. Does the paramecium swim with the same end always foremost, and same side uppermost? Can it move backwards? Avoid obstacles? Change shape in a narrow passage? Does refuse Fig. rg. - SHell of A Radiolarian.

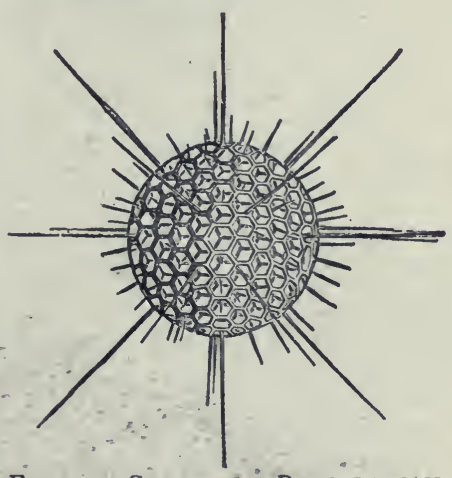


matter leave the body at any particular place? Trace movement of the food particles.

Draw the paramecium.

Which has more permanent parts, the amoba or paramecium? Name two anatomical similarities and three differences; four functional similarities and three differences.

The amoba belongs in the class of protozoans called Rhizopoda "root footed."

Other classes of Protozoans are the Infusorians (in the broad sense of the term), which have many waving cilia (Fig. I7) or one whip-like flagellum (Fig. I8), and the Foraminifers, which possess a calcareous shell pierced with holes (Fig. 19). Much chalky limestone has been formed of their shells. To which class does the paramecium belong?

Protozoans furnish a large amount of food to the higher animals. 


\section{CHAPTER III}

\section{SPONGES}

Suggestions.-In many parts of North America, fresh-water sponges may, iy careful searching. be found growing on rocks and logs in clear water. They are brown, creamy, or greenish in colour, and resemble more a cushion-like plant than an animal. They have a characteristic gritty feel. They soon die after removal to an aquarium.

A number of common small bath sponges may be bought and kept for use in studying the skeleton of an ocean spenge. These sponges should not have large holes in the bottom; if so, too much of the sponge has been cut away. A piece of marine sponge preserved in alcohol or formalin may be used for showing the sponge with its flesh in place. Microscopic slides may be used for showing the spicules.

The small fresh-water sponge (Fig. 2I) lacks the more or less vase-

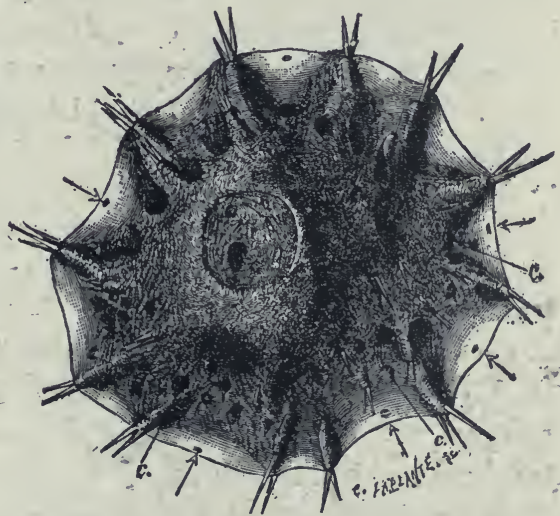

- Fig. 21. - Fresh-WATER SPONGe. like form typical of sponges. It is a rounded mass growing upon a rock or a log. As indicated by the Arrows, where does

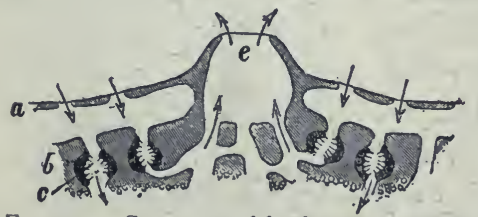

FiG. 22. - SECTION of fresh-water sponge (enlarged). water enter the sponge? This may be tested by putting colour ing matter in the water near the living sponge. Where does the water come out? (Fig. 22.) Does it pass through ciliated chambers in its course? Is the 
surface of the sponge rough or smooth? Do any of the skeletal spicules show on the surface? (Fig. 21.) Does the sponge thin out near its edge?

The egg of this sponge is shown in Fig. 23. It escapes from the parent sponge through the osculum, or large outlet. As in

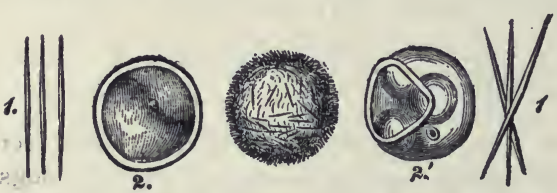

FIG. 23. - EGGS and SPICULES of fresh-water sponge (enlarged).

most sponges, the first stage after the egg is ciliated and free-swimming.

Marine Sponges. The grantia (Fig. 24) is one of the simplest of marine sponges. What is the shape of grantia? What is its length and cliameter? How does the free end differ from the fixed end? Are the spicules projecting from its body few or many?

Where is the osculum, or large outlet? IVith what is this surrounded? The osculum opens from a central cavity called the cloaca. The canals from the pores lead to the cloaca.

Buds are sometimes seen growing out from the sponge near its base. These are young sponges formed asexually. Later they become detached from the parent sponge.

Commercial "Sponge." - What part of the complete animal remains in the bath sponge? Slow growing sponges grow more at the top and form tall, simple, tubular or vase-like animals. Fast growing sponges

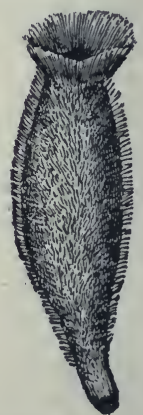

FIG. 24. Grantia. grow on all sides at once and form a complicated system of canals, pores, and oscula. Which of these habits of growth do you think

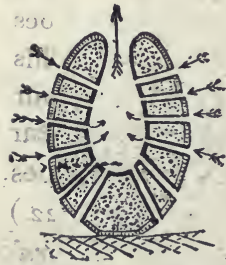

FIG. 25:- Plan of a sponge. belonged to the bath sponge? Is there a large hole in the base of your specimen? If so, this is because the cloaca was reached in trimming the lower part where it was attached to a rock. Test the elasticity of the sponge when dry and when wet by squeezing it. Is it softer when wet or dry? Is it more elastic when wet or dry? How many oscula does your specimen have? How many inhalent pores to a square inch? 
Using a probe (a wire with knob at end, or small hat pin), try to trace the canals from the pores to the cavities inside.

Do the fibres of the sponge appear to interlace, or join, according to any system? Do you see any fringe-like growths on the surface which show that new tubes are beginning to form? Was the sponge growing faster at the top, on the sides, or near the bottom?

Burn a bit of the sponge; from the odour, what would you judge of its composition?

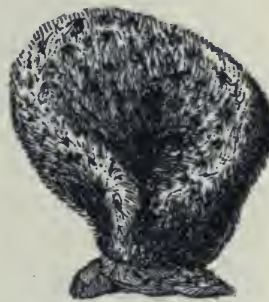

FIG. 26. - Bath Sponge. Is the inner cavity more conspicuous in a simple sponge or in a compound sponge like the bath sponge? Is the bath sponge

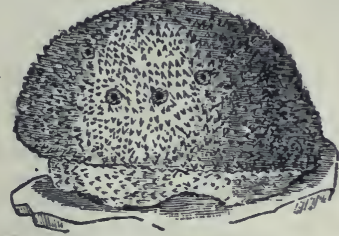

FIG. 27. - Bath Sponge.

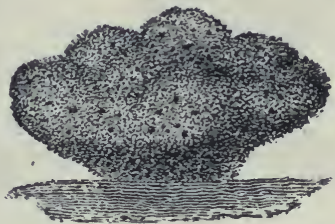

FiG. 28. - Bath Sponge.

branched or lobed? Compare a number of specimens (Figs. 26, 27,28 ) and decide whether the common sponge has a typical

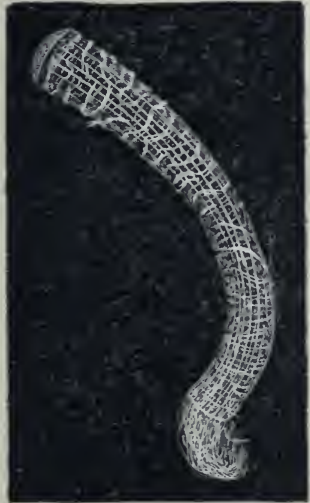

FIG. 29. - Skeleton of a glass sponge. shape. What features do their forms possess in common?

Sponges are divided into three classes, according as their skeletons are flinty (silicious), limy (calcareous), or horny.

Some of the silicious sponges have skeletons that resemble spun glass in their delicacy. Flint is chemically nearly the same as glass. The skeleton shown in Fig. 29 is that of -a glass sponge which lives near the Philippine Islands.

The horny sponges do not have spicules in their skeletons, as the flinty and - limy sponges have, but the skeleton is-composed of interweaving fibres of 
spongin, a durable substance of the same chemical nature as silk (Figs. 30 and $3 \mathrm{I}$ ).

The limy sponges have skeletons made of numerous spicules of lime. The three-rayed spicule is the commonest form.

The commercial sponge, seen as it grows in the ocean, appears as a roundish mass with a smooth, dark exterior, and having about the consistency of beef liver. Several large openings (oscula), from which the water flows, are visible on the upper surface. Smaller holes (inhalent pores - many of them so small as to be indistinguishable) are on the sides. If the sponge is disturbed,

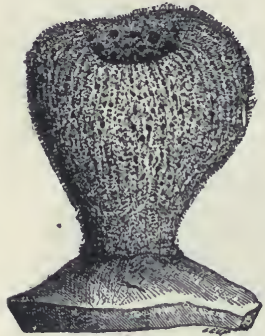

FiG. 30. - A horny sponge.

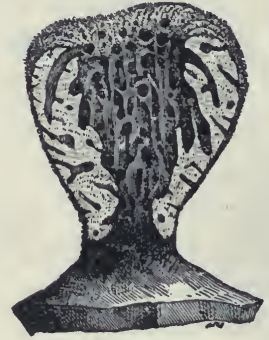

F1G. 3I. - Section of horny sponge. the smaller holes, and perhaps the larger ones, will close.

The outer layer of cells serves as a sort of skin. Since so much of the sponge is in contact with water, most of the cells do their own breathing, or absorption of oxygen and giving off of carbon dioxide. Nutriment is passed on from the surface cells to nourish the rest of the body.

Reproduction. - Egg-cells and sperm-cells are produced by certain cells along the canals. The egg-cell, after it is fertilized by the sperm-cell, begins to divide and form new cells, some of which possess cilia. The embryo sponge passes out at an osculum. By the vibration of the cilia, it swims about for a while. It afterwards settles down with the one end attached to the ocean floor and remains fixed for the rest of its life. The other end develops oscula. Some of the cilia continue to vibrate and create currents which bring food and oxygen.

The cilia in many species are found only in cavities called ciliated chambers. (Figs. 22, 32.) There are no distinct organs in the sponge and there is very little specialization of cells. The ciliated cells and the reproductive cells are the only specialized cells. The sponges were for a long time considered as colonies of separate one-celled animals classed as protozoans. They are, 
without doubt, many-celled animals. If a living sponge is cut into pieces, each piece will grow and form a complete sponge.

That the sponge is not a colony of one-celled animals, each like an a mœba, but is a many-celled animal, will be realized by examining Fig. 32, which shows a bit of sponge highly magnified. A sponge may be conceived as having developed from a one-celled animal as follows: Several one-celled animals happened to live side by side; each possessed a thread-like flagellum ( $\mathrm{E}$, Fig. 32) or whip-lash for striking the water. By lashing the water, they caused a stronger current (Fig. 25) than protozoans living singly could cause. Thus they obtained more food and multiplied more rapidly than those living alone. The habit of working together left its impress on the cells and was transmitted by inheritance.

Cell joined to cell formed a ring; ring

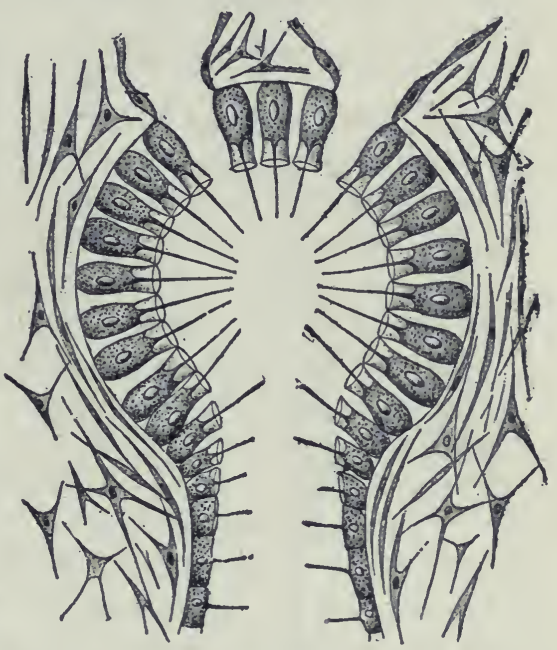

FIG. 32. - Microscopic plan of ciliated chamber. Each cell lining the chamber has a nucleus, a whip-lash, and a collar around base of whip-lash. Question: State two uses of whip-lash.

joined to ring formed a tube which was still more effective than a ring in lashing the water into a current and bringing fresh food (particles of dead plants and animals) and oxygen.

Few animals eat sponges; possibly because spicules, or fibres, are found throughout the flesh, or because the taste and the odour are unpleasant enough to protect them. Small animals sometimes crawl into sponges to hide. One sponge grows upon shells inhabited by hermit crabs. Moving of the shell from place to place is an advantage to the sponge, while the sponge conceals and thus protects the crab.

Special Report: Sponge "Fisheries." (Localities; how sponges are taken, cleaned, dried, shipped, and sold.) 


\section{CHAPTER IV}

\section{POLYPS (CUPLIKE ANIMALS)}

\section{The Hydra, or Fresh-Water Polyp}

Suggestions. - Except in the drier regions of North America the hydra can usually be found by careful search in fresh-water. ponds not too stagnant. It is found attached to stones, sticks, or leaves, and has a slender, cylindrical body from a quarter to half an

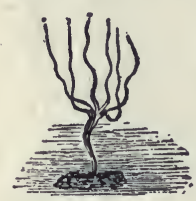

FIG. 33. -

A HYDRA. inch long, varying in thickness from that of a fine needle to that of a common pin. The green hydra and the brown hydra, both very small, are common species, though hydras are often white or colourless. They should be kept in a large glass dish filled with water. They may be distinguished by the naked eye but are not studied satisfactorily without a magnifying glass or microscope. Place a living specimen attached to a bit of wood in a watch crystal filled with water, or on a hollowed slip, or on a slip with a bit of weed to support the cover glass, and examine with hand lens or lowest power of microscope. Prepared microscopical sections, both transverse and longitudinal, may be bought of dealers in microscopic supplies. One is shown in Fig. 39.

Is the hydra's body round or twosided? (Fig. 35.) What is

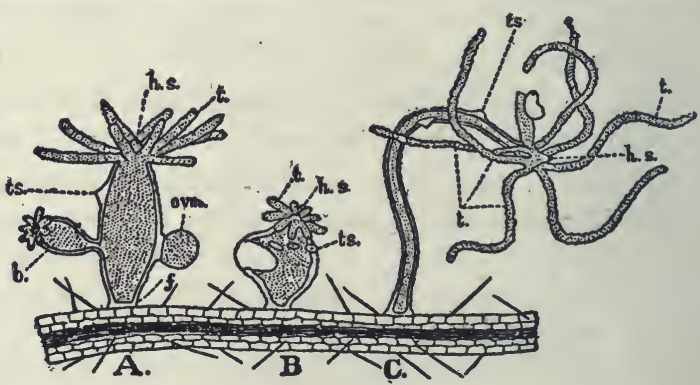

FIG. 34. - Forms assumed by Hydra. its general shape? Does one individual keep the same shape? (Fig. 34.) How does the length of the thread- 
like tentacles compare with the length of the hydra's body? About how many tentacles are on a hydra's body? Do all have the same number of tentacles? Are the tentacles knotty or smooth? (Fig. 35:) The hydra is usually extended and slender; sometimes it is contracted and rounded. In which of these conditions is the base (the foot) larger around than the rest of the body? (Fig. 34.) Smaller? How many openings into the body are visible? Is there a depression or an eminence at the base of the tentacles? For what is the opening on top of the body probably used? Why are the tentacles placed at the top of the hydra's body? Does the mouth have the most convenient location possible?

The conical projection bearing the mouth is called hypostome (Fig. 34). The mouth opens into the digestive cavity. Is this the same as the general

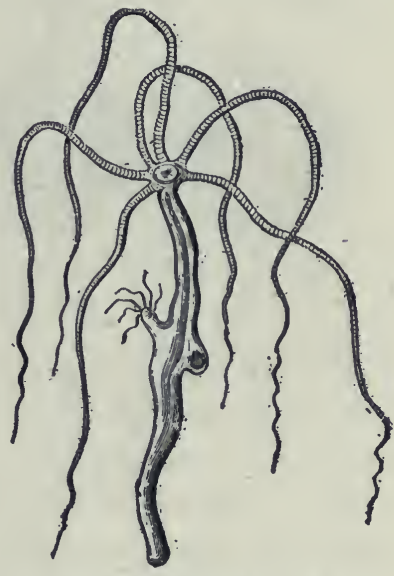

FIG. 35.- HYDRA (much enlarged). body cavity, or does the stomach have a wall distinct from the body cavity? How far down does the body cavity extend? Does it extend up into the tentacles? (Fig. 39.)

If a tentacle is touched, what happens? Is the body ever bent? Which is more sensitive, the columnar body or the tentacles? In searching for hydras would you be more likely to find the tentacles extended or drawn in? Is the hypostome ever extended or drawn in? (Fig. 34.)

Locomotion. - The round surface, or disk, by which the hydra is attached, is called its foot. Can you move on one foot without hopping? The hydra moves by alter. 
nately elongating and rounding the foot. Can you dis. cover other ways by which it moves? Does the hydra always stand upon its foot?

Lasso Cells. - Upon the tentacles (Fig. 35) are numerous cells provided each with a thread-like process (Fig. 36)

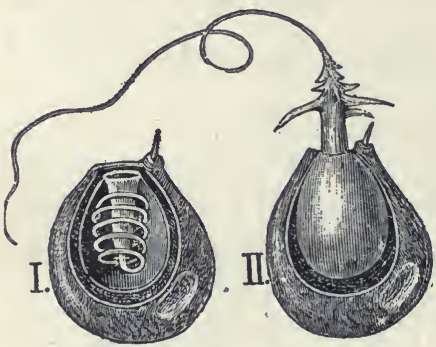

Fig. 36. - NeTtLing Cell.

II. discharged, and I. not discharged. which lies coiled within the cell, but which may be thrown out upon a water flea, or other minute animal that comes in reach. The touch of the lasso paralyzes the prey (Fig. 37). These cells are variously called lasso cells, nettling cells, or thread cells. The thread is hollow and is pushed out by the pressure of liquid within. When the pressure is withdrawn the thread goes back as the finger of a glove may be turned back into the glove by turning the finger outside in. When a minute animal, or other particle of food comes in contact with a tentacle, how does the tentacle get the food to the mouth? By bending and bringing the end to the mouth, or by shortening and changing its form, or in both ways? (Fig. 34, C.) Do the neighbouring tentacles seem to bend over to assist a tentacle in securing prey? (Fig. 34, C.)

Digestion. - The food particles break up before remaining

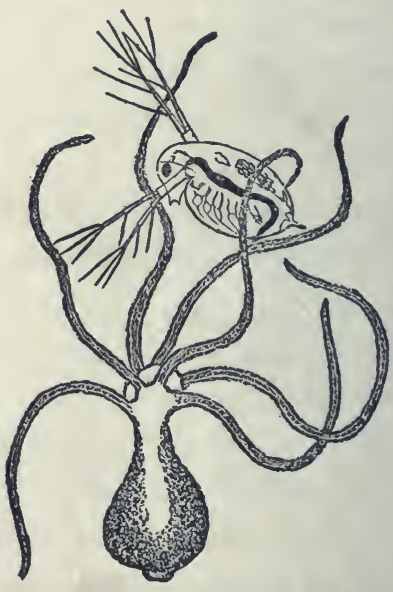

FIG. 37. - HYDRA capturing a water flea. 
long in the stomach, and the nutritive part is absorbed by the lining cells, or endoderm (Fig. 39). The indigestible remnants go out through the mouth. The hydra is not provided with a special vent. Why could the vent not be situated at the end opposite the mouth ?

Circulation and Respiration. - Does water have free access to the body cavity? Does the hydra have few or nearly all of its cells exposed to the water in which it lives? From its structure, decide whether it can breathe like a sponge or whether special respiratory cells are necessary to supply it with oxygen and give off carbon dioxide. Blood vessels are unnecessary for transferring oxygen and food from cell to cell.

Reproduction. - Do you see any swellings upon the

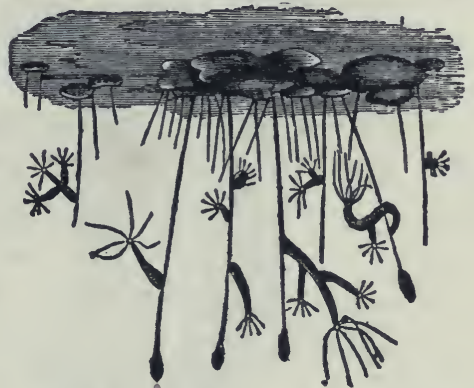

FIG. 38. - HYDRAS on the under surface of pondweed. side of the hydra? (Fig. 34, A.) If the swelling is near the tentacles, it is a spermary; if near the base, it is an ovary. A sperm coalesces with or fertilizes the ovum after the ovum is exposed by the breaking of the ovary wall. Sometimes the sperm from one hydra unites with the ovum of another hydra. This is called cross-fertilization. The same term is applied to the process in plants when the male element, developed in the pollen of the flower, unites with the female element of the ovule of the flower on another plant. The hydra, like most plants and some other animals, is hermaphrodite, that is to say, both sperms and ova are produced by one individual. In the autumn, eggs are produced with hard shells to withstand the cold until spring. Sexual reproduction takes place, when food is 
scarce. Asexual generation (by budding) is common with the hydra when food supply is abundant. After the bud

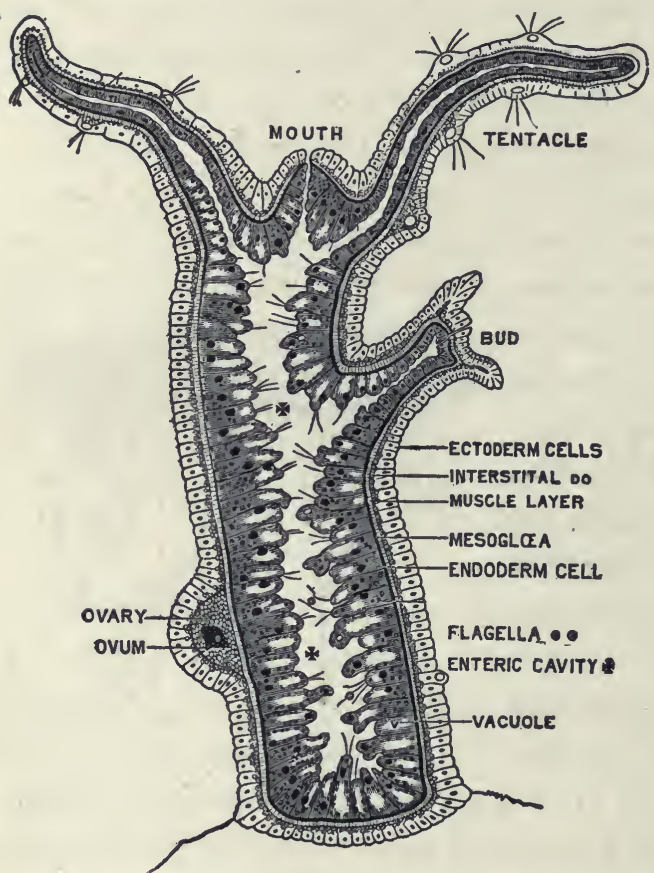

FIG. 39. - Longitudinal section of hydra (microscopic and diagrammatic). grows to a certain size, the. outer layer of cells at the base of the bud constricts and the young hydra is detached.

Compare the sponge and the hydra in the following respects: - many celled, or one celled; obtaining food; breathing; tubes and cavities; openings ; reproduction; locomotion. Which ranks higher among the metazoa? The metazoa, or many celled animals, include all animals except which branch?

Figure 39 is a microscopic vieze of a vertical section of a hydra to show the structure of the body wall. There is an outer layer called the ectoderm, and an inner layer called the endoderm. There is also a thin supporting layer (black in the figure) called the mesoglea. The mesoglea is the thinnest layer. Are the cells larger in the endoderm or the ectoderm? Do both layers of cells assist in forming the reproductive bud? 'The ectoderm cells end on the inside in contractile tails which form a thin line and have the effect of muscle fibres. They serve the hydra for its remarkable changes of shape. When the hydra is cut in pieces, each piece makes a complete hydra, provided it contains both endoderm and ectoderm. 
In what ways does the hydra show "division of labour"? Answer this by explaining the classes of cells specialized to serve a different purpose. Which cells of the hydra are least specialized? In what particulars is the plan of the hydra different from that of a simple sponge? An ingenious naturalist living more than a century ago, asserted that it made no difference to the hydra whether the ectoderm or the endoderm layer were outside or inside, - that it could digest equally well with either layer. He allowed a hydra to swallow a worm attached to a thread, and then by gently pulling in the thread, turned the hydra inside out. More recently a Japanese naturalist showed that the hydra could easily be turned inside out, but he also found that when left to itself it soon reversed matters and returned to its natural condition, that the cells are really specializad and each layer can do its own work and no other.

Habits. - The hydra's whole body is a hollow bag, the cavity extending even into the tentacles. The tentacles may increase in number as the hydra grows but seldom exceed eight. The hydra has more active motion than locomotion. It seldom moves from its place, but its tentacles are constantly bending, straightening, contracting, and expanding. The body is also usually in motion, bending from one side to another. When the tentacles approach the mouth with captured prey, the mouth (invisible without a hand lens) opens widely, showing five lobes or lips, and the booty is soon tucked within. A hydra can swallow an animal.larger in diameter than itself.

The endoderm cells have amoboid motion, that is, they extend pseudopods. They also resemble amœbas in the power of intra-cellular digestion; that is, they absorb the harder particles of food and digest them afterwards, rejecting the indigestible portions. Some of these cells have flagella (see Fig. 39) which keep the fluid of the cavity in constant motion.

Sometimes the hydra moves after the manner of a small caterpillar called a "measuring worm," that is, it takes hold first by the foot, then by the tentacles, looping its 


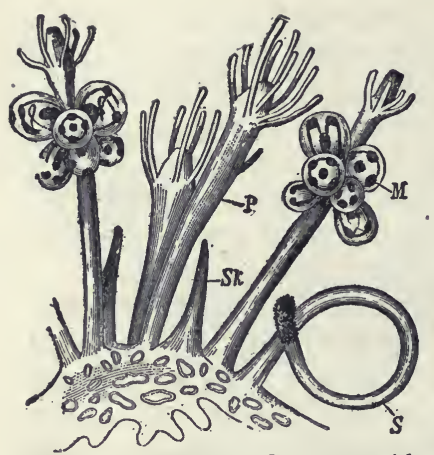

Fig. 40. - HYDroId Colony, with nutritive $(P)$ reproductive $(M)$ and defensive $(S)$ hydranths.

body at each step. Sometimes the body goes end over end in slow somersaults.

The length of the extended hydra may reach one half inch. When touched, both tentacles and body contract until it looks to the unaided eye like a round speck of jelly. This shows sensibility, and a few small star-shaped cells are believed to be nerve cells, but the hydra has not a nervous system. Hydras show their liking for light by moving to the side of the vessel or aquarium whence the light comes.

\section{The Branch Polyps} (sometimes called Colenterata). - The hydra is the chief fresh-water representative of this great branch of the animal kingdom. This branch is characterized by its members having only one opening to the body. The polyps also include the salt water animals called hydroids, jellyfishes, and coral polyps.

Hydroids. - Figure 40 shows a hydroid, or group of hydra-like growths, one of which

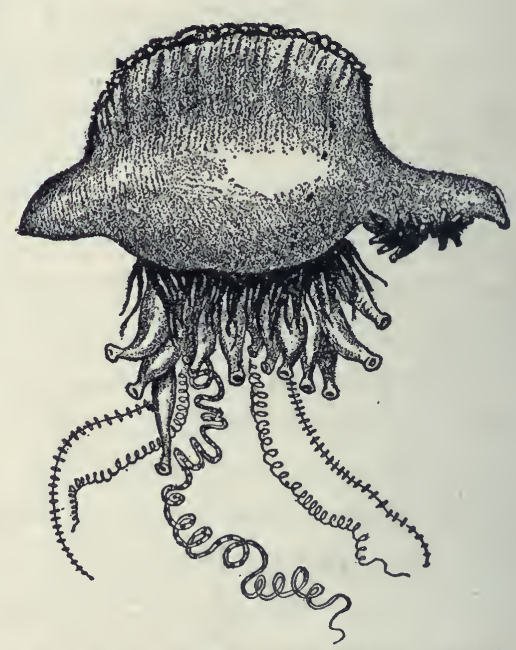

FIG. 4I. - "PORTUGUeSE MAN-O'-WAR" (compare with Fig. 40). A floating hydroid colony with long, stinging (and sensory) streamers. Troublesome to bathers in Gulf of Mexico. Notice balloon-like float. 
eats and digests for the group, another defends by nettling cells, another produces eggs. Each hydra-like part of a hydroid is called a hydranth. Sometimes the buds on the hydra remain attached so long that a bud forms upon the first bud. Thus three generations are represented in one organism. Such growths show us that it is not always easy to tell what constitutes an individual animal.

Hydroids may be conceived to have been developed by the failure of budding hydras to separate from the parent, and by

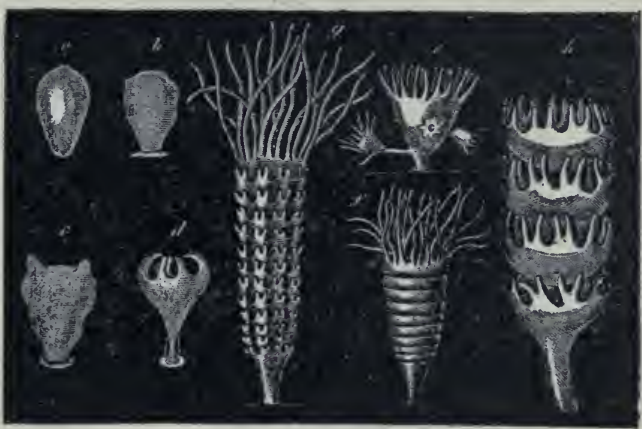

FIG. 42. - The formation of many free swimming jellyfishes from one fixed hydra-like form. The saucer-like parts $(h)$ turn over after they separate and become like Fig. 43 or 44 . Letters show sequence of diagrams. the gradual formation of the habit of living together and assisting one another. When each hydranth of the hydroid devoted itself to a special function of digestion, defence, or reproduction, this group lived longer and prospered; more eggs were formed, and the habits of the group were transmitted to a more numerous progeny than were the habits of a group where members worked more independently of one another.

As the sponge is a simple example of the devotion of special cells to special purposes, the hydroid is a primitive and simple example of the occurrence of organs, that is of special parts of the body set aside for a special work. 
How many mature hydranths are seen in the hydroid shown in Fig. 40? Why are the defensive hydranths

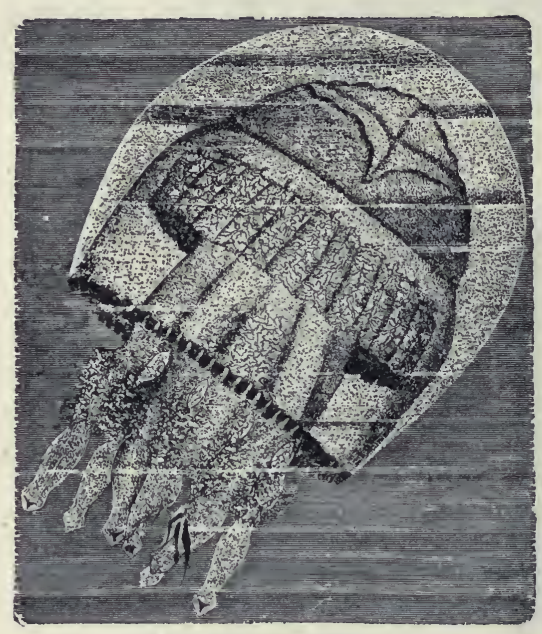

Fig. 43. - A JeLlyfish. on the outside of the colony? Which hydranths have no tentacles? Why not?

Jellyfish. - Alternation of Generations. Medusa. - With some species of hydroids, a very curious thing happens. - The hydranth that is to produce the eggs falls off and becomes independent of the colony. More surprising still, its appearance changes entirely and instead of being hydra-like, it becomes the large and complex creature called jellyfish (Fig. 43). But the egg of the jellyfish produces a small hydra-like animal which gives rise by budding to a hydroid, and the cycle is complete.

The bud (or reproductive hydranth) of the hydroid

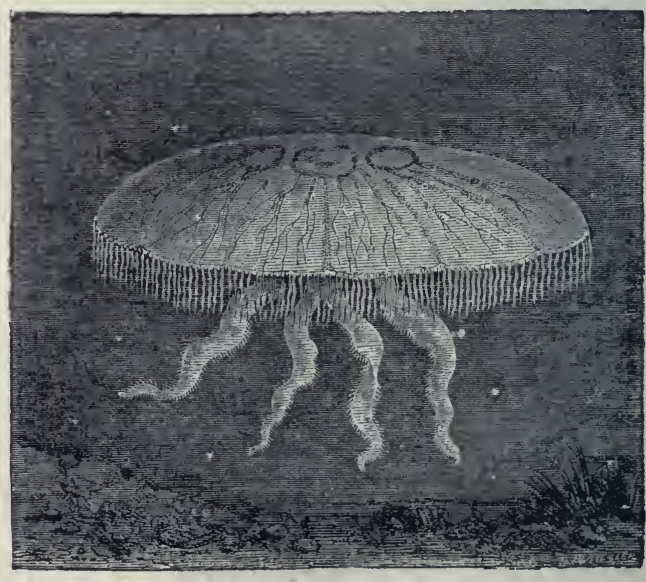

FIG. 44. - A Jellyfish (medusa). 
does not produce a hydroid, but a jellyfish; the egg of the jellyfish does not produce a jellyfish, but a hydroid. This is called by zoologists, alternation of generations. A complete individual is the life from the germination of one egg to the production of another. So that an "individual" consists of a hydroid colony fixed in one place together with all the jellyfish produced from its buds, which may now be floating miles away from it in the ocean. Bathers in the surf are sometimes touched and stung by the long, streamer-like tentacles of the jellyfish. These, like the tentacles of the hydra, have nettling cells (Fig. 4I).

The umbrella-shaped free swimming jellyfish is called a medusa (Fig. 44).

Coral Polyps. - Some of the salt water relatives of the hydra produce buds which remain attached to the parent without, however, becoming different from the parent in any way.

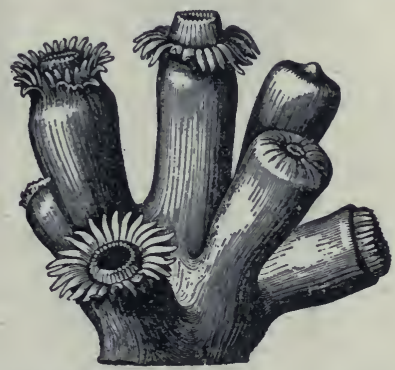

FIG. 45.-CoRAL POLYPS (tentacles, a multiple of six). Notice hypostome.

The coral polyps and corallines are examples of colonies of this kind, possessing a common stalk which is formed as the process of multiplication goes on. In the case of coral polyps, the separate animals and the flesh connecting them secrete within themselves a hard, limy, supporting structure known as coral. In some species, the coral, or stony part, is so developed that the polyp seems to be inserted in the coral, into which it withdraws itself for partial protection (Fig. 45).

The corallines secrete a smooth stalk which affords no protection, but they also secrete a coating or sheath which incloses both themselves and the stalk. The 
coating has apertures through which the polyps protrude in order to feed when no danger is near (Fig. 46).

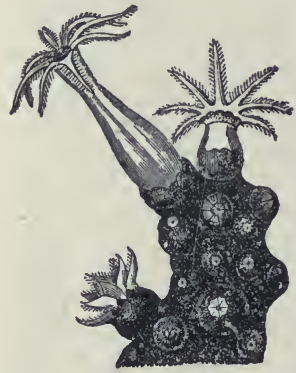

FIG. 46. - RED CORALLINE with crust and polyps (eight tentacles).

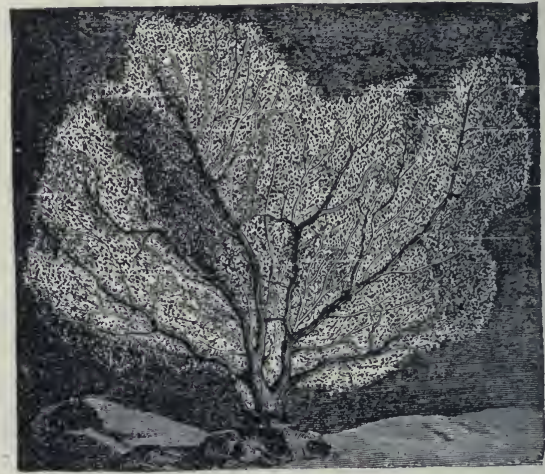

FIG. 47. - SEA FAN (a coralline).

The red "corals" used for jewelry are bits of stalks of corallines. The corallines (Figs. 47,48) are not so abundant

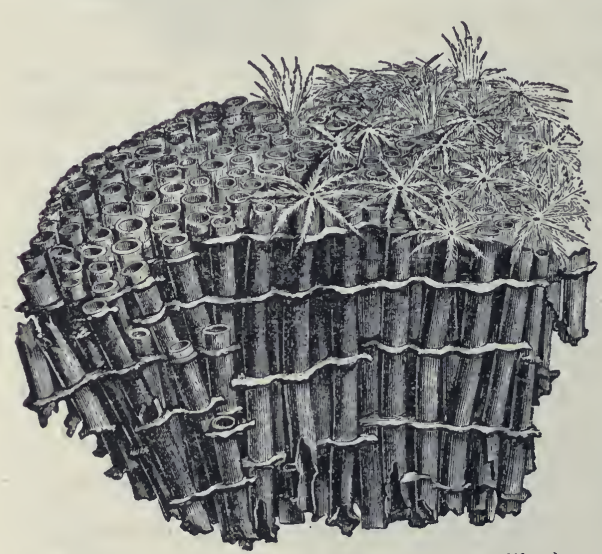

FIG. 48. - ORGAN PIPE "Coral" (a coralline). nor so important as the coral polyps (Figs. 45, 49).

Colonies of coral polyps grow in countless numbers in the tropical seas. The coral formed by successive colonies of polyps accumulates and builds up many islands and important additions to continents. The Florida "keys," or islands, and the southern part of the mainland of Florida were so formed. 
The Sea Anemone, like the coral polyp, lives in the sea, but like the fresh-water hydra, it deposits no limy support for its body. The anemone is much larger than the

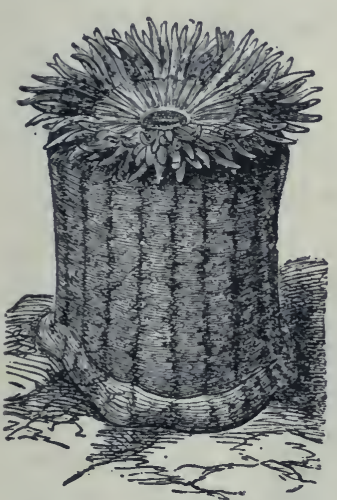

FIG. 50. - SEA ANEMONE.

hydra and

most coral

polyps, many spe-

cies attaining a height of severa 1 inches. It does not form colo-

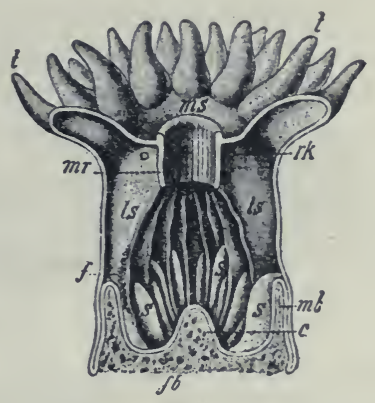

FIG. 49. - UPRIGHT CUT 1hrough coral polyp $\times 4$. $m s$, mouth; mirs gullet; $l s$, $l s$, fleshy partitions (mesenteries) extending from outer body wall to gullet (to increase absorbing surface): $s, s$, shorter partitions; $m b$, $f b$, stony support (of lime, called coral); $t$, tentacles.

nies. When its arms are drawn in, it looks like a large knob of shiny but opaque jelly. Polyps used to be called zoophytes (plant-animals), because of their flower-like appearance (Figs. 50, 5 I).

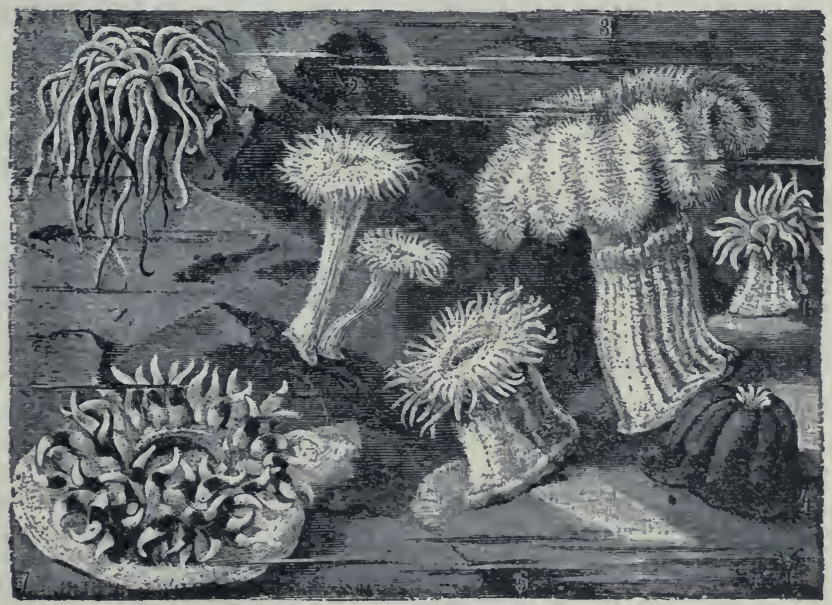




\section{CHAPTER V \\ ECHINODERMS (SPINY ANIMALS)}

The Starfish

Suggestions. Since the echinoderms are aberrant though interesting forms not in the regular line of development of animals, this

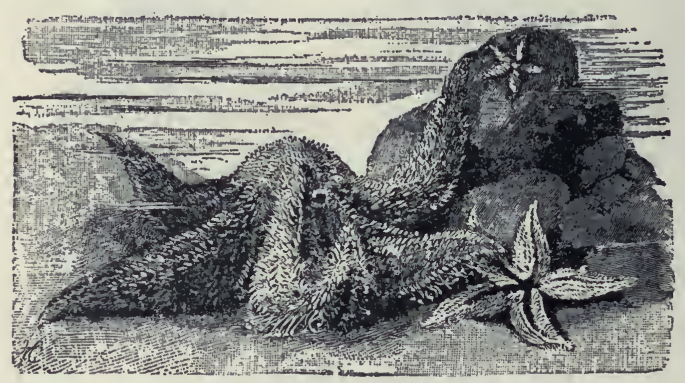

FIG. 52. - Starfish on a rocky shore. chapter may be omitted if it is desired to shorten the course. - The common starfish occurs along the Atlantic coast. It is captured by wading along the shore when the tide is out.

It is killed by immersion in warm, fresh water. Specimens are usually preserved in 4 per cent formalin. Dried starfish and sea urchins are also useful. A living starfish kept in a pail of salt water will be instructive.

\section{External Features. -} Starfish are usually brown or yellow. Why? (See Fig. 52.) Has it a head or a tail? Rightand left sides? What is the shape of the disk, or part which bears

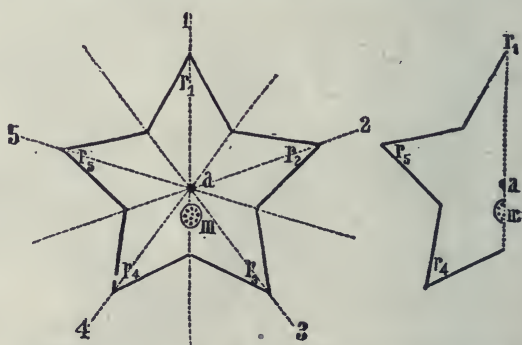

FIG. 53. - PLAN of starfish; III, madreporite. the five arms or rays? (Fig. 53.) Does the body as a whole have symmetry on two sides of a line (bilateral symmetry), or around a point (radial symmetry)? Do the separate rays have 
bilateral symmetry? The skeleton consists of limy plates embedded in the tough skin (Fig. 54). Is the skin rough or smooth? Hard or soft? Are the projections (or spines) in the skin long or short? The skin is

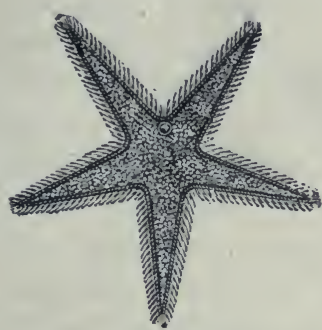

FIG. 55. - Starfish (showing MADREPORITE).

hardened by the limy plates, except around the mouth, which is at the centre of

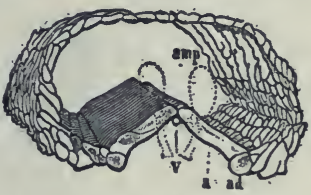

FIG. 54. - LiMY PlateS in portion of a ray. the lower side and surrounded by a membrane. Which is rougher, the mouth side, (oral side) or the opposite (aboral side)? Which side is more nearly flat? The vent is at or near the centre of the disk on the aboral surface. It is usually very small and sometimes absent. Why a vent is not of much use will be understood after learning how the starfish takes food.

An organ peculiar to animals of this branch, and called the madreporic plate, or madreporite, is found on the aboral surface between the bases of two rays (Fig. 55). It is wartlike, and usually white or red. This plate is a sieve; the small openings keep out sand but allow water to filter through.

Movements : the Water-tube System. - The water, which is filtered through the perforated madreporite, is needed to supply a system of canals (Fig. 56). The madreporite opens into a canal called the stone canal, the wall of which is hardened by the same kind of material as that found in the skin. The stone canal leads to the ring canal which surrounds the mouth (Fig. $5^{6}$ ). The ring

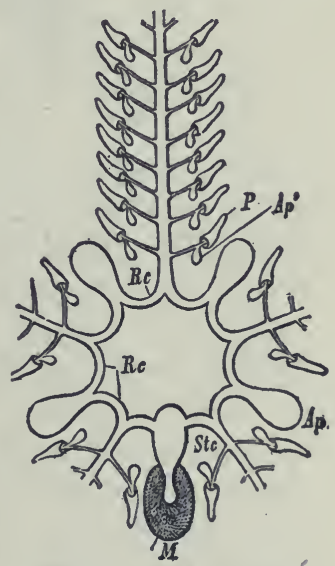

Fig. 56. - Water tube SYSTEM of starfish.

$m$, madreporite; stc, stone canal; $a p$, ampulla. canal sends radial canals into each ray to supply the double row of tube feet found in the groove at the lower side of each ray (Fig. 57). Because of their arrangement in rows, the feet are 
also called ambulacral feet (Latin ambulacra, "forest walks"). There is a water holder (ampulla), or muscular water bulb at the

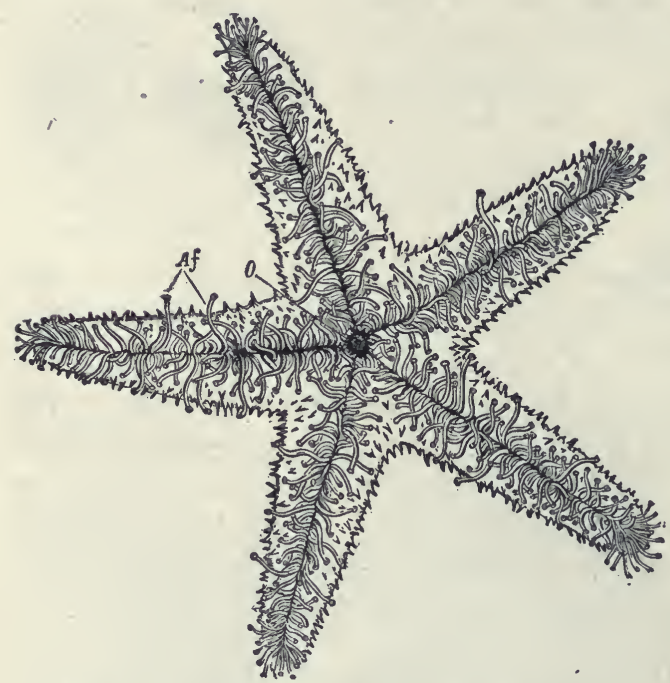

FiG. 57. - Starfish, from below; tube feet extended. base of each tube foot (Fig. 58). These contract and force the water into the tube feet and extend them. The cuplike ends of the tubes cling to the ground by suction. The feet contain delicate muscles by which they contract and shorten. Thus the animal pulls itself slowly along, hundreds of feet acting together. The tube feet, for their own protection, may contract and retire into the groove, the water which extended them being sent back into the ampulla. This system of water vessels (or watervascular system) of the echinodermata is characteristic of them; i.e. is not found elsewhere in the animal kingdom. The grooves and the plates on each side of them occupy the

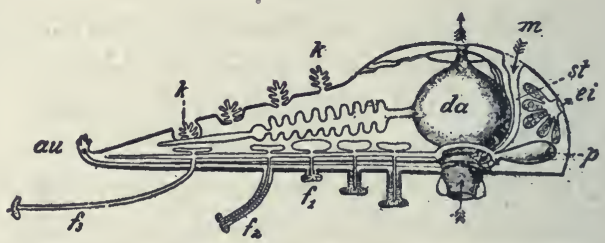

FIG. 58. - SECTION OF ONE RAY and central portion of starfish.

$f_{1}, f_{2}, f_{3}$, tube feet more or less extended; au, eye spot: $k$, gills; $d a$, stomach; $m$, madreporite; st, stone canal; $p$, ampulla; ei, ovary.

ambulacral areas. The rows of spines on each side of the grooves are freely movable. (What advantage?) The spines on the aboral surface are not freely movable. 
Respiration. - The system of water vessels serves the additional purpose of bringing water containing oxygen into contact with various parts of the body, and the starfish was formerly thought to have no special respiratory organs. However, there are holes in the aboral wall through which the folds of the delicate lining membrane protrude. These are now supposed to be gills ( $k$, Fig. $5^{8}$ ).

The nervous system is so close to the aboral surface that much of it is visible without dissection. Its chief parts are a nerve ring around the mouth, which sends off a branch along each ray. These branches may be seen by separating the rows of tube feet. They end in a pigmented cell at the end of each ray called the eye-spot.

The food of starfish consists of such animals as crabs, snails, and oysters. When the prey is too large to be taken into the mouth, the starfish turns its stomach inside out over the prey (Fig. 59). After the shells separate, the stomach is applied to the soft digestible parts. After the animal is eaten, the stomach is retracted. This odd way of eating is very economical to its digestive powers, for only

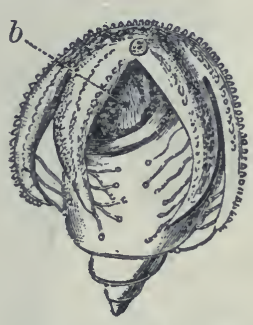

FIG. 59. - Starfish eating a sea snail.

$b$, stomach everted. that part of the food which can be digested and absorbed is taken into the body. Only the lower part of the stomach is wide and extensible. The upper portion (next to the aboral surface) is not so wide. This portion receives the secretion from five pairs of digestive glands, a pair of which is situated in each ray. Jaws and teeth are absent. (Why?) The vent is sometimes wanting. Why?

Reproduction. - There is a pair of ovaries at the base of each ray of the female starfish (Fig. 5 $^{8}$ ). The spermaries of the male have the same position and form as the ovaries, but they are of a lighter colour, usually white. ${ }^{1}$

Regeneration after Mutilation. - If a starfish loses one or more rays, they are replaced by growth. Only a very ignorant oysterman, angry at the depredations of starfish upon his oyster beds,

${ }^{1}$ The sperm cells and egg cells are poured out into the water by the adults, and the sperm cell, which, like nearly all sperm cells, has a vibratory, taile like flagellum to propel it, reaches and fertilizes the egg cell. 
would chop starfish to pieces, as this only serves to multiply them. This power simulates multiplication by division in the simplest animals.

Steps in Advance of Lower Branches. - The starfish and other echinodermata have a more developed nervous system, sensory organs, and digestion, than forms previously studied; most dis-

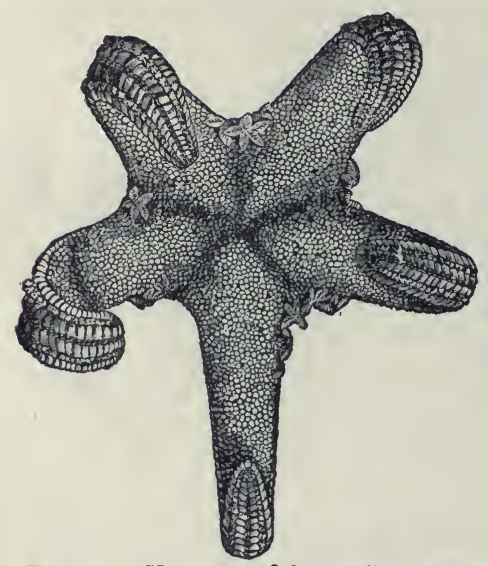

FIG. 60. - Young starfish crawling upon their mother. (Challenger Reports.) tinctive of all, they have a body cavity distinct from the food cavity. The digestive glands, reproductive glands, and the fluid which serves imperfectly for blood, are in the body cavity. There is no heart or blood vessels. The motions of the stomach and the bending of the rays give motion to this fluid in the body cavity. It cannot be called blood, but it contains white blood corpuscles.

The starfish when first hatched is an actively swimming bilateral animal, but it soon becomes starlike (Fig. 6o). The limy plates of the starfish belong neither to the outer nor to the inner layer (endoderm and ectoderm) of the body wall, but to a third or middle layer (mesoderm); for echinoderms, like the polyps, belong to the three-layered animals. In this its skeleton differs from the shell of a crawfish, which is formed by the hardening of the skin itself.

Protective Coloration. - Many starfish are brown or yellow. This makes them inconspicuous on the brown rocks or yellow sand. Brightly coloured species are usually chosen for aquaria.

\section{The Sea URChIN}

External Features. - What is the shape of the body? What kind of symmetry has it? Do you find the oral (or mouth) surface? The aboral surface? Where is the body flattened? What is the shape of the spines? What is their use? How are the tube 
feet arranged? Where do the rows begin and end? Would you think that a sea urchin placed upside down in water, could right itself less or more readily than a star-fish? What advantage in turning would each have that the other would not have? The name sea urchin has no reference to a mischievous boy, but means sea hedgehog (French oursin, hedgehog), the name being suggested by its spines.

Comparison of Starfish and Sea Urchin. - The water system of the sea urchin, consisting of madreporite, tubes, and water bulbs, or ampullæ, is similar to that of the starfish.

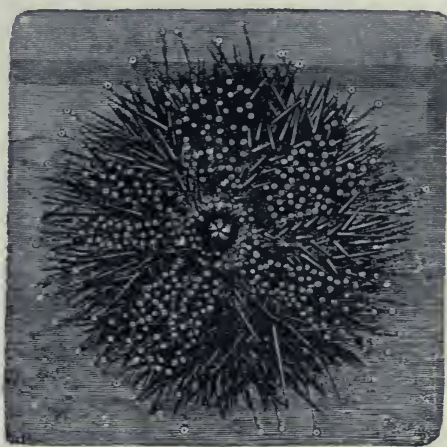

FIG. 61. - A SEA URCHIN crawling up the glass front wall of an aquarium (showing mouth spines and tube feet).

The tube feet and locomotion are alike. There is no need for well-developed respiratory organs in either animal, as the whole body, inside and out, is bathed in water. The method of reproduction is the same.

The starfish eats soft animal food. The food of the sea urchin is mainly vegetable, and it needs teeth (Fig. 62, 63);

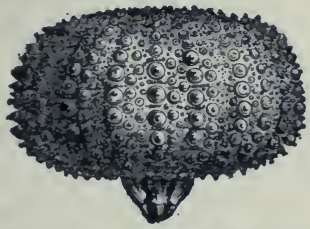

FIG. 62. - A SEA URCHIN with spines removed, the limy plates showing the knobs on which the spines grew.

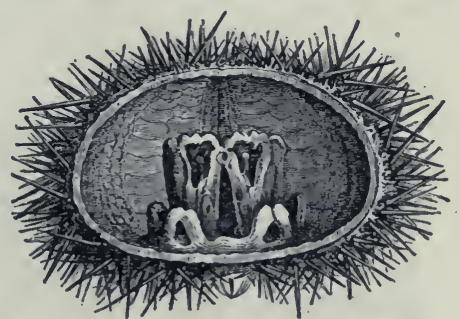

Fig. 63. - SECTION OF SEA URCHIN with soft parts removed, showing the jaws which bear the teeth protruding in Fig. 62.

its food tube is longer than that of a starfish, just as the food tube of a sheep, whose food digests slowly, is much longer than that of a dog. 
The largest species of sea urchins are almost as big as a child's head, but such size is unusual. The spines are mounted

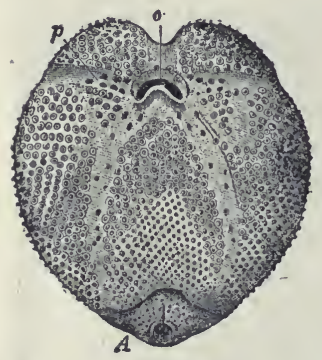

FIG. 64. - THE SEA OTTER, an urchin with mouth $(0)$ and vent $(A)$ on same side of body. on knobs, and the joint resembles a ball-and-socket joint, and allows a wide range of movement. Some sea urchins live on sandy shores, other species live upon the rocks. The sand dollars are of a lighter colour. (Why)? They are usually flatter and have lighter, thinner walls than the other species. The fiveholed sand cake or sand dollar has its weight still further diminished by the holes, which also allow it to rise more easily through the water.

Both starfish and sea urchin rest on the flattened lower surface of the body, while the tube feet are stretching forward for another step.

\section{Other Echinoderms}

The sea cucumbers, or holothurians, resemble the sea urchin in many respects,

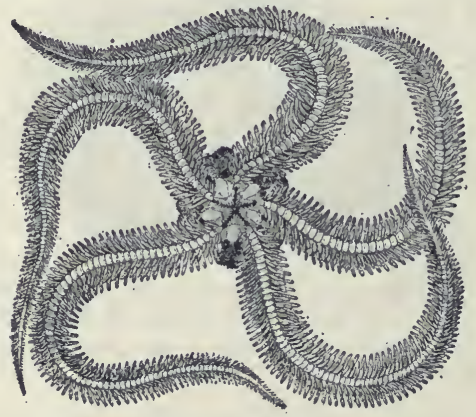

Fig. 66. - A BRITTLE STAR.

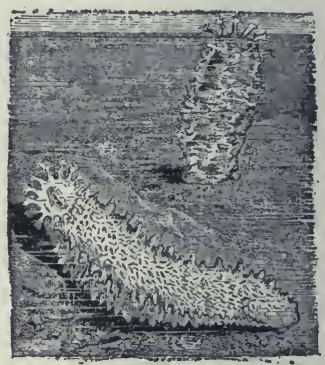

Fig. 65. - SEA CucumbrRS. but their bodies are elongated, and the limy plates are absent or very minute. The mouth is surrounded by tentacles (Fig. 65).

The brittle stars resemble the starfish in form, but their rays are very slender, more distinct from the disk, and the tube feet are on the edges of the rays, not under them (Fig. 66). 
The crinoids are the most ancient of the echinoderms. (Figs. 67, 68.) Their fossils are very abundant in the rocks. They inhabited the geological seas, and it is believed that some of the other echinoderms descended from them. A few now inhabit the deep seas. Some species are fixed by stems when young, and later break away and become freeswimming, others remain fixed throughout life.

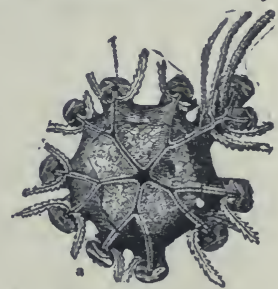

FIG.68.- DISK OF CRINoID from above, showing mouth in centre and vent near it, at right (arms removed).

The four classes of the branch echinoderms are Starfish (asteroids), Sea urchins (echinoids), Sea cucumbers (holothurians), and Sea lilies (crinoids).

\section{Comparative Review}

FIG. 67.-

CRINOID, arms closed.

Make a table like this as large as the page of the notebook will allow, and fill in without guessing.

\begin{tabular}{|c|c|c|c|c|c|}
\hline & Amcsba & SpoNGe & HYDRA & $\begin{array}{l}\text { Coral } \\
\text { Polyy }\end{array}$ & Starfish \\
\hline \multicolumn{6}{|c|}{$\begin{array}{l}\text { Is body round, two- } \\
\text { sided, or irregular }\end{array}$} \\
\hline What organs 0 & 18 & & & * & \\
\hline \multicolumn{6}{|c|}{ Openings into body } \\
\hline \multicolumn{6}{|c|}{$\begin{array}{l}\text { Hard or supporting } \\
\text { parts of body }\end{array}$} \\
\hline \multicolumn{6}{|c|}{ How food is taken } \\
\hline \multicolumn{6}{|l|}{ How move } \\
\hline How breathe & , & & & & \\
\hline
\end{tabular}




\section{CHAPTER VI}

\section{WORMS}

SugGestions : - Earthworms may be found in the daytime after a heavy rain, or by digging or turning over planks, logs, etc., in damp places. They may be found on the surface at night by searching with a lantern. Live specimens may be kept in the laboratory in a box packed with damp (not wet) loam and dead leaves. They may be fed on bits of fat meat, cabbage, onion, etc., dropped on the surface. When studying live worms, they should be allowed to crawl on damp paper or wood. An earthworm placed in a glass tube with rich, damp soil, may be watched from day to day.

External Features. - Is the body bilateral? Is there a dorsal and a ventral surface? Can you show this by a test with live worm? Do you know of an animal with dorsal

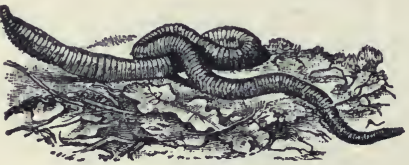

Fig. 69. - AN EARTHWORM. and ventral surface, but not bilateral?

Can you make out a head? A head end? A neck? Touch the head and test whether it can be made to crawl backwards. Which end is more tapering? Is the mouth at the tip of the head end or on the upper or lower surface? How is the vent situated? Its shape? As the worm lies on a horizontal surface, is the body anywhere flattened? Are there any very distinct divisions in the body? Do you see any eyes?

Experiment to find whether the worm is sensitive (I) to touch, (2) to light, (3) to strong odours, (4) to irritating liquids. Does it show a sense of taste? The experiments should show whether 
it avoids or seeks a bright light, as of a window; also whether any parts of the body are especially sensitive to touch, or all equally sensitive. What effect when a bright light is brought suddenly near it at night?

Is red blood visible through the skin? Can you notice any pulsations in a vessel along the back? Do all earthworms have the same number of divisions or rings? Compare the size of the rings or segments. Can it crawl faster on glass or on paper?

A magnifying glass will show on most species tiny bristlelike projections called sete. How are the setæ arranged? (d, Fig. 70.) How many on one ring of the worm? How do they point? Does the worm feel smoother when it is pulled forward or backward between

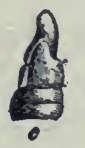

Fig. 70. - MOUTH AND SET\&.

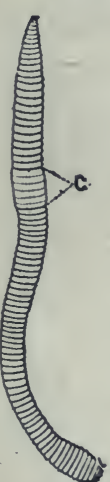

FIG.71.EARTHWORM, mouth end above. the fingers? Why? Are setæ on the lower surface? Upper surface? The sides? What is the use of the setæ? Are they useful below ground? Does the worm move at a uniform rate? What change in form occurs as the front part of the body is pushed forward? As the hinder part is pulled onward? How far does it go at each movement? At certain seasons a broad band, or ring, appears, covering several segments and making them seem enlarged (Fig. 7I). This is the clitellum, or reproductive girdle. Is this girdle nearer the mouth or the tail?

Draw the exterior of an earthworm.

Dorsal and Ventral Surfaces. - The earthworm always crawls with the same surface to the ground; this is called the ventral surface, the opposite surface is the dorsal surface. This is the first animal studied to which 


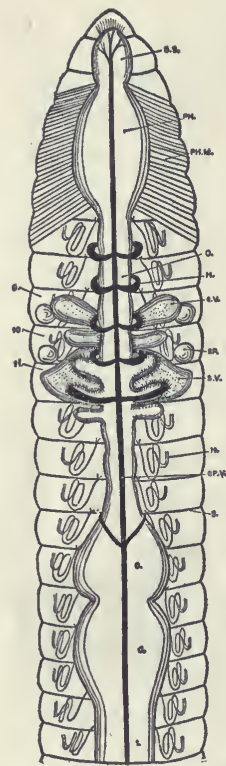

FIG. 72. - FOOD

TUBE of earthworm. (Top view.)

these terms are applicable. What are the ventral and dorsal surfaces of a fish, a frog, a bird, a horse, a man?

The name "worm" is often carelessly applied to various crawling things in general. It is properly applied, however, only to segmented animals without jointed appendages. Although a caterpillar crawls, it is not a worm for several reasons. It has six jointed. legs, and it is not a developed animal, but only an early stage in the life of a moth or a butterfly. A "grubworm" also has jointed legs (Fig. I67). It does not remain a grub, but in the adult stage is a beetle. A worm never develops into another animal in the latter part of its life; its setæ are not jointed.

The Food Tube. - The earthworm has no teeth, and the food tube, as might be

A inferred from the form of the body, is simple and straight. Its parts, recognizable because of slight differences in size and structure, are named the pharynx (muscular), gullet, crop, gizzard

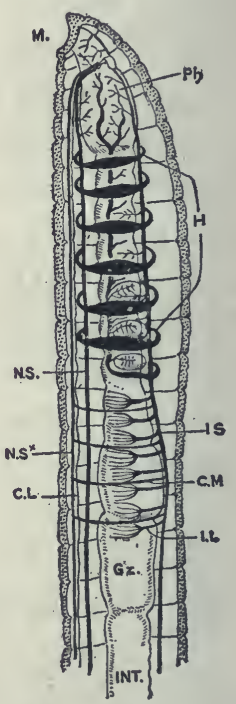

FIG. 73.-FOOD

TUBE AND BLOOD VESSELS of earthworm showing the ring-like hearts. (Side view.) (muscular), and stomach-intestine. The last extends through three fourths of the length of the body (Fig. 72). The functions of the parts of the food tube are indicated by their names.

Circulation. - There is a large dorsal blood Fig. 74. vessel above the food tube (Fig. 73). From the 
front portion of this tube arise several large tubular rings or "hearts" which are contractile and serve to keep the blood circulating. They lead to a ventral vessel below the food tube (Fig. 74). The blood is red, but the colouring matter is in the liquid, not in the blood cells.

Nervous System. - Between the ventral blood vessels is a nerve cord composed of two strands (see Fig. 75). There is a slight swelling, or ganglion, on each strand, in each segment (Fig. 75). The strands separate near the front end of the worm, and a branch goes up each side of the gullet and enters the two pear-shaped cerebral ganglia, or "brain" (Fig. 75).

Food. - The earthworm eats earth containing organic matter, the inorganic part passing through the vent in the form of circular casts; these are found in the morning at the top of the earthworm's burrow.

The earthworm has no teeth. It excretes through the mouth an alkaline fluid which softens and partly digests the food before it

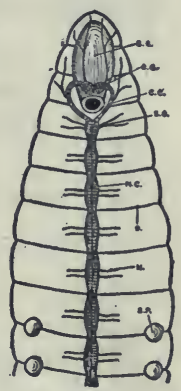

FIG. 75.GANGLia NEAR MOUTH and part of nerve chain of earthworm. is eaten. When this fluid is poured out upon a green leaf, the leaf at once turns brown. The starch in the leaf is also acted upon. The snout aids in pushing the food into the mouth.

Kidneys. - Since oxidation is occurring in its tissues, and impurities are forming, there must be some way of removing impurities from the tissues. The earthworm does not possess one-pair organs like the kidneys of higher animals to serve this purpose, but it has numerous pairs of small tubular organs called nephridia which serve the purpose. Each one is simply a tube with several coils. There is a pair on the floor of each segment. Each neph- 
ridium has an inner open end within the body cavity, and its outer end opens by a pore on the surface between the

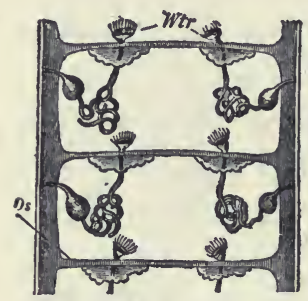

FIG. 76. - TWO PAIRS OF NEPHRIDIA in a worm (diagram). setæ. The nephridia absorb waste from the liquid in the celom, or body cavity surrounding the food tube, and convey it to the outside.

Respiration. - The skin of the earthworm is moist, and the blood capillaries approach so near to the surface of the body that the oxygen is constantly passing in from the air, and carbon dioxide passing out; hence it is constantly breathing through all parts of its skin. It needs no lungs nor special respiratory organs of any kind.

Reproduction.-When one individual animal produces both sperm cells and egg cells, it is said to be hermaphrodite. This is true of the earthworm. The egg cell is always fertilized, however, not by the sperm cells of the same worm, but by sperm cells formed by another worm. The openings of these ovaries consist of two pairs of small pores found in most species on the ventral surface of the fourteenth segment (see Fig. 77). There are also two pairs of small receptacles for temporarily holding the foreign sperm cells. One pair of the openings from these receptacles is found (with diffculty) in the wrinkle behind the ninth segment (Fig. 77), and the other pair behind the tenth segment. The sperm-

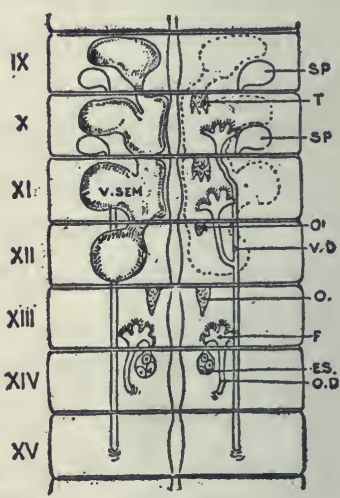

FIG. 77.-Sperm $(s p)$ and egg glands (es) of worm. aries are in front of the ovaries (Fig. 77), but the sperm ducts are longer than the oviducts, and open behind them on the fifteenth segment (Figs. 77, 78). The worms exchange sperm cells, but not 
egg cells. The reproductive girdle, or clitellum, already spoken of, forms the case which is to hold the eggs (see Fig. 7I). When the sperm cells have been exchanged, and the ova are ready for fertilization, the worm draws itself backward from the collar-like case or clitellum so that this slips over the head. As it passes the fourteenth segment, it collects the ova, and as it passes the ninth and tenth segments, it collects the sperm cells previously received from another worm. The elastic, collar-like clitellum closes at the ends after it has slipped over the worm's head, forming a capsule. The ova are fertilized in this capsule, and some of them hatch into worms in a few days. These devour the eggs which do not hatch. The eggs develop into complete but very small worms before escaping from the capsule.

Habits. - The earthworm is omnivorous. It will eat bits of meat as well as leaves and other vegetation. It has also the advantage, when digging its hole, of cating the earth which must be excavated. Every one has noticed the fresh "casts" piled up at the holes in the morning. As the holes are partly filled by rains, the casts are most abundant after rains. The chief showing setæ, enemies of the earthworm are moles and birds. The worms work at night and retire so early in $\begin{gathered}\text { pores, and } \\ \text { reproductive }\end{gathered}$ the morning that the very early bird has the openings. advantage in catching worms. Perhaps the nearest to an intelligent act the earthworm accomplishes is to conceal the mouth of its hole by plugging it with a pebble or a bit of leaf. Worms hibernate, going below danger of frost in winter. In dry weather they burrow several feet deep.

The muscular coat of the body wall is much thicker than the skin. It consists of two layers: an outer layer of fibres which run around the body just beneath the skin, and an 
inner, thicker layer of fibres which nun lengthwise. The worm crawls by shortening the longitudinal muscles. As the bristles (sete) point backward, they prevent the front part of the body from slipping back, so the hinder part is drawn forward. Next, the circular muscles contract, and the bristles preventing the hind part from slipping back, the fore portion is pushed forward. Is the worm thicker when the hinder part is being pulled up or when the fore part is being thrust forward? Does the earthworm pull or push itself along, or does it do both? Occasionally it travels backward, e.g. it sometimes goes backward into its hole. Then the bristles are directed forward.

The right and left halves of the body are counterparts of each other, hence the earthworm is bilaterally symmetrical. The lungs and the gills of animals must always be kept moist. The worm cannot live long in dry air, for respiration in the skin ceases when it cannot be kept moist. and the worm smothers. Long immersion in water is injurious to it, perhaps because there is far less oxygen in water than in the air.

Darwin wrote a book called "Vegetable Mould and Earthworms." He estimated that there were fifty thousand earthworms to the acre on farm land in England, and that they bring up eighteen tons of soil in an acre each year. As the acids of the food tube act upon the mineral grains that pass through it, the earthworm renders great aid in forming soil. By burrowing it makes the soil more porous and brings up the subsoil.

Although without eyes, the worm is sensitive to light falling upon its anterior segments. When the light of a lantern suddenly strikes it at night, it crawls quickly to its burrow. Its sense of touch is so keen that it can detect a light puff of breath. Which of the foods kept in a box of 
damp earth disappeared first? What is indicated as to a sense of taste?

Why is the bilateral type of structure better adapted for development and higher organization than the radiate type of the starfish? The earthworm's body is a double tube; the hydra's body is a single tube; which plan is more advantageous, and why? Would any other colour do just as well for an earthworm? Why, or why not?

The sandworm (Nereis) lives in the sand of the seashore, and swims in the sea at night (Fig. 79). It is more advanced in structure than the earthworm, as it has a distinct head (Fig. 80), eyes, two teeth, two lips, and several pairs of antennæ, and two rows of muscular projections which serve as feet. It is much used by fishermen for bait. If more easily obtained, it may be studied instead of the earthworm.

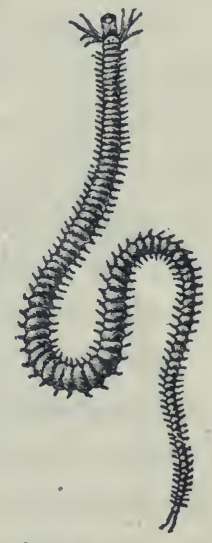

FIG. 79. - SAND WORM $\times \frac{2}{3}$

(Nereis).

There are four classes in the branch Vermes:

I) the worms, including sandworms and leeches; 2) the

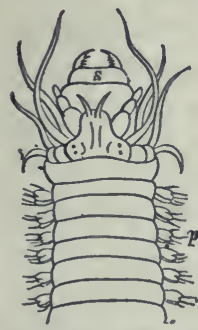

FIG. 80. - HEAD OF SANDWORM

(enlarged). roundworms, including trichina, hairworms, and vinegar eels; 3) flatworms, including tapeworm and liver fluke; 4) rotifers, which are microscopic aquatic forms.

The tapeworm is a flatworm which has lost most of its organs on account of its parasitic life. Its egg is picked up by an herbivorous animal when grazing. The embryo undergoes only partial development in the body of the herbivorous animal, e.g. an ox. The next stage will not develop until the beef is eaten by a carnivorous animal, to whose food canal it attaches itself and soon develops a long chain of segments called a "tape." Each segment absorbs fluid food through its 
body wall. As the segments at the older end mature, each becomes full of eggs, and the segments become detached and pass out of the canal, to be dropped and perhaps picked up by an herbivorous animal and the life cycle is repeated.

The trichina is more dangerous to human life than is the tapeworm. It gets into the food canal in uncooked pork (bologna sausage, for example), multiplies there, migrates into the muscles, causing great pain, and encysts there, remaining until the death of the host. It is believed to get into the bodies of hogs again when they eat rats, which in turn have obtained the cysts from carcasses.

Summary of the Biological Process. - An earthworm is a living machine which does work (digging and crawling; seizing, swallowing, and digesting food; pumping blood; growing and reproducing). To do the work it must have a continual supply of energy. The energy for its work is set free by the protoplasm (in its microscopic cells) undergoing a destructive chemical change (oxidation). The waste products from the breaking down of the protoplasm must be continually removed (excretion). The brokendown protoplasm must be continually replaced if life is to continue (the income must exceed the outgo if the animal is still growing). The microscopic cells construct more protoplasm out of food and oxygen (assimilation) supplied them by the processes of nutrition (eating, digesting, breathing, circulating). This protoplasm in turn oxidizes and releases more energy to do work, and thus the cycle of life proceeds. 


\section{CHAPTER VII}

\section{CRUSTACEANS}

\section{CRAWfish}

Suggestions.- In regions where Crayfish are not found, a live crab may be used. Locomotion and behaviour may be studied by providing a tub of water, or better, a large glass jar such as a broad candy jar. For suggestions on study of internal structure, see p. 58 .

Habitat. - Do you often see crawfish, or crayfish, moving about, even in water where they are known to be abundant? What does your answer suggest as to the time when they are probably most active?

Why do you never see one building its chimney, even where crayfish holes are abundant? Is the chimney always of the same colour as the surface soil? Are the crayfish holes only of use for protection? In what kind of spots are crayfish always dug; Why? What becomes of crayfish when the pond or the creek dries up? How deep are the holes? How large are the lumps of mud of which the chimney is built? How does it get them out of the hole? Why is the mud built into a chimney instead of thrown away? (What would happen to a well with its mouth no higher than the ground?) Why are crayfish scarce in rocky regions ?

How does the colour of the crayfish compare with its surroundings? Is its colour suited to live in clear or muddy water? Define protective colouration. 
Habits. - Does the crayfish walk better in water or out of it? Why? Does it use the legs with the large claws to assist in walking? Do the swimmerets (under the abdomen) move fast or slow? (Observe it from below in a large jar of clear water.) What propels it backward? Forward? Does the crayfish move at a more uniform rate when swimming backward or forward? Why? In which way can it swim more rapidly? Do the big legs with claws offer more resistance to the water while it is swimming backward or forward? How does it hold the tail after the stroke, while it is darting backward through the water? Hold a crayfish with its tail submerged and its head up. Can the tail strike the water with much force? Allow it to grasp a pencil: can it sustain its own weight by its grip?

Feeding.-Offer several kinds of food to a crayfish that has not been alarmed or teased. Does it prefer bread, meat, or vegetables? How does it get the food to its mouth? Does it eat rapidly or slowly? Does it tear the food with the big pincers? Can it gnaw with the small appendages near the mouth?

Breathing.-Does the crayfish breathe with gills or lungs? Place a few drops of ink near the base of the hind legs of a crayfish resting quietly in shallow water. Where is the ink drawn in? Where does it come out? To explain the cause and the purpose of this motion, place a crayfish in a large glass jar containing water, and see the vibratory motion of the parts under the front portion of the body. There is under the shell on each side of the body a gill paddle, or gill bailer, that moves at the same rate.

Senses.-Crayfish are best caught with a piece of meat or beef's liver tied to a string. Do they always lose hold as soon as they are lifted above the water? What do you 
conclude as to the alertness of their senses? Does the cov. ering of their bodies suggest the possession of a delicate or a dull sense of touch?

Of what motions are the eyes capable? Touch one of the eyes. The result? Can a crayfish see in all directions? To test this, place a crayfish on a table and try whether you can move to a place where you can see the

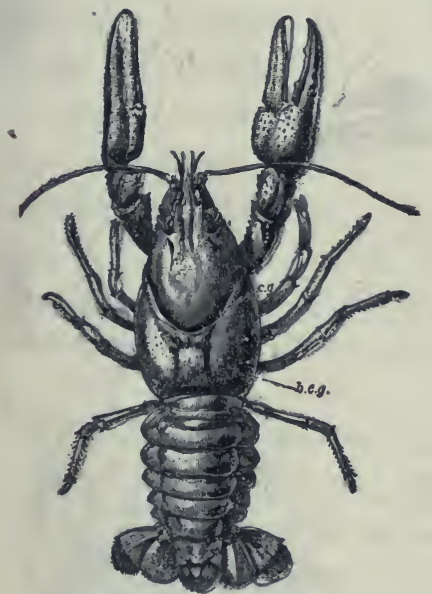

Fig. 8I. - CRAWFish

(dorsal surface).

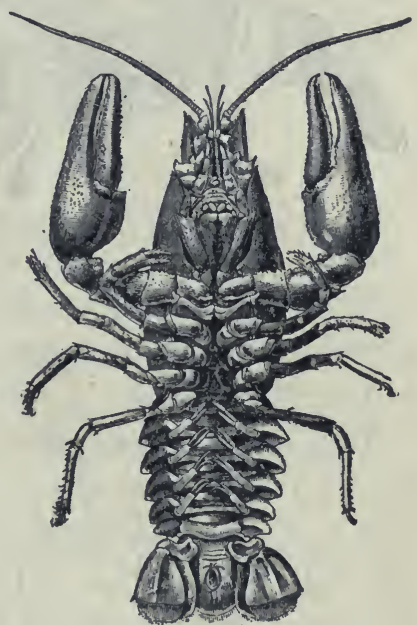

FIG. 82.

crayfish without seeing its eyes. What are the advantages and disadvantages of having the eyes on stalks?

Touch the body and the several appendages of the crayfish. Where does it seem most sensitive to touch? Which can reach farther, the antennæ or the big claws? Why are short feelers needed as well as long ones?

Make a loud and sudden noise without jarring the crayfish. Is it affected by sound?

External Anatomy (Figs. 81, 82, 83, 84). - - Is the body of the crayfish rounded out (convex) everywhere, or is any part of its surface either flat or rounded in (concave)? 
What colour has the crayfish? Is this colour of any use to the crawfish?

Make out the two distinct regions or divisions of the body (Fig. 8I). The anterior (front) region is called the headchest or cephalothorax, and the posterior (rear) region is

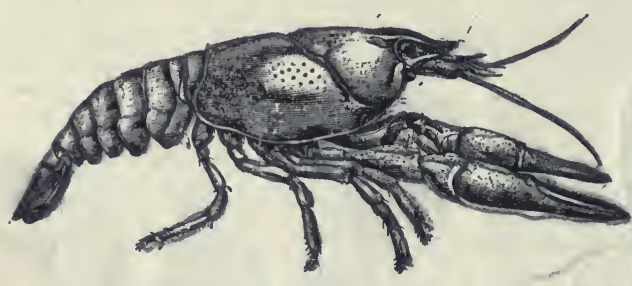

Fig. 83. - LATERAL view OF Crawfish. called the tail. Which region is larger? Why? Which is flexible? Why?

Is the covering of the body hard or soft? What is the advantage of such a covering? What are its disadvantages? How is the covering modified at the joints to permit motion?

Tail. - How many joints, or segments, of the tail ? (Figs. 8I, 83.) Does the hard covering of each segment slip under or over the segment behind it when the tail is straight? Does this lessen friction while swimming forward?

Is there a pair of swimmerets to each segment of the tail? (Figs. 82, 86.) Notice that each swimmeret has a main stalk (protopod), an outer branch (exopod), and an inner branch (endopod) (Fig. 84). Are the stalk and the branches each in

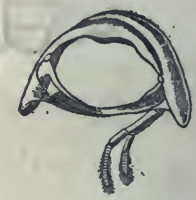

FIG. 84. FOURTH ABDOMINAL, SEGMENT OF CRAWFISH with swimmeret. one piece or jointed? The middle part of the tail fin is called the telson. By finding the position of the vent, decide whether the food tube goes into the telson (Fig. 82). Should it be called an abdominal segment. Are the side pieces of the tail fin attached to the telson or to the sixth segment? Do these side pieces correspond 
to swimmerets? Do they likewise have the Y-shaped structure? (Fig. 86.)

If the swimmerets on the first abdominal segment are large, the specimen is a male. If they are small, it is a female. Which sex is shown in Fig. 82 ? Fig. 86 ?

Carapace. - The covering of the head chest (cephalothorax) is called the carapace. Has it free edges? The gills are on the sides of the body and are covered by the carapace (Fig. 87). The projection in front is called the rostrum, meaning beak. Does the rostrum project beyond the eyes? There is a transverse grocve across the cara-

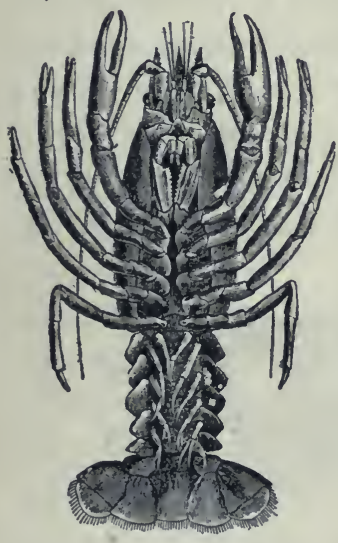

FIG. 86.-CRAYFish (ventral surface). pace which may be said to divide the head from the
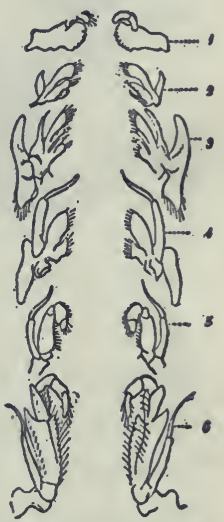

FIG. 85.-I, mandible; 2,3 , maxillæ; $4,5,6$, maxillipeds.

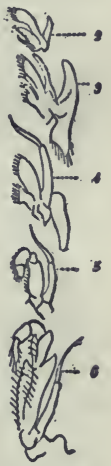
abdomen. Where does this groove end at the sides?

Legs. - How many legs has the crayfish? How many are provided with large claws? Small claws? Is the outer claw hinged in each of the large grasping pincers? The inner claw?

Appendages for Taking Food. If possible to watch a living crayfish eating, notice whether it places the food directly into the mouth with the large claws. Bend the large claws under and see if they will reach the mouth. Attached just in front of the legs the crayfish has three pairs of finger-like appendages, called foot jaws (maxillipeds), with which it passes the food from the large pincers 
to its mouth (Figs. 85, 86). They are in form and in use more like fingers than feet. In front of the foot jaws are two

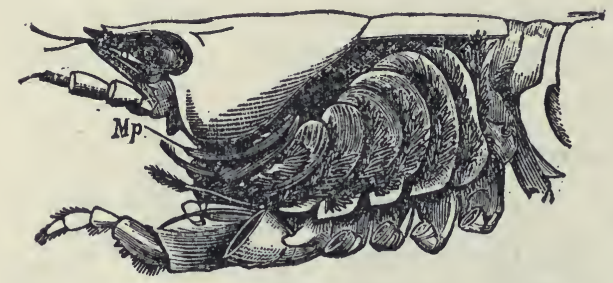

FIG. 87. - Gill cover removed and gills exposed. $M p$, gill bailer.

pairs of thin jaws

(maxillæ) and in front of the thin jaws are a pair of stout jaws (mandibles) (Fig. 85). Do the jaws move sidewise or up and down? Which of the jaws has a jointed finger (palp) attached to it? Do all the appendages for taking food have both exopod and endopod branches on a basal stalk or protopod? Which of the appendages have a scalloped edge? How would you know from looking at the crayfish that it is not merely a scavenger? Why are there no pincers on the hind feet?

Sense Organs. - Find the antenne, or long feelers (Figs. $82,90)$. Are the antennæ attached above or below the eyes? (Fig. 87.)

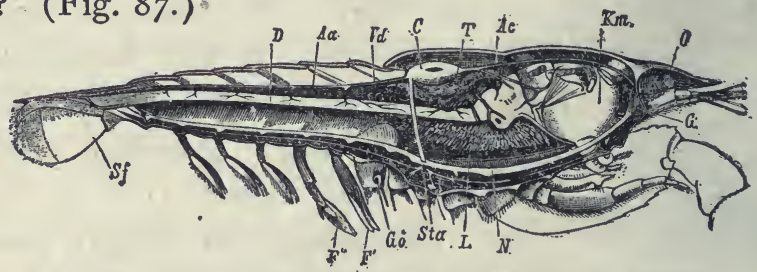

Fig. 88. - Lengthwise Section of Male Crawfish.

c, heart; $A c$, artery to head; $A a$, artery to abdomen; $K m$, stomach; $D$, intestine;

$L$, liver; $T$, spermary; Go, opening of sperm duct; $G$, brain; $N$, nerve chain.

Find the pair of antenmules, or small feelers. Are their divisions like or unlike each other? Compare the length of the antennules and the antennæ. Compare the flexibility of the antennæ with that of the other appendages. 
Observe the position of the eyes (Figs. $8 \mathrm{I}, 88$ ). How long are the eyestalks? Is the stalk flexible or stiff ? Touch the eye. Where is the joint which enables the stalk to move? Is the outer covering of the eye hard or soft? A mounted preparation of the transparent covering (cornea) of the eye, seen with lower power of microscope, reveals that the cornea is made up of many divisions, called facets. Each facet is the front of a very small eye, hundreds of which make up the whole eye, which is therefore called a compound eye. The elongated openings to the ear sacs are located each on the upper side of the base of a small feeler just below the eye.

Respiratory System. - The respiratory organs are gills located on each side of the thorax in a space between the carapace and the body (Fig. 87). The gills are white, curved, and feathery. Is the front gill the largest or the smallest? The gills overlap each other; which is the outermost gill? On the second maxilla is a thin, doubly curved plate called a gill bailer (Fig. 85). The second maxilla is so placed that the gill bailer comes at the front end of the gill chamber. The bailer paddles continually, bringing the water forward out of the gill. The gills are attached below at the base of the legs. Are the gills thick or thin ? How far upward do they go? Does the backward motion in swimming aid or hinder the passage of the water through the gills? Does a crayfish, when at rest on the bottom of a stream, have its head up or down stream? Why?

Openings. - The slitlike vent is on the under side of the telson (Figs. 82, 88). The mouth is on the under side of the thorax behind the mandibles. At the base of the long antennæ are the openings from the green glands, two glands in the head which serve as kidneys (Fig. 89). The openings of the reproductive organs are on the third 


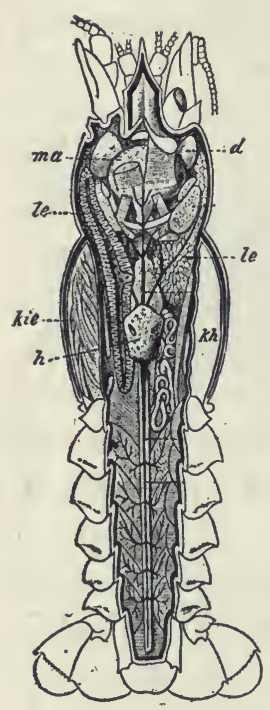

FIG. 89. - Level lengthwist section showing
$h$, heart.
$d$, green gland.
le, liver.
kie, gills.
$k h$, gill cavity.
ma, stomach.

(After Huxley.)

pair of legs in the female, and the fifth pair of legs in the male (Fig. 88). The eggs are carried on the swimmerets.

Internal Structure. - SugGESTIONS. If studied by dissection, it will be necessary to have several crayfish for each pupil, one for gaining general knowledge, and others for studying the systems in detail. Specimens should have lain in alcohol for several days.

The Food Tube. - Is the stomach in the head portion of the cephalothorax or in the thoracic portion? (Figs. 88, 89). Is the stomach large or small? What is its general shape? Does the gullet lead upward or backward? Is it long or short? (Fig. 88.) The mid tube, which is the next portion of the food tube, is smaller than the stomach. On each side of it are openings from the bile ducts which bring the secretion from the digestive gland, sometimes called the liver. Does this gland extend the whole length of the thorax? Is it near the floor or the top of the cavity? The third and last portion of the food tube is the intestine. It extends from the thorax

to the vent. Is it large or small? Straight or curved? The powerful flexor muscles of the tail lie in the abdomen below the intestines. Compare the size of these muscles with the extensor muscle above the intestine (Fig. 9o). Why this difference? Does the food tube extend into the telson? Locate the vent (Fig. 90).

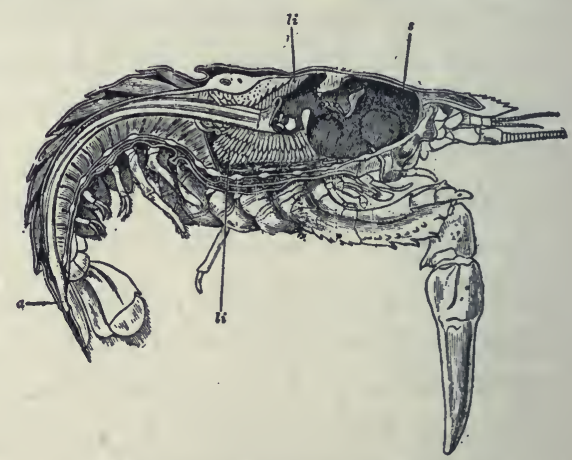

Fig. 90.-Section of CRAYFisH showingstomach $s$, liver $l i$, and vent $a$. 
The Circulation. - The blood is a liquid containing white corpuscles. It lacks red corpuscles and is colourless. The heart is in the upper part of the thorax. It is surrounded by a large, thin bag, and thus it is in a chamber (called the pericardial sinus). The blood from the pulmonary veins enters this sinus before it enters the heart. The origin of this pericardial sinus by the fusing of veins is shown in Fig. i 30 . Does one artery, or do several arteries, leave the heart? There is a larger dorsal artery lying on the intestine and passing back to the telson; there are three arteries passing forward close to the dorsal surface (Figs. 89, 9I). One large artery (the sternal) passes directly downward (Figs. $88,9 \mathrm{I})$, and sends a branch forward and another backward near the ventral surface. The openings into the heart from the sinus have valvular lips which prevent a backward flow of blood into the sinus. Hence, when

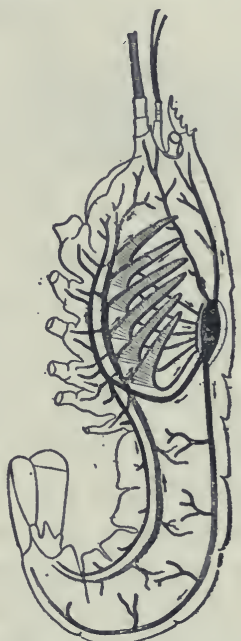

FIG. 9I. - Showing heart and main blood vessels. the heart contracts, the blood is sent out into the sev-

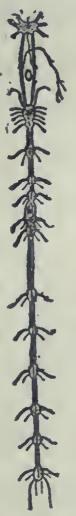

FIG. 92. eral arteries. The arteries take a supply of fresh blood to the eyes, stomach, muscles, liver, and the various organs. After it has given oxygen to the several organs and taken up carbon dioxide, it returns by veins to pass through the gills on each side, where it gives out the useless gas and takes up oxygen from the water. It is then led upward by veins into the pericardial sinus again.

The central nervous system consists of a double, chain of ganglia (Fig. 92). This main nerve chain lies along the ventral surface below the food tube (Fig. 90), except one pair of ganglia which lie above the œsophagus or gullet (Fig. 88), and are called the supra-œsophageal ganglia, or brain.

Crustacea - The crayfish and its kindred are placed in the class called Crustacea. 
Decapods. - All crustacea which have ten feet belong in the order called decap'oda (ten-footed). This order

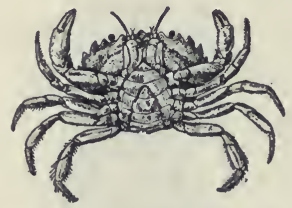

FIG. 93.- CRAB · FROM BELOW. includes the crabs, lobsters, shrimp, etc. The crabs and the lobsters are of considerable importance because of use as food. Small boys sometimes catch crayfish, and in some instances are known to cook and eat them for amusement,

the only part cooked being the muscular tail. The crab's tail is small and flat and held under the body (Fig. 93).

Since the limy covering to serve the purpose of protection is not

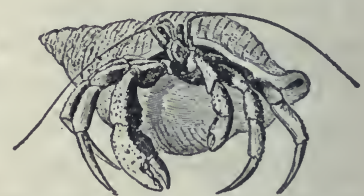

Fig. 94. - HERMIT CRAB, using shell of sea snail for a house. soft enough to be alive and growing, it is evident that the crustacea are hampered in their growth by their crusty
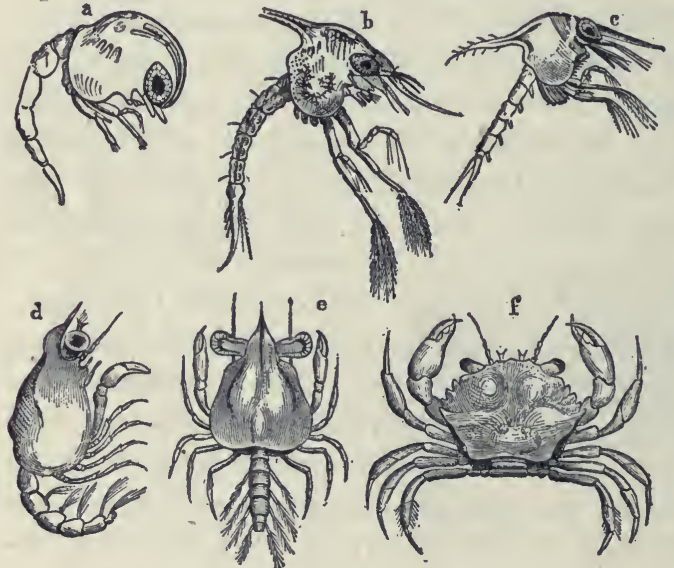

Fig. 95. - Development of a Crab.

$a$, nauplius just after hatching; $b, c, d, z o e ̈ a ; e$, megalops; $f$, adult.

Question: Which stage is most like a crayfish? Compare with metamorphoses of insects. covering. During the first year the crayfish sheds its covering, or moults three times, and once each year thereafter. It. grows very fast for a few days just after moulting, while the covering is soft and extensible. Since it is at 
the mercy of birds, fish, and other enemies while in this soft and defenceless condition, it stays hidden until the covering hardens. Hence it cannot eat much, but probably by the absorption of water the tissues grow; that is, enlarge. In the intervening periods, when growth is impossible, it develops; that is, the tissues and organs change in structure and become stronger. "Soft-shelled crab" is a popular dish, but there is no species by that name, this being only a crab just after moulting which has been found by fishermen in spite of its hiding.

General Questions. - How do crayfish choose their food? How long can they live out of water? Why do their gills remain moist out of water longer than a fish? How do they breathe out of water? Are they courageous or cowardly animals? When they lose appendages in fighting or moulting these are readily reproduced, but an organ moults several times in regaining its size. Have you seen crayfish with one claw smaller than the Compare the crayfish and crab (Figs. 81,93 , and 95) in the following particulars: shape, body, eyes, legs, abdomen, habitat, movement.

KEY TO THE FOUR CLASSES IN BRANCH ARTHROPODS

I. INSECTS . . 3 body divisions, 6 legs

2. ARACHNIDS . . 2 body divisions, 8 legs

3. MYRIAPODS . . many body divisions, many legs

4. CRustaceans . gill breathers, skeleton (external) limy

By the aid of the key and of figures 96-105, classify the following Arthropods : tick, thousand-leg centipede, king crab, pill bug, spider, scorpion, beetle. 


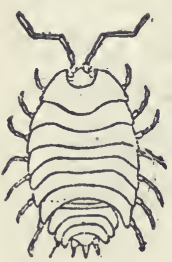

FIG. 96. - PILL Bug.

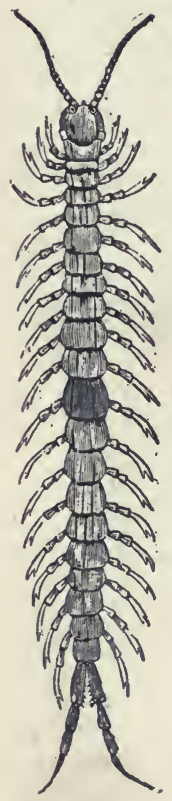

FIG. 100. -

Centipede.

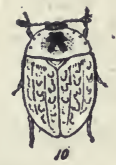

FIG. 97.-

LADY BEETLE.

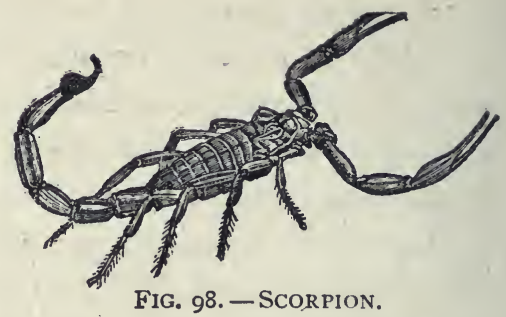

FIG. 98. - SCORPION.

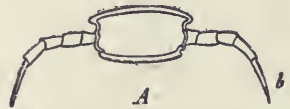

Fig. IOI. - ONE SEGMENT OF CENTIPEDE with one pair of legs.

$B$

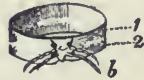

Fig. 102.ONE SEGMENT OF THOUSAND LEGS with two pairs of legs.

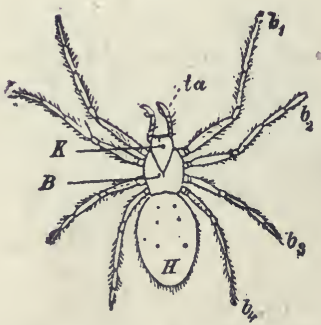

FIG. IO4.-A SPIDER.

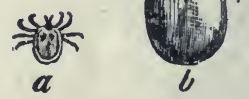

FIG. 99. - TICK before and after feeding.

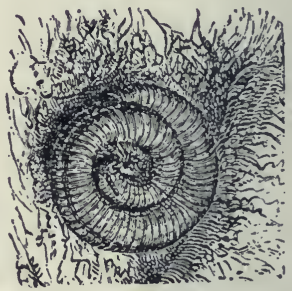

FIG. I03. - THOUSAND LEGS.

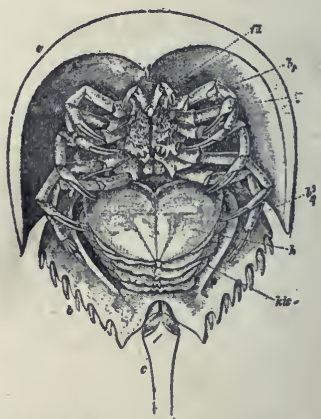

FIG. I05. - KING CRAB.

Illustrated Study. Classification of ARthropods. Key on p. 6I. 


\section{CHAPTER VIII}

\section{INSECTS}

\section{The GRASShopper}

SugGestions. - Collect grasshoppers, both young and fullgrown, and keep alive in broad bottles or tumblers and feed on tresh grass or lettuce. When handling a live grasshopper, never hold it by its legs, as the joints are weak. To keep them for some time and observe their moults, place sod in the bottom of a box and cover the box with mosquito netting or wire gauze.

What is the general shape of its body? (Fig. 106.) Where is the body thickest? Is it bilaterally symmetrical, that is, are the two sides of the body alike? Is the skeleton, or hard part of the body, internal or external? Is the skeleton as stiff and thick as that of a crayfish? What is the length of your specimen? Its colour?

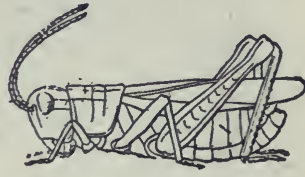

FIG. I06. - A GRASSHOPPER. Why does it have this coloration? In what ways does the grasshopper resemble the crayfish? Differ from it?

The Three Regions of the Body.-The body of the grasshopper is dividedinto three regions-the head, the thorax, and the abdomen. Which of these three divisions has no distinct subdivisions? The body of the grasshopper, like that of the earthworm, is made of ringlike segments. Are the segmen ts most distinctin the head, the thorax,or the abdomen ? Which region is longest? Shortest? Strongest ? Why? Which region bears the chief sense organs? The appendages for taking food? The locomotory appendages? Which division of the body is most active in breathing? 
The Abdomen. - About how many segments or rings in the abdomen? 'Do all grasshoppers have the same number of rings? (Answer for different species and different individuals of the same species.) The first segment and the last two are incomplete rings. Does the flexibility of the abdomen reside in the rings orin the joints between the rings? Is there merely a thin, soft line between the rings, or is there a fold of the covering? Does one ring slip into the ring before it or behind it when the abdomen is bent?

As the grasshopper breathes, does each ring enlarge and diminish in size? Each ring is divided into two parts

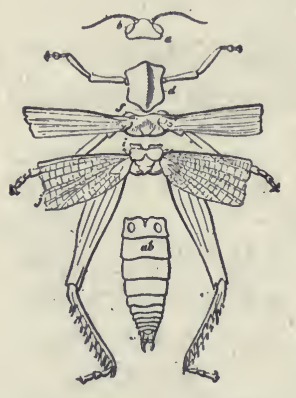

FIG. I07.-A GRASSHOPPER DISSECTED. by folds. Does the upper half-ring overlap the lower half-ring, or the reverse? With magnifying glass, find a small slit, called a spiracle, or breathing hole, on each side of each ring just above the side groove (Fig. I06). A tube leads from each spiracle. While the air is being taken in, do the two portions of the rings move farther apart? When they are brought together again, what must be the effect? In pumping the air, the abdomen may be said to work like a bellows. Bellows usually have folds to allow motion. Is the comparison correct?

How many times in a minute does the grasshopper take in air? If it is made to hop vigorously around the room and the breathing is again timed, is there any change?

Find the ears on the front wall of the first abdominal ring (Fig. 107). They may be seen by slightly pressing the abdomen so as to widen the chink between it and the thorax. The ears are merely glistening, transparent membranes, oval in form. A nerve leads from the inner 
surface of each membrane. State any advantage or disadvantage in having the ears located where they are.

Ovipositor. - If the specimen is a female, it has an eggplacer or ovipositor, consisting of four blunt projections at the end of the abdomen (Fig. 107). If it is a male, there are two appendages above the end of the abdomen, and smaller than the parts of the ovipositor. Females are larger and more abundant than males. In laying the eggs, the four blunt points are brought tightly together and then forced into the ground and opened (Fig. I08). By repeating this, the grasshopper makes a pit almost as deep as the abdomen is long. The eggs are laid in the bottom of the pit.

Draw a side view of the grasshopper.

Thorax. - This, the middle portion of the body, consists of three

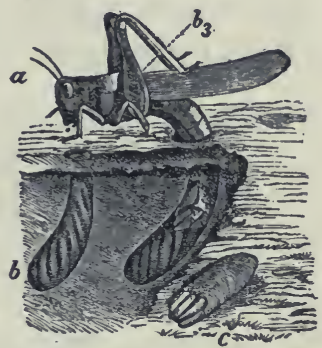

FiG. I08. - GRASSHOPPER LAYING EGgS. (Riley.) segments or rings (Fig. 107). Is the division between the rings most apparent above or below? Which two of the three rings are more closely united?

The front ring of the thorax is called prothorax. Is it larger above or below? Does it look more like a collar or a cape? (Fig. 106.) A spiracle is found on the second ring (mesothorax, or middle thorax) just above the second pair of legs. There is another in the soft skin between the prothorax and the mesothorax just under the large cape or collar. The last ring of the thorax is called the metathorax (rear thorax).

How many legs are attached to each ring of the thorax? Can a grasshopper walk? Run?. Climb? Jump? Fly? Do any of the legs set forward? (See Fig. 106.) 
Outward? Backward? Can you give reasons for the position of each pair? (Suggestion: What is the use of each pair?) If an organ is modified so that it is suited to serve some particular purpose or function, it is said to be specialized. Are any of the legs specialized so that they serve for a purpose different from that of the other legs?

The leg of a grasshopper (as of all insects) is said to have five parts, all the small parts after the first four parts being counted as one part and called the foot. Are all the legs similar, that is, do the short and the long joints in all come in the same order? Numbered in order from the

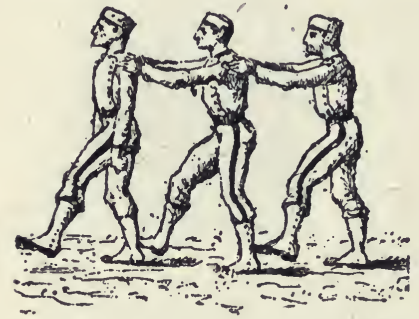

FIG. IO9. - HOW A GRASSHOPPER WALKS.

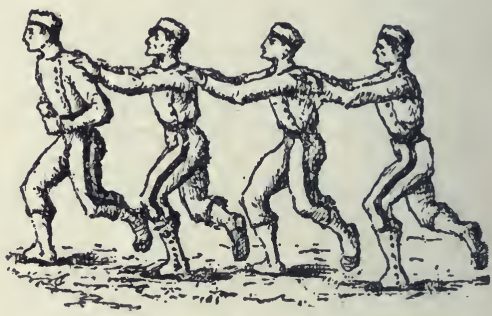

Fig. IIO. - How A SPIDER

WALKS.

body, which joint of the leg is the largest, - the first, second, third, or fourth ? Which joint is the shortest? The slenderest? Which joint has a number of sharp points or spines on it? Find by experiment whether these spines are of use in walking (Fig. 106). Jumping? Climbing? In what order are the legs used in walking? How many legs support the body at each step?

All animals that have ears have ways of communicating by sounds. Why would it be impossible for the grasshopper to have a voice, even if it had vocal cords in its throat? The male grasshoppers of many species make a chirping, or stridulation, by rubbing the wing against the leg. Look on the inner side (why not outer side ?) of the 
largest joint of the hind leg for a row of small spines visi. ble with the aid of a hand lens (Fig. I I I). The sound is produced by the outer wings rubbing against the spines. Have you noticed whether the sound is produced while the insect is still or in motion? Why? The male grasshoppers of some species, instead of having spines, rub the under side of the front wing on the upper side of the hind wing.

Wings. - To what is the first pair of wings attached? The second pair? Why are the wings not attached to the prothorax? Why are the wings attached
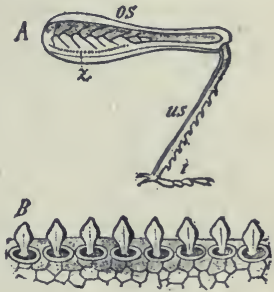

FIG. III. $-A$, Row of SPINES, $z$, used in chirping.

$B$, the same more enlarged. so near the dorsal line of the body? Why are the second and third rings of the thorax more solidly joined than the first and second rings?

Compare the first and second pairs of wings in shape, size, colour, thickness and use (Fig. II2). How are the

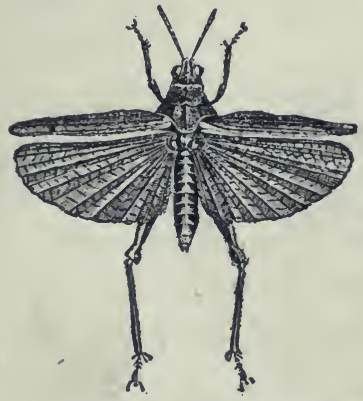

FIG. II2. - GRASSHOPPER IN FLight. second wings folded so as to go under the first wings? About how many folds in each?

Draw a hind wing opened out.

Head. What is the shape of the head viewed from the front, the side, and above? Make sketches. What can you say of the neck? Is the head movable in all directions?

What is the position of the large eyes? Like the eyes of the crayfish, they are compound, with many facets. But the grasshopper has also three simple eyes, situated one in the middle of the forehead and one just above each antenna. They are too small to be seen without a hand lens. How does 
the grasshopper's range of vision compare with that of the crayfish?

Are the antennæ flexible? What is their shape? Position? Are they segmented? Touch an antenna, a wing, a leg, and the abdomen in succession. Which seems to be

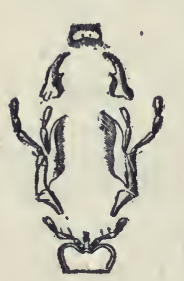
the most sensitive to touch? The antennæe are for feeling. In some species of insects they also are organs of hearing and smelling. The mouth parts of a grasshopper should be compared with the mouth parts of a beetle shown in Fig. I I3, since they correspond

FIG. ri3. closely. If the grasshopper is fed with a blade of fresh grass, the function of each organ may be plainly seen. It is almost impossible to understand these functions by studying a dead specimen, but a fresh specimen is much better than a dry one.

The upper lip, or labrum, is seen in front. Is it tapering or expanded? In what direction is it movable? The dark pointed biting jaws (mandibles) are next. Are they curved

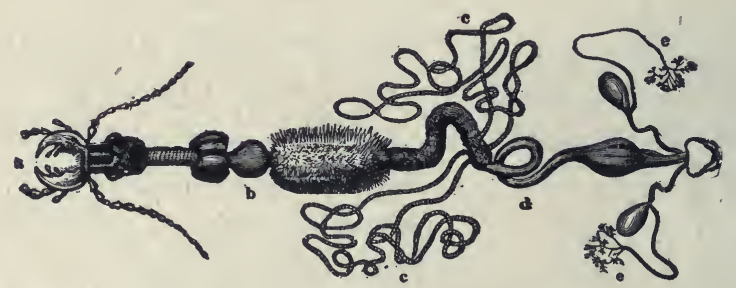

FIG. II4. $-a$, FOOD TÜBE OF BEeTLE.

b, gizzard; $d$, intestine; $c$, biliary vessels. See Fig. 127.

or straight? Sharp or blunt pointed ? Notched or smooth? Do they work up and down, or sideways? The holding jaws (maxilla), each with two jaw fingers (maxillary palpi), are behind the chewing jaws. Why? The lower lip (labium) has a pair of lip fingers (labial palpi) upon it. The brown 
tongue, usually bathed in saliva, is seen in the lower part of the mouth. Since the grasshopper has no lips, or any way of producing suction, it must lap the dew in drinking. Does it merely break off bits of a grass blade, or does it chew?

The heart, circulation, nervous system, digestive and respiratory organs of the grasshopper agree mainly with the general description of the organs of insects given in the next section.

Microscopic Objects. - These may be bought ready mounted, or may be examined fresh. A portion of the covering of the large eye may be cut off and the dark layer on the inside of the covering scraped off to make it transparent. What is the shape of the facets? Can you make any estimate of their number? A portion of the transparent hind wing may be used, and the "veins" in it studied. A
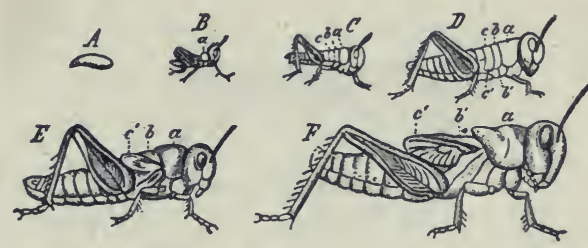

Fig. 115.-Egg AND Moults of A Grasshopper.

thin bit of an abdominal segment containing a spiracle will show the structure of these important organs.

Growth of the Grasshopper. - Some species hibernate in sheltered places and lay eggs in the spring, but adult species are scarce at that season. Most species lay the eggs in the fall ; these withstand the cold and hatch out in the spring. Those hatched from one set of eggs sometimes stay together for a few days. They eat voraciously, and as they grow, the soft skin becomes hardened by the deposit of horny substance called chitin. This retardsfurthergrowth until the insect moults, the skin first splitting above the prothorax. After hatching, there are five successive periods of growth. At which moult do the very short wings first appear? (Fig.115) 
After the last moult the animal is complete, and changes no more in size for the rest of its life. There has been an

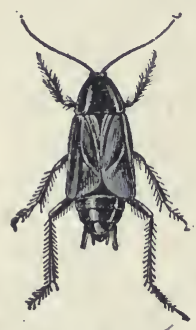

FIG. I16. COCKROACH. attempt among writers to restrict the term grasshopper to the long-winged, slender family, and to call the shorter winged, stouter family locusts, according to old English usage.

Economic Importance of Grasshoppers. Great injury is often done to vegetation by grasshoppers; however, the millions of tiny but ravenous eaters hatched in early spring are usually soon thinned out by the birds. The migratory locusts constitute a plague when they appear, and

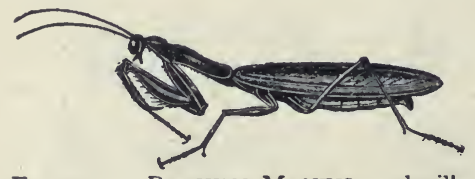

FIG. I17. - PRAYING MANTIS, or devil's horse.

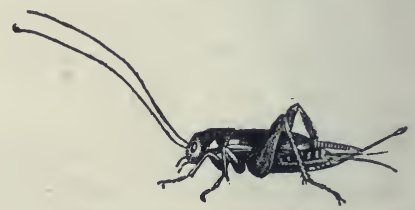

FIG. II8. - CRICKET.

they have done so since ancient times. The Rocky Mountain locusts flying eastward have darkened the sky, and where they settled to the earth ate almost every green thing. In $1874-5$ they produced almost a famine in Kansas, Nebraska,

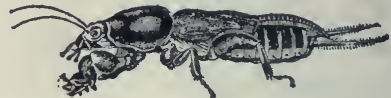

Fig. IIg. - MOĹE CRICKET. and other Western states. The young hatched away from the mountains were not healthy,

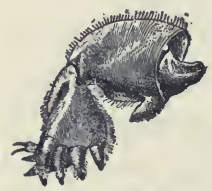

FIG. I20. - FRONT

LEG OF MOLE Cricket. $\times 3$. and died prematurely, and their devastations came to an end. Of course the migrations may occur again. Packard calculates that the farmers of the West lost $\$ 200,000,000$ because of grasshopper ravages in $1874-5$. 
The cockroaches (Fig. 116), kindred of the grasshoppers, are household pests that have migrated almost everywhere that ships go. The praying mantis (Fig. II 7 ), or devil's horse, also belongs to this order. It is beneficial, since it destroys noxious insects. Which of its legs are specialized? The walking stick (Fig. 121) and the cricket (Fig. 118), like most members of the order, are vegetarian.

Are grasshoppers more common in fields and meadows, or in wooded places? How many different colours have you seen on grasshoppers? Which colours are most common?

Grasshoppers are very scarce in Europe as they love dry, warm countries. Why do locusts migrate? Give an instance in ancient times.

How long do most grasshoppers live? Does a grasshopper spread its wings before it flies? Does it jump and fly together? Can it select the place for alighting?

Note TO TEACHER. - Ficld work in Zoology should be systematic. Every trip has a definite region and definite line of

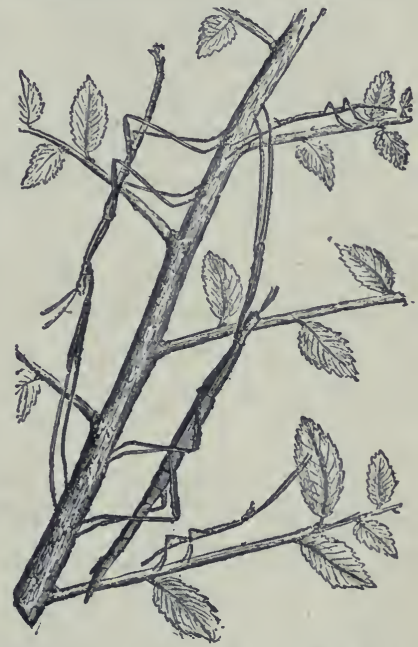

FIG. I2I. - FOUR WALKING STICK INSECTS.

study in view, but every animal seen should be noted. The habitat, adaptation by structure and habits to the environment, relations to other animals, classification of animals seen, should be some of the ideas guiding the study. The excursions may be divided somewhat as follows, according as opportunities offer: Upland woods, lowland woods, upland pastures, fields, swamps, a freshwater lake, a pond, lower sea beach, higher sea beach, sand hills along shore, roadside, garden, haunts of birds, insect visits to flowers, ground insects, insects in logs. 
Collecting Insects.- In cities and towns insects, varying with the season, are attracted by electric lights. Beetles and bugs will be found under the lights, moths on posts near the lights, grasshoppers and crickets and other insects in the grass near by. A lamp placed by a window brings many specimens. In the woods and in rocky places insects are found under logs and stones, and under the bark of dead trees. In open places, prairies, meadows, and old fields with grass and flowers, it will be easy to find grasshoppers, butterflies, and some beetles. Ponds and streams are usually rich in animal forms, such as bugs and beetles, which swim on or under the surface, and larvæ of dragon flies crawling on the bottom. Dragon flies and other insects that lay eggs on the water are found flying in the air above. (In the spring, newly hatched crayfish, tadpoles, and the eggs of frogs and toads should also be collected, if found.) Moths may be caught at night by daubing molasses or syrup made from brown sugar upon the trunks of several trees, and visiting the trees at intervals with a lantern.

An insect net for catching butterflies and for dredging ponds may be made by bending a stout wire into a circle one foot in diameter, leaving enough straight wire to fasten with staples on an old broomstick. To the frame is fastened a flour sack, or cone made of a piece of mosquito netting.

Butterflies and moths should be promptly killed, or they will beat their wings to pieces. The quickest method is by dropping several drops of gasoline upon the ventral (under) side of the thorax and abdomen. (Caution: Gasoline should never be used near an open fire, or lamp, as explosions and deaths result from the flame being led through the gasoline-saturated air to the vessel containing it.) 
A cigar box and a bottle with a notched cork may be used for holding specimens. Cigar boxes may be used for holding collections of dried insects. Cork or ribbed packing paper may be fixed in the bottom for supporting the insect pins. Moth balls or tobacco may be placed in each box to keep out the insect pests which infest collections.

Captured insects which, in either the larval or the perfect stage, are injurious to vegetation, should always be killed after studying their actions and external features, even if the internal structure is not to be studied. Beneficial insects, such as ladybugs, ichneumon flies, bees, mantis (devil's horse), dragon flies, etc., should be set free uninjured.

Anatomy and General Characteristics of the Class INSECTA

The body of an insect is divided by means of two marked narrowings into three parts: the head, the chest, and the abdomen.

The head is a freely movable capsule bearing four pairs of appendages. Hence it is regarded as having been formed by the union of four rings, since the ancestor of the insects is believed to have consisted of similar rings, each ring bearing a pair of unspecialized legs.

The typical mouth parts of an insect (Fig. 123) named in order

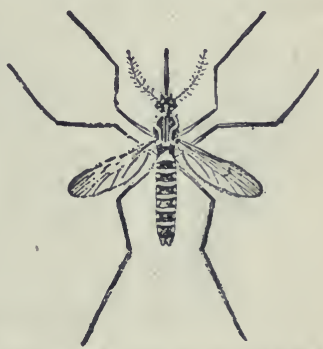

Fig. 122. - YeLLOW FEVER Mosquito, showing head, thorax, abdomen.

from above, are (I) an upper lip (labrum, ol), (2) a pair 
of biting jaws (mandibles, ok), (3) a pair of grasping jaws (maxillæ, $A, B$ ), and (4) a lower lip (labium, $m, a, b$ ).

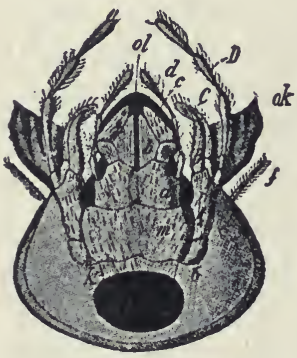

Fig. I23. - MOUTH The grasping jaws bear two pairs of jointed jaw fingers (maxillary palpi, $D, C)$, and the lower lip bears a pair of similar lip fingers (labial palpi, $d$ ). The biting jaws move sideways; they usually have several pointed notches which serve as teeth. Why should the grasping jaws be beneath the chewing jaws? Why is it better for the lower lip to have fingers than the upper lip?

Why are the fingers (or palpi) jointed? (Watch a grasshopper or beetle eating.) Why does an insect need grasping jaws?

The chest, or thorax, consists of three rings (Fig. I24) called the front thorax (prothorax), middle thorax (mesothorax) and hind thorax (metathorax), or first, second, and third rings.

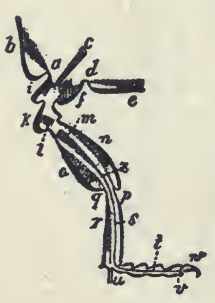

FIG. 125. - LEG OF INSECT.
The first ring bears the first pair of legs, the second ring bears the second pair of legs and the upper or front wings, and the third ring bears the third pair of legs and the under or hind wings.

The six feet of insects are characteristic of them, since no other adult animals have that number, the spider having eight, the cray fish and crabs having ten, the centipedes still more, while birds and beasts have less than six. Hence the insects 
are sometimes called the Six-Footed class (Hexapoda). The insects are the only animals that have the body in three divisions. Man, beasts, and birds have only two divisions (head and trunk). Worms are not divided.

Define the class insecta by the two facts characteristic of them (i.e. possessed by them alone), viz. : Insects are animals with — and Why would it be ambiguous to include "hard outer skeleton" in this definition? To include "bilateral symmetry"? "Segmented body"? The definition of a class must include all the individuals of the class, and exclude all the animals that do not belong to the class.

The leg of an insect (Fig. 125) has five joints (two short joints, two long, and the foot). Named in order from above, they are (I) the hip (coxa), (2) thigh ring (trochanter), (3) thigh (femur), (4) the shin (tibia), (5) the foot, which has five parts. Which of the five joints of a wasp's leg (Fig. 16I) is thickest? Slenderest? Shortest? One joint (which?) of the foot (Fig. I6I) is about as long as the other four joints of the foot combined. Is the relative length of the joints of the leg the same in

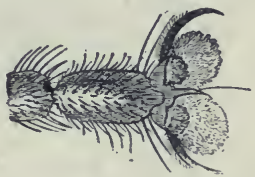

FIG. 126. - FooT OF FLY, with climbing pads. grasshoppers, beetles, etc., as in the wasp (Figs.)? Figure 125 is a diagram of an insect's leg cut lengthwise. The leg consists of thick-walled tubes $(o, n)$ with their ends held together by thin, easy-wrinkling membranes which serve as joints. Thus motion is provided for at the expense of strength. When handling live insects they should never be held by the legs, as the legs come off very easily. Does the joint motion of insects most resemble the motion of hinge joints or ball-and-socket joints? Answer by tests of living insects. There are no muscles in the foot of an insect. The claw is moved by a muscle $(m)$ in the thigh with which it is connected by the long tendon $(z, s, t, v)$. In which part are the breathing muscles? As the wings are developed from folds of the dorsal skin, the wing has two layers, an upper and a lower layer. These inclose the so-called "nerves" or ribs of the wing, each of which consists of a blood tube inclosed in an air tube. 
The abdomen in various species consists of from five to eleven overlapping rings with their foldlike joints between them. Does each ring overlap the ring in front or the one behind it?

The food tube (Fig. 127) begins at the mouth, which usually bears salivary glands (4, Fig. I27, which represents internal organs of the grasshopper). The food tube expands first into a croplike enlargement; next to this is an organ (6, Fig. 127), which resembles the gizzard

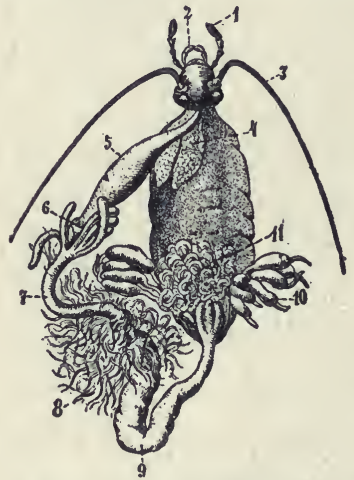

FIG. I27. - VISCERA OF

GRASSHOPPER. Key in text. Compare with Fig. II4.

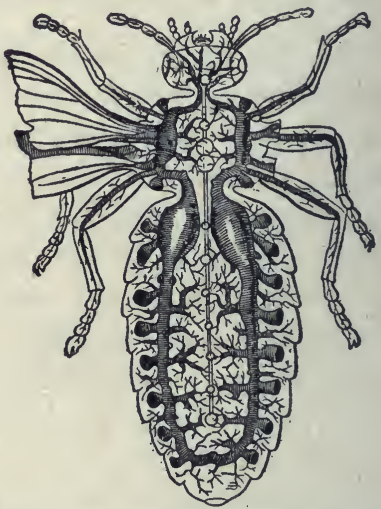

FIG. 128. - AIR TUBES OF INSECT.

in birds, as its inner wall is furnished with chitinous teeth (b, Fig. I I 4$)$. These reduce the food fragments that were imperfectly broken up by the biting jaws before swallowing. Glands comparable to the liver of higher animals open into the food tube where the stomach joins the small intestine. At the junction of the small and the large intestine (9) are a number of fine tubes (8) which correspond to kidneys and empty their secretion into the large intestine.

The breathing organs of the insects are peculiar to them (see Fig. 128). They consist of tubes which are 
kept open by having in their walls continuous spirals of horny material called chitin. Most noticeable are the two large membranous tubes filled with air and situated on each side of the body. Do these tubes extend through the thorax? (Fig. 128.) The air reaches these two main tubes by a number of pairs of short windpipes, or tracheas, which. begin at openings (spiracles). In which division are the spiracles most numerous? (Fig. 128.)

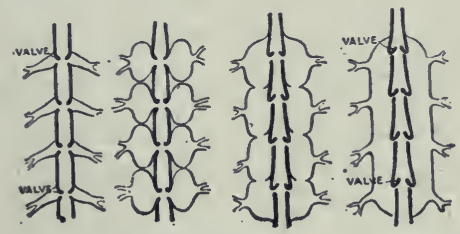

Fig. 130. - Diagrams of Evolution OF PERICARdial SAC around insect's heart from a number of veins (Lankester).

Which division is

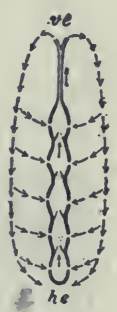

FIG. I29. INSECT'S HEART (plan). be drowned, i.e. smothered, by holding its body 'under water? Could it be drowned by immersing all of it but its head? The motion of the air through the breathing tubes is caused by a bellowslike motion of the abdomen. This is readily observed in grasshoppers, beetles, and wasps. As each ring slips into the ring in front of it, the abdomen is shortened, and the impure air, laden with carbon dioxide, is forced out. As the rings slip out, the abdomen is extended and the fresh air comes in, bringing oxygen.

\section{The Circulation. -} Near the dorsal surface of the abdomen (Fig.

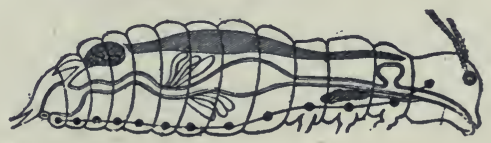

I3 I) extends the long, slender heart (Fig. I29). The heart has divisions separated by valvelike partitions. The blood comes into each of the heart compartments through a pair of openings. The heart contracts from the rear toward 
the front, driving the blood forward. The blood contains bodies corresponding to the white corpuscles of human blood, but lacks the red corpuscles and the red colour. The blood is sent even to the wings. The veins in the wings consist of horny tubes inclosing air tubes surrounded by blood spaces, and the purification of the blood

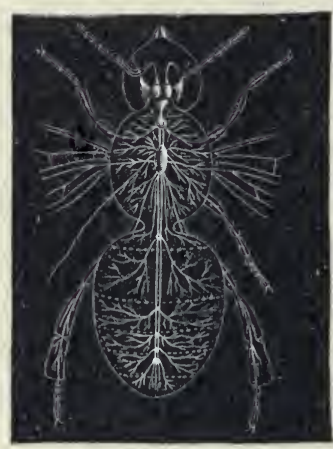

FIG. I32. - NERVOUS SYSTEM OF BEE. takes place throughout the course of the circulation. Hence the imperfect circulation is no disadvantage. The perfect provision for supplying oxygen explains the remarkable activity of which insects are capable and their great strength, which, considering their size, is unequalled by any other animals.

The Nervous System. - The heart in backboned animals, e.g. man, is ventral and the chief nerve trunk is dorsal. As already stated, the heart of an insect is dorsal; its chief nerve chain, consisting of a double row of ganglia, is near the ventral surface (Fig. 13I). All the ganglia are below the food tube except the first pair in the head, which are above the gullet. This pair may be said to correspond somewhat to the brain of backboned animals; the nerves from the eyes and the feelers lead to it. With social insects, as bees and ants, it is large and complex (Fig. I 32). In a typical insect they are the largest ganglia.

The Senses. - The sense of smell of most insects is believed to be located in the feelers.

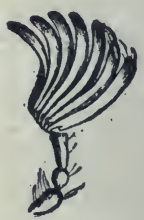

FIG. I33.FEELER of a beetle. The organ of hearing is variously located in different insects. Where is it in the grasshopper? The organs of 
sight are highly developed, and consist of two compound eyes on the side of the head and three simple eyes on the top or front of the head between the compound eyes. The simple eye has nerve cells, pigments, and a lens resembling the lens in the eyes of vertebrates (Fig. 134). The compound eye (Fig. I35) has thousands of facets, usually hexagonal, on its surface, the facets being the outer ends of cones which have their inner ends directed toward the centre of the eye. It is probable that the large, or

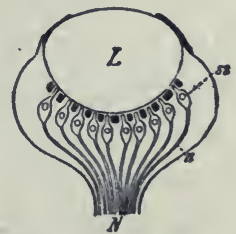

FIG. 134.-Diagram of simple eye of insect.

$L$, lens: $N$, optic nerve. compound, eyes of insects only serve to distinguish bright objects from dark objects. The simple eyes afford dis-

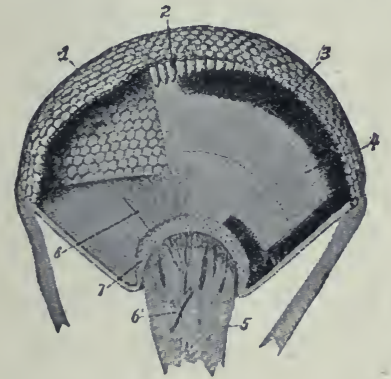

Fig. 135. - COMPOUND Eye OF INSECT.

I, hexagonal facets of crystalline cones. 6 , blood vessel in optic nerve. tinct images of objects within a few inches of the eye. In general, the sight of insects, contrary to what its complex sight organs would lead us to expect, is not at all keen. Yet an insect can fly through a forest without striking a twig or branch. Is it better for the eyes that are immovable in the head to be large or small? Which has comparatively larger eyes, an insect or a beast?

Inherited Habit, or Instinct. - Insects and other animals inherit from their parents their particular form of body and of organs which perform the different functions. For example, they inherit a nervous system with a structure similar to that of their parents, and hence with a tendency to repeat similar impulses and acts. Repeated acts constitute a habit, and an inherited habit is called an in- 
stinct. Moths, for example, are used to finding nectar in the night-blooming flowers, most of which are white. The habit of going to white flowers is transmitted in the structure of the nervous system; so we say that moths have an instinct to go to white objects; it is sometimes more obscurely expressed by saying they are attracted or drawn thereby.

Instincts are not Infallible. - They are trustworthy in. only one narrow set of conditions. Now that man makes many fires and lights at night, the instinct just mentioned often causes the death of the moth. The instinct to provide for offspring is necessary to the perpetuation of all but the simplest animals. The dirt dauber, or mud wasp, because of inherited habit, or instinct, makes the cell of the right size, lays the egg, and provides food for offspring that the mother will never see. It seals stung and semiparalyzed spiders in the cell with the egg. If you try the experiment of removing the food before the cell is closed, the insect will bring more spiders; if they are removed again, a third supply will be brought; but if taken out the third time, the mud wasp will usually close the cell without food, and when the egg hatches the grub will starve.

The Development of Insects.-The growth and the moulting of the grasshopper from egg to adult has been studied. All insects do not develop exactly by this plan. Some hatch from the egg in a condition markedly different from the adult. The butterfly's egg produces a wormlike caterpillar which has no resemblance to the butterfly. After it grows it forms an inclosing case in which it spends a quiet period of development and comes out a butterfly. This change from caterpillar to butterfly is called the metamorphosis. The life of an insect is divided into four 
stages : (I) egg, (2) larva, (3) pupa, and (4) imago, or perfect insect (Figs. I 36, I 37, I 38).

The egg stage is one of development, no nourishment being absorbed. The larval stage is one of voracious feeding and rapid growth. In the pupa stage no food is taken and there is no growth in size, but rapid development takes place. In the perfect stage food is eaten, but no growth in size takes place. In this stage the eggs are produced. When

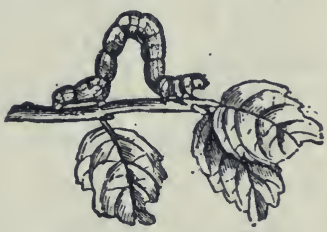

FIG. I36. - Measuring worm, the larva of a moth.

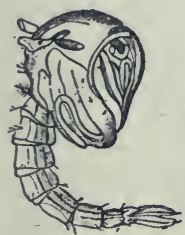

FIG. 137.- Pupa

there is very little resemblance between the larva and the imago, and pupal stage, the metamorphosis, or change, is said to be complete. When, as with the grasshopper, no very marked change takes place between the larva and the imago, there being no pupal stage, the metamorphosis is said to be incomplete. By studying the illustrations and specimens, and by thinking of your past observations of insects, determine which of the insects in the following list have a complete metamorphosis : beetle, house fly, grasshopper, butterfly, cricket, wasp.
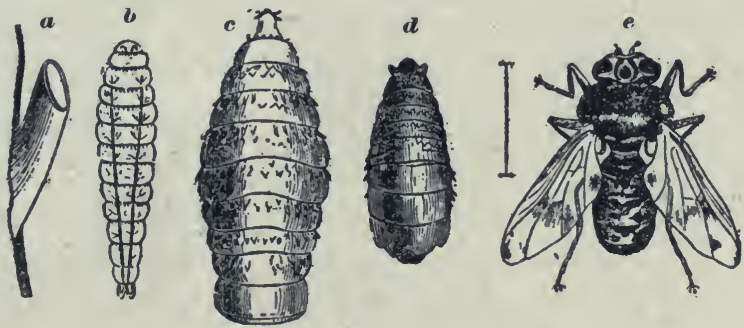

FIG. 138. - The Four Stages of A Botfly, all enlarged.

$a$, egg on hair of horse (bitten off and swallowed): $b$, larva; $c$, larva with hooks for holding to lining of stomach; $d$, pt: pal stage, passeu in the earth; $e$, adult horse fly. 


\section{RECOGNITION-CHARACTERS FOR THE PRINCIPAL ORDERS OF ADULT WINGED INSECTS}

(All are wingless when young, and wingless adult forms occur in all the orders: order APTERA lacks wing-bearing thoracic structures.)

A single pair of wings is characteristic of the order Diptera.

A jointed beak, that is sheath-like, inclosing the other mouth parts, is characteristic of the order HEMIPTERA.

A coiled sucking proboscis and a wing covering of dust-like microscopic scales are characteristic of the order LEPIDOPTERA.

Horny sheath-like fore wings, covering the hind wings and meeting in a straight line down the middle of the back, will dis. tinguish the order COLEOPTERA.

Hind wings folded like a fan beneath the thickened and overlapping fore wings, will distinguish most members of the order ORTHOPTERA.

The possession of a sting (in females) and of two pairs of thin membranous wings - the small hind wing hooked to the rear margin of the fore wing - will distinguish the common HymenopterA.

Besides these, there remain a number of groups most of which have in the past been included under the order Neuroptera, among which the Mayflies will be readily recognized by the lack of mouth parts and by the possession of two or three long tails ; the dragon flies by the two pairs of large wings, enormous eyes, and minute bristle-like antennæ; the scorpion flies, by the possession of a rigid beak, with the mouth parts at its tip; the caddis flies, by their hairy wings and lack of jaws; the lace wings, by the exquisite regularity of the series of cross veins about the margin of their wings, etc. 


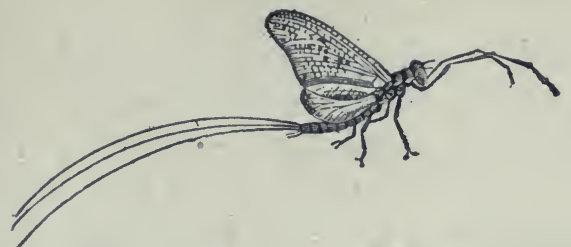

FIG, 139. - MAY FLY. What order (see table)?

Exercise in the Use of the Table or Key.Write the name of the order after each of the following names of insects :-

Wasp (Fig. 122)

Weevil (Fig. 163)

Squash bug ( Fig. 184)

Ant lion (Fig. 170)

Dragon fly (Fig. I77)

Ichneumon fly (Fig. 159)
House fly (Fig. 172)

Flea (Fig. 173)

Silver scale or earwig

(Fig. 140)

Codling moth (Fig. I4I)

Botfly (Fig. 1 38 )

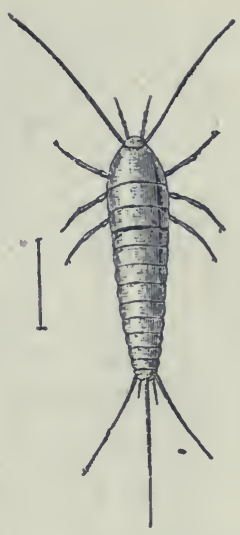

FIG. I40. - SILVER SCALE. (Order?)

\section{Moths and Butterflies._- Order___ ? Why__ (p. 82)?}

The presence of scales on the wings is a never-failing test of a moth or a butterfly. The wings do not fold at all. They are so large and the legs so weak and delicate that the butterfly keeps its balance with difficulty when walking in the wind.

The maxillæ are developed to form the long sucking proboscis. How do they fit together to form a tube? (See Fig. 147.) The proboscis varies from a fraction of an inch in the "miller" to five inches in some tropical moths, which use it to extract nectar from long tubular flowers. When not in use, it is held coiled like a watch spring under the head (Fig. I48). The upper lip (labrum), under lip (labium), and lip fingers (labial palpi) are very small, and the mandibles small or wanting (Fig. 146).

The metamorphosis is complete, the contrast between the caterpillar or larva of the moth and the butterfly and the adult form being very great. The caterpillar has the three pairs of jointed legs typical of insects; these are 
found near the head (Fig. I4I). It has also from three to five pairs of fleshy unjointed proplegs, one pair of which is always on the last segment. How many pairs of pro-legs has the silkworm caterpillar? (Fig. 143.) The measuring worm, or looper? (Fig. 136.) The pupa has a thin shell. Can you see external signs of the antennæ, wings, and legs in this stage? (Fig. I43.) The pupa is concealed by protective coloration and is sometimes inclosed in a silken cocoon which was spun by the caterpillar before the last moult. Hairy caterpillars are uncomfortable for birds to eat. The naked and brightly marked ones (examples of warning coloration) often contain an acrid and distasteful fluid. The injuries from lepidoptera are done in the caterpillar stage. The codling moth (Fig. I4I) destroys apples to the estimated value of $\$ 6,000,000$ annually. The clothes moth (Fig. I7I) is a household pest. The tent caterpillar denudes trees of their leaves. The only useful caterpillar is the silkworm (Fig. 143). In Italy and Japan many of the country dwellings have silk rooms where thousands of these caterpillars are fed and tended by women and children. Why is the cabbage butterfly so called? Why can it not eat cabbage? Why does sealing clothes in a paper bag prevent the ravages of the clothes moth?

Flight of Lepidoptera. - Which appears to use more exertion to keep afloat, a bird or a butterfly? Explain why. Of all flying insects which would more probably be found highest up mountains? How does the butterfly suddenly change direction of flight? Does it usually fly in a straight or a zigzag course? Advantage of this? Bright colours are protective, as lepidoptera are in greatest danger when at rest on flowers. Are the brightest colours on upper or under side of wings of butterfly?. Why? (Think of the 
colours in a flower.) Why is it better for moths to hold their wings flat out when at rest? Where are moths during the day? How can you test whether the colour of the wings is,given by the scales?

State how moths and butterflies differ in respect to: body, wings, feelers, habits.

Insects and Flowers. - Perhaps we are indebted to insects for the bright colours and sweet honey of flowers. Flowers need insects to carry their pollen to other flowers, as cross-fertilization produces the best seeds. The insects need the nectar of the flowers for food, and the bright colours and sweet odours are the advertisements of the flowers to attract insects. Flowers of brightest hues are the ones that receive the visits of insects. Moths, butterflies, and bees carry most pollen (see Beginners' Botany, Chap. VI).

Comparative Study. - Make a table like this, occupying entire page of notebook, leaving no margins, and fill in accurately:-

\begin{tabular}{|c|c|c|c|c|c|c|}
\hline & $\begin{array}{l}\text { GRASS- } \\
\text { HOPPER }\end{array}$ & $\begin{array}{l}\text { BUTrER- } \\
\text { FLY }\end{array}$ & \begin{tabular}{|c|} 
FLY \\
pp. 92,93
\end{tabular} & \begin{tabular}{|c|} 
DRAGON \\
FLY, p. 93 \\
\end{tabular} & \begin{tabular}{|c|} 
BEETLE \\
pp. $90,9 I$
\end{tabular} & $\begin{array}{c}\text { BEE } \\
\text { pp. } 88,89\end{array}$ \\
\hline $\begin{array}{l}\text { Number and kind } \\
\text { of wings }\end{array}$ & I/ $/ 40$ & aphing & & & & \\
\hline Description of legs & & & & & & \\
\hline $\begin{array}{l}\text { Antennæ (length, } \\
\text { shape, joints) }\end{array}$ & & & & & & \\
\hline $\begin{array}{l}\text { Biting or sucking } \\
\text { mouth parts }\end{array}$ & 13 & 5 & 5 & 5 & $S$ & 83 \\
\hline $\begin{array}{l}\text { Complete or incom- } \\
\text { plete metamor- } \\
\text { phosis. }\end{array}$ & & & & & & \\
\hline
\end{tabular}




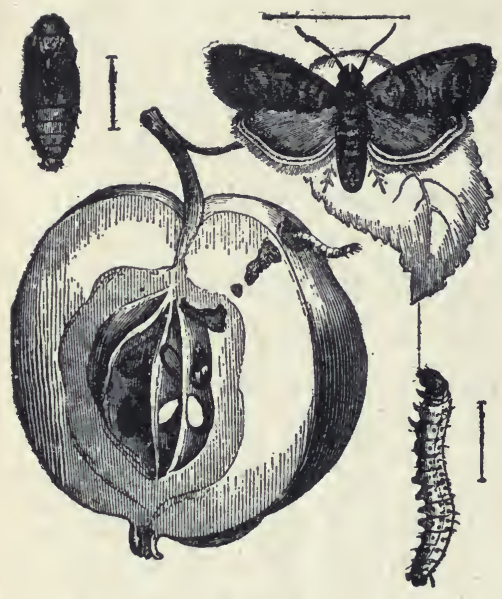

FIG. I4I. - CoDLING MoTH, from egg to adult. (See Farmers' Bulletin, p. 95.)

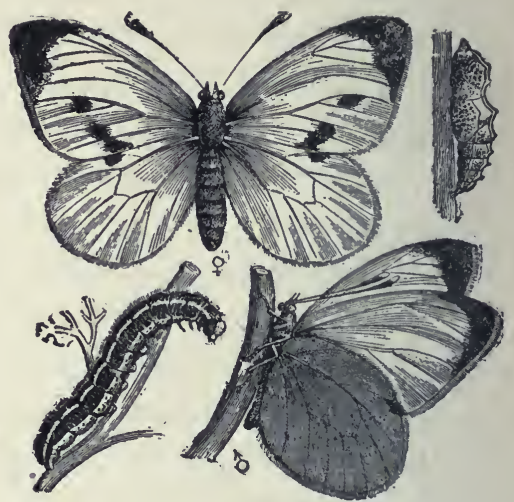

Fig. I42. - CABbage BUtTerfly, male and female, larva and pupa.

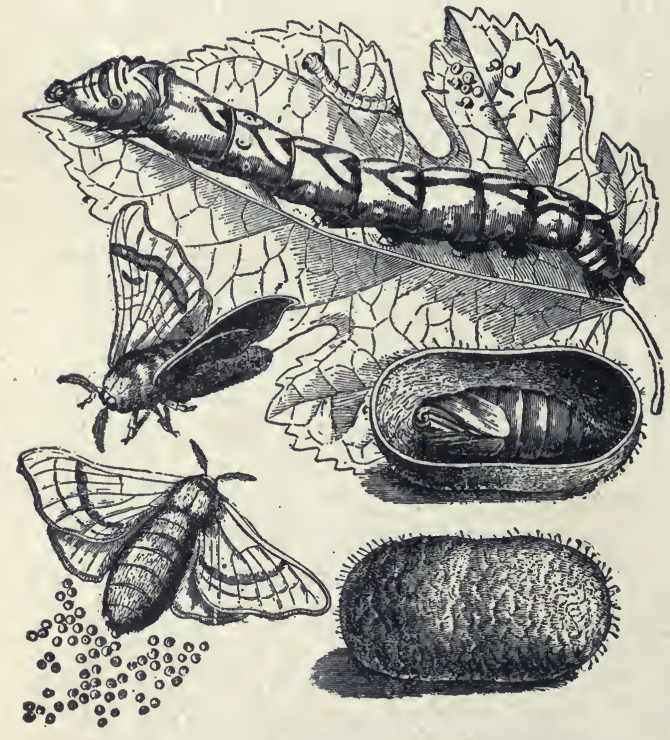

FIG. I43. - LIFE HISTORY OF SILKWORM.
(4) (1)
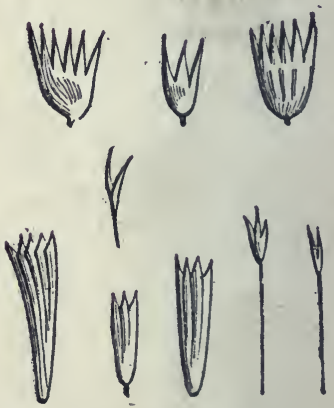

FIG. I44. - SCALES FROM BUTTERFLIES' WINGS, as seen under microscope. 
TO THE TEACHER: These illustrated studies require slower and more careful study than the text. One, or at most two, studies will suffice for a lesson. The questions can. be answered by studying the figures.

FIGS I4I-I48. Illustrated Study of Lepidoptera.Study the stages in the development of codling moth, silkworm moth, and cabbage butterfly.

Where does each lay its eggs? What does the larva of each feed upon? Describe the pupa of each. Describe the adult forms. Find the spiracles and prolegs on the silkworm. Compare antenna of moth and butterfly. Which has larger body compared to size of wings?

Describe the scales from a butterfly's wings as seen under microscope (I44). How are the scales arranged on moth's wing (145)? By what part is scale attached to wing? Do the scales overlap?

Study butterfly's head and proboscis (Figs. I46-I48). What shape is compound eye? Are the antennæ jointed? Is the proboscis jointed? Why not call it a tongue? (See text.)

Which mouth parts have almost disappeared? What is the shape of cut ends of halves of proboscis? How are the halves joined to form a tube?

If you saw a butterfly on a flower, for what purpose would you think it was there? What, if you saw it on a leaf? How many spots on fore wing of female cabbage butterfly? (Fig. 124, above.)

Does the silkworm chrysalis fill its cocoon ?

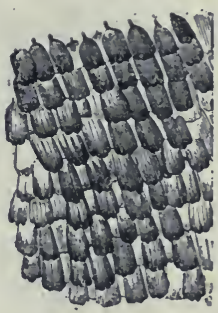

FIG. 145.-SCALES ON MOTH'S WING.

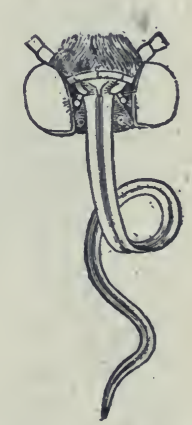

FIG. I46. - HEAD OF BUTTERFLY.

FIG. I48. - HEAD OF BUTTERFLY (side view).
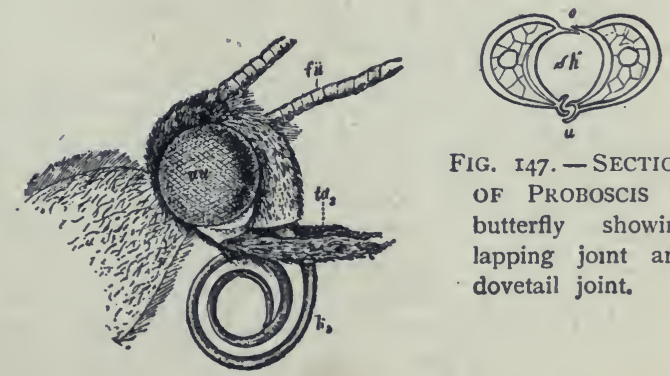

FIG. I47. - SECTION of РRовоscis of butterfly showing lapping joint and dovetail joint. 


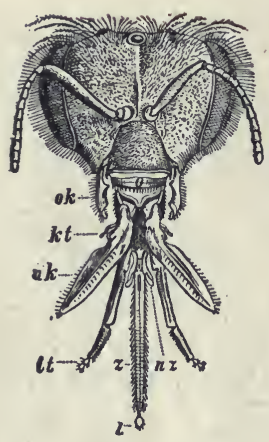

FIG. I49.

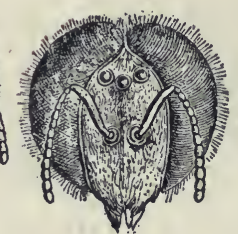

FIG. I50.

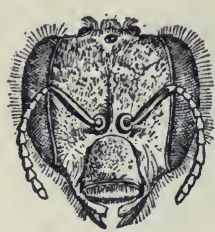

FIG. I5I.

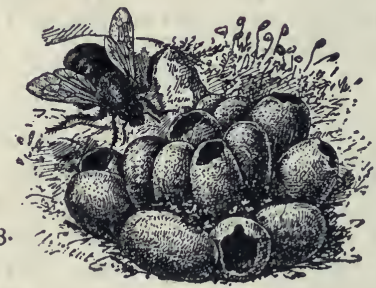

FIG. I53.

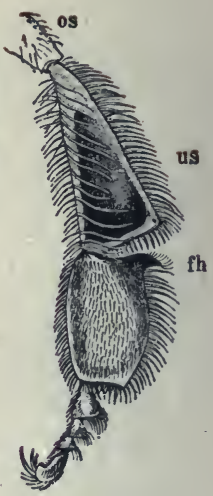

FIG. 152 .

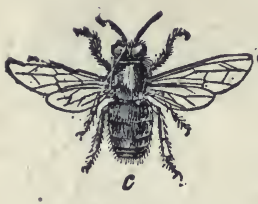

FIG. I54.

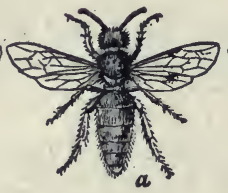

FIG. I55.

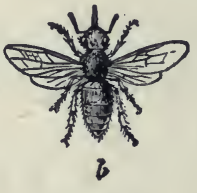

FIG. I56.

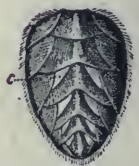

FIG. 157 .

FIGs. I49-16I. Illustrated Study of Bees and their Kindred. - Head of worker (Fig. I49) : $o$, upper lip; $o k$, chewing jaws; $u k$, grasping jaws; $k t$, jaw finger: $l t$, lip finger; $z$, tongue.

How do heads of drone (I5O) and queen (I5I) differ

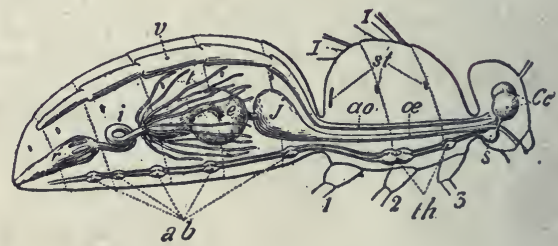

FIG. I58. - Anatomy of bee. as to mouth, size of the two compound eyes, size and position of the three simple eyes? Is the head of a worker more like head of drone or head of queen ? Judging by the head, which is the queen, drone, and worker in Figs. $154-156$ ? Which of the three is largest ? Smallest? Broadest?

Figure 152 shows hind leg of worker. What surrounds the hollow, $u$ s, which serves as pollen basket? The point, $f h$, is a tool for removing wax which is secreted ( $c$, Fig. I57) between rings on abdomen. In Fig. 158, find relative positions of heart, $v$, food tube, and nerve chain. Is crop, $J$, in thorax or abdomen? In this nectar is changed to honey, that it may not spoil. Compare nerve chain in Fig. I32. 
Compare the cells of bumble bee (Fig. 153) with those of hive bee. They differ not only in shape but in material, being made of web instead of wax, and they usually contain larvæ instead of honey. Only a few of the queens among bumble bees and wasps survive the winter. How do ants and honey bees provide for the workers also to survive the win-

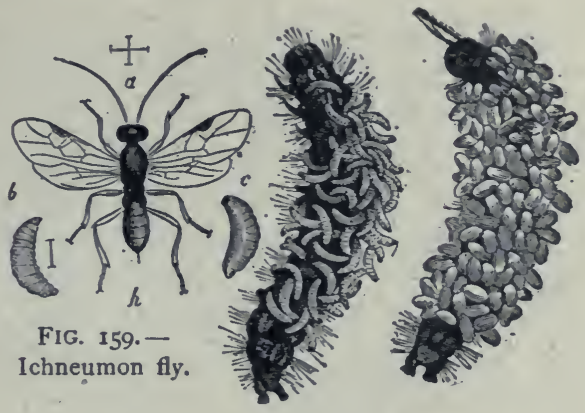
ter? Name all the social insects that you can think of. Dc they all belong to the same order ?

The ichneumon fly shown enlarged in Fig. I59 lays its eggs under a caterpillar's skin. What becomes of the eggs? The true size of the insect is shown by the cross lines at $a$. The eggs are almost microscopic in size. The pupæ shown (true size) on caterpillar are sometimes mistaken for eggs. The same mistake is made about the pupa cases of ants. Ichneumon flies also use tree-borers as "hosts" for their eggs and larva. Is this insect a friend of man?

The diggrng wasp (Figs. 160 and 161 ) supplies its larva with caterpillars and closes the hole, sometimes using a stone as pounding tool. Among the few other uses of tools among lower animals are the elephant's use of a branch for a fly brush, and the ape's use of a walking stick. This wasp digs with fore feet like a dog and kicks the dirt out of the way with its hind feet.

Are the wings of bees and wasps more closely or less closely veined than the wings of dragon flies? (Fig. 177.)

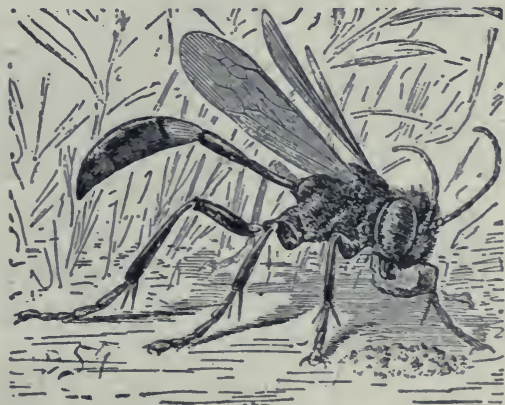

FIG. I6I. - Wasp using pebble.

From Peckham's "Solitary Wasps," Houghton, Mifflin \& Co. 


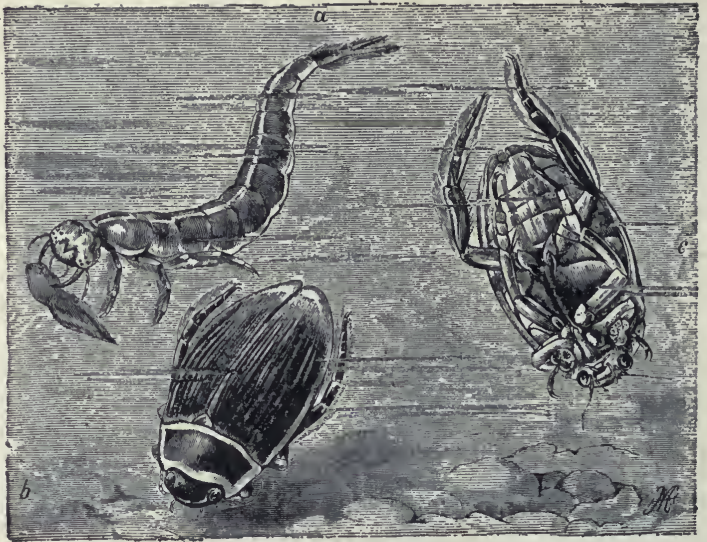

Illustrated Study of

Beetles.

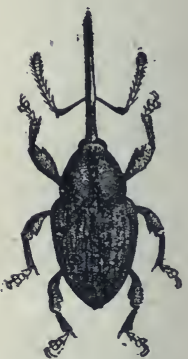

F1G. 162, - Diving beetle (Dytiscus), with larva, $a_{0}$

FIG. 163. -Weevil.

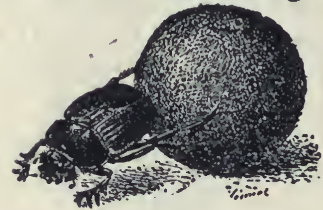

FIG. I64.

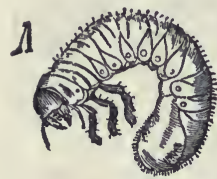

FIG. I67. - MAY BEETLE.

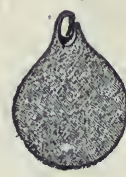

FIG. I65.

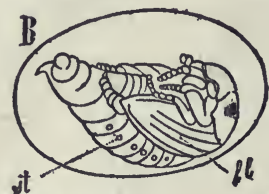

ot

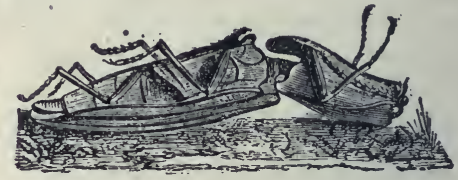

FIG. I66. - Click beetle.

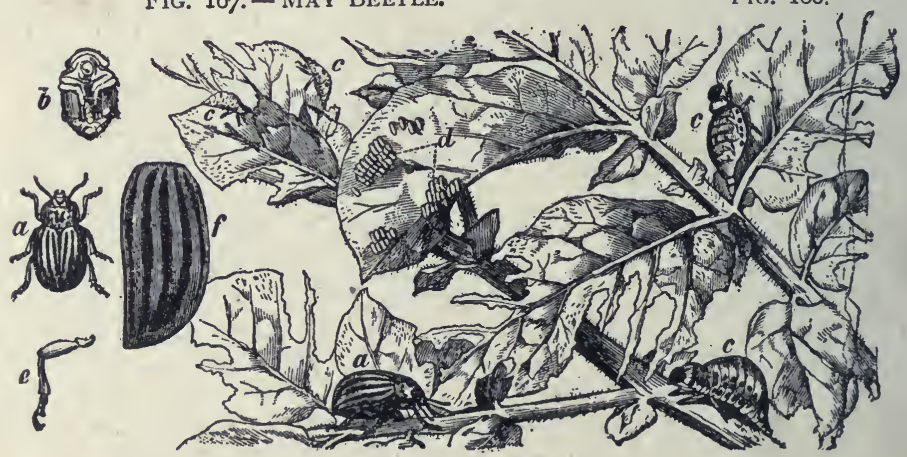

FIG. I69. - Colorado beetle (potato bug). 
Mlustrated Study of Beetles (Figs. I62-169). - Write the life history of the Colorado beetle, or potato bug (Fig. I69), stating where the eggs are laid and describing the form and activities of each stage (the pupal stage, $b$, is passed in the ground).

Do the same for the May beetle (Figs. 167-I68). (It is a larva - the white grub - for three years; hogs root them up.) Beetles, like moths, may be trapped with a lantern set above a tub of water.

Where does a Scarab (or sacred beetle of the Egyptians), also called tumble bug (Fig. I64), lay its eggs (Fig. I65)? Why ?

How does the click beetle, or jack snapper (Fig. I66), throw itself into the air? For what purpose?

The large proboscis of the veevil (Fig. I63) is used for piercing a hole in which an egg is laid in grain of corn, boll of cotton, acorn, chestnut, plum, etc.

How are the legs and body of the diving beetle suited for swimming (Fig. 162)? Describe its larva.

What is the shape of the lady bug (Fig. 97)? It feeds upon plant lice (Fig. 185). Is any beetle of benefit to man?

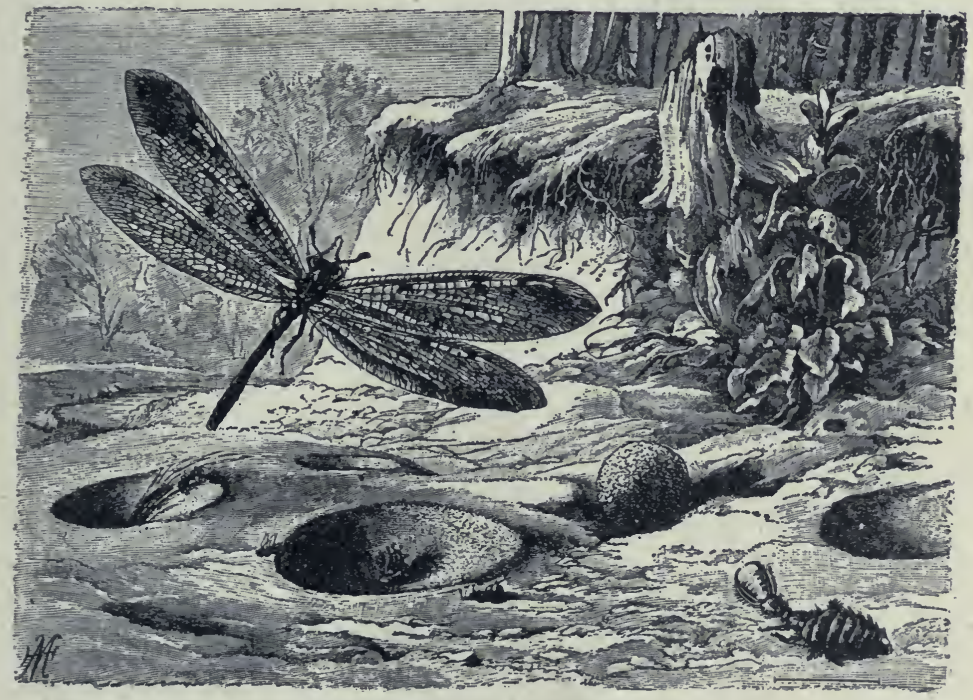

FIG. I70. - Life history of ant lion.

Illustrated Study of Ant Lion, or Doodle Bug (Fig. I70). - Find the pitfall (what shape ?) ; the larva (describe it) ; the pupa case (ball covered with web and sand); the imago. Compare imago with dragon fly (Fig. 177).

How does ant lion prevent ant from climbing out of pitfall (see Fig. 170)? What is on edge of nearest pitfall? Explain.

Ant lions may be kept in a box half filled with sand and fed on ants. How is the pitfall dug? What part of ant is eaten? How is unused food removed?

How long is it in the larval state? Pupal state? Keep net over box to prevent adult from flying away when it emerges. 


\section{Illustrated Studies}

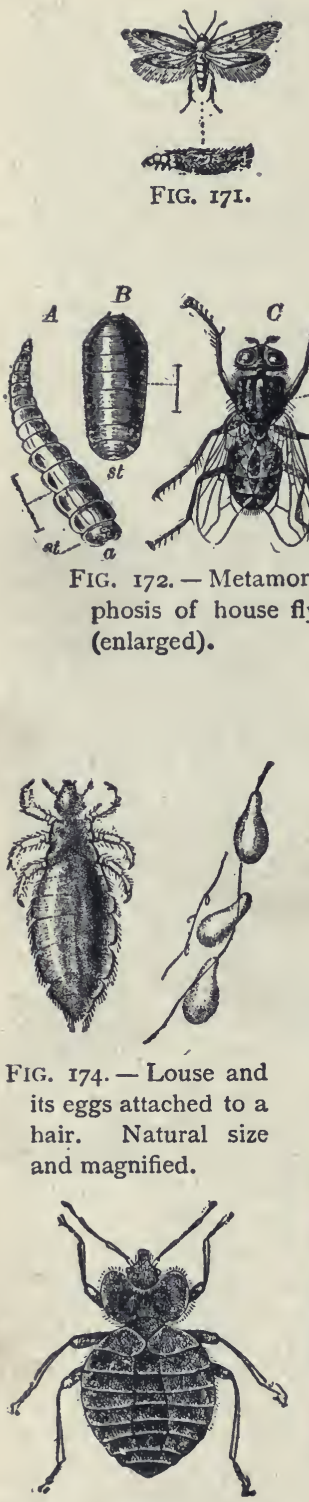

FIG. I75. - Bed bug. $\times 5$.

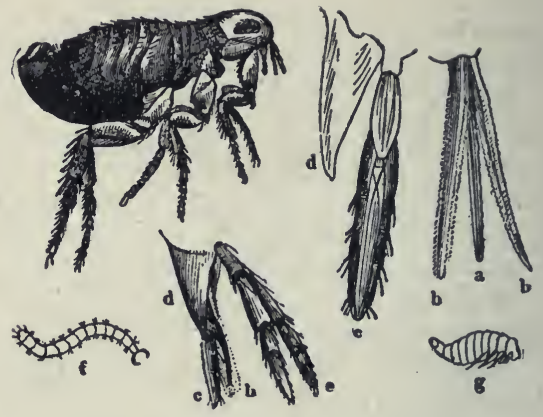

FIG. I73. - Metamorphosis of flea.
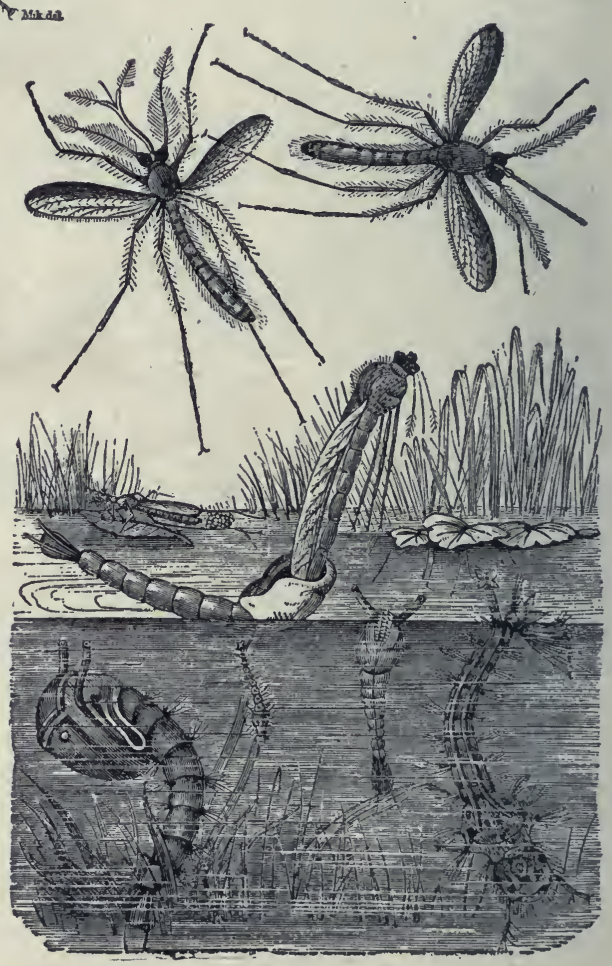

FIG. I76. - Life history of mosquito. 
Illustrated Study of Insect Pests (Figs. I7I-I76). - Why does the clothes moth (I7I) lay its eggs upon woollen clothing ? How does the larva conceal itself ? The larva can cut through paper and cotton, yet sealing clothes in bags of paper or cotton protects them. Explain.

The house fly eats liquid sweets. It lays its eggs in horse dung. Describe its larval and pupal forms. Banishing horses from city would have what beneficial effect ?

Describe the louse and its eggs, which are shown attached to a hair, natural size and enlarged.

Describe the bed bug. Benzine poured in cracks kills bed bugs. Do bed bugs bite or suck ? Why are they wingless?

Describe the larva, $f$, pupa, $g$, and the adult fiea, all shown enlarged. Its mandibles, $b, b$, are used for piercing. To kill fleas lather dog or cat completely and let lather remain on five minutes before washing. Eggs are laid and first stages passed in the ground.

How does the mosquito lay its eggs in the water without drowning (I76) ? Why are the eggs always laid in still water? Which part of the larva (wiggletail) is held to the surface in breathing? What part of the pupa (called tumbler, or bull head) is held to the surface in breathing? Give differences in larva and pupa. Where does pupa change to perfect insect ? Describe mouth parts of male mosquito (at left) and female (at right). Only female mosquitoes suck blood. Males suck juice of plants. Malarial mosquito alights with hind end of body raised at an angle. Why does killing fish and frogs increase mosquitoes? $1 \mathrm{oz}$. of kerosene for $15 \mathrm{ft}$. of surface of water, renewed monthly, prevents mosquitoes.

What is the use to the squash bug (Fig. 184) of having so bad an odour?

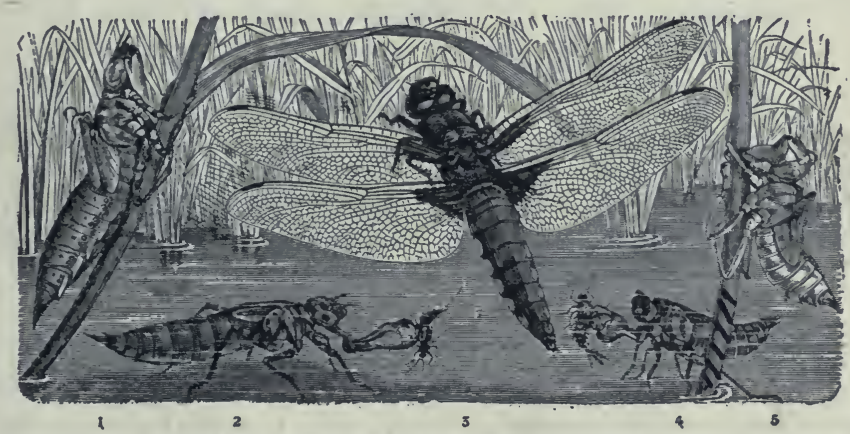

FIG. I77. Illustrated Study of Dragon Fly. -3 shows dragon fly laying its eggs in water while poised on wing. Describe the larval form (water tiger). The extensible tongs are the maxillæ enlarged. The pupa (I) is active and lives in water. Where does transformation to adult take place (5)? Why are eyes of adult large? its legs small ? Compare front and hind wings.

Do the eyes touch each other? Why is a long abdomen useful in flight ? Why would long feelers be useless? What is the time of greatest danger in the development of the dragon fly? What other appropriate name has this insect ? Why should we never kill a dragon fly ? 

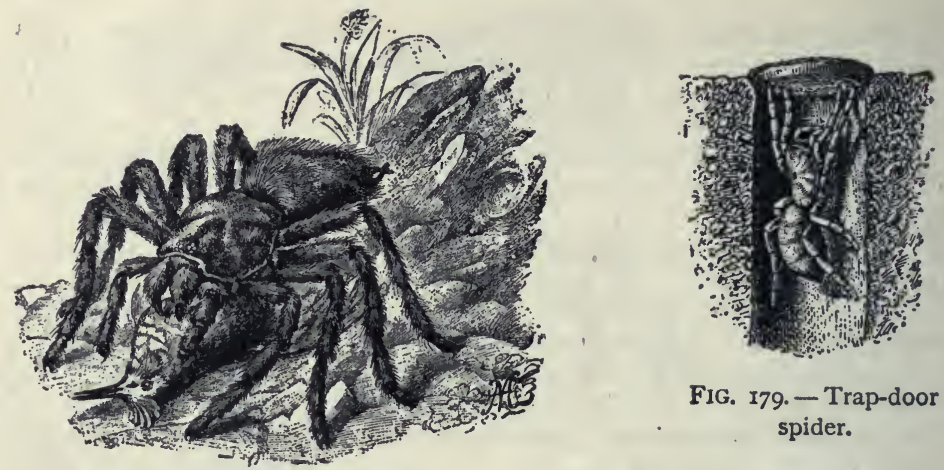

FIG. 179. - Trap-door spider.

FIG. 178, - The tarantula.

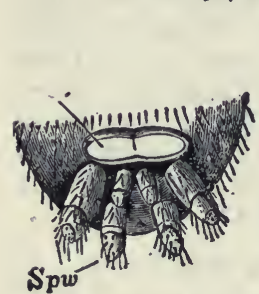

FIG. 180.

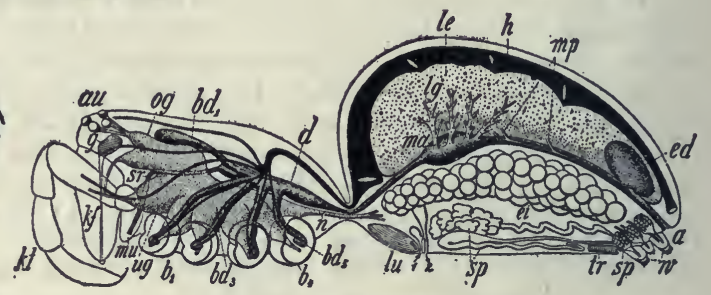

FIG. I8I. - Anatomy of spider.

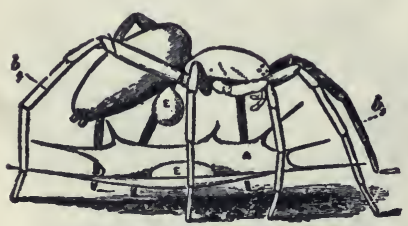

FIG. I82. - Laying egg.

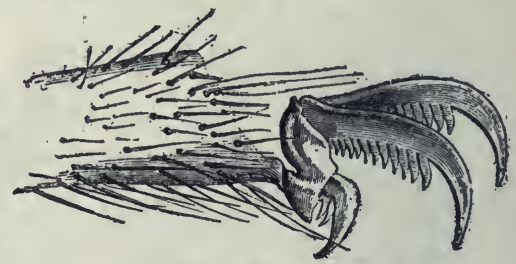

FIG. I83. - Foot of spider.

Illustrated Study of Spiders (Figs. 178-183). - The tarantula, like most spiders, has eight simple eyes (none compound). Find them (Fig. 178). How do spiders and insects differ in body? Number of legs ? Which have more joints to legs? Does trap-door spider hold the door closed (Fig. 179)? How many pairs of spinnerets for spinning web has a spider $(S p w$, I80)? Foot of spider has how many claws? How many combs on claws for holding web? Spiders spin a cocoon for holding eggs. From what part of abdomen are eggs laid $\left(E, \mathrm{r}_{2}\right.$; 2, I8I) ? Find spider's air sacs, $l u$, Fig. I8I ; spinning organs, $s p$; fang, $k f$; poison gland, $g$; palpi, $k t$; eyes, $a u$; nerve ganglia, $o g, u g$; sucking tube, sr; stomach, $d$; intestine, $m a$; liver, le; heart, $h$, (black); vent, $a$. Give two reasons why a spider is not an insect. How does it place its feet at each step(Fig. Iro) ? (Does the size of its nerve ganglia indicate great or little intelligence? Why do you think first part of body corresponds to both head and thorax of insects? 
The following Farmer's Bulletins, (revised to 1921) are available for distribution to those interested, by the United States Department of Agriculture, Washington, D.C.-

Farmer's Bulletin No. 47, Insects Affecting the Cotton Plant; No. 447, Bee Keeping; No. 440, The Peach Twig Borer; No. 120, The Principal Insects Affecting the Tobacco Plant; No. 856, Important Insecticides; No. 835, The Principal Insect Enemies of Growing Wheat; No. 799, Carbon Bisulphide as an Insecticide; No. 243, Insecticides and Fungicides; No. 152 (revised) Mange in Cattle; No. 155, How Insects Affect Health in Rural Districts; No 492, The Control of the Codling Moth; No.172, Scale Insects and Mites on Citrus Trees; No. 196, Usefulness of the Toad; No. 209, Controlling the Boll Weevil in Cotton Seed and at Ginneries; No. 211, The Use of Paris Green in Controlling the Cotton Boll Weevil; No. 872, The Cotton Bollworm; No. 848, The Control of the Boll Weevil; No. 223, Miscellaneous Cotton Insects in Texas; No. 908, The Control of the Codling Moth and Apple Scab.

Bulletins of the Bureau of Entomology may be obtained from the same source, while the supply lasts, as follows:

Destructive Locusts; The Honey Bee; The San José Scale; The Principal Household Insects of the United States; The Gypsy Moth in America; The Periodical Cicada; The Chinch Bug; The Hessian Fly; Insects Injurious to Vegetables; Notes on Mosquitoes; Some Insects Attacking the Stems of Growing Wheat, Rye, Barley, and Oats. 
Bulletins on Similar Topics, Published by the Department of Agriculture, Ontario-

(Write to the Publications Branch)

Bulletin No. 187-The Codling Moth Bulletin No. 195-The Insecticides and Fungicides Bulletin No. 198-Lime Sulphur Wash Bulletin No. 219--The San José and Oyster-shell Scales Bulletin No. 241-Peach Growing in Ontario Bulletin No. 250-Insects Attacking Fruit Trees Bulletin No. 251-Insects Affecting Vegetables Bulletin No. 256-The Wintering of Bees Bulletin No. 257-The More Important Fruit Tree Diseases in Ontario

Bulletin No. 258-The More Important Fungus and Bacterial Diseases of Vegetables in Ontario Bulletin No. 271-The Apple Maggot Bulletin No. 276-Bee Diseases in Ontario

Bulletins Published by the Department of Agriculture, Ottawa-

(Write to the Publications Branch)

Bulletin No. 9-The Army Worm Bulletin No. 10-Cutworms and their Control Bulletin No. 26-Bees and How to Keep Them Circular No. 9-1921-Common Garden Insects and their Control 


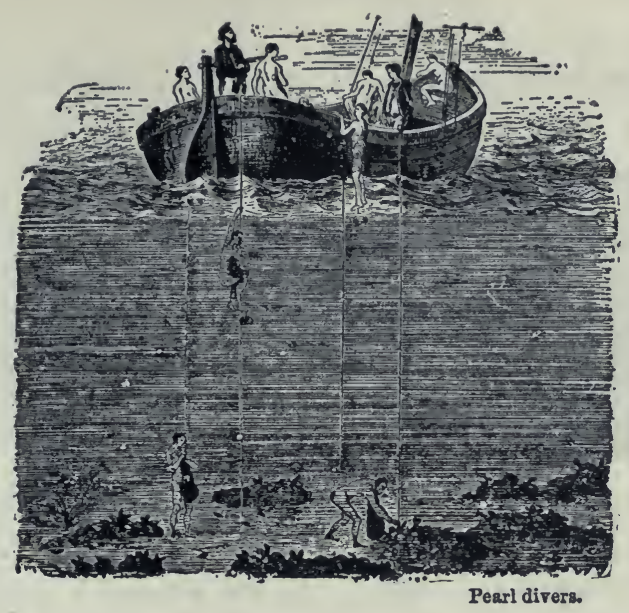

\section{CHAPTER IX}

\section{MOLLUSCS}

\section{The Fresh-water Mussel}

Suggestions. - The mussel is usually easy to procure from streams and lakes by raking or dredging. In cities the hardshelled clam, or quahog, is for sale at the markets, and the following descriptions apply to the anodon, unio, or quahog, with slight changes in regard to the siphons. Mussels can be kept alive for a long time in a tub with sand in the bottom. Pairs of shells should be at hand for study.

External Features. - The shell is an elongated oval, broader and blunter at one end (Fig. 188). Why does the animal close its shell? Does it open the shell? Why? Does it thrust the foot forward and pull up to it, or thrust the foot back and push? (Mussels and clams have no bones.) Does it go with the blunt end or the more tapering end of the shell forward? (Fig. I88.) Can a mussel swim? Why, or why not? 
Lay the shells, fitted together, in your hand with the hinge side away from you and the blunt end to the left (Fig. I88).

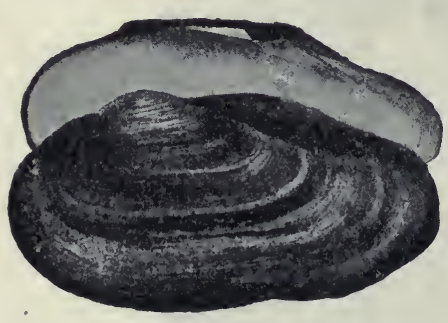

FIG. I88. - ANODON, or fresh-water mussel.

Is the right or the left shell uppermost? Which is the top, or dorsal, side? Which is the front, or anterior, end? Is the straight edge at the top or at the bottom? Our word "valve" is derived from a word meaning shell, because the Romans used shells for valves in pumps. Is the mussel a univalve or a bivalve? Which kind is the oyster? The snail?

Does the mussel have bilateral symmetry? Can you find a horny covering, or epidermis, over the limy shell of a fresh specimen? Why is it necessary? Does water dissolve lime? Horn? Find a bare spot. Does any of the shell appear to be missing there?

The bare projection on each shell is called the umbo. Is the umbo near the ventral or the dorsal line? The posterior or anterior end? Is the surface of the umbones worn? Do the umbones rub against the sand as the mussel ploughs its way along? How are the shells held together? Where is the ligament attached? (Fig. 189.) Is it opposite the umbones or more to the front or to the rear? Fig.189.) Is the liga-

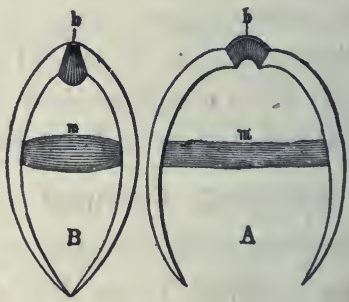

Fig. I89. - DIAGRAM OF SHell open and closed, showing muscle, $m$, and ligament, $b$. ment of the same material as the shell? Is the ligament in a compressed condition when the shell is open or when it is closed? (Fig. I89.) When is the muscle relaxed? 
Notice the lines on the outside of the shell (Figs. 188 and 190). What point do they surround? They are lines of growth. Was each line once the margin of the shell? If the shell should increase in size, what would the present margin become? (Fig. 19I.) Does growth take place on the margin only? Did the shell grow thicker as it grew larger? Where is it thinnest?

Draw the outside of the shell from

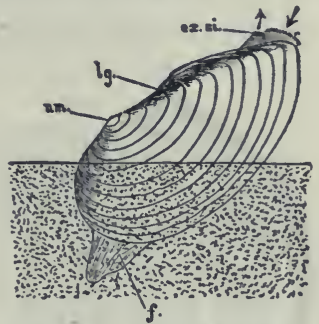

Fig. Ig0. - MUSSEL crawling in sand. the side. Draw a dorsal view. Near the drawings write the names of the margins of the shell (p. 98) and of other parts learned, using lines to indicate the location of the parts.

Study the surface of the shell inside and out. The inside is called mother-of-pearl. Is it of lime? Is the deeper layer of the shell of lime? (When weak hydrochloric acid or strong vinegar is dropped on limy substances, a gas, carbon dioxide, bubbles up.) Compare the thickness of the epidermal layer, the middle chalky layer, and the inner, pearly layer.

Anatomy of the Mussel. - What parts protrude at any time beyond the edge of the shell? (Fig. 190.) The shell

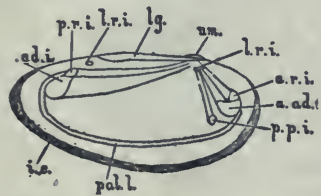

FIG. IgI. - DIAGRAM. Change of points of attachment of muscles as mussel enlarges. (Morgan.) is secreted by two folds of the outer layer of the soft body of the mussel. These large, flaplike folds hang down on each side, and are called the mantle. The two great flaps of the mantle hang down lower than the rest of the body and line the shell which it secretes (Fig. 192). The epidermis of the mantle secretes the shell just as the epidermis of the crayfish secretes its crust. Can you find 
the pallial line, or the line to which the mantle extended on each shell when the animal was alive? A free portion of the mantle extended like a fringe below the pallial line.

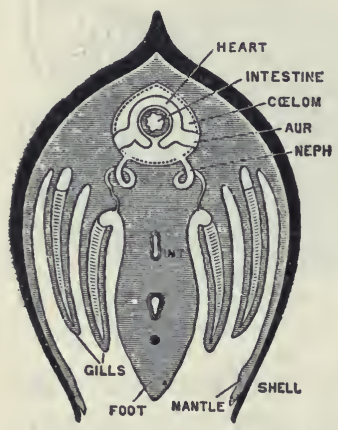

Fig. 192. - CROSS SECTION OF MUSSEL. (Diagram, after Parker.)

The shells were held together by two large adductor muscles. The anterior adductor (Fig. 193) is near the front end, above the foot. The posterior adductor is toward the rear end, but not so near the end as the anterior. Can you find both muscle scars in the shells? Are they nearer the ventral or the dorsal surface? The points of attachment travelled downward and farther apart as the animal grew (see Fig. 191). Higher

than the larger scars are small scars, or impressions, where the protractor and retractor muscles that extend and draw in the foot were attached.

The muscular foot extends downward in the middle, halfway between the shells (Fig. 193). On each side of the foot and behind it hang down the two pairs of gills, the outer pair and the inner pair (Fig. 192). They may be compared to four V-shaped troughs with

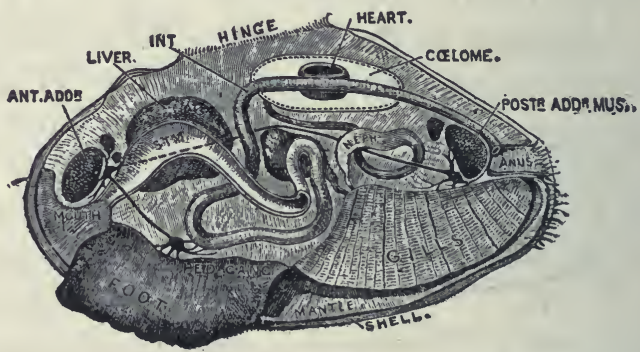

Fig. I93.- ANATomy of Mussel. (Beddard.)

their sides full of holes. The water enters the troughs through the holes and overflows above. Is there a marked difference in the size of the two pairs of gills? A kind of 
chamber for the gills is made by the joining of the mantle flaps below, along the ventral line. The mantle edges are separated at two places, leaving openings called exhalent and inhalent siphons.

Fresh water with its oxygen, propelled by cilia at the opening and on the gills, enters through the lower or inhalent siphon, passes between the gills, and goes to an upper passage, leaving the gill chamber by a slit which separates the gills from the foot. For this passage, see arrow (Fig. 194). The movement of the water is opposite to the way the arrow points. After going upward and backward, the water emerges by the exhalent siphon. The gills originally consisted of a great number of filaments. These are now united, but not completely so, and the gills still have a perforated or lattice structure. Thus they present a large surface for absorbing oxygen from the water.
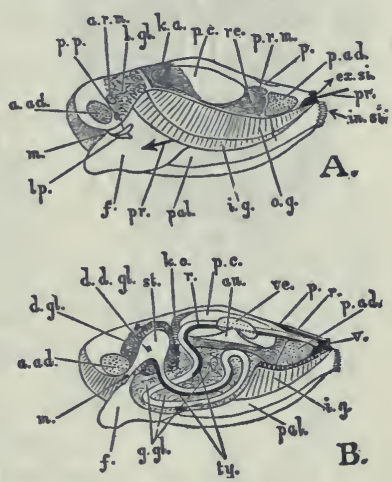

FIG. I94. - MưSSEL.

$A$, left shell and mantle flap removed. $B$, section through body.

Question: Guided by other figures, identify the parts to which lines are drawn.

The mouth is in front of the foot, between it and the anterior adductor muscle (Fig. 194). On each side of the mouth are the labial palps, which are lateral lips (Fig. 195). They have cilia which convey the food to the mouth after the inhalent siphon has sent food beyond the gill chamber and near to the mouth. Thus both food and oxygen enter at the inhalent siphon. The foot is in the position of a lower lip, and if regarded as a greatly extended lower lip, the animal may be said to have what is to us the absurd habit of using its lower lip as a foot. The foot is some- 
times said to be hatchet-shaped (Fig. 195). Do you see any resemblance? Does the foot penetrate deep or shal-

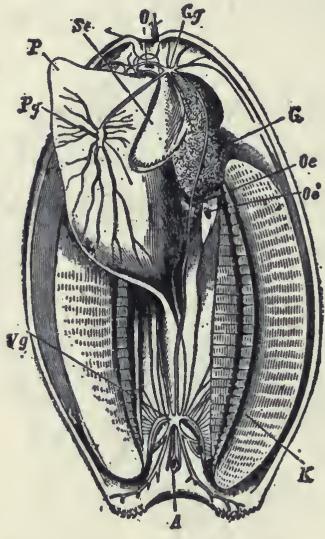

FIG. 195.-MUSSEL. From below. Level cut across both shells.

Se, palp; $P$, foot; $O$, mouth; $G$, liver: $G g, V g, P g$, ganglia. low into the sand? (Fig. 190.) Why, or why not?

The food tube of the mussel is comparatively simple. Behind the nouth it enlarges into a swelling called the stomach (Fig. 193). The bile ducts of the neigh bouring liver empty into the stomach. The intestine makes several turns in the substance of the upper part of the foot and then passing upward, it runs approximately straight to the vent (or anus), which is in the wall of the exhalent siphon. The intestine not only runs through the pericardial cavity (celome) surrounding the heart, but through the ventricle of the heart itself (Fig. 196).

The kidneys consist of tubes which open into the pericardial chamber above and into the gill chamber below (Neph., Fig. 193). The tubes are surrounded by numerous blood vessels (Fig. 198) and carry off the waste matter from the blood.

The nervous system consists of three pairs of ganglia and nerves (Fig. I97). The ganglia are distinguishable because of

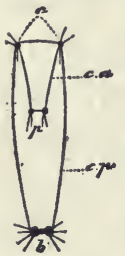

their orange colour. The pedal ganglia on the front of the foot are easily seen also; the visceral ganglia on the posterior adductor muscle may be seen without removing the mussel from, the shell (Fig. I93). The reproductive organs FIG. 197 .

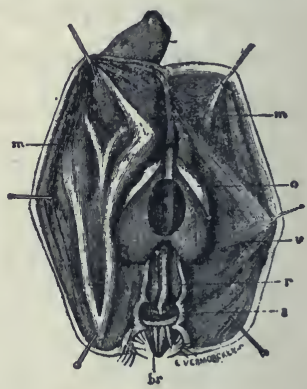

FIG. Ig6. - HEART OF MUSSEL, with intestine passing through it. The sperms, having been set free in the water, are drawn into the ova by the same current that brings the food. The eggs 
are hatched in the gills. After a while the young mussels go out through the siphon.

Summary. - In the gills (Fig. 198) the blood gains what? Loses what? From the digestive tube the blood absorbs nourishment. In the kidneys the blood is partly purified by the loss of nitrogenous waste.

The cilia of the fringes on the inhalent, or lower, siphon, vibrate continually and drive water and food particles into the mouth cavity. Food particles that are brought near the labial palps are conveyed by them to the mouth. As the water passes along the perforated gills, its oxygen is absorbed; the mantle also absorbs oxygen from the water as it passes. The water, as stated before, goes next through a passage between the foot and the palp into the cavity above the gills and on out through the exhalent siphon. By stirring the water, or placing a drop of ink near the siphons of a mussel keptin a tub, the direction of its flow may be seen. The pulsations of the heart are plainly visible in a living mollusc.

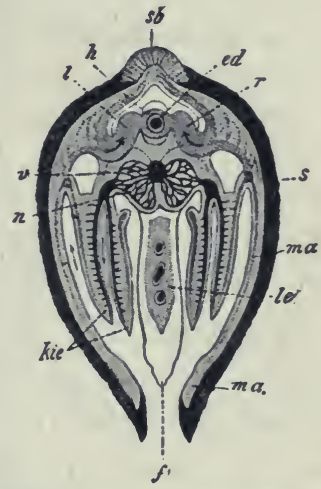

Fig. I98. - Diagram OF MUSSEL CUT ACROSS, showing mantle, $m a$; gills, kie; foot, $f$; heart, $h$; intestine, ed.

Habits of the Mussel.-Is it abundant in clear or in muddy water; swift, still, or slightly moving water? Describe its track or furrow. What is its rate of travel? Can you distinguish the spots where the foot was attached to the ground? How long is one "step " compared to the length of the shell? The animal usually has the valves opened that it may breathe and eat. The hinge ligament acts like the case spring of a watch, and holds the valves open unless the adductor muscles draw them together (Fig. I89). 
When the mussel first hatches from the egg, it has a triangular shell. It soon attaches itself to some fish and thus

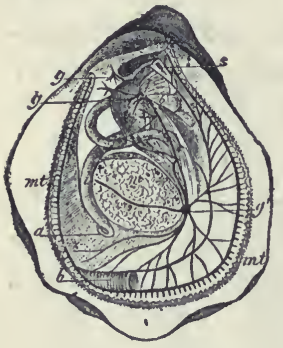

FIG. I99.-OVSTER.

$C$, mouth; $a$, vent; $g, g^{\prime}$, ganglia; $m t$, mantle; $b$, gill.

travels about. After two months it drops to the bottom again.

Other Mollusca. - The oyster's shells are not an exact pair, the shell which lies upon the bottom being hollowed out to contain the body, and the upper shell being flat. Can you tell by examining an oyster shell which was the lower valve? Does it show signs of having been attached to the bottom? The young oyster, like the young mussel, is free-swimming. Like the arthropoda, most molluscs undergo a metamorphosis to reach the adult stage (Fig. I99).

Examine the shells of clams, snails, scallops, and cockles. Make drawings of their shells. The slug is very similar to the snail except

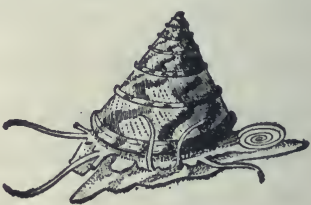

FIG, 200.-TROCHUS. that it has no shell. If the shell of the snail shown in Fig. 202 were removed, there would be left a very good

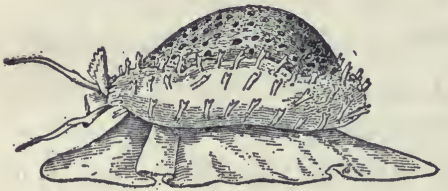

Fig. 20I.-CYPRAA. (Univalve, with a long opening to shell.) representation of a slug.

Economic Importance of Mollusca. - Several species of clams are eaten. One of them is the hard-shell clam (quahog) found on the Atlantic coast from Cape Cod to Texas. Its shell is white. It often burrows slightly beneath the surface. The soft-shell clam is better liked as food. It lives along the shores of all northern seas. It burrows a foot beneath the surface and extends its siphons 
through the burrow to the surface when the tide is in, and draws into its shell the water containing animalcules and oxygen.

Oysters to the value of many millions of dollars are gathered and sold every year. The most valuable oyster fisheries of North America are in Chesapeake Bay. The young oysters, or "spat," after they attach themselves to the bottom in shallow water, are transplanted. New oyster beds are formed in this way. The beds are sometimes strewn with pieces of rock, broken pottery, etc., to encourage the oysters to attach themselves. The dark spot in the fleshy body of the oyster is the digestive gland, or liver. The cut ends of the tough adductor muscles are noticeable in raw oysters. The starfish is very destructive in oyster beds.

Pearls are deposited by bivalves around some irritating particle that gets between the shell and the mantle. The pearl oyster furnishes most of the pearls; sometimes pearls of great value are obtained from fresh-water mussels. Name articles that are made partly or wholly of motherof-pearl.

Study of a Live Snail or Slug. - Is its body dry or moist? Do land

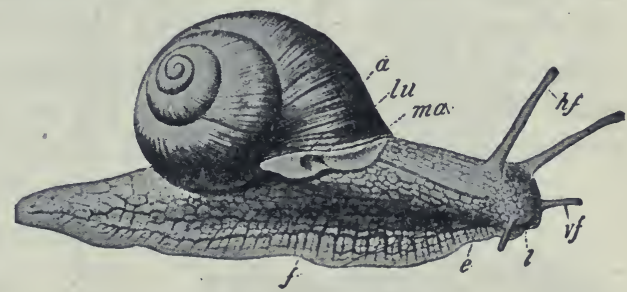

FIG. 202. - A SNAIL.

l, mouth; $v f, h f$, feelers; $e$, opening of egg duct; $f$, foot; $m a$, mantle; $l u$, opening to lung: $a$, vent. snails and slugs have lungs or gills? Why? How many pairs of tentacles have they? What is their relative length and position? The eyes are dark spots at bases of tentacles of snail and at the tips of the rear tentacles of slug. Touch the tentacles. What happens? Do the tentacles simply stretch, or do they turn inside 
out as they are extended? Is the respiratory opening on the right or the left side of the body? On the mantle fold or on the body?

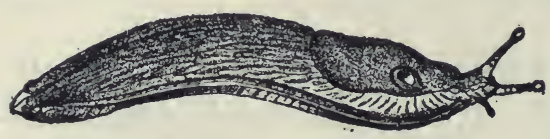

FIG. 203. - A SLUG.

(Figs. 202-3-4.) How often does the aperture open and close ?

Place the snail in a moist tumbler. Does the whole under surface seem to be used in creeping? Does the creeping surface change shape as the snail creeps? Do any folds or wrinkles seem to move either toward the front or the rear of its body? Is enough mucus left to mark the path travelled? The fold moves to the front, adheres, and smooths out as the slug or snail is pullea forward.

Cephalopods. - The highest and best developed molluscs are

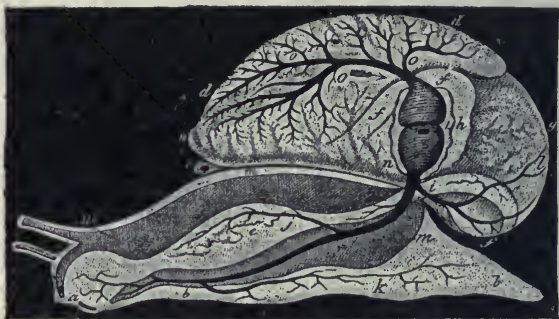

Fig. 204. - CirCulation AND Respiration IN SNAIL.

$a$, mouth; $b, b$, foot; $c$. vent: $d, d$, lung; $h$, heart. Blood vessels are black. (Perrier.) the cephalopods, or "head-footed" molluscs. Surrounding the mouth are eight or ten appendages which serve both as feet and as arms. These appendages have two rows of sucking disks by which the animal attaches itself to the sea bottom, or seizes fish or other prey with a firm grip. The commonest examples are the

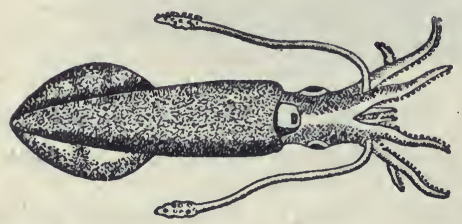

FIG. 205.-A SQUID. squid, with a long body and ten arms, and the octopus, or devilfish, with a short body and eight arms. Cephalopods have strong biting mouth parts and complex eyes somewhat resembling the eyes of backboned, or vertebrate, animals. The large and staring eyes add to the uncanny, terrifying appearance.

The sepia or "ink" discharged through the siphon of the squid makes a dark cloud in the water and favours its escape from 
enemies almost as much as does its swiftness (Fig. 205). The squid sometimes approaches a fish with motion so slow as to be imperceptible, and then suddenly seizes it, and quickly kills it by biting it on the back behind the head.

The octopus is more sluggish than the squid. Large species called

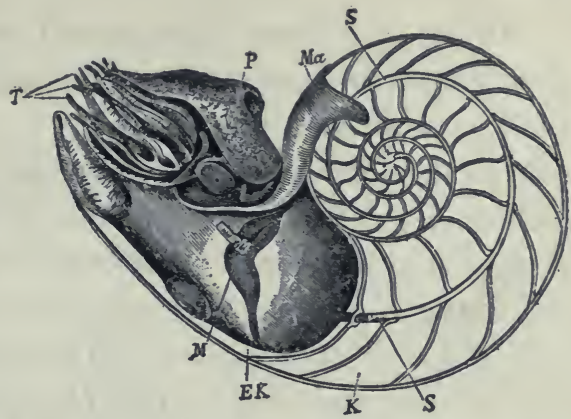

Fig. 206. - PEARLy Nautilus. (Shell sawed through to show chambers used when it was smaller, and siphuncle, $S$, connecting them. Tentacles, $T$.)

devilfish sometimes have a spread of arms of twenty-five feet. The pearly nautilus (Fig. 206) and the female of the paper argonaut (Fig. 207) are examples of cephalopods that thave shells. The cuttlefish is closely related to the squid.

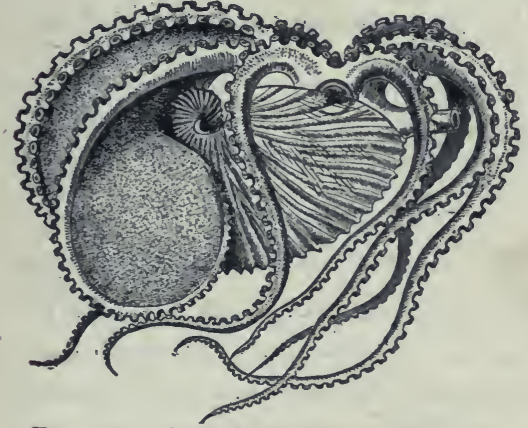

Fig. 207.- PAPER ARgonaUt (female). $\times 1 / 3$ (i.e. the animal is three times as long and broad as figure).

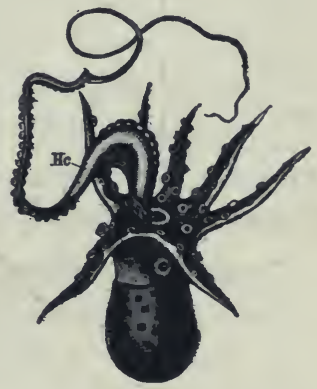

FIG. 208. - PAPER ARGONAUT (male). $\times 1 / 2$.

General Questions. - The living parts of the mussel are very soft, the name mollusca being derived from the Latin word mollis, soft. Why is it that the softest animals, the molluscs, have the hardest coverings?

To which class of molluscs is the name acephala (headless) appropriate? Lamellibranchiata (platelike gills)? 
Why is a smooth shell suited to a clam and a rough shell suited to an oyster? Why are the turns of a snail's shell so small near the centre?

Why does the mussel have no use for head, eyes, or projecting feelers? In what position of the valves of a mussel is the hinge ligament in a stretched condition? How does the shape of the mussel's gills insure that the water current and the blood current are brought in close contact?

The three main classes of molluscs are: the pelecypoda (hatchet-footed); gastropoda (stomach-footed); and cephalopoda (head-footed). Give an example of each class.

\section{Comparison of Mollusks}

\begin{tabular}{l|l|l|l}
\hline \hline Shell & Mussel & SNaIL & SQuID \\
\hline Head & & & \\
\hline Body & & & \\
\hline Foot & & & \\
\hline Gills & & & \\
\hline Eyes & & & \\
\hline
\end{tabular}

Comparative Review. - (To occupy an entirts page in notebook.)

\begin{tabular}{|c|c|c|c|c|c|}
\hline & $\begin{array}{l}\text { GRASS- } \\
\text { HOPPER }\end{array}$ & SPIDER & Craynish & Centipede & Mussel \\
\hline \multicolumn{6}{|l|}{ Bilateral or radiate } \\
\hline \multicolumn{6}{|l|}{$\begin{array}{l}\text { Appendages for lo- } \\
\text { comotion }\end{array}$} \\
\hline \multicolumn{6}{|l|}{$\begin{array}{l}\text { Names of divisions } \\
\text { of body }\end{array}$} \\
\hline \multicolumn{6}{|l|}{$\begin{array}{l}\text { Organs and method } \\
\text { of breathing }\end{array}$} \\
\hline Locomotion & & & & & \\
\hline
\end{tabular}




\section{CHAPTER $\mathrm{X}$}

\section{FISHES}

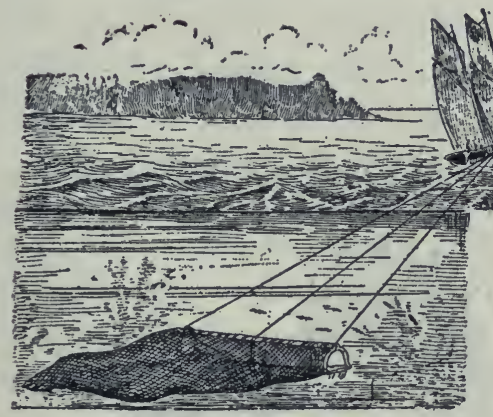

Suggestions. The behaviour of a live fish in clear water, preferably in a glass vessel or an aquarium, should be studied. A skeleton may be prepared by placing a fish in the reach of ants. Skeletons of animals placed on ant beds are cleaned very thoroughly. The study of the perch, that follows, will apply to almost any other common fish.

Movements and External Features. - What is the general shape of the body of a fish? How does the dorsal, or upper, region differ in form from the ventral? Is there a narrow part or neck where the head joins the trunk? Where is the body thickest? What is the ratio between the length and the height? (Fig. 209.) Are the right and the left sides alike? Is the symmetry of the fish bilateral or radial?

The body of the fish may be divided in to three regions-the head, the trunk, and the tail. The trunk begins with the foremost scales; the tail is said to begin at the vent, or anus. Which regions bear appendages? Is the head movable independently of the trunk, or do they move together? State the advantage or the disadvantage in this. Is the body depressed (flattened vertically) or compressed 
(flattened laterally)? Do both forms occur among fishes? (See figures on pages 123, 124.)

How is the shape of the body advantageous for movement? Can a fish turn more readily from side to side, or up and down? Why? Is the head wedge-shaped or conical? Are the jaws flattened laterally or vertically? The fish swims in the water, the bird swims in the air. Account for the differences in the shape of their bodies.

Is the covering of the body like the covering of any animal yet studied? The scales are attached in little pockets,

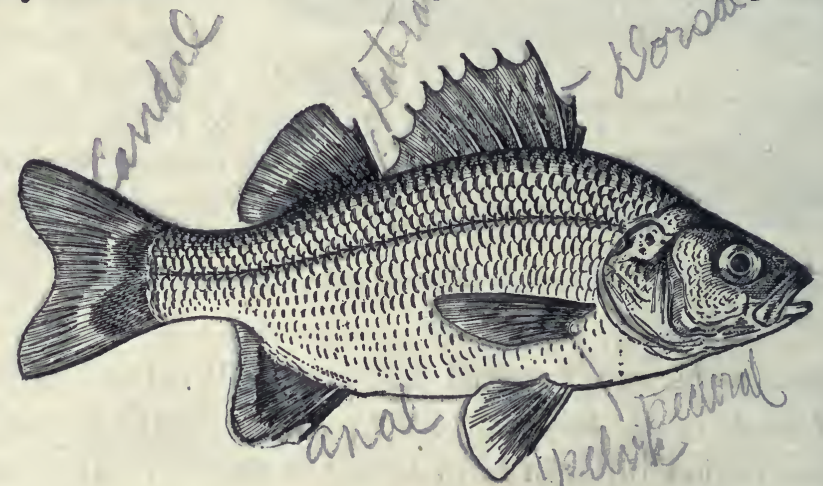

Fig. 209. - White PerCh (Morone Americana).

or folds, in the skin. Observe the shape and size of scales on different parts of the body. What parts of the fish are without scales? Examine a single scale; what is its shape? Do you see concentric lines of growth on a scale? Sketch a few of the scales to show their arrangement. What is the use of scales? Why are no scales needed on the head? How much of each scale is hidden? Is there a film over the scale? Are the colours in the scale or on it?

The Fins. - Are the movements of the fish active or sluggish? Can it remain stationary without using its fins? 
Can it move backward? How are the fins set in motion? What is the colour of the flesh, or muscles, of a fish? Count the fins. How many are in pairs? (Fig. 209.) How many are vertical? How many are on the side? How many are on the middle line? Are the paired or the unpaired fins more effective in balancing the fish? In turning it from side to side? In raising and lowering the fish? In propelling it forward? How are some of the fins useful to the fish besides for balancing and swimming?

The hard spines supporting the fins are called the fin rays. The fin on the dorsal line of the fish is called the dorsal fin. Are its rays larger or smaller than the rays of the other fins? The perch is sometimes said to have two dorsal fins, since it is divided into two parts. The fin forming the tail is called the tail fin, or caudal fin. Are its upper and its lower corners alike in all fishes? (Fig. 228.) On the ventral side, just behind the vent, is the ventral fin, also called the anal fin. The three fins mentioned are unpaired fins. Of the four-paired fins, the pair higher on the sides (and usually nearer the front) are the pectoral fins. The pair nearer the ventral line are the pelvic fins. They are close together, and in many fish are joined across the ventral line. The ventral fins are compared to the legs, and the pectoral fins to the arms, of higher vertebrates. (Fig. 244.) Compare fins of fish, pages 123, I24.

Make a drawing of the fish seen from the side, omitting the scales unless your drawing is very large.

Are the eyes on the top or on the sides of the head, or on both? Can a fish shut its eyes? Why, or why not? Is the eyeball bare, or covered by a membrane? Is the covering of the eyeball continuous with the skin of the head? Is there a fold or wrinkle in this membrane or the surrounding skin? Has the eye a pupil? An iris? Is the eye of 
the fish immovable, slightly movable, or freely movable? Can it look with both eyes at the same object? Is the range of vision more upward or downward? To the front

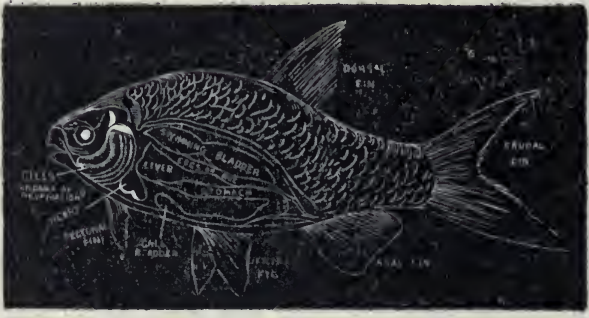

Fig. 210. - BLACKBOARD OU'TLINE OF Fish. or the side? In what direction is vision impossible? Can a fish close its eyes in sleep? Does the eyeball appear spherical or flattened in front? The ball is really spherical, the lens is very convex, and fish are nearsighted. Far sight would be useless in a dense medium like water. In what direction from the eyes are the nostrils (Fig. 211.) There are two pair of nostrils, but there is only one pair of nasal cavities, with two nostrils opening in to each. There are no nasal passages to the mouth, as the test with a probe shows that the cavities do not open into the mouth. What two functions has the nose in man? What function has it in the fish?

There are no external ears. The ear sacs are embedded in the

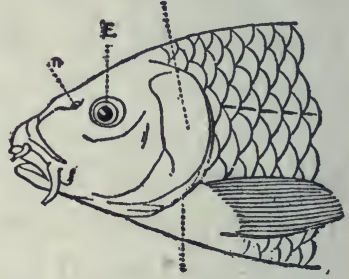

FIG. 2II. - HEAD OF CARP. bones of the skull. Is hearing acute or dull? When you are fishing, is it more necessary not to talk or to step lightly, so as not to jar the boat or bank?

What is the use of the large openings found at the back of the head on each side? (Fig. 21I.) Under the skin at the sides of the head are thin membrane bones formed from the skin ; they aid the skin in protection. Just under these membrane bones are the gill covers, of true bone. Which 
consists of more parts, the membranous layer, or the true bony layer in the gill cover? (Figs. 2 I I and 212.)

Is the mouth large or small? Are the teeth blunt or pointed? Near the outer edge, or far in the mouth? (Fig. 212.) Does the fish have lips? Are the teeth in one continuous row in either jaw? In the upper jaw there are also teeth on the premaxillary bones. These bones are in front of the maxillary bones, which are without teeth. Teeth are also found in the roof of the mouth, and the tongue bears horny appendages similar to teeth. Are the teeth of the fish better suited for chewing or for

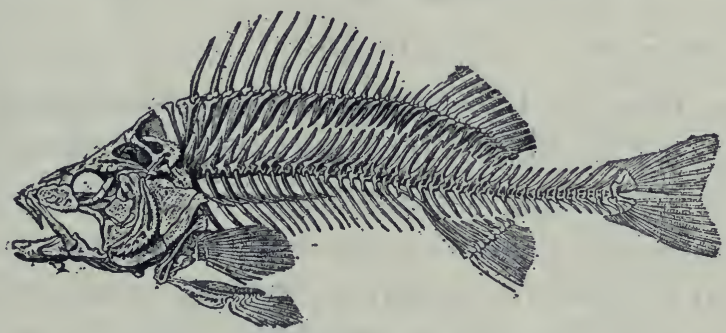

Fig. 212. - SKELETON OF PERCH.

grasping? Why are teeth on the tongue useful? Watch a fish eating: does it chew its food? Can a fish taste? Test by placing bits of brown paper and food in a vessel or jar containing a live fish. Is the throat, or gullet, of the fish large or small?

The skeleton of a fish is simpler than the skeleton of other backboned animals. Study Fig. 212 or a prepared skeleton. At first glance, the skeleton appears to have two vertebral columns. Why? What bones does the fish have that correspond to bones in the human skeleton? Are the projections (processes) from the vertebræ long or short? The ribs are attached to the vertebræ of the trunk, the last rib being above the vent. The tail begins at the 
vent. Are there more tail vertebræ or trunk vertebræ? Are there any neck (cervical) vertebræ (i.e. in front of those that bear ribs)? The first few ribs (how many ?) are attached to the central body of the vertebræ. The re-

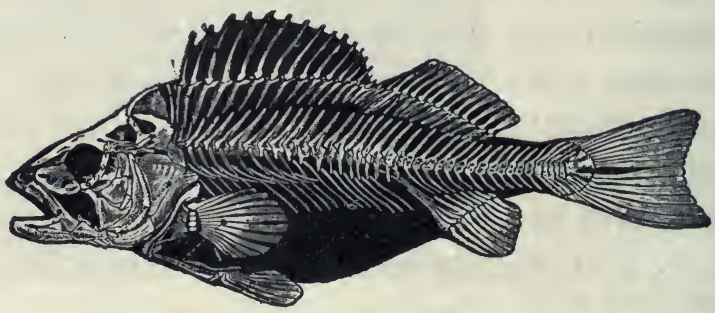

FIG. 213.

maining ribs are loosely attached to processes on the vertebræ. The ribs of bony fishes are not homologous with the ribs of the higher vertebrates. In most fishes there are bones called intermuscular bones attached to the first ribs (how many in the perch?) which are possibly homologous to true ribs; that is, true ribs in the higher vertebrates may have been developed from such beginnings.

Which, if any, of the fin skeletons (Fig. 214) are not attached to the general skeleton? Which fin is composed chiefly of tapering, pointed rays? Which fins consist of
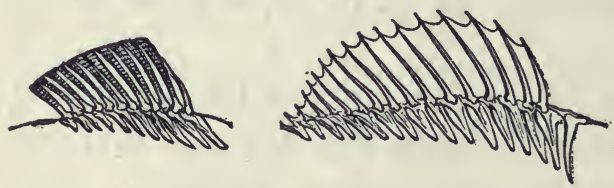

FIG. 214. - SOFT-RAYED AND SPINY-RAYED FINS. rays which subdivide and widen toward the end? Which kind are stiff, and which are flexible? Which of the fin rays are segmented, or in two portions? The outer segment is called the radial, the inner the basal segment. Which segments are longer? There is one basal segment that lacks a radial segment. Find it (Fig. 212). 
What is the advantage of the backbone plan of structure over the armour-plate plan? You have seen the spoollike body of the vertebra in canned salmon. Is it concave, flat, or convex at the ends ?

The gills are at the sides of the head (Fig. 2 I 5) under the opercula, or gill covers. What is the colour of the gills? Do the blood vessels appear to be very near the surface of the gills, or away from the surface? What advantage in this? Are the gills smooth or wrinkled? (Fig. 2I5.) What advantage? The bony supports of the gills, called the gill arches, are shown in Fig. $216\left(k_{1}\right.$ to $\left.k_{4}\right)$. How many

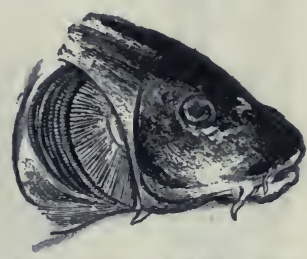

FIG. 2I5. - CARP, with right gill cover removed to show gills. arches on each side? The gill arches have projections on their front sides, called gill rakers, to prevent food

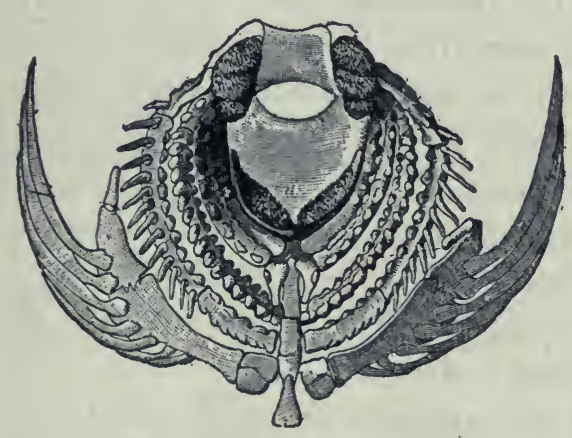

FIG. 216. - SKELETON AROUND THROAT OF FISH. from being washed through the clefts between the arches. The fringes on the rear of the gill arches are called the gill filaments $(a$, Fig. 216). These filaments support the thin and muchwrinkled borders of the gills, for the gills are constructed on the plan of exposing the greatest possible surface to the water. Compare the plan of the gills and that of the human lungs. The gill opening on each side is guarded by seven rays ( $k h$, Fig. 2I6) along the hinder border of the 
gill cover. These rays grow from the tongue bone. ( $Z u$, Fig. 216. This is a rear view.)

Watch a live fish and determine how the water is forced between the gills. Is the mouth opened and closed in the

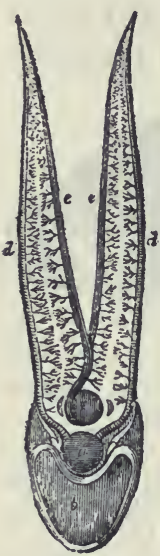

FiG. 217. Circulation IN GiLLS. act of breathing? Are the openings behind the gill covers opened and closed? How

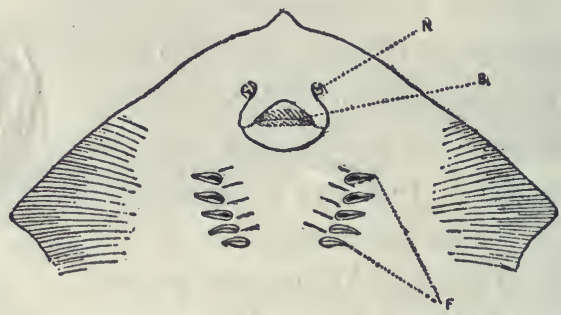

FIG. 218. - NOSTRILS, MOUTH, AND GILL OPENINGS OF STING-RAY.

many times per minute does fresh water reach the gills? Do the mouth and the gill covers open at the same time? Why must the water in contact with the gills be changed constantly? Why does a fish usually rest with its head up stream? How may a fish be kept alive for a time after it is removed from the water? Why does drying of FIG. 219.-GiLl OPENings of the gills prevent breathing? If

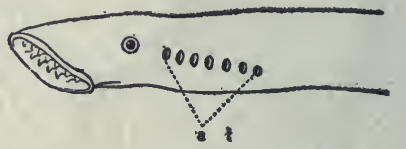
EEL. the mouth of a fish were propped open, and the fish returned to the water, would. it suffocate? Why, or why not?

Food Tube. - The gullet is short and wide. The stomach is elongated (Fig. 220). There is a slight constriction, or narrowing, where it joins the intestine. Is the intestine straight, or does it lie in few or in many loops? (Fig. 220.) The liver has a gall bladder and empties into the intestine through a bile duct. Is the 
liver large or small? Simple or lobed? The spleen (mi, Fig. 220) lies in a loop of the intestine. The last part of the intestine is straight and is called the rectum. Is it of the same size as the other portions of the intestine? 'The fish does not possess a pancreas, the most important digestive gland of higher vertebrates.

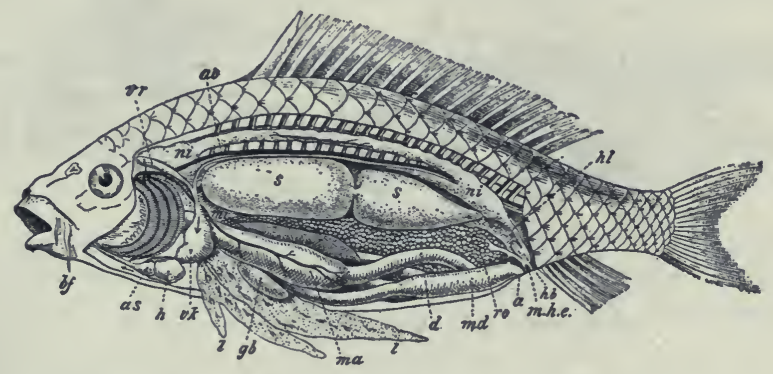

Fig. 220. - ANATOMY OF CARP. (See also coloured figure 4.)

$b f$, barbels on head (for feeling): $h$, ventricle of heart; as, aortic bulb for regulating flow to gills; $v k$, venous sinus; $a o$, dorsal aorta; $m a$, stomach; $l$, liver; $g b$, gall cyst; $m i$, spleen: $d$, small intestine; $m d$, large intestine; $a$, vent; $s, s$, swim bladder; $n i, n i$, kidney; $h l$, ureter; $h b$, bladder; ro, eggs (roe); mhe, opening of ducts from kidney and ovary.

Questions : Are the kidneys dorsal or ventral ? The swim bladder? Why ? Why is the swim bladder double? Does blood enter gills above or below ?

The ovary lies between the intestine and the air bladder. In Fig. 220 it is shown enlarged and filled with egg masses called roe. It opens by a pore behind the vent. The silver lining of the body cavity is called the peritoneum.

Is the air bladder in the perch simple or partly divided? In the carp? (Fig.220.) Is it above or below the centre of the body? Why? The air bladder makes the body of the fish about as light as water that it may rise and sink with little effort. When a fish dies, the gases of decomposition distend the bladder and the abdomen, and the fish turns over. Why?

Where are the kidneys? (Fig. 220.) Their ends unite close under the spinal column. The ureters, or tubes, leading from them, unite, and after passing a small urinary bladder, lead to a tiny urinary pore just behind the opening from the ovary. (Coloured figure 4.)

The Circulation. - The fish, unlike other vertebrates, has its breathing organs and its heart in its head. The gills have already been described. The heart of an air-breathing vertebrate is near 
its lungs. Why? The heart of a fish is near its gills for the same reason. The heart has one auricle and one ventricle. (Coloured figure r.)

Blood returning to the heart comes through several veins into a sinus, or antechamber, whence it passes down through a valve

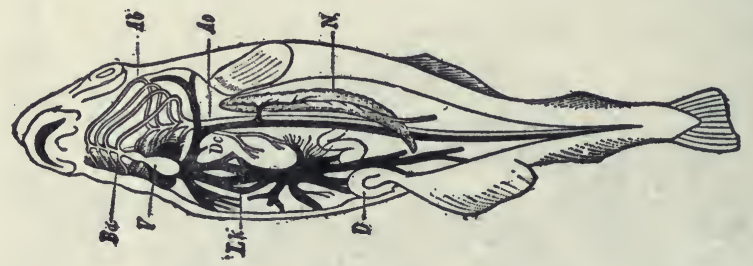

Fig. 221. - Plan OF Circulation.

$A b$, arteries to gills; $B a$, aortic bulb; $V$, ventricle.

into the auricle; from the auricle it goes forward into the ventricle. The ventricle sends it into an artery, not directly, but through a

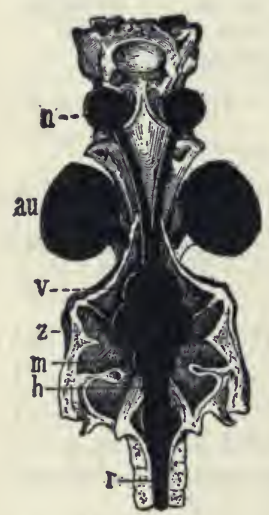

FIG. 222. - BRAIN OF PERCH, from above.

$n$, end of nerve of smell; $a u$, eye; $v, z, m$, fore, mid, and hind brain; $h$, spinal bulb; $r$, spinal cord.

and consists of the two optic lobes. From these lobes the optic nerves pass beneath the brain to the eyes ( $S n$, Fig. 223). In bulb (as, Fig. 220), which serves to maintain a steady flow, without pulse beats, into the large artery (aorta) leading to the gills. The arteries leading from the gills join to form a dorsal aorta (Ao, Fig. $22 \mathrm{I}$ ), which passes backward, inclosed by the lower processes of the spinal column. After going through the capillaries of the various organs, the blood returns to the heart through veins.

The colour of the blood is given by red corpuscles. These are nucleated, oval, and larger than the blood corpuscles of other vertebrates. The blood of the fish is slightly above the temperature of the water it inhabits.

Notice the general shape of the brain (Fig. 222). Are its subdivisions distinct or indistinct? Are the lobes in pairs? The middle portion of the brain is the widest, 
front of the optic lobes lie the two cerebral lobes, or the cerebrum. The small olfactory lobes are seen (Fig. 224) in front of the cerebrum. The olfactory nerves may be traced to the nostrils. Behind the optic lobes (mid brain) is the cerebellum (hind brain) and

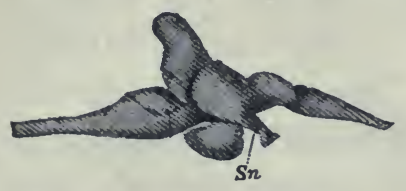

Fig. 223. - BRAIN OF PERCH, side view. behind it is the medulla oblongata or beginning of the spinal cord.

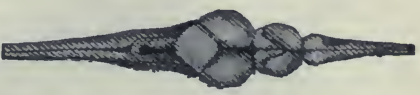

Fig. 224. - BRAIN OF PERCH, from above.

If you take the eyeball for comparison, is the whole brain as large as one eyeball? (Fig. 222.) If you judge from the size of the parts of the brain, which is more important with the fish, thinking or perception? Which is the most important sense?

The scales along a certain line on each side of the fish, called the lateral line, are perforated over a series of lateral line sense organs, supposed to be the chief organs of touch (see Fig. 209).

Questions. - Which of the fins of the fish have a use which corresponds to the keel of a boat? The rudder? A

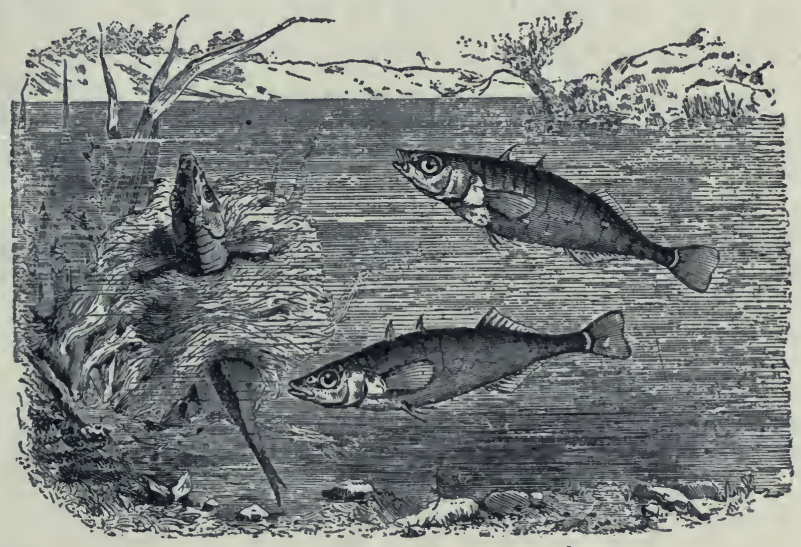

FIG. 225. - THE STICKLEBACK. Instead of depositing the eggs on the bottom, it makes a nest of water plants - the only fish that does so - and bravely defends it. 


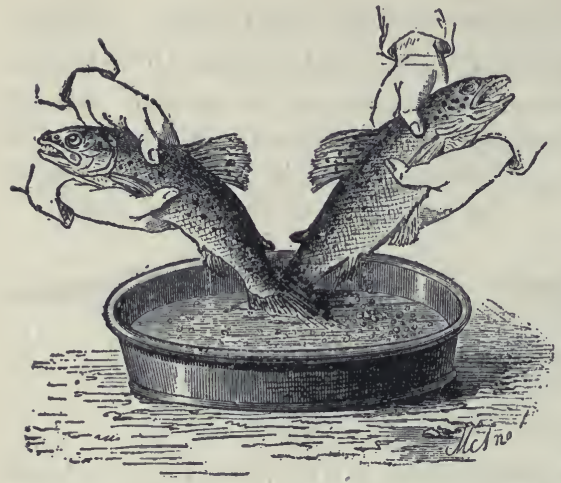

Fig. 226. - ARtificial Fecundation. The egg-cells and sperm-cells are pressed out into a pan of water.

paddle for sculling? An oar? State several reasons why the head of the fish must be very large, although the brain isvery small. Does all the blood go to the gills just after leaving the heart?

Make a list of the different species of fish found in the waters of your neigh-

bourhood; in the markets of your town.

Reproduction. - The female fish deposits the unfertilized eggs, or ova, in a secluded spot on the bottom. Afterward the male fish deposits the sperms in the same place (see Fig. 225). The eggs, thus unprotected, and newly hatched fish as well, are used for food by fish of the same and other species. To compensate for this great destruction, most fish lay (spawn) many thousands of eggs, very few of which reach maturity. Higher vertebrates (e.g. birds) have, by their superior intelligence, risen above this wasteful method of reproduction. Some kinds of marine fish, notably cod, herring, and salmon, go many miles up fresh rivers

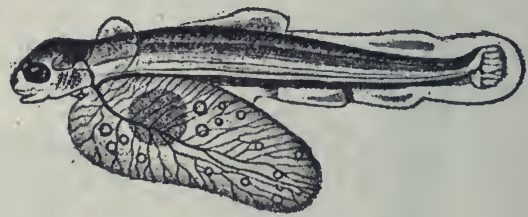

FIG. 227. - NEwLY HATChed TROUT, with yolk-sac adhering, eyes large, and fins mere folds of the skin. (Enlarged.)

to spawn. It is possible that this is because they were originally fresh-water species; yet they die if placed in fresh water except during the spawning season. They go 
because of instinct, which is simply an inherited habit. Rivers may be safer than the ocean for their young. They are worn and exhausted by the journey, and never survive to lay eggs the second time.

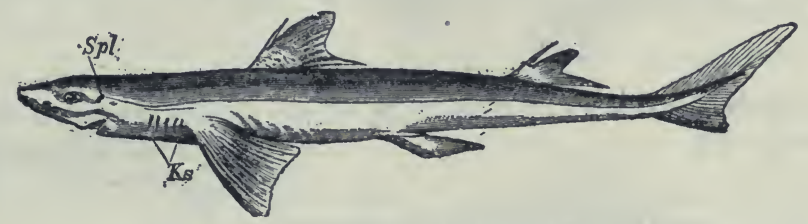

FIG. 228.-A SHARK (Acanthias vulgaris).

The air bladder is developed from the food tube in the embryo fish, and is homologous with lungs in the higher vertebrates. Are their functions the same?

Fish that feed on flesh have a short intestine. Those that eat plants have a long intestine. Which kind of food is more quickly digested?

There are mucous glands in the skin of a fish which supply a secretion to facilitate movement through the water; hence a freshly caught fish, before the secretion has dried, feels very slippery.

The air bladder, although homologous to lungs, is not a breathing organ in common fishes. It is filled by the formation of gases from the blood, and can obe made smaller by the contraction of muscles along the sides of the body; this causes the fish to sink. In the gar and other ganoids, the air bladder contains blood vessels, is connected with the gullet, and is used in breathing. Organs serving the same purpose in different animals are said to be analogous. To what in man are the gills of the fish analogous? Organs having a like position and origin are said to be homologous. The air bladders of a fish are homologous witn the lungs of man; but since they have not the same use they are not analogous. 
How does the tail of a shark or a gar differ from the tail of common fishes'? (Fig. 228.) Do you know of fish destitute of scales? Do you know of fish with whiplike feelers on the head? (Figs.) Why are most fishes white on the under side?

Comparative Review. - (Copy table on one page or two facing pages of notebook.)

\begin{tabular}{|c|c|c|c|c|c|}
\hline & $\begin{array}{l}\text { Is THERE } \\
\text { A HEAd? } \\
\text { A NeCK? }\end{array}$ & $\begin{array}{c}\text { Method of } \\
\text { FEEDING }\end{array}$ & $\begin{array}{c}\text { Digestive } \\
\text { ORgans AND } \\
\text { Digestion }\end{array}$ & $\begin{array}{l}\text { REPRODUC- } \\
\text { TION }\end{array}$ & SENSES \\
\hline \multicolumn{6}{|l|}{ A mœ ba } \\
\hline Sponge & - & & & & \\
\hline \multicolumn{6}{|l|}{ Hydra } \\
\hline \multicolumn{6}{|l|}{ Starfish } \\
\hline \multicolumn{6}{|c|}{ Earthworm } \\
\hline \multicolumn{6}{|l|}{ Wasp } \\
\hline \multicolumn{6}{|l|}{ Mussel } \\
\hline Fish & . & & & & \\
\hline
\end{tabular}

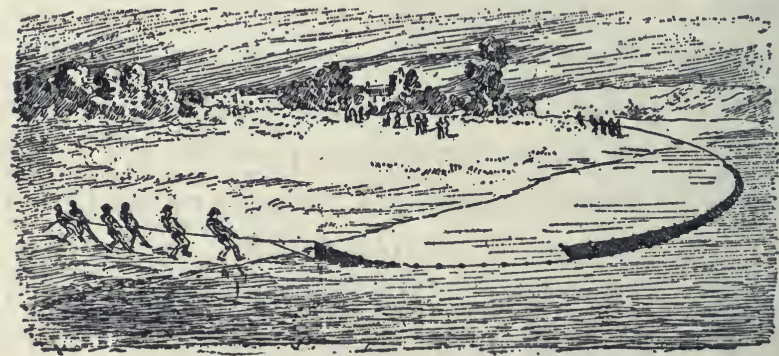

FIG. 229. - DRAWING THE SEINE. 

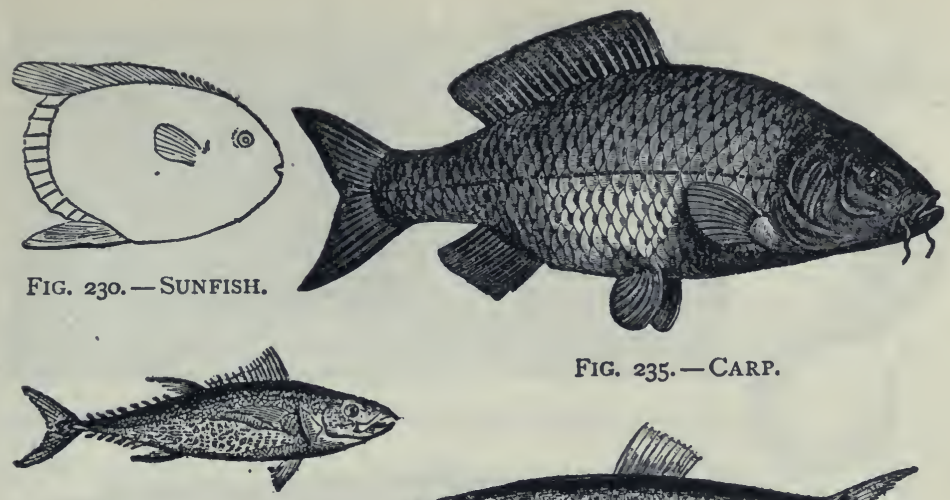

FIG. 235.-CARP.

FIG. 231. - TUNNY.
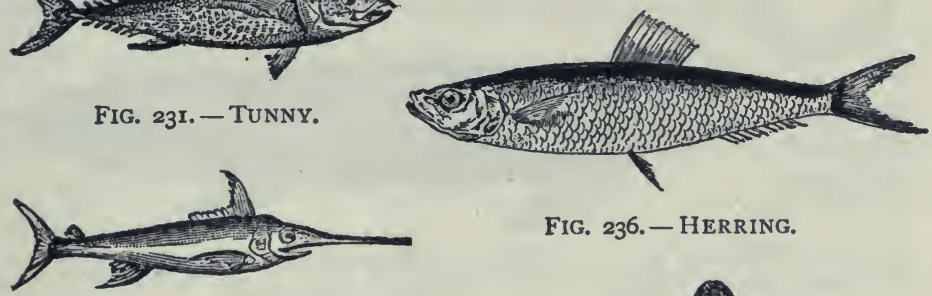

FIG. 232. - SWORDFISH.
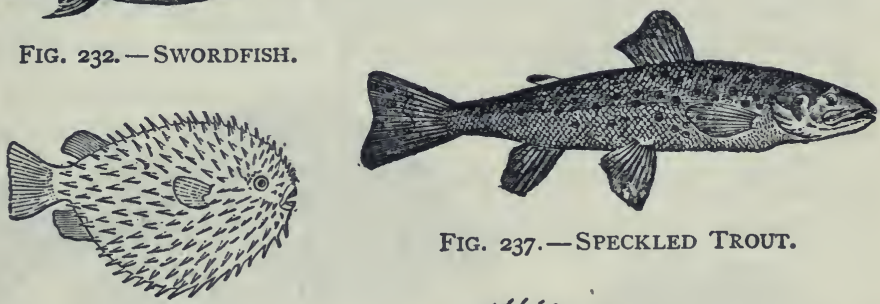

FIG. 237.-SPECKLED TROUT.

FiG. 233.-SWELLFISH.

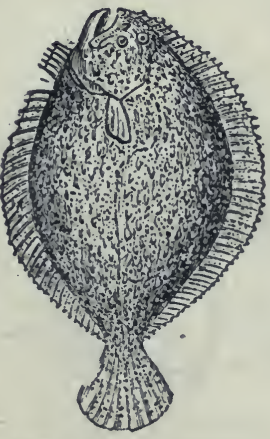

FIG. 234. - TURBOT.

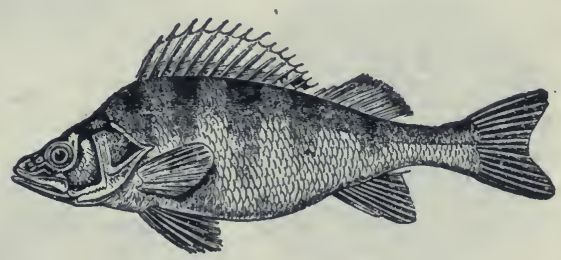

FIG. 238. - PERCH.

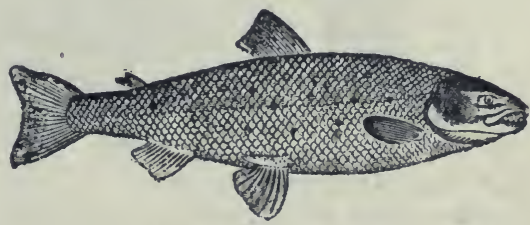

Fig. 239. - SALMON.

Seven Food Fish. Three Curious Fish.

SPECIAL REPORTS. (Encyclopedia, texts, dictionary.) 

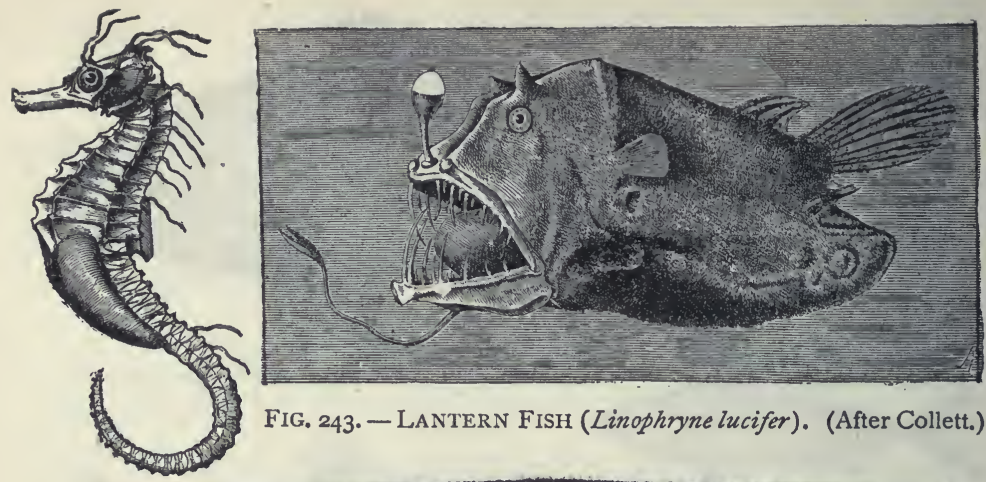

FIG. 243. - LANTERN FISH (Linophryne lucifer). (After Collett.)

FIG. 240.-

SEA HORSE

(Hippocampus), with incubating pouch, Brt.
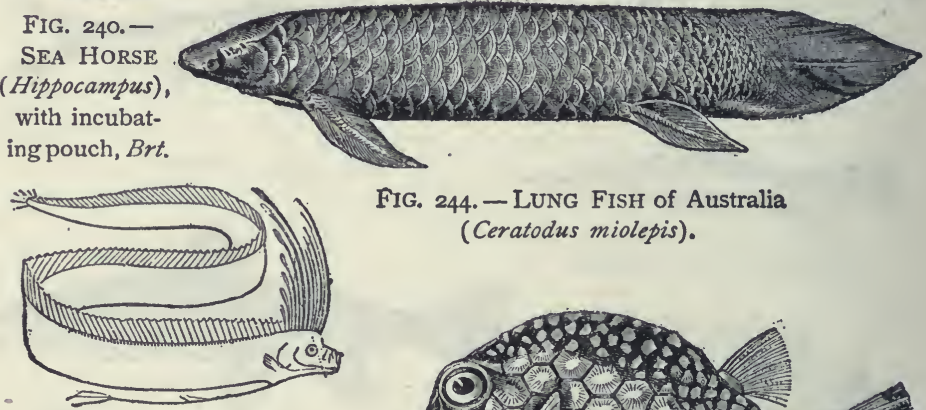

FIG. 241. - BAND FISH.

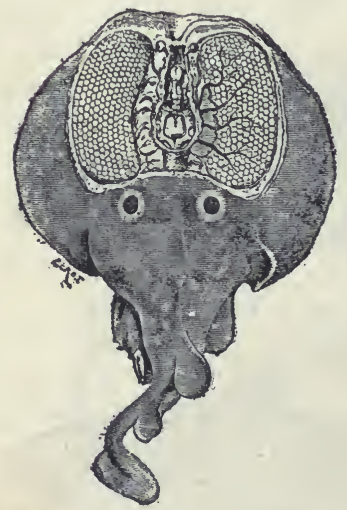

FIG. 242. - TCRPEDO. Electrical organs at right and left of brain.

FIG. 244. - LUNG FISH of Australia (Ceratodus miolepis).

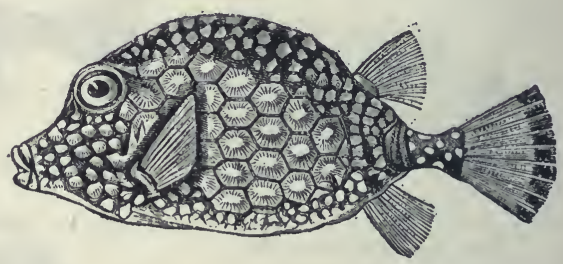

FIG. 245. - TRUNK FISH.

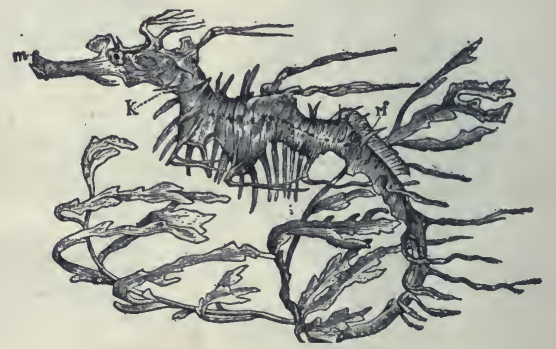

FIG. 246. - SEAWEED FISH. $\times \frac{\frac{1}{6}}{6}$ (Phyllopteryx eques).

Remarkable Fish. SPECIAL REPORTS. (Encyclopedia, texts, dictionary.) 


\section{RECOGNITION GROUP CHARACTERS}

The commoner members of the several branches may be recog. nized by the following characters:-

r. The Protozoans are the only one-celled animals.

2. The Sponges are the only animals having pores all over the body for the inflow of water.

3. The Polyps are the only many-celled animals having a single opening into the body, serving for both mouth and vent. They are radiate in structure, and usually possess tentacles.

4. The Echinoderms are marine animals of more or less radiate appearance, having a food tube in the body separate from the body wall.

The following groups are plainly bilateral : that is, dorsal and ventral surfaces, front and hind ends are different.

5. The Vermes have usually a segmented body but lack jointed legs.

6. The Arthropods ${ }^{1}$ have an external skeleton and jointed legs.

7. The Molluscs have soft bodies, no legs, no skeleton, but usually a limy shell.

8. The Vertebrates have an internal skeleton of bones, and usually two pairs of legs.

1 Insects and crustaceans.

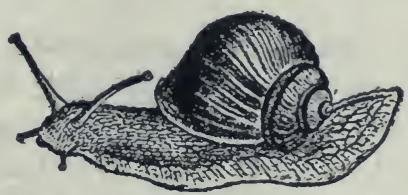

FIG. 247.-A SNAIL. (Which branch? Why?) 


\section{CHAPTER XI}

\section{BATRACHIA}

THE theory of evolution teaches that animal life began in a very simple form in the sea, and that afterward the higher sea animals lost their gills and developed lungs and legs and came out to live upon the land; truly a marvellous procedure, and incredible to many, although the process is repeated every spring in countless instances in pond and brook.

In popular language, every cold-blooded vertebrate breathing with lungs is - called a reptile. The name reptile is properly applied only to lizards, snakes, turtles, and alligators. The common mistake of speaking of frogs and salamanders as reptiles arises from considering them only in their adult condition. Reptiles hatch from the egg as tiny reptiles resembling the adult forms; frogs and salamanders, as every one knows, leave the egg in the form of tadpoles (Fig. 248). The fact that frogs and salamanders begin active life as fishes, breathing by gills, serves to distinguish them from other cold-blooded animals, and causes naturalists to place them in a separate class, called batrachia (twice breather) or amphibia (double life).

\section{TADPOLES}

SugGeSTIONS. - - Tadpoles may be studied by placing a number of frog's eggs in a jar of water, care being taken not to place a large number of eggs in a small amount of water. When they hatch, water plants (e.g. green algæ) should be added for food. The behaviour of frogs may be best studied in a tub of water. A toad in captivity should be given a cool, moist place, and fed well. A piece of meat placed near a toad may attract flies, and the toad may be observed while catching them, but the motion is so swift as to be almost imperceptible. Live flies may be put into a glass jar with a toad. Toads do not move about until twilight, except 
in cloudy, wet weather. They return to ponds and brooks in spring at the time for laying eggs. This time for both frogs and toads is shown by trilling. All frogs, except tree frogs, remain in or near the water all the year.
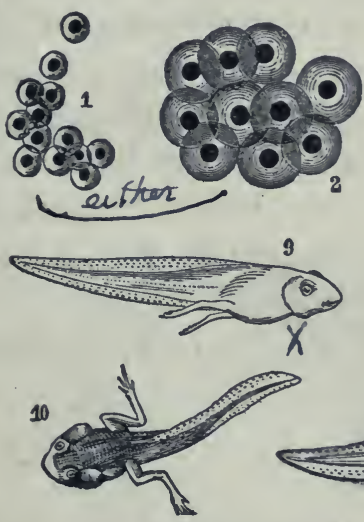

FIG. 248. - METAMORPHOSES OF THE FROG, numbered in order.
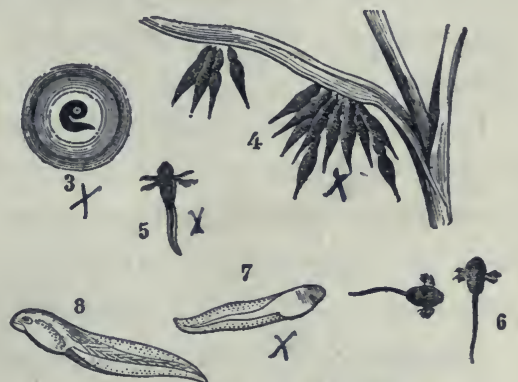

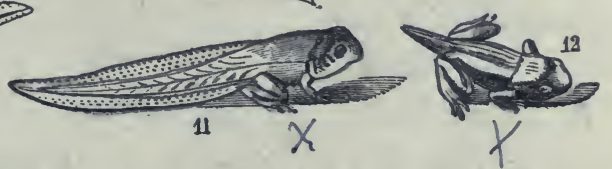

Do eggs hatch and tadpoles grow more rapidly in a jar of water kept in a warm place or in a cold place? In pond water or in drinking water? Can the tadpoles be seen to move in the eggs before hatching? When do the external gills show? (Fig. 248.)

What parts may be described in a tadpole? What is the shape of the tail? Compare the tadpole with the fish as to (I) general shape, (2) covering, (3) fins, (4) tail, (5) gills.

Do the external gills disap-

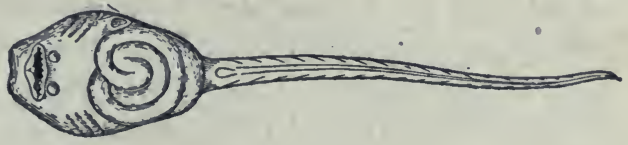
FIG. 249. - TADPOLE, from below, showing intestine and internal gills. (Enlarged.) pear before or after any rudiments of limbs appear? (6, 7, Fig. 248.) Can you locate the gills after they become internal? (Fig. 249.) 
In what state of growth are the legs when the tadpole first goes to the surface to breathe? Which legs appear first? Of what advantage is this? What becomes of the tail? Is the tail entirely gone before the frog first leaves the water? Are tadpoles habitually in motion or at rest?

Is the intestine visible through the skin? (Fig. 249.) Is it straight or coiled? Remembering why some fish have larger intestines than others, and that a cow has a long intestine and a cat a short one, state why a tadpole has a relatively longer intestine than a frog.

Compare the mouth, jaws, eyes, skin, body, and habits of tadpole and frog.

\section{FROGS}

Prove that frogs and toads are beneficial to man. Did you ever know of a frog or a toad destroying anything useful, or harming any on e, or causing warts? How many pupils in class ever had warts? Had they handled frogs before the warts came? Frogs are interesting, gentle, timid animals. Why are they repulsive to some people?

Environment.-Where are frogs found in greatest numbers? What occurs when danger threatens them? What enemies do they have? What colour, or tint, is most prominent on a frog? Does the colour "mimic" or imitate its surroundings? What is the colour of the under side of the body? (Fig. 250.) Why is there greater safety in that colour? What enemies would see water frogs from below? Do tree frogs mimic the bark? The leaves?

Can a frog stay under water for an indefinite tíme? Why, or why not? What part of a frog is above the 
surface when it floats or swims in a tub of water ? Why? Do frogs croak in the water or on the bank? Why do they croak after a rain? Do toads croak?

Are the eggs laid in still or in flowing water? In a clear place or among sticks and stems? Singly, or in strings or in masses? (Fig. 248.) Describe an egg. Why do frogs dig into the mud in autumn in cold climates? Why do they not dig in mud at the bottom of a pond?

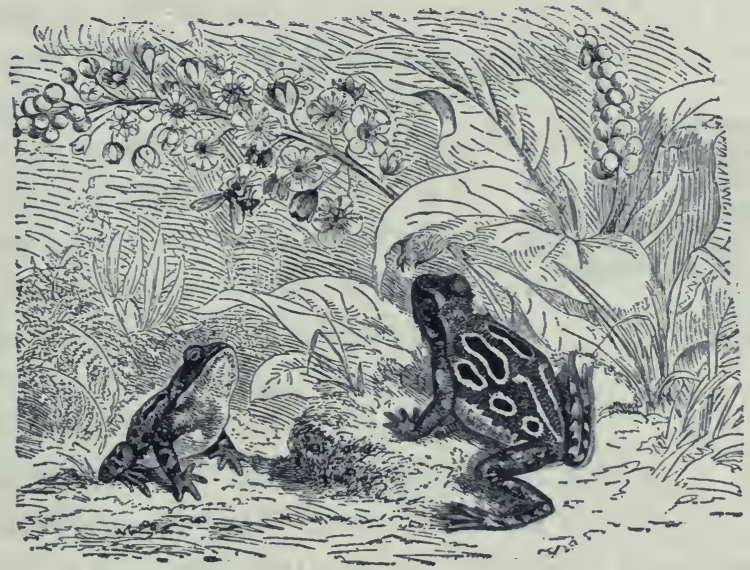

FIG. 250. - PAINTED FROG (Chorophilus ornatus), of Mexico.

Describe the position of the frog when still (Fig. 250). Of what advantage in this position? Does the frog use its fore legs in swimming or jumping? Its hind legs? How is the frog fitted for jumping? Compare it in this respect with a jumping insect; a jumping mammal. "How is it fitted for swimming? Is the general build of its body better fitted for swimming or for jumping? How far can a frog jump?

External Features. - The frog may be said to have two regions in its body, the head and the trunk. A neck hardly 
exists, as there is only one vertebra in front of the shoulders (Fig. 252), while mammals have seven neck (cervical) vertebræ. There are no tail (caudal) vertebræ, even in the tadpole state of frogs and toads.

The head appears triangular in shape when viewed from what direction? The head of a frog is more pointed than the head of a toad. Is the skull a closed case of broad bones or an open structure of narrow bones?

(Fig. 252.)

Describe the mouth. Observe the extent of the mouth opening (Fig. 25I). Are teeth present in the upper jaw? The lower jaw? Are the teeth sharp or dull? Does the

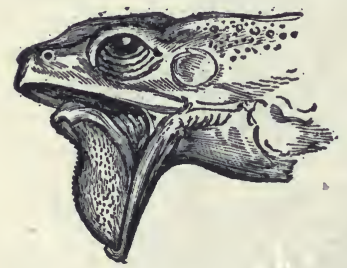

FIG. 25I. - HEAD OF FROG. frog chew its food? Is the tongue slender or thick? (Fig. 25I.) Is it attached to the front or the back of the mouth? In what direction does the free end extend when the tongue lies flat? Is the end pointed or lobed? How far out will the tongue stretch?' For what is it used? Why is it better for the teeth to be in the upper jaw rather than in the lower jaw? That the teeth are of little service is shown by the fact that the toad with similar habits of eating has no teeth. Will a toad catch and swallow a bullet or a pebble rolled before it? The toad is accustomed to living food, hence it prefers a moving insect to a still one.

The Senses. - Compare the eyes with the eyes of a fish in respect to position and parts. Are the eyes protruding or deep-set? Touch the eye of a live frog. Can it be retracted? What is the shape of the pupil? The colour of the iris? Is the eye bright or dull? What probably gave rise to the superstition that a toad had a jewel in its head? Is there a third eyelid? Are the 
upper and lower eyelids of the same thickness? With which lid does it wink? Close its eye?

Observe the large oval ear drum or tympanum. Wha: is its direction from the eye? (Fig. 25I.) The mouth? Is there a projecting ear? Does the frog hear well? What reason for your answer? As in the human ear, a tube (the Eustachian tube) leads from the mouth to the inner side of the tympanum.

How many nostrils? (Fig. 25I.) Are they near together or separated? Large or small? A bristle passed into the nostril comes into the mouth not far back in the roof. Why must it differ from a fish in this?

How do the fore and hind legs differ? How many toes on the fore foot or hand? On the hind foot? On which foot is one of the toes rudimentary? Why is the fore limb of no assistance in propelling the body in jumping? Do the toes turn in or out? (Fig. 250.) How does the frog give direction to the jump? What would be the disadvantage of always jumping straight forward when fleeing? Which legs are more useful in alighting ?

Divisions of the Limbs. - Distinguish the upper arm, forearm, and hand in the

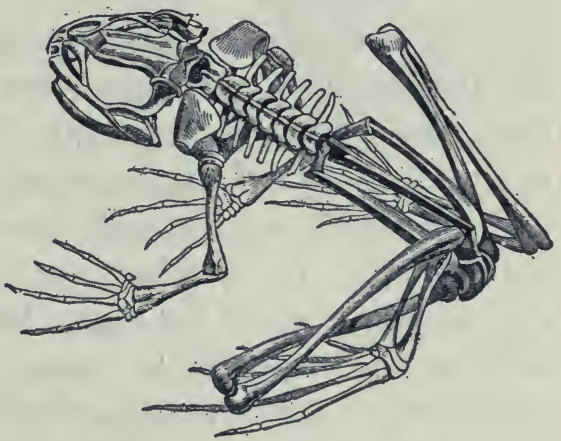

Fig. 252. - SKELETON OF FroǴ. fore limb (Figs. 252 and 253). Compare with skeleton of man (Fig. 399). Do the arms of a man and a frog both have one bone in the upper arm and two in the forearm? Both have several closely joined bones in the wrist and 
five separate bones in the palm. Do any of the frog's fingers have three joints? Compare also the leg of man

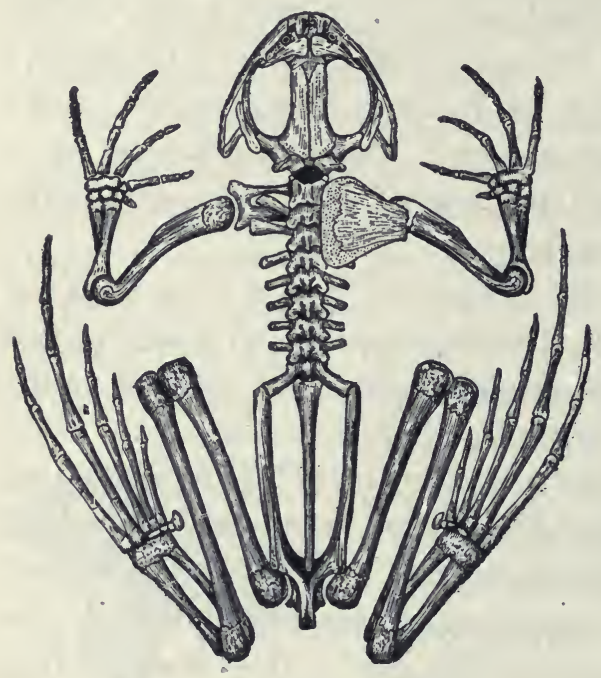

FiG. 253.-SKELETON OF Frog. and the hind leg of the frog (Figs. 253 and 399). Does the thigh have one bone in each? The shank of man has two bones, shin and splint bone. Do you see a groove near the end in the shank bone of a frog (Fig. 252), indicating that it was formed by the union of a shin and a splint bone? The

first two of the five bones of the ankle are elongated, giving the hind leg the appearance of having an extra joint (Fig. 253). The foot consists of six digits, one of which, like the thumb on the fore limb, is rudimentary. The five developed toes give the five digits of the typical vertebrate foot. Besides the five bones corresponding to the instep, the toes have two, three, or four bones each. How is the hind foot specialized for swimming? Which joint of the leg con-

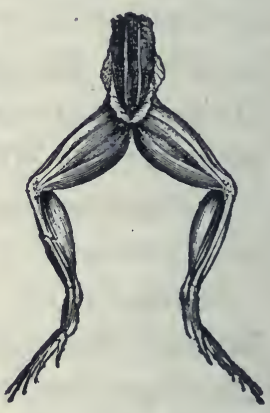

FIG. 254. - LEG MUSCLES OF FROG. tains most muscle? (Fig. 254.) Find other bones of the frog analogous in position and similar in form to bones in the human skeleton. 
Is the skin of a frog tight or loose? Does it have any appendages corresponding to scales, feathers, or hair of other vertebrates? Is the skin rough or smooth? The toad is furnished with glands in the skin which are sometimes swollen; they form a bitter secretion, and may be, to some extent, a protection. Yet birds and snakes do not hesitate to swallow toads whole. Show how both upper and under surfaces of frog illustrate protective colouration.

All batrachians have large and numerous blood vessels in the skin by which gases are exchanged with the air, the skin being almost equal to a third lung. That the skin may function in this way, it must not become dry. Using this fact, account for certain habits of toads as well as frogs.

If a frog is kept in the dark or on a dark surface, its skin will become darker than if kept in the light or on a white dish. Try this experiment, comparing two frogs. This power of changing colour is believed to be due to the diminution in size of certain pigment cells by contraction, and enlargement from relaxation. This power is possessed to a certain degree not only by batrachians but also by many fishes and reptiles. The chameleon, or green lizard, surpasses all other animals in this respect (Fig. 280). What advantage from this power?

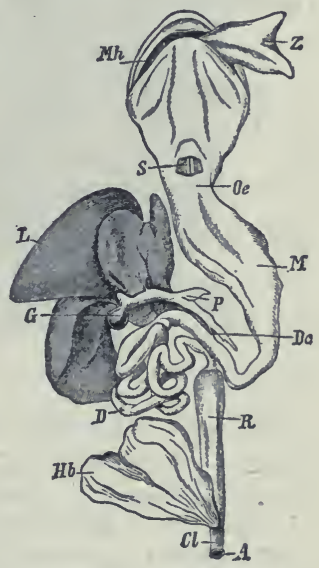

Fig. 255.-Digestive CANAL OF Frog.

$M h$, moutb; $Z$, tongue pulled outward; $S$, opening to larynx; Oe, gullet; $M$, stomach; $D$, intestine; $P$, pancreas; $L$, liver; $G$, gall bladder; $R$, rectum; $H b$, bladder; $C l$, cloaca; $A$, vent.

Digestive System. - The large mouth cavity is connected by a short throat with the gullet, or œsophagus (Fig. 255). 
A slit called the glottis opens from the throat into the lungs (Fig. 255). Is the gullet long or short? Broad or narrow? Is the stomach short or elongated? Is the division distinct between stomach and gullet, and stomach and intestine? Is the liver large or small? Is it simple or lobed? The pancreas lies between the stomach and the first bend of the intestines (Fig. 255). What is its shape? A bile duct connects the liver with

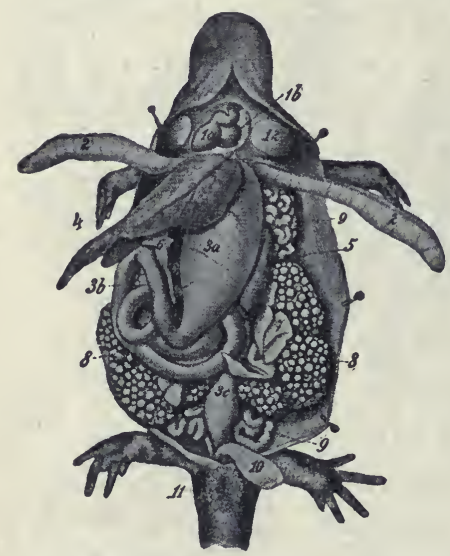

Fig. 256. - ANATOMY OF SALAMANDER.

$I a$, heart; 2 , lungs: $3 a$, stomach; $3 b$, intestine: $3 c$, large intestine; 4 , liver: 8, egg masses; 10, bladder; 11 , vent. the small intestine ( $D c$, Fig. 255). It passes through the pancreas, from which it receives several pancreatic ducts. After many turns, the small intestine joins the large intestine. The last part of the large intestine is called the rectum (Latin, straight). The last part of the rectum is called the cloaca (Latin, a drain), and into it the ducts from the kidneys and the reproductive glands also open. The kidneys are large, elongated, and flat. They lie under the dorsal wall. The urinary bladder is also large. Does the salamander have a similar digestive system? (Fig. 256) Why are the liver and the lungs (Fig. 256) longer in a salamander than in a frog?

Respiration. - How many lungs? Are they simple or lobed? (Fig. 256.) A lung cut open is seen to be baglike, with numerous ridges on its inner surface. This increases the surface with which the air may come in contact. In the walls of the lungs are numerous 
capillaries. Does the frog breathe wit/ mouth open or closed? Does the frog have any ribs for expanding the chest? What part of the head expands and contracts? Is this motion repeated at a slow or a rapid rate? Regularly or irregularly? There are valves in the nostrils for opening and closing them. Is there any indication of opening and closing as the throat expands and contracts? The mouth and throat (pharynx) are filled with air each time the throat swells, and the exchange of gases (which gases?) takes place continually through their walls and the walls of the lungs. At intervals the air is forced through the glottis into the lungs. After a short time it is expelled from the lungs by the muscular abdominal walls, which press upon the abdominal organs, and so upon the lungs. Immediately the air is forced back into the lungs, so that they are kept filled. In some species the-lungs regularly expand at every second contraction of the throat. This is shown by a slight outward motion at the sides. Does the motion of the throat cease when the frog is under water? Why would the frog be unable to breathe (except through the skin) if its mouth were propped open? Why does the fact that the breathing is so slow as almost to cease during hibernation, aid the frog in going through the winter- without starving? (Chap. I.) Why must frogs and toads keep their skins moist? Which looks more like a clod? Why?

The Heart and Circulation. - What is the shape of the heart? (Fig. 257.) Observe the two auricles in front and the conical ventricle behind them. The great arterial trunk from the ventricle passes forward beyond the auricles; it divides into two branches which turn to the right and the left (Fig. 257). Each branch immediately subdivides into three arteries (Fig. 257), one going to the head, one to the lungs and skin, and a third, the largest, 
passes backward in the trunk, where it is united again to its fellow.

Both the pulmonary veins, returning to the heart with pure blood from the lungs, empty into the left auricle. Veins with the impure blood from the body empty into the right auricle. Both

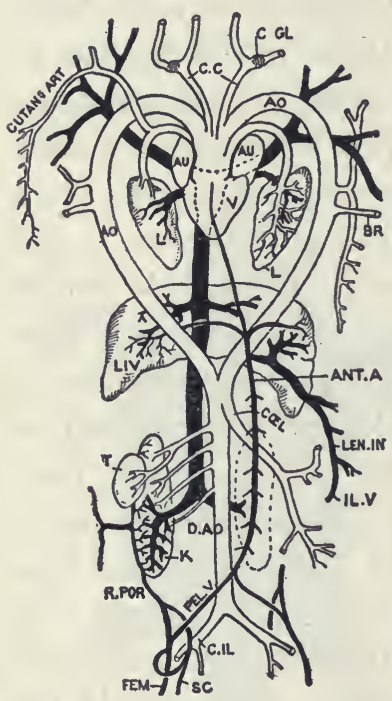

FIG. 257. - PLAN OF FROG'S Circulation.

Venous system is black; the arterial, white. $A U$, auricles; $V$; ventricle: $L$, lung; $L I V$, liver. Aorta has one branch to right reunite below. Right branch only persists in birds, left branch in beasts and man. the auricles empty into the ventricles, but the pure and the impure blood are prevented from thoroughly mixing by ridges on the inside of the ventricle. Only in an animal with a four-chambered heart does pure blood from the lungs pass unmixed and pure to all parts of the body,

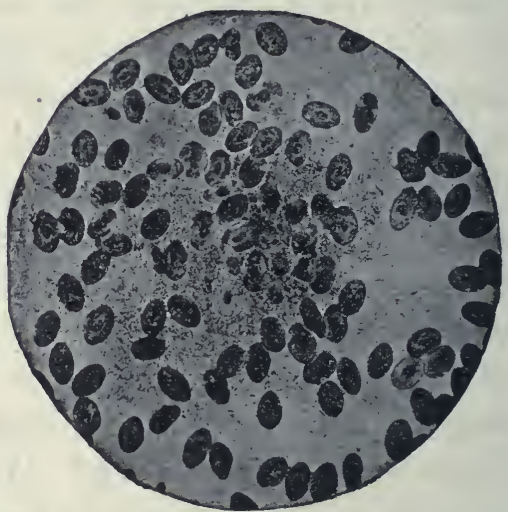

FIG. 258. - FroG'S BLOOD (magnified 2500 areas). Red cells oval, nucleated, and larger than human blood cells. Nuclei of two white cells visible near centre. (Peabody.)

and only such animals are warm-blooded. The purer (i.e. the more oxygenated) the blood, the greater the oxidation and warmth.

The red corpuscles in a frog's blood are oval and larger than those of man. Are all of them nucleated? (Fig. 258.) The flow of blood in the web of a frog's foot is a striking and interesting sight. It may be easily shown by wrapping a small frog in a wet cloth and laying it with one foot extended upon a glass slip on the stage of a miscroscope. 
The brain of the frog (Fig. 259) is much like that of a fish (Fig. 224). The olfactory, cerebral, and optic lobes, cerebellum and medulla are in the same relative position, although their rela-

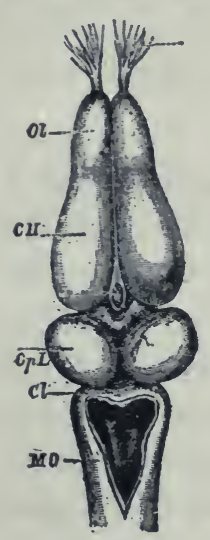
FIG. 259.-
BRAIN OF FROG. tive sizes are not the same. Compared with the other parts, are the olfactory lobes more or less developed than in a fish? The cerebralhemispheres? The optic lobes? The cerebellum? There is a cavity in the brain. It is readily exposed on the under surface of the medulla by cutting the membrane, which is there its only covering (Fig. 259).

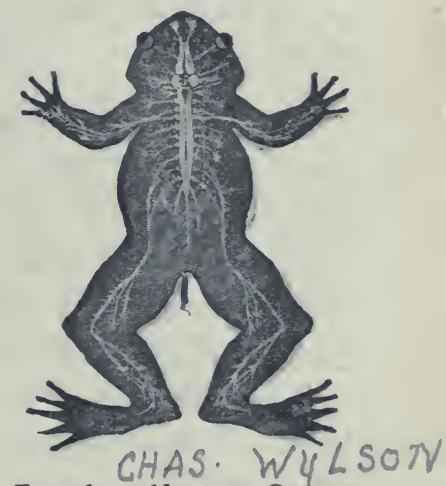

FIG. 260. - NERVOUS SYSTEM OF FROG.

Frogs and toads are beneficial (why?) and do not the slightest injury to any interest of man. If toads are encouraged to take up their abode in a garden, they will aid in ridding it of insects. A house may be made in a shady corner with four bricks, or better still, a hole a foot deep may be dug to furnish them protection from the heat of the day. A toad's muzzle is not so tapering as a frog's (why?), its feet are not so fully webbed (why?), and its skin is not so smooth (why?). In case of doubt, open the mouth and rub the finger along the upper jaw ; a frog has sharp

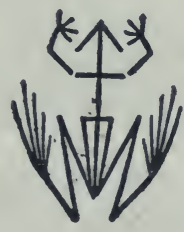

A.

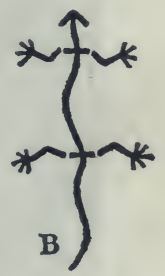

Fig. 26r. - Position of legs in tailless $(A)$ and tailed $(B)$ amphibian. teeth, a toad none at all. The tadpoles of frogs, toads, and salamanders are much alike. In toad's spawn the eggs lie in strings inclosed in jelly; frogs spawn is in masses (Fig. 248). 
Any batrachian may easiiy be passed around the class after, placing it in a tumbler with gauze or net tied over top. It should be kept in a box with two inches of moist earth on the bottom. If no live insects are obtainable for feeding a toad, bits of moist meat may be dangled from the end of a string. If tadpoles are placed in a pool or a tub in a garden, the toads hatched will soon make destructive garden insects become a rarity.

Does a frog or a salamander have the more primitive form of body? Why do you think so? Salamanders are sometimes called mud puppies. The absurd belief that salamanders are poisonous is to be classed with the belief that toads cause warts. The belief among the ancients that salamanders ate fire arose perhaps from seeing them coming away from fires that had been built over their holes on river banks by travellers. Their moist skin protected them until the fire became very hot.

Describe the "mud puppy" shown in Fig. 262. The pouched gopher, or rat (Fig. 371), is sometimes absurdly called a salamander.

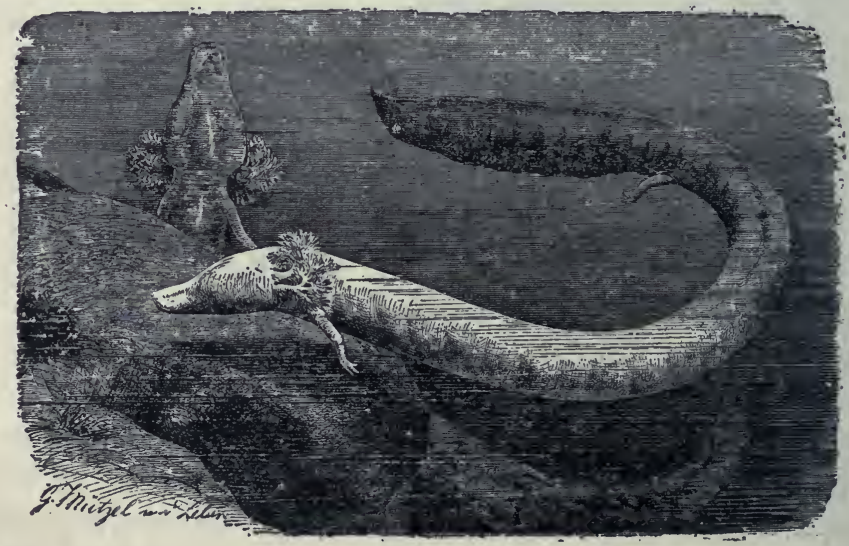

Fig. 262. - Blind Salamander (Proteus anguinus). $\times \frac{2}{2}$. Found in caves and underground streams in Balkans. Gills external, tail finlike, legs small. 


\section{CHAPTER XII}

\section{REPTILIA (REPTILES)}

THIS class is divided into four orders which have such marked differences of external form that there is no diffculty in distinguishing them. These orders are represented by Lizards, Snakes, Turtles, and Alligators. Of these, only the forms of lizards and alligators have similar proportions, but there is a marked difference in their size, lizards being, in general, the smallest, and alligators the largest of the reptiles.

Comparison of Lizards and Salamanders. - To make clear the difference between reptiles and batrachians, it will be well to compare the orders in the two classes which resemble each other in size and shape; namely, lizards and

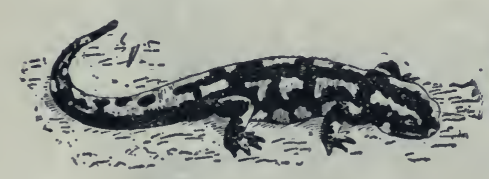

Fig. 263. - A SALAMANDER.

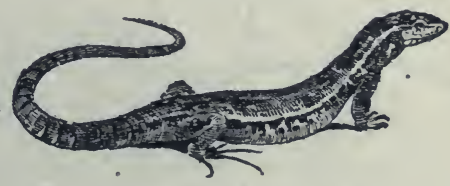

FIG. 264. - A LIZARD.

salamanders (Figs. 263 and 264). State in a tabular form their differences in skin, toe, manner of breathing, development from egg, shape of tail, habitat, habits. Each has an elongated body, two pairs of limbs, and a long tail, yet they are easily distinguished. Are the differences suggested above valid for the other batrachians (frogs) and other reptiles (e.g. turtles)? Trace the same differences 
between the toad or frog (Fig. 250) and the "horned toad," which is a lizard (Fig. 265).

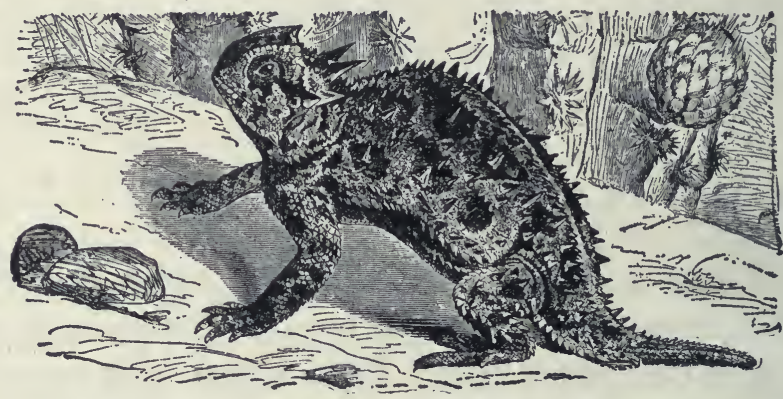

FIG. 265. - "HORNED TOAD" LIZARD, of the Southwest (Phrynosoma cornita). $\times \frac{2}{3}$.

\section{Study of A Turtle or a TORTOISE}

Suggestrons. - Because of the ease with which a tortoise or a turtle may be caught and their movements and habits studied, it is suggested that one of these be studied as an example of reptiles. Besides a live specimen, a skeleton of one species and the shells of several species should be available.

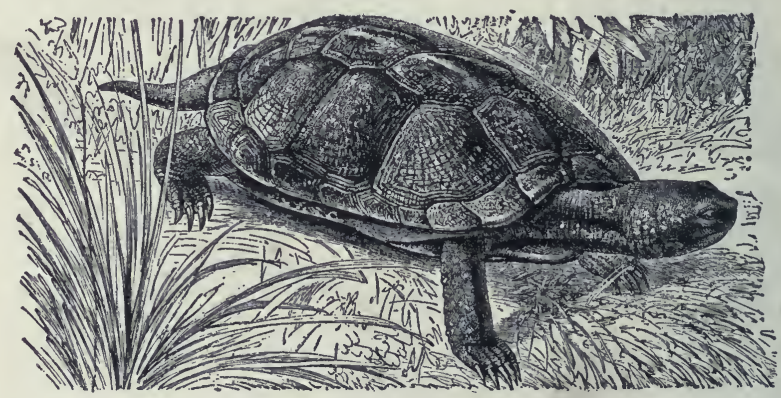

Fig. 266. - EURopean Pond Turtile (Emys lutaria). (After Brehms.)

The body (of a turtle or a tortoise) is divided distinctly into regions (Fig. 266). Is there a head? Neck? Trunk? Tail? The trunk is inclosed by the so-called shell, which 
consists of an upper portion, the carapace, and a lowet portion, the plastron. How are the other regions covered? What is the shape of the head? Is the mouth at the front, or on the under side? Where are the nostrils? Are the motions of breathing visible? Is there a beak or snout? Do the jaws contain teeth?

Do the eyes project? Which is thinner and more movable, the upper or the lower lid? Identify the third eyelid (nictitating membrane). It is translucent and comes from, and is drawn into, the inner corner of the eye. It cleanses the eyeball. Frogs and birds have a similar membrane. The circular ear drum is in a depression back of the angle of the mouth. What other animal studied has an external ear drum?

The tortoise has a longer, more flexible neck than any other reptile. Why does it have the greatest need for such a neck? Is the skin over the neck tight or loose? Why?

Do the legs have the three joints or parts found on the limbs of most vertebrates? How is the skin of the legs covered? Do the toes have clares? Compare the front and the hind feet. Does the tortoise slide its body or lift it when walking on hard ground? Lay the animal on its back on a chair or a table at one side of the room in view of the class. Watch its attempts to right itself. Are the motions suited to accomplish the object? Does the tortoise succeed?

What are the prevailing colours of turtles? How does their colouration correspond to their surroundings?

What parts of the tortoise extend at times beyond the shell? Are any of these parts visible when the shell is closed?. What movements of the shell take place as it is closed? Is the carapace rigid throughout? Is the plastron? 
The Skeleton (Fig. 267). - The carapace is covered with thin epidermal plates which belong to the skin. The bony nature of the carapace is seen when the plates are removed, or if its inner surface is viewed (Fig. 267). It is seen to consist largely of wide ribs (how many?) much flattened and grown together at their edges. The ribs are seen to be rigidly attached to the vertebræ. The rear projections of the vertebræ are flattened into a series of bony plates which take the place of the sharp ridge found along the backs of most

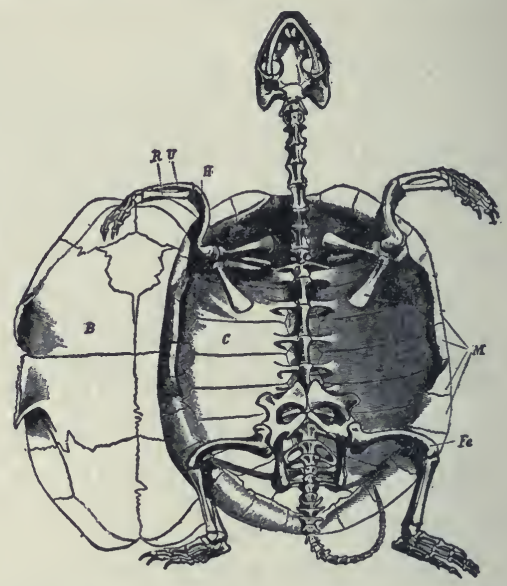

FIG. 267. - SKELETON OF EUROPEAN TORTOISE.

$C$, rib plates; $M$, marginal plates; $B$, plastron; $H$, humerus bone; $R$, radius: $U$, ulna; Fe, femur.

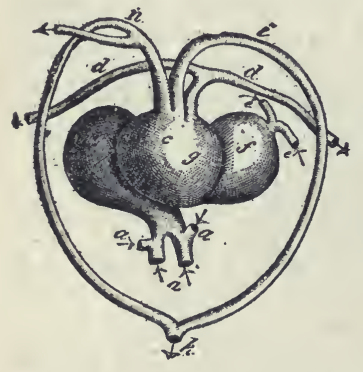

FIG. 268. - THREE-CHAM BERED HEART OF A REPTILE (tortoise).

$a$, veins; $b, f$, right and left auricles; $c g$, ventricle; $d$, àrteries to lungs; $e$, veins from lungs; $i, n$, two branches of aorta. Compare with Fig. 269 and coloured Fig.2.

vertebrates. Show that the shell of a turtle is not homologous with the shells of mollusks. Does the turtle have shoulder blades and collar bones? Hip bones? Thigh bones? Shin bone (fibia) and splint bone (fibula)? (Fig. 267.)

Do the plates formed by the ribs extend to the edge of the carapace? See Fig. 267. About how many bony plates form the carapace? The plastron? Do the horny plates outside correspond to the bony plates of the shell? 
How many axial plates? How many costal (rib) plates? How many border plates? Which plates are largest? Smallest? Do the horny plates overlap like shingles, or meet edge to edge? Is there any mark where they meet on the bony shell? Basing it upon foregoing facts, give a connected and complete description of the structure of the carapace. Compare the skeleton of the turtle with that of the snake, and correlate the differences in structure with differences in habits.

Draw the tortoise seen from the

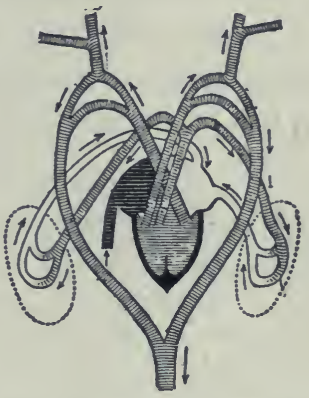

FIG. 269. - PLAN OF REPTILIAN CIRCULATION. See arrows. side or above, with its shell closed, showing the arrange-

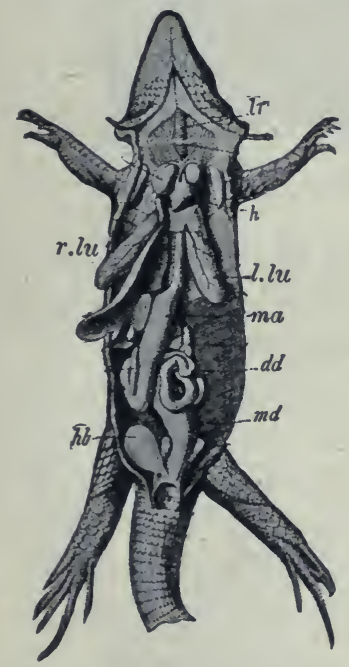

Fig. 270.-REPTILIAN VISCERA (lizard).

lr, windpipe; $h$, heart; $l u$, lungs; Ir, liver: $m a$, stomach; $d d$, $m d$, intestines; $h b$, bladder. ment of the plates.

Place soft or tender vegetable food, lettuce, mushroom, roots, berries, and water, also meat, in reach of the turtle. What does it prefer? How does it eat? It has no lips; how does it drink?

Study the movements of its eyeballs and eyelids, and the respiratory and other movements already mentioned. State a reason for thinking that no species of land animals exists that lacks the simple power of righting itself when turned on its back.

Tortoise, Turtle, Terrapin. - The turtles belong to the order of reptiles called chelonians. No one 
can have any difficulty in knowing a member of this order. The subdivision of the order into families is not so easy, however, and the popular attempts to classify chelonians as turtles, tortoises, and terrapins have not been entirely successful. Species with a vaulted shell and imperfectly webbed toes and strictly terrestrial habits are called tortoises. Species with flattened shells and strictly aquatic habits should be called terrapins (e.g. mud terrapin). They have three instead of two joints in the middle toe of each foot. The term turtle may be applied to species which are partly terrestrial and partly aquatic (e.g. snapping turtle (Fig. 27I)). Usage, however, is by no means uniform.

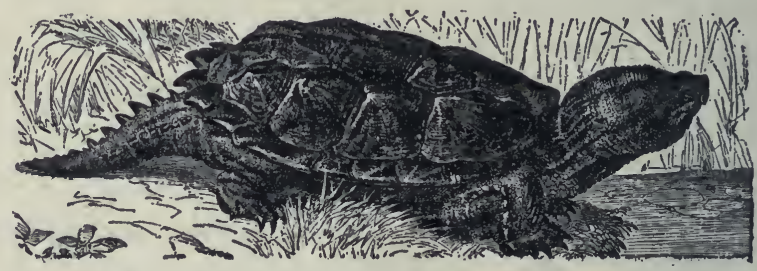

Fig. 27I. - SNAPPING TURTLE (Chelydra serpentina).

Most reptiles eat animal food; green terrapins and some land tortoises eat vegetable food. Would you judge that carnivorous chelonians catch very active prey?

The fierce snapping turtle, found in ponds and streams, sometimes has a body three feet long. Its head and tail are very large and cannot be withdrawn into the shell. It is carnivorous and has great strength of jaw. It has been known to snap a large stick in two. The box tortoise is yellowish brown with blotches of yellow, and like its close kinsman, the pond turtle of Europe (Fig. 266), withdraws itself and closes its shell completely. Both lids of the plastron are movable, a peculiarity belonging to these two species. The giant tortoise of the Galapagos Islands, ac- 
cording to Lyddeker, can trot cheerfully along with three full-grown men on its back. "Tortoise shell" used for combs and other articles is obtained from the overlapping scales of the hawkbill turtle, common in the West Indies. The diamond-back terrapin, found along the Atlantic Coast from Massachusetts to Texas, is prized for making soup.

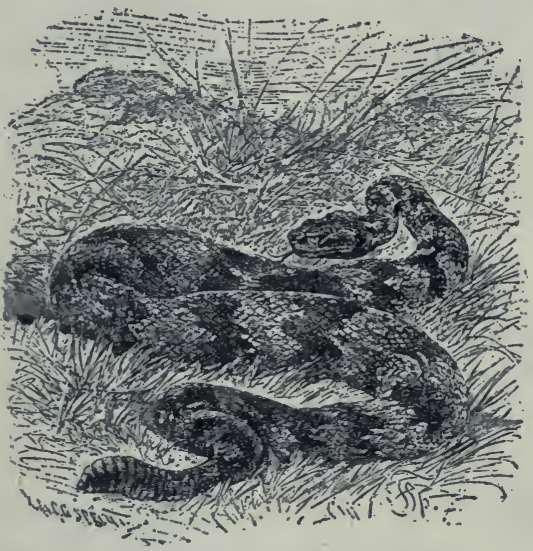

Fig. 272.-A RATTLESNAKE.

Venomous snakes named in order of virulence: 1 . Coral snakes, Elaps, about seventeen red bands bordered with yellow and black (coloured figure 6) (fatal). 2. Rattlesnakes (very deadly). 3. Copperhead (may kill a small animal of the size of a dog). 4. Water moccasin (never fatal). 5. Ground rattler.- Effects: Pulse fast, breathing slow, blood tubes dilated, blood becomes stored in abdominal blood tubes, stupefaction

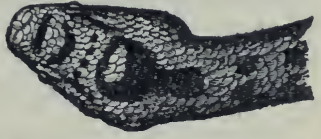

FIG. $273 a .-\mathrm{HEAD}$ OF VIPER, showing typical triangular shape of head of venomous snake.

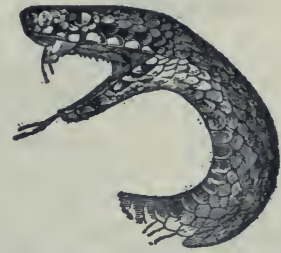

FIG. 273 б. - SIDE VIEW, showing poison fangs; also tongue (forked, harmless).

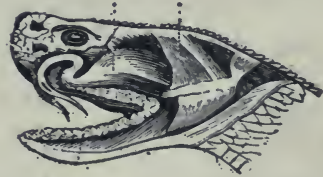

FIG. 274. - VIPE?'S HEAD, showing poison sac at base of fangs.

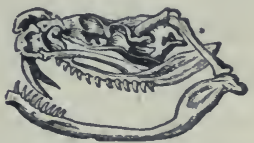

FIG. 275.-SKULL, showing teeth, fangs, and quadrate bone to which lower jaw is joined. See Fig. 284 . 
and death from blood being withdrawn from brain. Al. ways two punctures, the closer together the smaller the snake. Remedies: Ligature between wound and heart, lance wound and suck; inject into wound three drops of I per cent solution of chromic acid or potassium permanganate. Give strychnine, hypodermically, until strychnine symptoms (twitchings) appear. No one but a physician should give strychnine. Digitalin or caffein acts like strychnine; alcohol has opposite effect.

Protective Coloration and Mimicry.-When an animal imitates the colour or form of its inanimate surroundings it

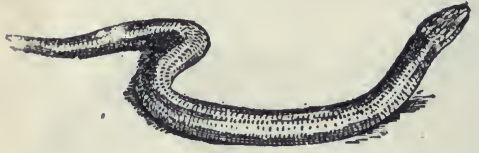

FIG. 276. - " Glass SNAKE," a lizard without legs.

is said to be protectively coloured or formed. Give an instance of protective Coloration or form among lizards; butterflies; grasshoppers; a mphi -

bians; echinoderms.

When an animal imitates the colour or the form of another animal it is said to mimic the animal. Mimicry usually enables an animal to deceive enemies into mistaking it for an animal which for some reason they avoid. The milkweed butterfly has a taste that is repulsive to birds. The viceroy butterfly is palatable to birds, but it is left untouched because of its close resemblance to the repulsive milkweed butterfly. The harlequin snake (Elaps) of the Gulf states is the most deadly snake of North America

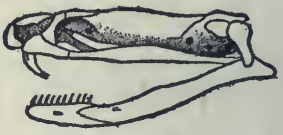

FIG. 277.-SKULL OF ELAPS. See colored Fig. 5 .

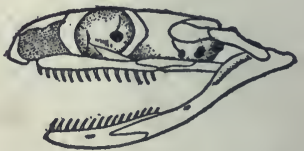

FIG. 278. = SKULL OF LAMPROPELTIS. (Figs. 277, 278). It is very strikingly coloured with rings of scarlet, yellow, and black. This is an example of warning coloration. The scarlet snake (Lampropeltis) has bands of 

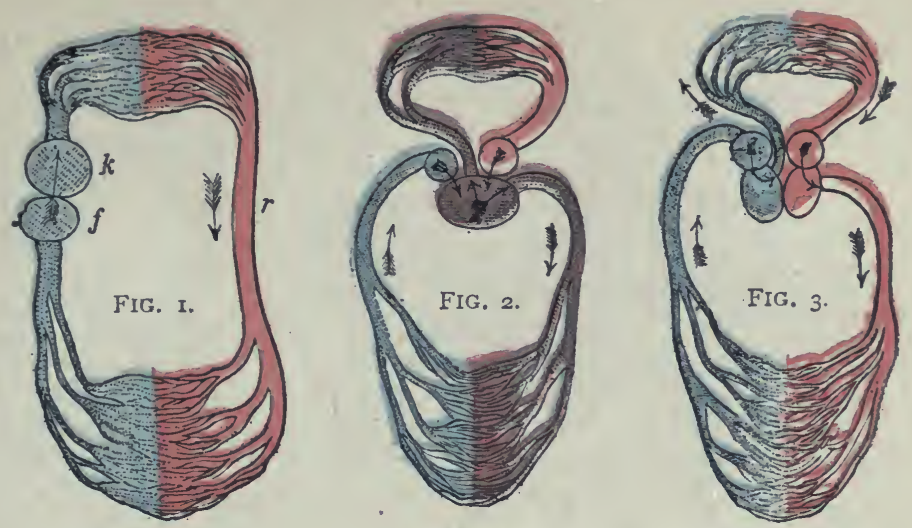

Coloured Figures $1,2,3 .-$ Circulation in Fish, Reptile, MAamal. In which is blood from heart a!l impure? Mixed? Both pure and inpure?

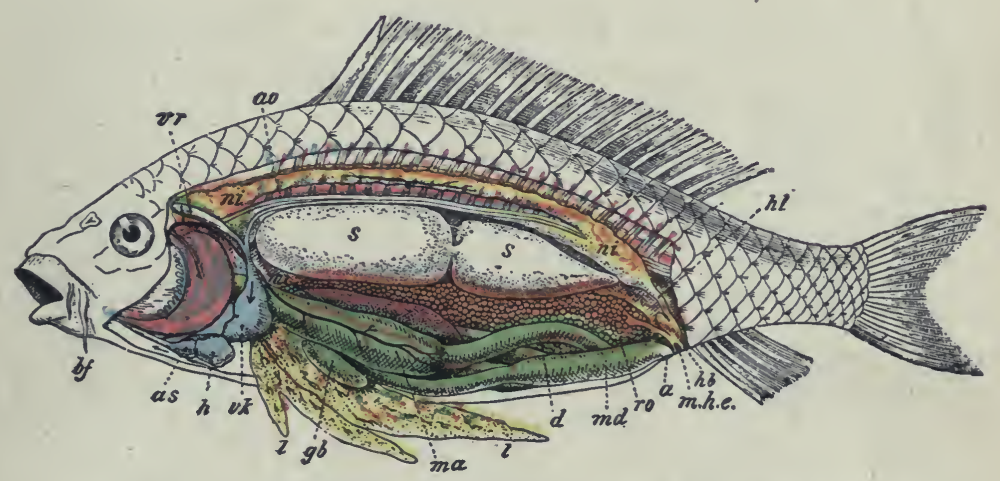

Fig. 4. - Anatomy of Carp. For description see Fig. 220, page II7.

THE DEADLY

HARLEQUIN SNAKE

IS MIMICKED BY THE

HARMLESS SCARLET SNAKE.

Fig. 5. - HARLEQUiN STAKE (Elaps).
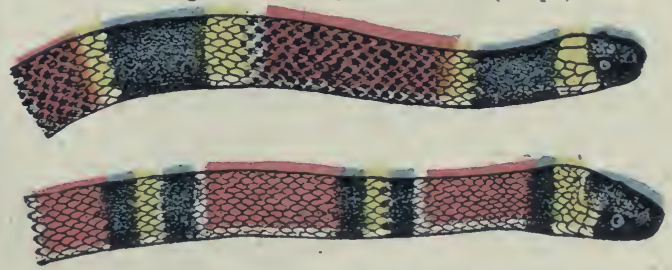

FIG. 6.-SCARLET SNAKE (Lampropeltis). 

scarlet, yellow, and black (coloured Fig.6) of the same tints, and it is hardly distinguishable from the harlequin. The

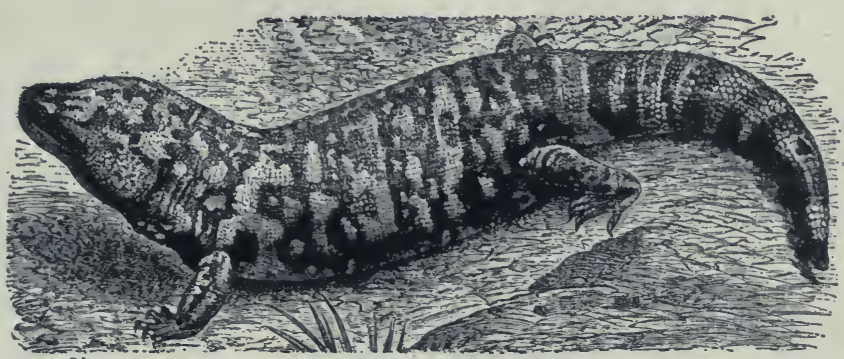

FIG. 279. - Gila Monster (Heloderma suspectum), of Arizona. If poisonous, it is the only instance among lizards. It is heavy-built, orange and black mottled, and about 16 inches long. Compare it with the green lizard (Fig. 280).

scarlet snake is said to mimic the harlequin snake. It also imitates the quiet inoffensive habits of the harlequin snake, which fortunately does not strike except under the greatest provocation. The rattles of the less poisonous but deadly rattlesnake (Fig. 272) may be classed as an example of warning sound which most animals are quick to heed and thus avoid encounters which might be destructive to either the snake or its enemy.

Survival of the Fittest. - The two facts of most far-reaching importance in the history of animals and plants are: (I) Heredity; animals inherit the characteristics of their parents. (2) Variation; animals are not exactly like their parents. The first fact gives stability, the second makes

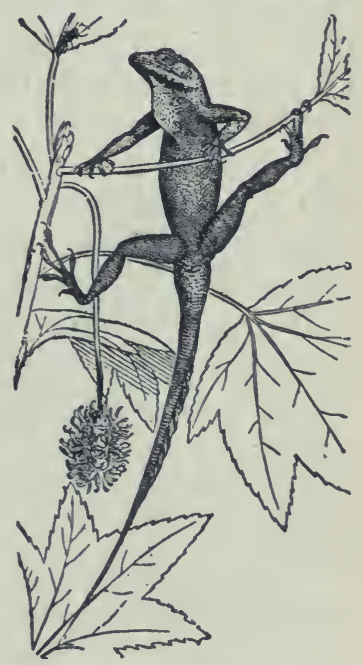

Fig. 280. - Chameleon (Anolis), or green lizard of southern U.S. Far excels European chameleon (Fig. 28I) and all known animals in power of changing colour (green, gray, yellow, bronze, and black). 
evolution possible. The climate of the world is slowly changing, and animals must change to adapt themselves to it. A more sudden change of environment (surroundings) of animals occurs because of migration or isolation; these in turn are caused

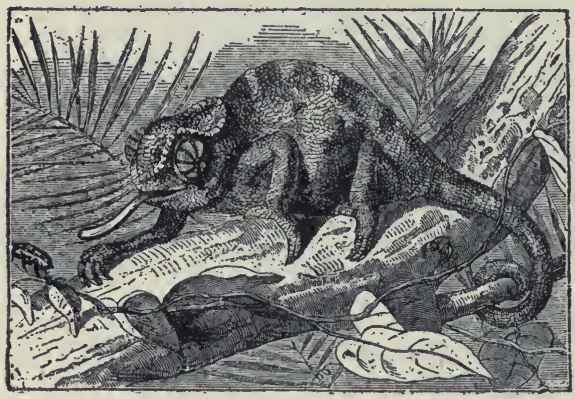

Fig. 28I. - ChAMELEon OF SOUTHERN EUROPE.

by the crowding of other animals or by the formation or disappearance of geographical barriers, such as deserts, water, mountain chains.

The young vary in many ways from their parents. Some have a more protective colour or form, sharper claws, swifter movements, etc. The individuals possessing such beneficial variations live longer and leave more offspring, and because of heredity transmit the desirable qualities to some of their young. Variations which are disadvantageous for getting food, defence, etc., cause shorter life and fewer offspring. Thus the fittest survive, the unfit perish; an automatic natural selection occurs.

Darwin taught that variations are infinitesimal and gradual. Recent experiments and observations seem to show that many variations are by sudden jumps, somewhat resembling so-called "freaks of nature." As to whether these "sports," or individuals with new peculiarities, survive, depends upon their fitness for their environment. "Survival of the fittest" results from this natural selection, but the selection occurs between animals of marked, not infinitesimal, differences; as Darwin taught. Darwin's theory is

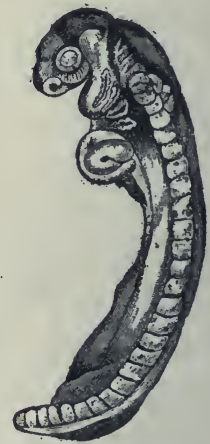

FIG. 282. - EMBRYO OF A TURTLE, showing four gill slits. (Challenger Report.) probably true for species in the usual state of nature; the new theory (of De Vries) is probably true for animals and plants under domestication and during rapid geographical changes. 
Table for Review (for notebooks or blackboards).

\begin{tabular}{|c|c|c|c|c|c|}
\hline & FISH & TADPOLE & FroG & Turtle & LIZARD \\
\hline \multicolumn{6}{|l|}{$\begin{array}{l}\text { Limbs, kind and } \\
\text { number }\end{array}$} \\
\hline $\begin{array}{l}\text { Are claws present? } \\
\text { How many? }\end{array}$ & & & & & - \\
\hline Covering of body & & & & 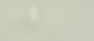 & \\
\hline \multicolumn{6}{|l|}{$\begin{array}{l}\text { Teeth, kind of, if } \\
\text { present }\end{array}$} \\
\hline $\begin{array}{l}\text { Which bones found } \\
\text { in man are lacking? }\end{array}$ & - & & & & \\
\hline \multicolumn{6}{|l|}{ Chambers of heart } \\
\hline \multicolumn{6}{|l|}{ Respiration } \\
\hline Movements & & & & & \\
\hline
\end{tabular}

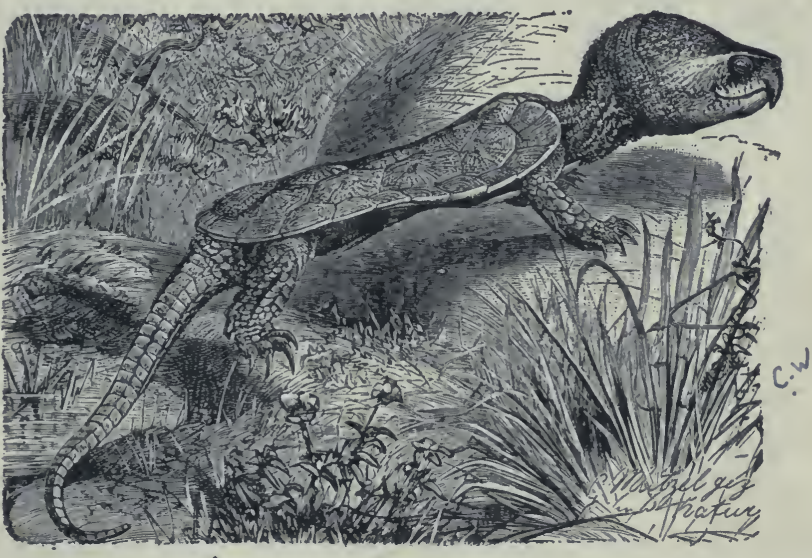

FIG. 283. - BIG-HEADED TURTLE (Platysternum megalocephalum). $\times \frac{2}{3}$. China. This and Fig. 282 suggest descent of turtles from a lizardlike form. Figure 282 shows earlier ancestors to have been gill breathers. 


\section{CHAPTER XIII}

\section{BIRDS}

Suggestions. - The domestic pigeon, the fowl, and the English sparrow are most commonly within the reach of students. The last bird has become a pest and is almost the only bird whose destruction is desirable. The female is somewhat uniformly mottled with gray and brown in fine markings. The male has a black throat with the other markings of black, brown, and white, in stronger contrast than the marking of the female. As the different species of birds are essentially alike in structural features, the directions and questions may be used with any bird at hand. When studying feathers, one or more should be provided for each pupil in the class. The feet and the bills of birds should be kept for study.

Does the body of the bird like the toad and the turtle, have a head, a trunk, a tail, and two The pairs of limbs? Do the fore and 5. less than the limbs of other backboned animals? Does any other vertebrate use them for purposes as widely different?

Eye.- Does the eyeball have parts corresponding to the eyeball of a fish or a frog; viz., cornea, iris, pupil? Which is more movable, the upper or the lower eyelid? Are there any lashes? The bird (like what other animal?) has a third eyelid, or nictitating membrane. Compare its thickness with that of the other lids. Is it drawn over the eyeball from the inner or the outer corner of the eye? Can you see in the human eye any wrinkle or growth which might be regarded as remains, or vestige, of such a membrane? 
How many nostrils? In which mandible are they located? Are they nearer the tip or the base of the mandible? (Fig. 284.) What is their shape? Do the nasal passages go directly down through the mandible or do they go backward? Is the inner nasal opening into the mouth or into the throat?

The beak or bill consists of the upper and lower mandibles. The outside of the beak seems to be of what kind of material? Examine the decapitated head of a fowl or of a dissected bird, and find if there is a covering on the bill which can be cut or scraped off. Is the mass of the bill of bony or horny material? With what part of the human head are the mandibles homologous? (Fig. 284.)

Ears. - Do birds have

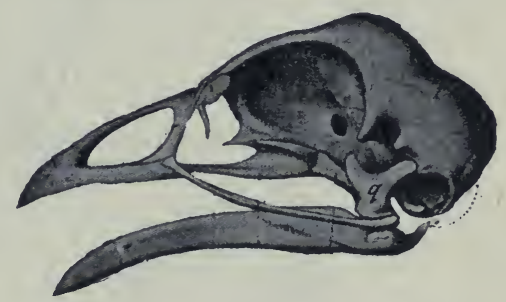

Fig. 284. - SkUll of Domestic Fowl. q, quadrate ("four-sided") bone by which lower jaw is attached to skull (wanting in beasts, present in reptiles; see Fig. 277).

external ears? Is there an external opening leading to the ear? In searching for it, blow or push forward the feathers. If found, notice its location, size, shape, and what surrounds the opening. There is an owl spoken of as the long-eared owl. Are its ears long?

The leg has three divisions: the uppermost is the thigh (called the "second joint" in a fowl); the middle division is the shank (or "drumstick"); and the lowest, which is the slender bone covered with scales, is formed by the union of the ankle and the instep. (The bones of the three divisions are named femur, tibiotarsus, and tarsometatarsus.) The foot consists entirely of toes, the bones of which are called phalanges. Is there a bone in each claw? (See Fig. 285.) Supply the numerals in this sentence: 
The pigeon has — toes, the hind toe having — joints; of the three front toes, the inner has — joints (count the claw as one joint), the

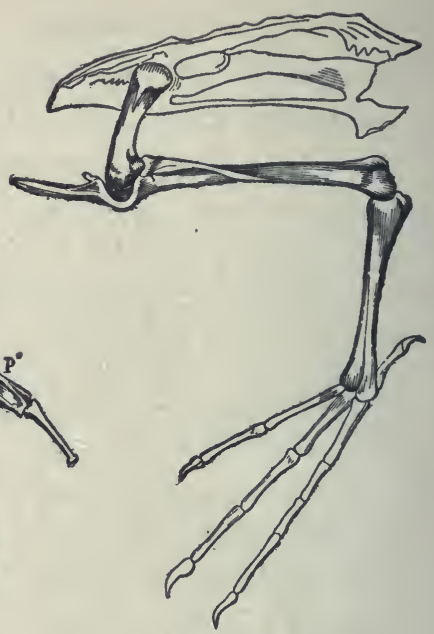

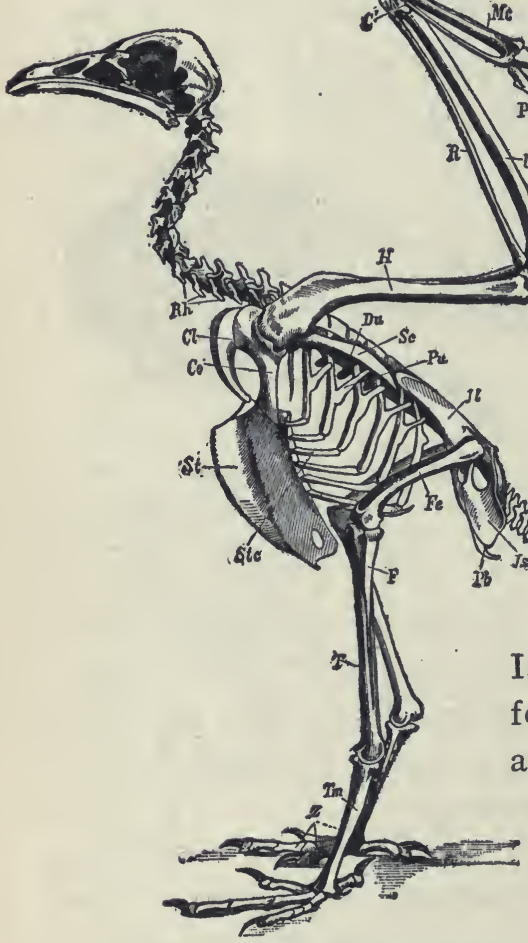

FIG. 286. - SKELETON OF BIRD.

$R h$, vertebræ; $C l$, clavicle; $C o$, coracoid; $S c$, scapula; St, sternum; $H$, humerus; $R$, radius; $U$, ulna; $P$, thumb; $F e$, femur; $T$, tibia. See Fig. 394. Questions: Which is the stiffest portion of the vertebral column? How are the ribs braced against each other? Which is longer, thigh bone or shin ? Compare shoulder blade with man's (Fig. 399). Which is the extra shoulder bone? Compare tail vertebræ with those of extinct bird, Fig. $29 a$
FIG. 285. - LEG BONES OF BIRD.

middle has joints, and the outer toe has joints (Fig. 285). Is the thigh of a bird bare or feathered? The shin? The ankle? Where is the ankle joint of a bird? Do you see the remains of another bone (the splint bone, or fibula) on the shin bone of the shank? (Fig. 285 or 286.) Why would several joints in the ankle be a disadvan. tage to a bird? 
The thigh hardly projects beyond the skin of the trunk, as may be noticed in a plucked fowl. The thigh extends forward from the hip joint (Figs. 286, 299) in order to bring the point of support forward under the centre of weight. Why are long front toes more necessary than long hind toes? As the bird must often bring its head to the ground, the hip joints are near the dorsal surface and the body swings between the two points of support somewhat like a silver ice pitcher on its two pivots. Hence stooping, which makes a man so unsteady, does not cause a bird to lose steadiness.

The wing has three divisions which correspond to the upper arm, the forearm, and the hand of man (Fig. 286). When the wing is folded, the three divisions lie close alongside one another. Fold your arm in the same manner. The similarity of the bones of the first and second divisions to the bones of our upper arm and forearm is very obvious (Fig. 286). Explain. The hand of a bird is furnished with only three digits (Fig. 287). The three palm bones (metacarpals) are firmly united (Fig. 287). This gives firmness to the stroke in flying.

That the bird is descended from animals which had the

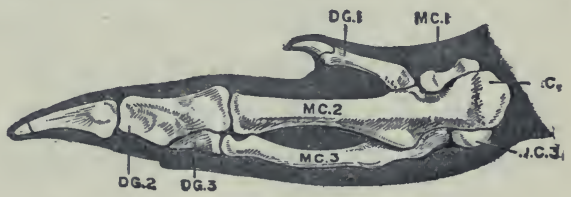

FIf. 287. - HAND AND WRIST OF FOWL (after Parker).

DG. $x-3$, digits; $M C$. $1-3$, metacarpals; CC. 3 , wrist.

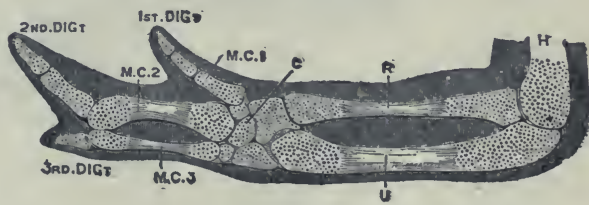

FIG. 288. - HAND, WRIST (c), FOREARM, AND Elbow of Young Chick (after Parker). fingers and palm bones less firmly united is shown by comparing the hands of a chick and of an adult fowl (Figs. 287, 288). The wrist also solidifies with age, the 
five carpals of the chick being reduced to two in the fowl (Figs. 287, 288). The thumb or first digit has a covering of skin separate from that of the other

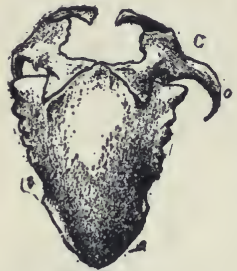

FIG. 289. - BREASTBONE AND SHOULDER BONES OF CASSOWARY. digits, as may be seen in a plucked bird. The degenerate hand of the fowl is of course useless as a hand (what serves in its place?) but it is well fitted for firm support of the feathers in flying. The two bones of the forearm are also firmly joined. There are eighteen movable joints in our arm and hand. The bird has only the three joints which enable it to fold its wing. The wrist joint is the joint in the forward angle of the wing.

Since the fore limbs are taken up with locomotion, the grasping function has been assumed by the jarws. How does their shape adapt them to this use? For the same reason the neck of a bird surpasses the necks of all other animals in what respect? Is the trunk of a bird flexible or inflexible? There is thus a cor. relation between structure of neck and trunk. Explain. The same correlation is found in which of the reptiles? (Why does rigidity of trunk require flexibility of neck?) Why does

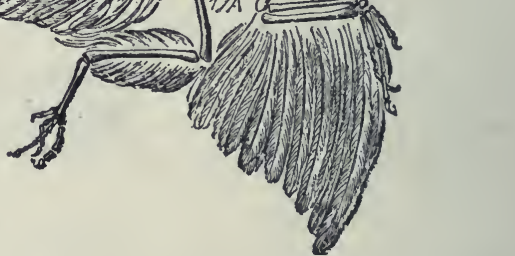

FIG. 290.-A FossIL BIRD (archaopteryx) found in the rocks of a former geological epoch.

Question: Find two resemblances to reptiles in this ex tinct bird absent from skeletons of extant birds. 
the length of neck in birds correlate with the length of legs? Examples? (See Figs. 314, 315, 332.) Exceptions? (Fig. 324.) Why does a swan or a goose have a long neck, though its legs are short?

To make a firm support for the wings the vertebræ of the back are immovably joined, also there are three bones in each shoulder, the collar bone, the shoulder blade, and the coracoid bone (Fig. 286). The collar bones are united (why?) and form the "wishbone" or "pulling bone." To furnish surface for the attachment of the large flying muscles there is a prominent ridge or keel on the breastbone (Fig. 286). It is lacking in most birds which do not fly (Fig. 289).

The feathers are perhaps the most characteristic feature of birds. The large feathers of the wings and tail are called quill feathers. A quill feather (Fig. 29I) is seen to consist of two parts, the shaft, or supporting axis, and the broad vane or web.

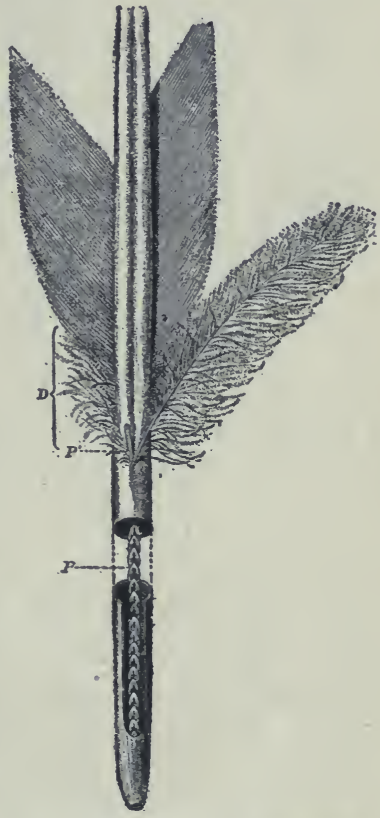

Fig. 29I.-QUiLl FEATHER $D$, downy portion. What part of the shaft is round? Hollow? Solid? Is the shaft straight? Are the sides of the vane usually equal in width? Can you tell by looking at a quill whether it belongs to the wing or the tail, and which wing or which side of the tail it comes from? Do the quills overlap with the wide side of the vane above or beneath the next feather? Can you cause two parts of the vane to unite again 
by pressing together the two sides of a split in the vane? Does the web separate at the same place when pulled until

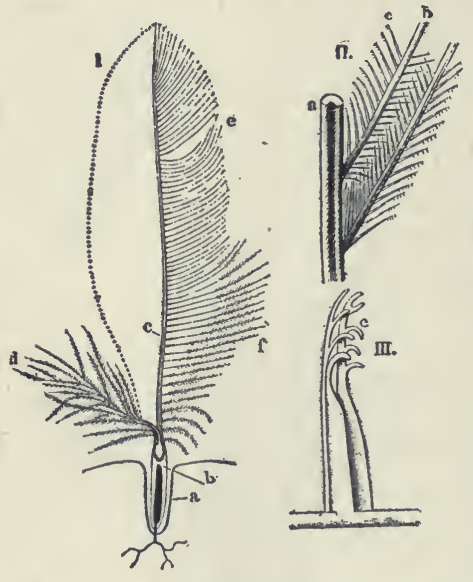

Fig. 292. - I, Contour Feather. II, III, Parts of Quill Feather, enlarged.

it splits again?

The hollow part of the shaft of a quill feather is called the quill. The part of the shaft bearing the vane is called the rachis (rā-kis). The vane consists of slender barbs which are branches of the shaft (II, Fig. 292). As the name indicates (see dictionary), a barb resembles a hair. The barbs in turn bear secondary branches called barbules, and these again have shorter branches called bar-

bicels (III, Fig. 292). These are sometimes bent in the form of hooklets (Fig. 292, III), and the hooklets of neighbouring barbules interlock, giving firmness to the vane. When two barbules are split apart, and then reunited by stroking the vane between the thumb and the finger, the union may be so strong that a pull upon the vane will cause it to split in a new place next time.

There are four kinds of feathers, (I) the quill feathers, just studied; (2) the contour feathers (I, Fig. 292),

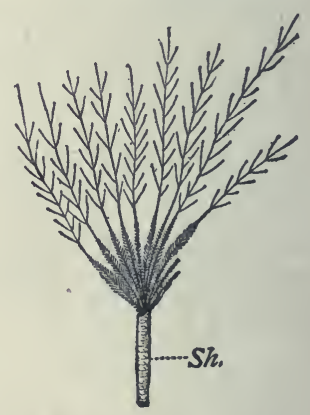

FIG. 293.-A Down FEATHER, enlarged. which form the general surface of the body and give it its outlines; (3) the downy feathers (Fig. 293), abundant on 
nestlings and found among the contour feathers of the adult but not showing on the surface ; (4) the pin feathers, which are hair-like, and which are removed from a plucked bird by singeing. The contour feathers are similar in structure to the quill feathers. They protect the body from blows, overlap so as to shed the rain, and, with the aid of the downy feathers, retain the heat, thus accounting for the high temperature of the bird. The downy feathers are soft and fluffy, as they possess few or no barbicels; sometimes they lack the rachis (Fig. 293). The pin feathers are delicate horny shafts, greatly resembling hairs, but they may have a tuft of barbs at the ends.

A feather grows from a small projection (or papilla) found at the bottom of a depression of the skin. The quill is formed by being moulded around the papilla. Do you see any opening at the tip of the quill for blood vessels to enter and nourish the feather? What is in the quill? (Fig. 29I.) The rachis? A young contour or quill feather is inclosed in a delicate sheath which is cast off when the feather has been formed. Have you seen the sheath incasing a young feather in a moulting bird?

There are considerable areas or tracts on a bird's skin without contour feathers. Such bare tracts are
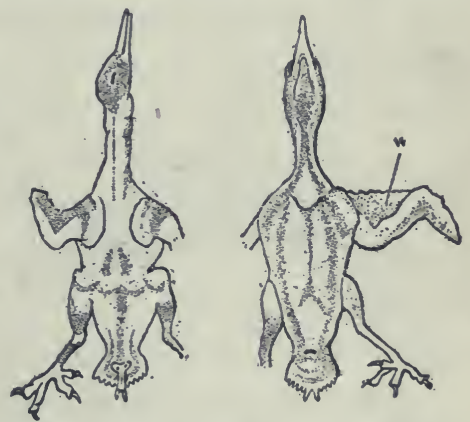

FIG. 294.-DORSAL AND VENTRAL VIEW OF PLUCKEd BIRD, showing regions where feathers grow. found along the ridge of the breast and on the sides of the neck. However, the contour feathers lie so as to overlap and cover the whole body perfectly (Fig. 294).

The shedding of the feathers is called moulting. Feathers, 
like the leaves of trees, are delicate structures and lose perfect condition with age. Hence the annual renewal

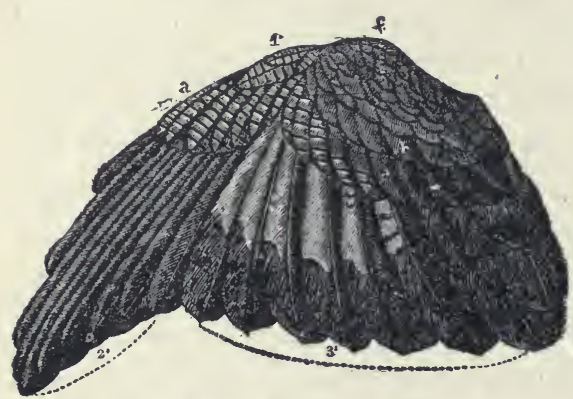

FIG. 295. - WING OF BIRD.

$\boldsymbol{x}$, false quills (on thumb); 2 , primaries; 3 , secondaries; tertiaries (dark) are one above another at right; $a, b$, coverts. of the feathers is an advantage. Most birds shed twice a year, and with many the summer plumage is brighter coloured than the winter plumage. When a feather is shed on one side, the corresponding feather on the other side is always shed with it. (What need for this?) A large oil gland is easily found on the dorsal side of the tail. How does the bird apply the oil to the feathers?

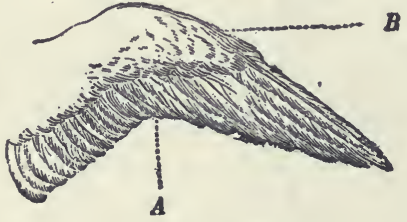

FIG. 296.

$A$, point dividing primaries from secondaries; $\dot{B}$, coverts.

In describing and classifying birds, it is necessary to know the names of the various external regions of the body and plumage. These may be learned by studying Figs. 295, 296, 297, 298.

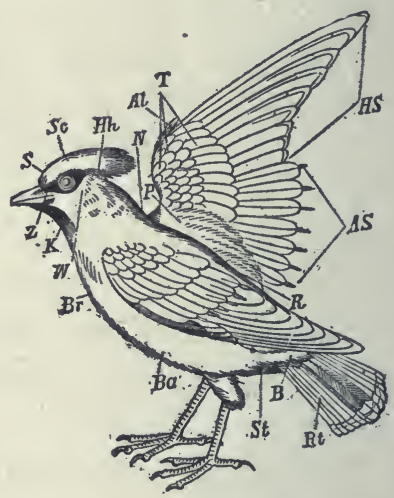

FIG. 297. - CEDAR WAXWING, with regions of body marked.

$S$, forehead; $S c$, crown (with crest); $H h$, nape; $K$, throat; $B r$, breast: $B a$, lower parts; $R$, back; $R t$, tail; $B$, tail coverts; $P$, shoulder feathers (scapulars) ; $T$, wing coverts; $H S$, primaries; $A S$, secondaries; $A l$, thumb feathers.

The quills on the hand 
are called primaries, those on the forearm are the secondaries, those on the upper arm are the tertiaries. Those on the tail are called the tail quills. The feathers at the base of the quills are called the coverts. The thums bears one or more quills called the spurious quills. Is the wing concave on the lower or the upper side? Of what advantage is this when the bird is at rest? When it is flying?

Control of Flight. - Did you ever see a bird sitting on a swinging limb? What was its chief means of balancing itself ? When flying, what does a bird do to direct its course upward? Downward? Is the body level when it turns to either side? Birds with long,

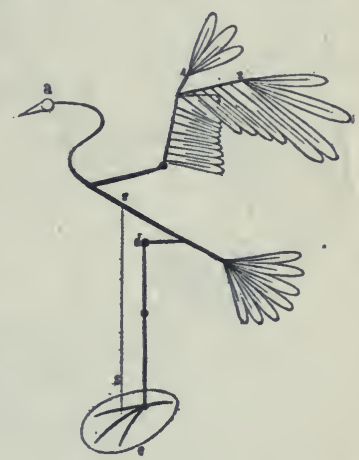

FIG. 298. - PLAN OF BIRD. $s$, centre of gravity. pointed wings excel in what respect? Examples? Birds with great wing surface excel in what kind of flight? Examples. Name a common bird with short wings which has a laboured, whirring flight. Is its tail large or small?

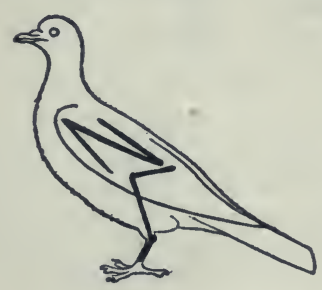

Fig. 299. - POSITION OF

Limbs of Pigeon.

Does it avoid obstacles and direct its flight well? Why or why not? When a boat is to be turned to the right, must the rudder be pulled to the right or to the left? (The rudder drags in the water and thus pulls the boat around.) When the bird wishes to go upward, must its tail be turned up or down? How when it wishes to go down? When a buzzard soars for an hour without flapping its wings, does it move at a uniform rate? For what does it use the momentum gained when going with the wind? 
Flying. - When studying the quill feathers of the wing, you saw that the wider side of the vane is beneath the feather next behind it. During the downward stroke of the wing this side of the vane is pressed by the air against

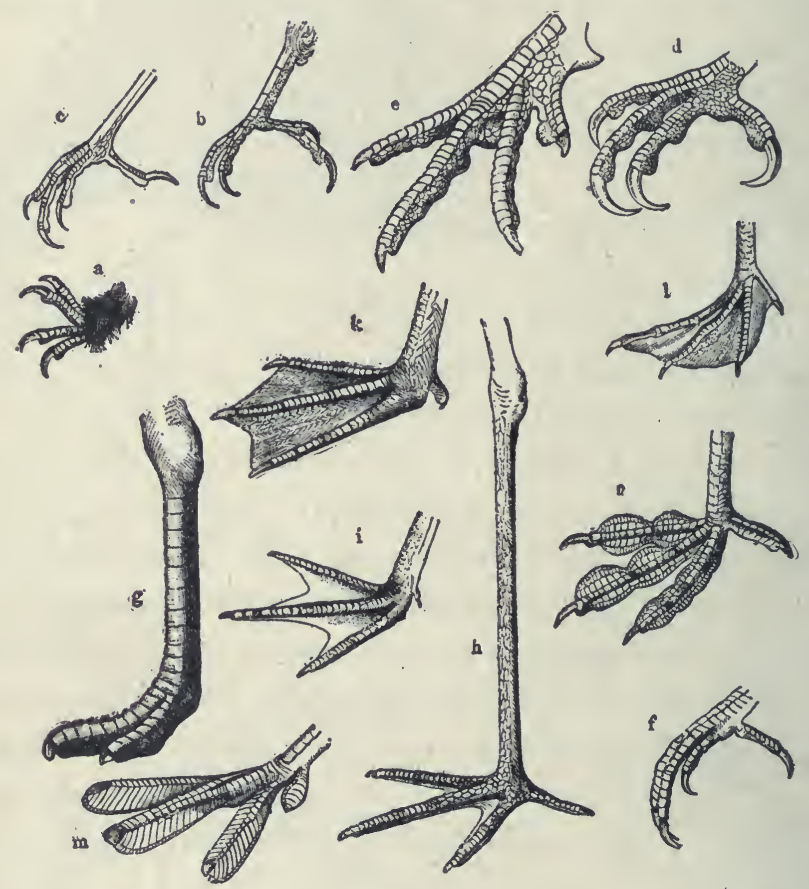

FIG. 300 .

$a$, clambering foot of chimney sweep; $b$, climbing foot of woodpecker; $c$, perching foot of thrush; $d$, seizing foot of hawk; $e$, scratching foot of pheasant; $f$, stalking foot of kingfisher; $g$, running foot of ostrich; $h$, wading foot of heron; $i$, paddling foot of gull; $k$, swimming foot of duck; $l$, steering foot of cormorant; $m$, diving foot of grebe; $n$, skim. ming foot of coot. Question: Does any bird use its foot as a hand? (Fig. 320.)

the feather above it and the air cannot pass through the wing. As the wing is raised the vanes separate and the air passes through. The convex upper surface of the wing also prevents the wing from catching air as it is raised. Spread a wing and blow strongly against 
its lower surface; its upper surface. What effects are noticed?

Study the scales on the leg of a bird (Fig. 300). Why is the leg scaly rather than feathered from the ankle downward? Which scales are largest? (Fig. 300.) How do the scales on the front and the back differ? What can you say of the scales at the bottom of the foot; at the joints of the toes? Explain. How does the covering of the nails and the bill compare in colour, texture, hardness,and firmness of attachment with the scales of the leg?

Draw an outline of the bird seen from the side. Make drawings of the head and the feet more detailed and on a larger scale.

Why does a goose have more feathers suitable for making pillows than has a fowl? In what country did the domestic fowl originate? (Encyclopædia.) Why does a cock crow for dawn? (Consider animal life in jungle.)

Activities of a Bird. - Observe a bird eating. Does it seem to chew or break its food before swallowing? Does it have to lift its head in order to swallow food? To swallow drink? Why is there a difference? After feeding the bird, can you feel the food in the crop, or enlargement of the gullet at the base of the neck? (Fig. 304.)

Feel and look for any move-

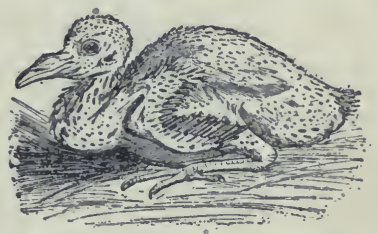

Fig. 3OT. - AN Altrical Bird, i.e. poorly developed at hatching. Young pigeon, naked. beak too weak for eating.

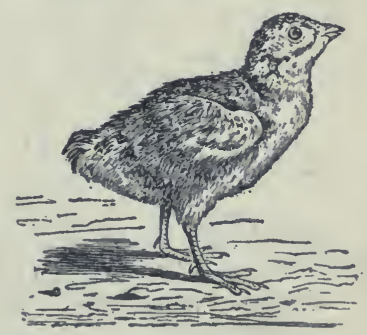

Fig. 302.-A Precocial BIRD (well developed at hatching). Feathered, able to run and to pick up food. Precocity is a sign of instinctive life and low intelligence. A baby is not precocious.

Question: Is pigeon or fowl exposed to more dangers in infancy ? 
ments in breathing. Can you find how often it breathes per minute? Place hand under the bird's wing. What do you think of its temperature; or better, what temperature is shown by a thermometer held under its wing? Do you see any connection between the breathing rate and the temperature? Test (as with the crayfish) whether a bird can see behind its head? Notice the movements of the nictitating membrane. Does it appear to be transparent?

Watch a bird $f y$ around a closed room and review the questions on Control of Flight.

Bend a bird's leg and see if it has any effect upon its toes. Notice a bird (especially a large fowl) walk, to see if it bends its toes as the foot is lifted. Pull the rear tendon in a foot cut from a fowl for the kitchen. Does the bird have to use muscular exertion to grasp a stick upon which it sits? Why, or why not? When is this bending of the toes by bending the legs of special advantage to a hawk? To a duck ? To a wading bird? Why is a fowl safe from a hawk if it stands close to a tree ?

Do you see any signs of teeth in the bird's jaws? Why are duck's " teeth" (so called by children) not teeth?

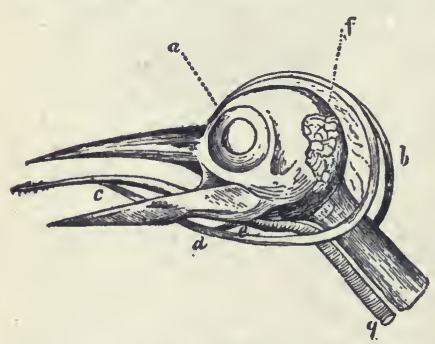

FIG. 303. - HEAD OF WOODPECKER. $c$, tongue; $a, b, d$, hyoid bone; $e, q$, windpipe; $f$, salivary gland. - Can the tongue of a bird be pulled forward ? ' (Fig. 303.) What is its shape? If there is opportunity, dissect and study the slender, bony (hyoid) apparatus to which the base of the tongue is attached (Fig. 303), the opening of the windpipe, or trachea, the slit-like opening of windpipe, which is so narrow as to prevent food falling into the windpipe. 
The Internal Organs, or Viscera (Figs. 304 and 305). - The viscera (vis'se-ra), as in most vertebrates, include the food tube and itsglands; the lungs, the heart, and the larger blood vessels; the kidneys and bladder and the reproductive organs. The lower part, or gullet, is enlarged into a crop. It is largest in grain-eating birds. It

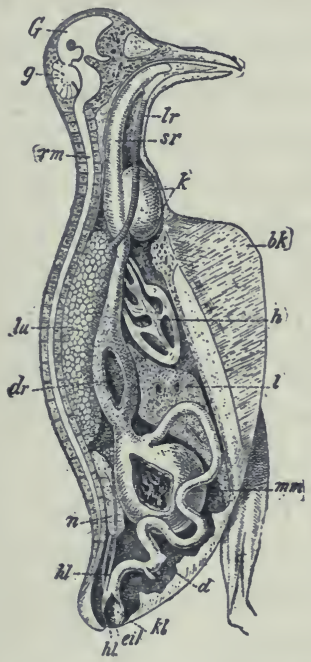

Fig. 304. - ANATOMY OF DOVE $\times 1 / 2$. $b k$, keel of breastbone; $G, g$, brain; $l r$, windpipe; $l u$, lung; $h$, heart; $s r$, gullet; $k$, crop; $d r$, glandular. stomach; $m m$, gizzard; $d$, intestine; $n$, kidney: $h l$, ureter; eil, openings of ureter and egg duct into cloaca, $\mathrm{kl}$.

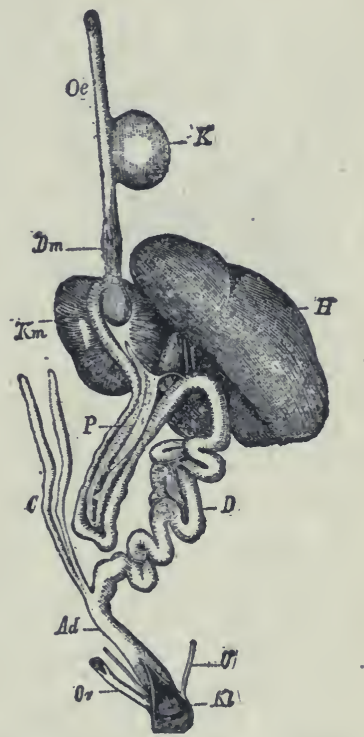

Fig. 305. - Food TUBE OF BIRD.

$P$, pancreas: $C$, cæca.

Question: Identify each part by means of Fig. 304.

is found in the V-shaped depression at the angle of the wishbone, just before the food tube enters the thorax. The food is stored and softened in the crop. From the crop the food passes at intervals into the glandular stomach. Close to this is the muscular stomach, or gizzard. Are the places of entrance and exit on opposite sides of the gizzard, or near together? (Fig. 304.) Is the lining of the gizzard 
rough or smooth? Why? Is the gizzard tough or weak ? Why are small stones in the gizzard? Why do not hawks and other birds of prey need a muscular gizzard? The liver and pancreas empty their secretions into the intestines by several ducts a little way beyond the gizzard. Beyond the mouths of two cæca (Fig. 305) the many-coiled

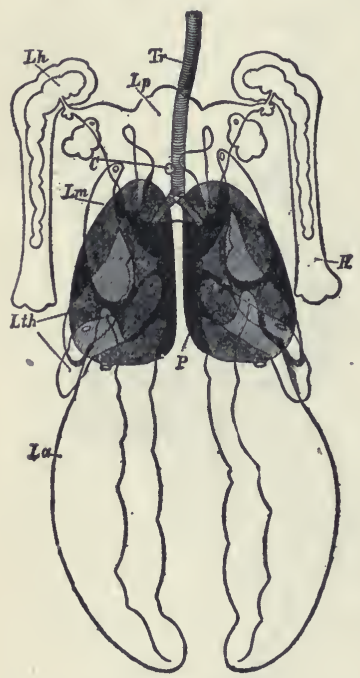

Fig. 306.-Position of LUNGS AND AIR. SACS (Pigeon).

$T r$, windpipe; $P$, lungs; $L m$, sac under clavicle with prolongation $(L h)$ into humerus; $L a$, sacs in abdomen. intestine empties into the straight rectum, which terminates in a widened part called the cloaca. Not only the intestine, but the two ureters of the urinary system and the two genital ducts of the reproductive system all empty into the cloaca (Figs. 304, 305).

The lungs have their rear sur. faces attached to the spinal column and ribs ( $h$, Fig. 304). They are connected with thinwalled, transparent air sacs which aid in purifying the blood. When inflated with warm air, they probably make the body of the bird more buoyant. For the names, location, and. shape of several pairs of air sacs, see Fig. 306. The connection of the air sacs with hollows in the humerus bones is also shown in the figure. Many of the bones are hollow; this adds to the buoyancy of the bird. The pulmonary artery, as in man, takes dark blood to the lungs to exchange its carbon dioxide for oxygen. Of two animals of the same weight, which expends more energy, the one that flies, or the one that runs the same distance? Does a bird require more oxygen 
or less, in proportion to its weight, than an animal that lives on the ground? Are the vocal chords of a bird higher or lower in the windpipe than those of a man? (Fig. 307.)

The heart of a bird, like a man's heart, has four cham bers; hence it keeps the purified blood separate from the impure blood. Since pure blood reaches the organs of a bird, oxidation is more perfect than in the body of any animals yet studied. Birds have higher

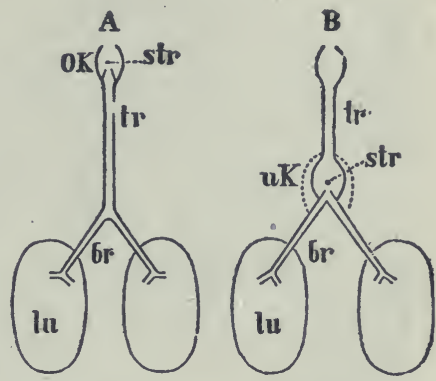

Fig. 307. - Position of Vocal CoRds (str) OF MAMMAL AND BIRD.

Question: Does a fowl ever croak after. its head and part of its neck are cut off? Explain.

temperature than any other class of animals whatsoever. Tell how the jaws, the tail, and the wings of the fossil bird Archæopteryx differed from living birds (Fig. 290).

Suggestions. - In the field work, besides seeking the answers to definite questions, pupils may be required to hand in a record of the places and the times of seeing a certain number of birds (20-40) with the actions and features which made each distinguishable. Also, and more important, each pupil should hand in a record of a careful and thorough outdoor study of one common species (see below) as regards habits, nesting, relation to environment, etc.

Field Study of a Common Species. - (For written report.) Name of species. Haunts. Method of locomotion when not flying. Flying (rate, sailing, accompanying sound if any, soaring).

What is the food? How obtained? Association with birds of its own species. Relation to birds of other species.

Where does it build its nest? Why is such a situation selected? Of what is the nest built? How is the material carried, and how built into the nest? Does the bird's body fill the nest?

Describe the eggs. Does the male bird ever sit or otherwise assist female before hatching? Does it assist after hatching? 


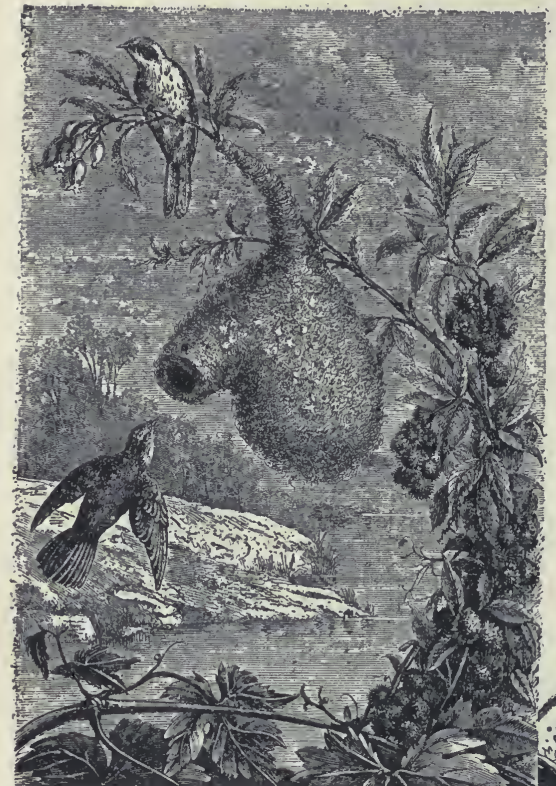

How long is taken to lay a sitting of eggs? How long before the birds are hatched? When hatched are they helpless? Blind? Feathered? (Figs. 30I, 302.) Do the nestlings require much food? How many times in an hour is food brought? How distributed? Even if the old birds sometimes eat fruit do they take fruit to the young? What do they feed to the young? How long be-

Fig. 308. - EUROPEAN TOMTIT'S NEST. What are the advantages of its shape?

fore they leave the nest? Do the parents try to teach them to fly? Do the parents care for them after the nest is left? What songs or calls has the bird?

General Field Study. -(For written report.) Name the best and poorest flyers you know; birds that fly most of the time; birds that seldom fly. Observe birds that pair; live in flocks. Does their sociability vary

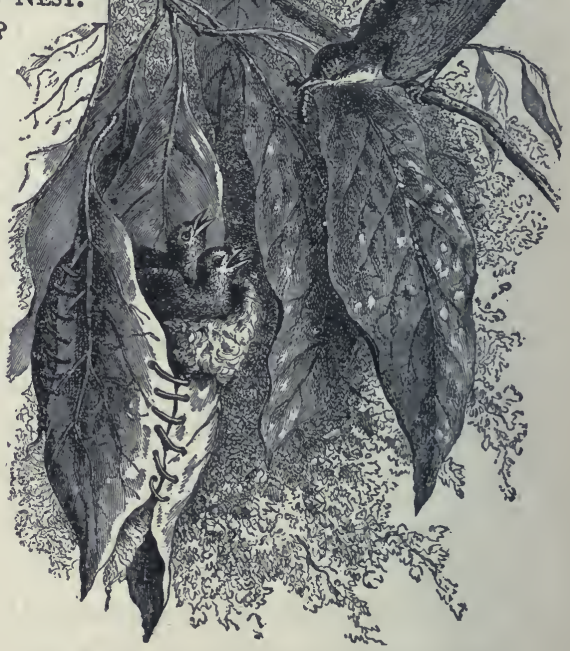

FIG. 309. - TAILOR BIRD'S NEST (India). Instinct for nest building highly perfected. with the season? Do you ever see birds quarrelling? 
Fighting? What birds do you observe whipping or driving birds larger than themselves? Which parent do young birds most resemble? Name the purposes for which birds sing. Which senses are very acute? Why? Dull? Why? Can you test your statements by experiment? A partridge usually sits with 18 to 24 eggs in nest. About how long after laying first egg before sitting begins? Do several partridge hens lay in the same nest?

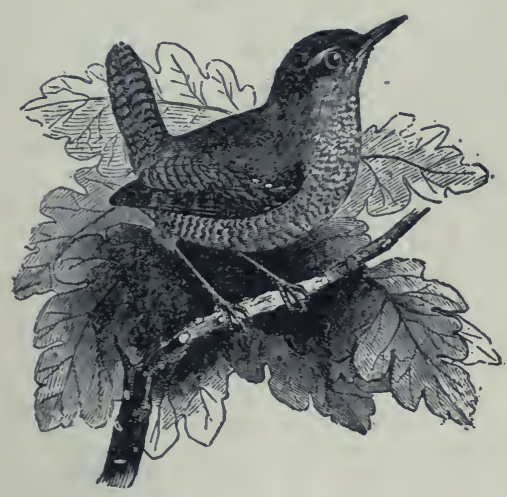

FIG. 3IO.-HOUSE WREN.

Haunts.-Name some birds that are found most; often in the following lo; calities: about our homes, in gardens and orchards, fields and meadows, in bushes, in the woods, in secluded woods, around streams of water, in thickets, in pine woods. Size.-Name birds as large as a robin or larger, nearly as large, half as large, much smaller.

Colours.-Which sex is more brilliant? Of what advantage are bright colou's to one sex? Of what advantage are dull colours to the other sex? Which have yellow breasts, red patch on heads, red or chestnut breasts, blue backs, black all over?

Habits. - Name the birds that walk, jump, swim, live in flccks, sing while flying, fly in undulations, in circles, have laboured flight.

Economic Importance of Birds. - Farmers find their most valuable allies in the class aves, as birds are the deadliest enemies of insects and gnawing animals. To the innumerable robbers which devastate our fields and gardens, nature opposes the army of birds. They are less numerous 


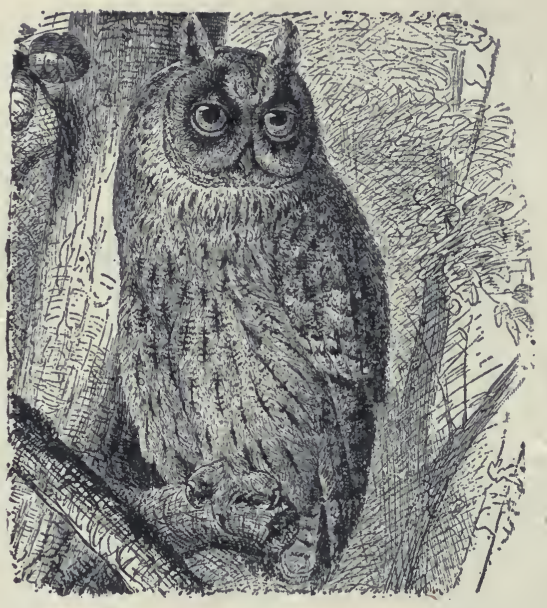

FIG. 3Ir. - SCREECH OWL (Megascops asio).

Question: Compare posture of body, position of eyes, and size of eyes, with other birds. than insects and other robbers, it is true, but they are skilful and zealous in pursuit, keen of eye, quick, active, and remarkably voracious. The purely insectivorous birds are the most useful, but the omnivorous and graminivorous birds do not disdain insects. The perchers and the roodpeckers should be protected most carefully. The night birds of prey (and those of the day to a less degree) are very destructive to field mice, rabbits, and other gnawing animals. Some ignorant farmers complain continually. about the harm done by birds. To destroy them is as unwise as it would be to destroy the skin which protects the human body because it has a spot upon it! It cannot be repeated too plainly that to hunt useful birds is a wrong and mischievous act, and it is stupid and barbarous to destroy their nests.

Injurious birds are few.

Of course birds which are the enemies of other birds are enemies

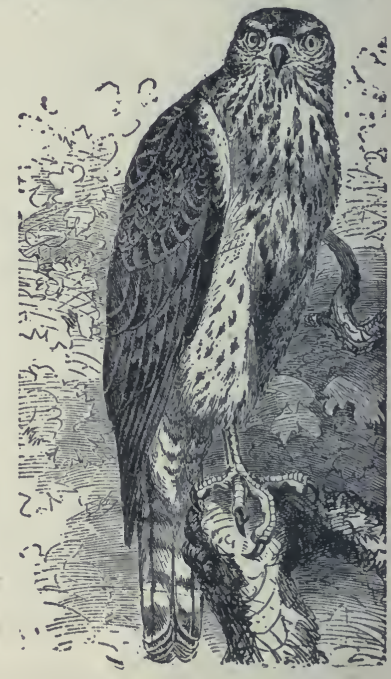

F1G. 312. - GosHAWK, or chicken hawk. 


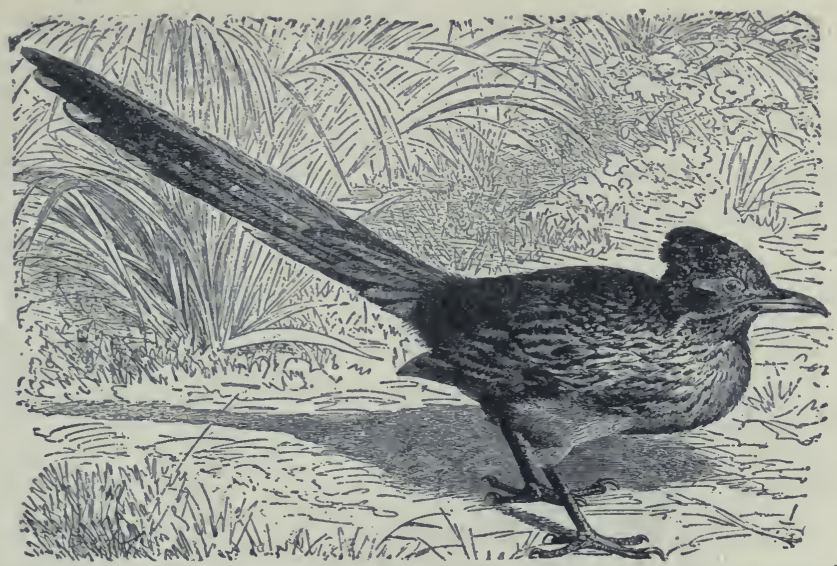

FIG. 3I3. - ROAD RUNNER, or chaparral bird (Tex. to Cal.). What order? (Key, p. I77.)

of mankind, but examples are scarce (some owls and hawks). Many birds of prey are classed thus by mistake. Sparrow-hawks, for instance, do not eat birds except in rare instances; they feed chiefly upon insects. A sparrow hawk often keeps watch over a field where grasshoppers are plentiful and destroys great numbers of them. When a bird is killed because it is supposed to be injurious, the crop should always be examined, and its contents will often surprise those who are sure it is a harmful bird. The writer once found two frogs, three grasshoppers, and five beetles that had been swallowed by a "chicken hawk" killed by an irate farmer, but no sign of birds having been used for food. Fowls should not be raised in open places, but among trees and bushes, where hawks cannot swoop. Birds which live exclusively upon fish are, of course, opposed to human interests. Pigeons are destructive to grain; eagles feed chiefly upon other birds.

If the birds eat the grapes, do not kill the birds, but plant more grapes. People with two or three fruit trees or a small 
garden are the only ones that lose a noticeable amount of food. We cut down the forests from which the birds obtain part of their food. We destroy insect pests at great cost of spraying, etc. The commission the birds charge for such work is very small indeed. (See pages $177-183$.

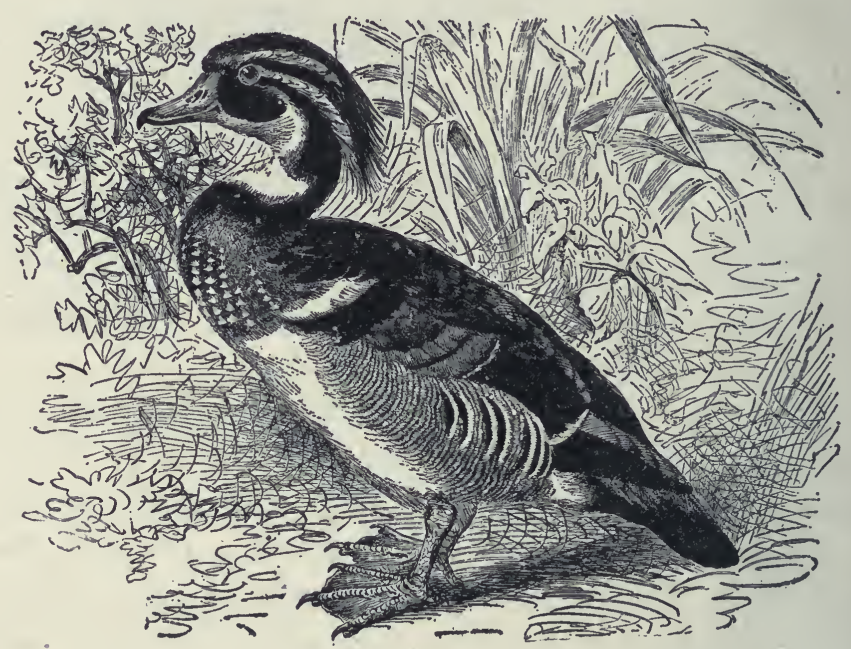

FIG. 314. - WoOD DUCK, male (Aix sponsa). Nests in hollow trees throughout North America. Also called summer duck in South. Why?

The English sparrow is one bird of which no good word may be said. Among birds, it holds the place held by rats among beasts. It is crafty, quarrelsome, thieving, and a nuisance. It was imported in 1852 to eat moths. The results show how ignorant we are of animal life, and how slow we should be to tamper with the arrangements of nature. In Southern cities it produces five or six broods each year with four to six young in each brood. (Notice what it feeds its young.). It fights, competes with and drives away our native useful birds. It also eats grain and preys upon gardens. They have multiplied more in Aus- 
tralia and in North America than in Europe, because they left behind them their native enemies and their new enemies (crows, jays, shrikes, etc.) have not yet developed, to a sufficient extent, the habit of preying upon them. Nature wili, perhaps, after a long time, restore the equilibrium destroyed by presumptuous man.

Protection of Birds. - I. Leave as many trees and bushes standing as possible. Plant trees, encourage bushes.

2. Do not keep a cat. A mouse trap is more useful than a cat. A tax should be imposed upon owners of cats.

3. Make a bird house and place it on a pole; remove bark from pole that cats may not climb it; or put a broad band of tin around the pole.

4. Scatter food in winter. In dry regions and in hot weather keep a shallow tin vessel containing water on the roof of an outhouse, or in an out-of-the-way place, for shy birds.

5. Do not wear feathers obtained by the killing of birds. What feathers are not so obtained?

6. Report all violators of laws for protection of birds.

7. Destroy English sparrows.

Migration. - Many birds, in fact most birds, migrate to warmer climates to spend the winter. Naturalists were

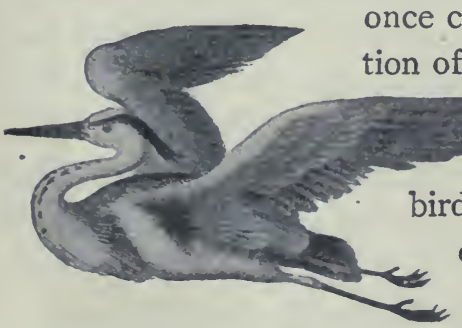

once content to speak of the migration of birds as a wonderful instinct,

Fig. 315.-Great Blue Heron. pose of escaping the cold; it In flight, balancing with legs.

and made no attempt to explain it. As birds have the warmest covering of all animals, the winter migration is not for the pur. is probably. to escape starva. tion, because in cold countries food is largely hidden by snow in winter. On the other hand, if the birds remained 
in the warm countries in summer, the food found in northern countries in summer would be unused, while they would have to compete with the numerous tropical birds for food, and they and their eggs would be in danger from snakes, wild cats, and other beasts of prey so numerous in warm climates. These are the best reasons so far given for migration.

The manner and methods of migration have been studied more carefully in Europe than in America. Migration is

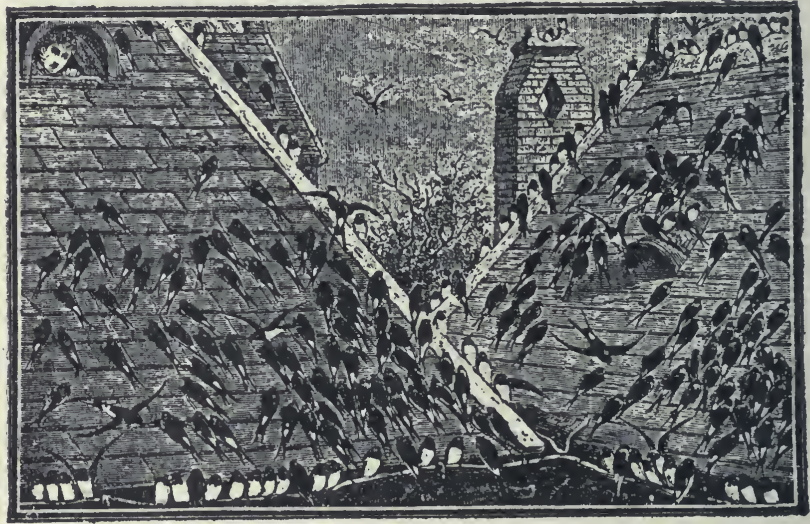

FIG. 3I6. - EUROPEAN SwALlows (Hirundo urbica), assembling for autumn flight to South.

not a blind, infallible instinct, but the route is learned and taught by the old birds to the young ones; they go in flocks to keep from losing the way (Fig. 316); the oldest and strongest birds guide the flocks (Fig. 317). The birds which lose their way are young ones of the last brood, or mothers that turn aside to look for their strayed young. The adult males seldom lose their way unless scattered by a storm. Birds are sometimes caught in storms or join flocks of another. species and arrive in countries unsuited for them, and perish. For example, a sea or 
marsh bird would die of hunger on arriving in a very dry country.

The landmarks of the route are mountains, rivers, valleys, and coast lines. This knowledge is handed down from one generation to another. It includes the location of certain places on the route where food is plentiful and the birds can rest in security. Siebohm and others have studied

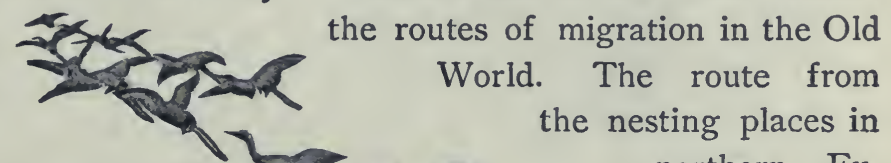
Africa follows the Rhine, the Lake of Geneva, the Rhone, whence some spenorthern Eucies follow the Italian and others the Span- FIG. 317.-CRanes ish coast line to Africa. Birds choose the Migrating, with lowest mountain passes. The Old World leader at point of martin travels every year from the North Cape to the Cape of Good Hope and back again! Another route has been traced from Egypt along the coast of Asia Minor, the Black Sea and Ural Mts. to Siberia.

Field Study of Migration. - Three columns may be filled on the blackboard in an unused corner, several months in spring or fall being taken for the work. First column, birds that stay all the year. Second column, birds that come from the south and are seen in summer only. . Third column, birds that come from the north and are seen in winter only. Exact dates of arrival and departure and flight overhead should be recorded in notebooks. Many such records will enable American zoologists to trace the migration routes of our birds. 
Moulting.- How do birds arrange their feathers after they have been ruffled? Do they ever bathe in water?

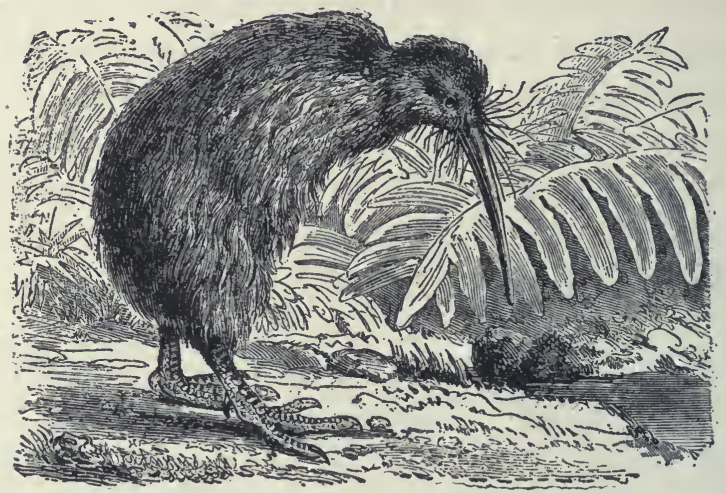

FIG. 318. - APTERYX, of New Zealand. Size of a hen, wings and tail rudimentary, feathers hair-like.

In dust? Dust helps to remove old oil. At what season have birds the brightest feathers? Why? Have you ever

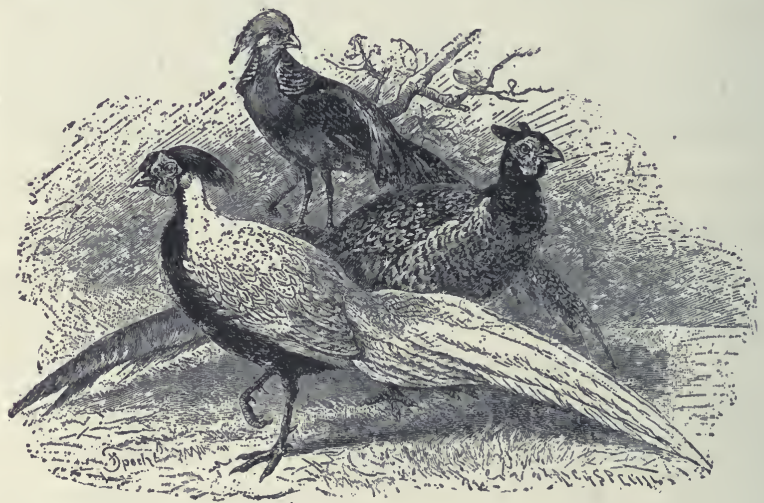

Fig. 3I9. - Golden, Silver, and Noble Pheasants, males. Order ? (Key, p. I77.) Ornaments of males, brightest in season of courtship, are due to sexual selection (Figs. 32I-7-9, 333).

seen evidence of the moulting of birds? Describe the moulting process (page 120). 


\section{Adaptations for} Flying. - Flight is the most difficult and energyconsuming method of moving found among animals, and careful adjustment is necessary. For balancing, the. heaviest muscles are placed at the lower and central

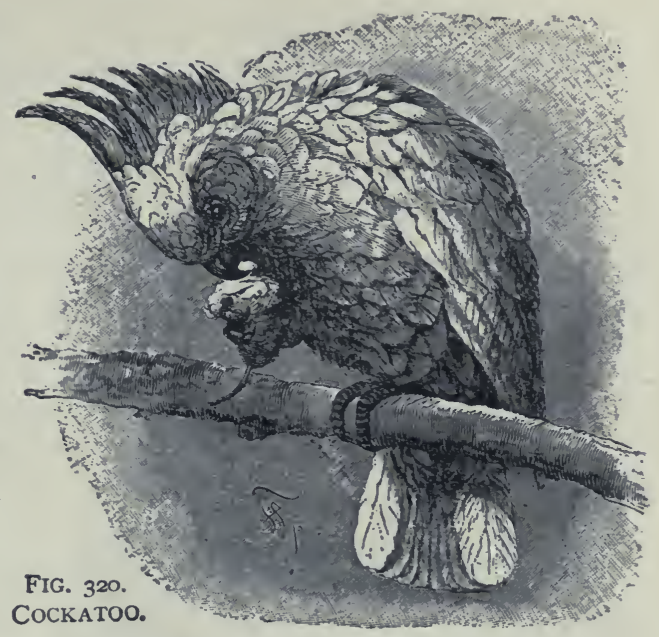
portion of the body. These are the flying muscles, and in some birds (humming birds) they make half of the entire weight. Teeth are the densest of animal structures; teeth and the strong chewing muscles required would make the head heavy and balancing

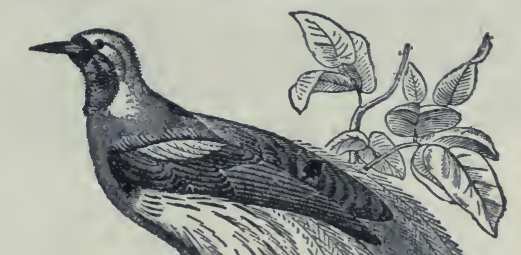
difficult; hence the chewing apparatus is transferred to the heavy gizzard near the centre of gravity of the body. The bird's neck is long and excels all other necks in flexibility, but it is very slender (although apparently heavy), being inclosed in a loose, feathered skin. A cone is the best

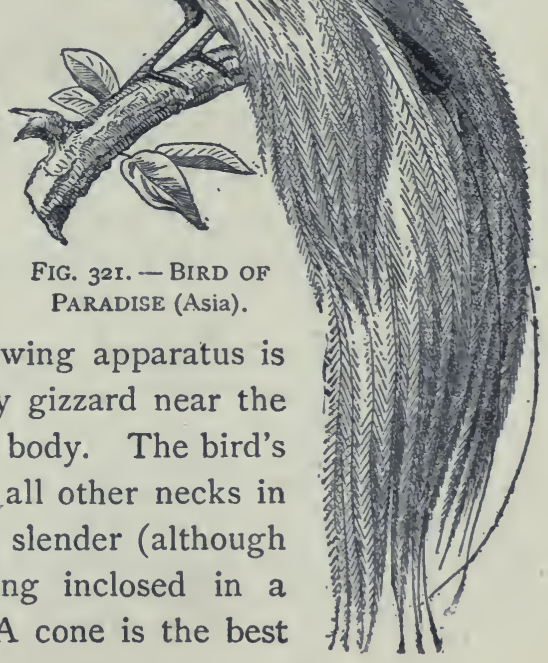


shape to enable the body to penetrate the air, and a small neck would destroy the conical form. The internal organs are compactly arranged and rest in the cavity of the breast bone. The bellows-like air sacs filled with warm air lighten the bird's weight. The bones are hollow and very thin. The large tail quills are used by the bird only in guiding its flight up and down, or balancing on a limb.

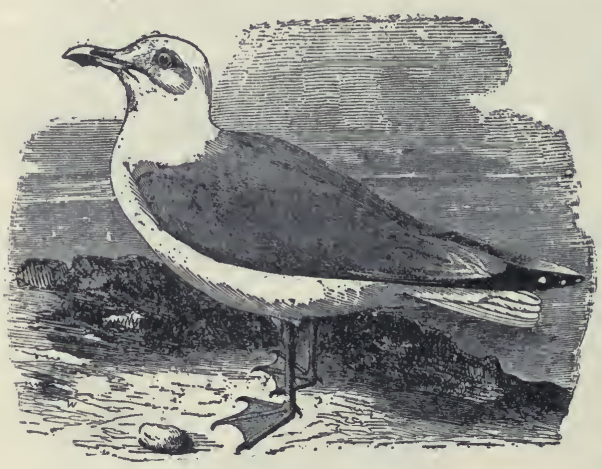

FIG. 322. - HERRING GULL. (Order ?) The feet also aid a flying bird in balancing. The wing is so constructed as to present to the air a remarkably large surface compared with the small bony support in the wing skeleton. Are tubes ever resorted to by human architects when lightness combined with strength is desired? Which quills in the wing serve to lengthen it? (Fig. 296.) To broaden it? Is flight more difficult for a bird or for a butterfly? Which of them do the flying machines more closely resemble? Can any bird fly for a long time without flapping its wings?

Exercise in the Use of the Key. - Copy this list and write the name of the order to which each of the birds belongs. (Key, page 177.)

Cockatoo (Fig. 320) Wren (Fig. 310)

Sacred Ibis (Fig. 328) Apteryx (Fig. 318)

Screech Owl (Fig. 31 I) Lyre bird (Fig. 327)

Nightingale (Fig. 325) Road Runner (Fig. 313)

Top-knot Quail (Fig. Ostrich (Fig. 332)

329)

Penguin (Fig. 330)
Pheasant (Fig. 319)

Wood Duck (Fig. 314)

Jacana (Fig. 324)

Sea Gull (Fig. 322)

Heron (Fig. 315)

Hawk (Fig. 312) 
KEY, OR TABLE, FOR CLASSIFYING BIRDS (Class Aves) INTO ORDERS

$A_{1}$ Wings not suited for flight, 2 or 3 toes

ORDERS

RUNNERS

$A_{2}$ Wings suited for flight (except the penguin)

$\mathrm{B}_{1}$ Toes united by a web for swimming, legs short

$C_{1}$ Feet placed far back; wings short, tip not reaching to base of tail (Fig. 300)

$\mathrm{C}_{2}$ Bill flattened, horny plates under margin of upper bill (Fig. 323)

$\mathrm{C}_{3}$ Wings long and pointed, bill slender

$\mathrm{C}_{4}$ All four toes webbed, bare sac under throat

$\mathrm{B}_{2}$ Toes not united by web for swimming

$\mathrm{C}_{1}$ Three front toes, neck and legs long, tibia (shin, or "drumstick") partly bare

$\mathrm{C}_{2}$ Three front toes, neck and legs not long

$\mathrm{D}_{1}$ Claws short and blunt (e, Fig. 300)

$\mathrm{E}_{1}$ Feet and beak stout, young feathered, base of hind toe elevated

$E_{2}$ Feet and beak weak, young naked

$\mathrm{D}_{2}$ Claws long, curved and sharp, bill hooked and sharp

$\mathrm{D}_{3}$ Claws long, slightly curved, bill nearly straight

$\mathrm{C}_{3}$ Two front and two hind toes (Fig. 300)

$\mathrm{D}_{1}$ Bill straight, feet used for climbing

$D^{1}$ Bill hooked, both bill and feet used for climbing

DIVERS

BiLl-STRAINERS

SEA-FLIERS

GORGERS

WADERS

SCRATCHERS

MESSENGERS

ROBBERS

PERCHERS

FOOT-CLIMBERS

BILL-CLIMBERS

The Food of Birds. - Extracts from Bulletin No. 54 (United States Dept. of Agriculture), by F. E. L. Beal.

The practical value of birds in controlling insect pests should be more generally recognized. It may be an easy matter to exterminate the birds in an orchard or grain field, but it is an extremely difficult one to control the insect pests. It is certain, too, that the value of our native sparrows as weed destroyers is not appreciated. Weed seed forms an important item of the winter food of many of these birds, and it is impossible to estimate the immense numbers of noxious weeds which are thus annually 
destroyed. If crows or blackbirds are seen in numbers about cornfields, or it woodpeckers are noticed at work in an orchard,

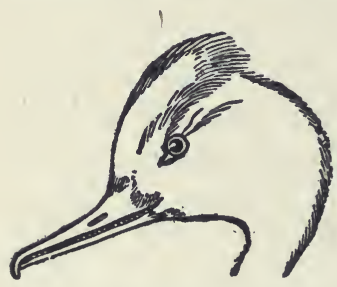

FIG. 323. - HEAD OF DUCK.

it is perhaps not surprising that they are accused of doing harm. Careful investigation, however, often shows that they are actually destroying noxious insects; and also that even those which do harm at one season may compensate for it by eating insect pests at another. Insects are eaten at all times by the majority of land birds. During the breeding season most kinds subsist largely on this food, and rear their young exclusively upon it.

Partridges. - Speaking of $\mathrm{I}_{3}$ birds which he shot, Dr. Judd says : These $1_{3}$ had taken weed seed to the extent of 63 per cent of

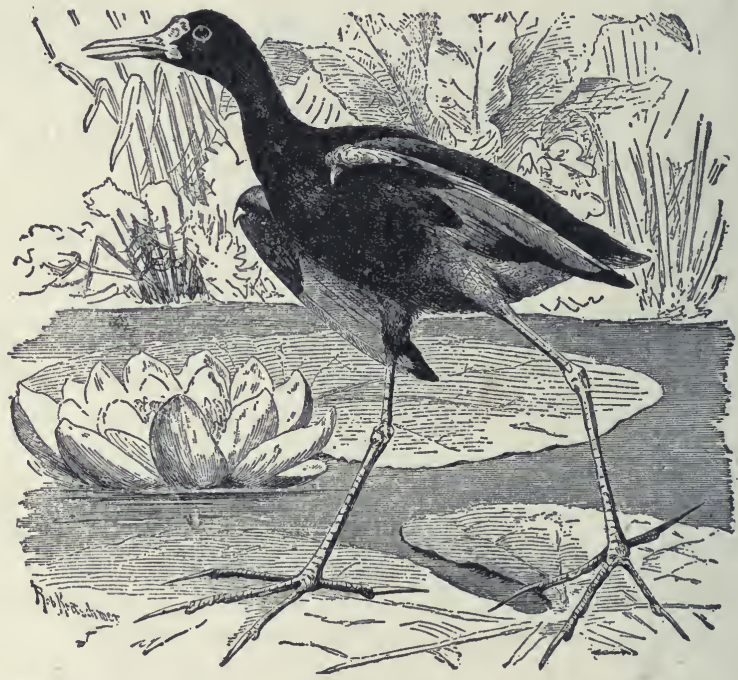

FIG. 324. - JACANA. (Mexico, Southwest Texas, and Florida.)

Questions: What appears to be the use of such long toes? What peculiarity of wing? head? their food. Thirty-eight per cent was ragweed, 2 per cent tick trefoil, partridge pea, and locust. seeds, and 23 per cent seeds of miscellaneous weeds. About I 4 per cent of the quail's food for 
the year consists of animal matter (insects and their allies). Prominent among these are the Colorado potato beetle, the striped squash beetle, the cottonboll-weevil, grasshoppers. As a weed destroyer the quail has few, if any, superiors. Moreover, its habits are such that it is almost constantly on the ground, where it is brought in close contact with both weed seeds and ground-living insects. It is a good ranger, and, if undisturbed, will patrol every day all the fields in its vicinity as it searches for food.

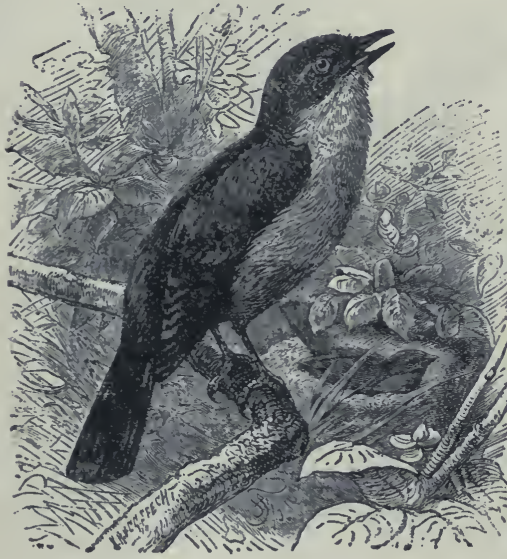

Fig. 325. - Nightingale, $\times 3$.

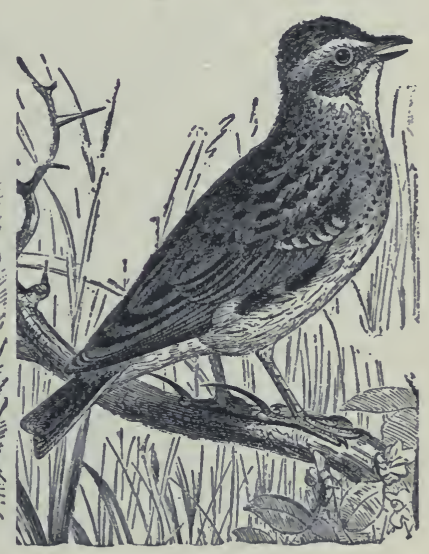

FIG. 326. - SKYLARK, $\times$ 3ै.

Two celebrated European songsters.

Doves. - The food of the dove consists of seeds of weeds, together with some grain. The examination of the contents of 237 stomachs shows that over 99 per cent of the food consists wholly of vegetable matter.

Cuckoos. - An examination of the stomachs of 46 black-billed cuckoos, taken during the summer months, showed the remains of 906 caterpillars, 44 beetles, 96 grảsshoppers, Ioo sawflies, 30 stink bugs, and 15 spiders. Of the yellow-billed cuckkoos, or " rain-crow," Io9 stomachs collected from May to October, inclusive, were examined. The contents consisted of $\mathbf{r}, 865$ caterpillars, 93 beetles, 242 grasshoppers, 37 sawflies, 69 bugs, 6 flies, and 86 spiders. 
Woodpeckers. - Careful observers have noticed that, excepting a single species, these birds rarely leave any conspicuous mark on a healthy tree, except when it is affected by wood-boring larvæ, which are accurately located, dislodged, and devoured by the woodpecker. Of the flickers' or yellowhammers' stomachs examined, three were completely filled with ants. Two of the birds each contained more than $3,000^{\circ}$ ants, while the third bird contained fully 5,000. These ants belong to species which live in the ground. It is these insects for which the flicker is reaching when it runs about in the grass. The yellow-bellied woodpecker or sapsucker

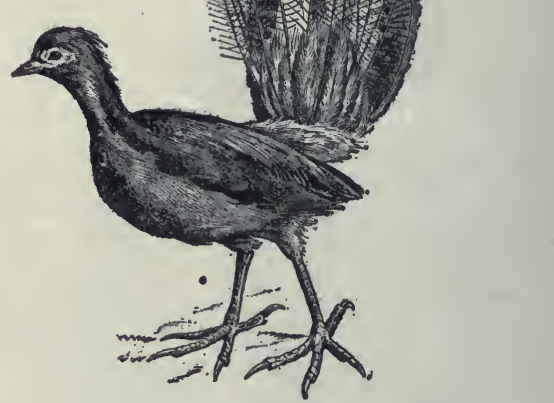

FIG. 327. - LyRE BIRD, male. (Sphyrapicus varius) was shown to be guilty of pecking holes in the bark of various forest trees, and sometimes in that of apple

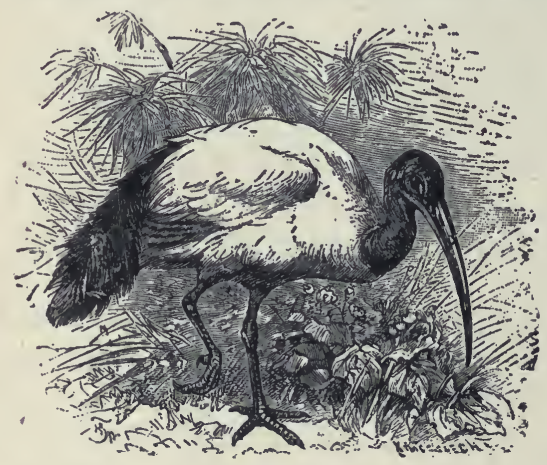

FIG. 328. - SACRED IBIS. (Order ?) trees, and of drinking the sap when the pits became filled. It has been proved, however, that besides taking the sap the bird captures large numbers of insects which are attracted by the sweet fluid, and that these form a very considerable portion of its diet. The woodpeckers seem the only agents which can successfully cope with certain insect enemies of the forests, and, to some extent, with those of fruit trees also. For this reason, if for no other, they should be protected in every possible way. 
The night hawk, or "bull bat," may be seen most often soaring high in air in the afternoon or early evening. It nests upon rocks or bare knolls and flat city roofs. Its food consists of insects taken on the wing; and so greedy is the bird that when food is plentiful, it fills its stomach almost to bursting. Ants (except workers) have wings and fly as they are preparing to propagate. In destroying ants night hawks rank next to, or even with, the woodpeckers, the acknowledged ant-eaters among birds.

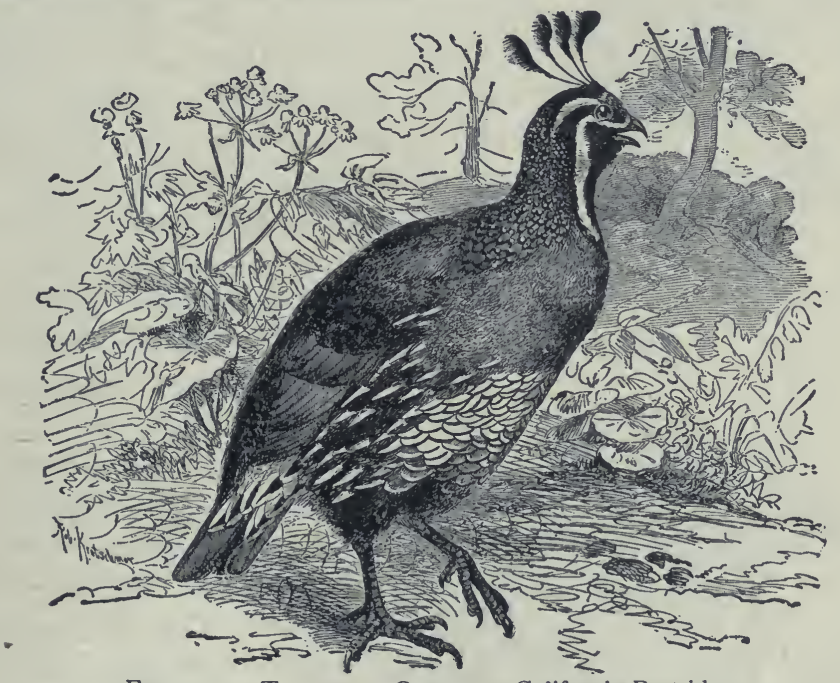

FIG. 329. - TOP-KNOT QUAIL, or California Partridge.

(West Texas to California.)

The kingbird, or martin, is largely insectivorous. In an examination of 62 stomachs of this bird, great care was taken to identify every insect or fragment that had any resemblance to a honeybee; as a result, 30 honeybees were identified, of which 29 were males or drones and I was a worker.

Blue Jay. - In an investigation of the food of the blue jay 300 stomachs were examined, which showed that animal matter comprised 24 per cent and vegetable matter 76 per cent of the bird's diet. The jay's favourite food is mast (i.e. acorns, chestnuts, chinquapins, etc.), which was found in 200 of the 300 stomachs, and amounted to more than 42 per cent of the whole food. 
Crow. - That he does pull up sprouting corr, destroy chickens, and rob the nests of small birds has been repeatedly proved. Nor are these all of his sins. He is known to eat frogs, toads, sala-

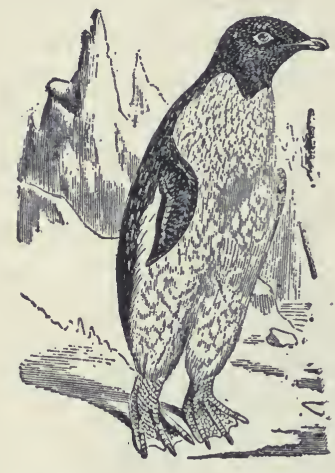

Fig. 330. - Penguin of PataGoNIA. Wings used as flippers for swimming.

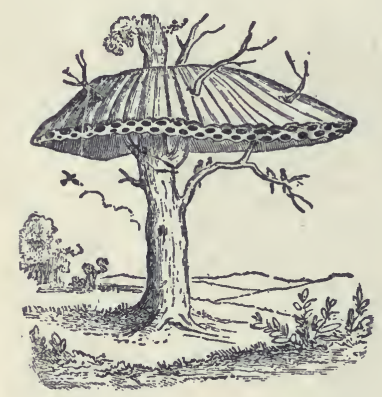

FIG. 33I. - Umbrella holding the nests of social weaver bird of Africa; polygamous. manders, and some small snakes, all harmless creatures that do some good by eating insects. Experience has shown that they may be prevented from pulling up young corn by tarring the seed, which not only saves the corn but forces them to turn their attention to insects. May beetles, "dorbugs," or June bugs, and others of the same family constitute the principal food during spring and early summer, and are fed to the young in immense quantities.

Ricebird. - The annual loss to rice growers on account of bobolinks has been estimated at $\$ 2,000,000$.

Meadow Lark. - Next to grasshoppers, beetles make up the móst important item of the meadow lark's food, amounting to nearly $2 \mathrm{I}$ per cent. May is the month when the dreaded cut‘worm begins its deadly career, and then the lark does some of its best work. Most of these caterpillars are ground feeders, and are overlooked by birds which habitually frequent trees, but the meadow lark finds and devours them by thousands.

Sparrows. - Examination of many stomachs shows that in winter the tree sparrow feeds entirely upon seeds of weeds. Probably each bird consumes about one fourth of an ounce a day. Farther south the tree sparrow is replaced in winter by the white-throated sparrow, the white-crowned sparrow, the fox sparrow, the song sparrow, the field sparrow, and several others; so that all over the land a vast number of these seed eaters are at 
work during the colder months reducing next year's crop of worse than useless plants.

Robin. - An examination of 500 stomachs shows that over 42 per cent of its food is animal matter, principally insects, while the remainder is made up largely of small fruits or berries. Vegetable food forms nearly $5^{8}$ per cent of the stomach contents, over 47 per cent being wild fruits, and only a little more than 4 per cent being possibly cultivated varieties. Cultivated fruit amounting to about 25 per cent was found in the stomachs in June and July, but only a trifle in August. Wild fruit, on the contrary, is eaten in every month, and constitutes during half the year a staple food.

Questions. - Which of these birds are common in your neighbourhood? Which of them according to the foregoing report are plainly injurious? Clearly beneficial? Doubtful? Which are great destroyers of weed seeds? Wood-borers? Ants? Grain? Why is the destruction of an ant by a night hawk of greater benefit than the destruction of an ant by a woodpecker? Name the only woodpecker that injures trees. If a bird eats two ounces of grain and one ounce of insects, has it probably done more good or more evil?

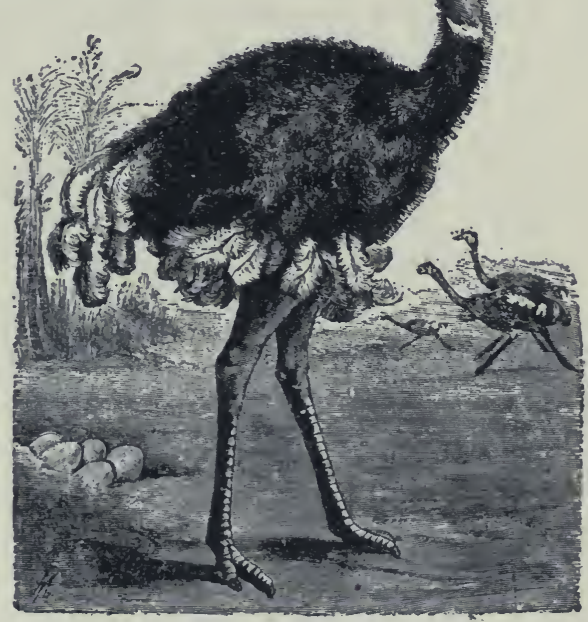

FIG. 332.-AFRICAN OSTRICH, $\times \frac{2}{30}$. (Order ?) 


\section{CHAPTER XIV}

\section{Mammals}

SugGestions. - A tame rabbit, a house cat, or a pet squirrel may be taken to the school and observed by the class. "Domestic animals may be observed at home and on the street. A study of the teeth will give a key to the life of the animal, and the teacher should collect a few mammalian skulls as opportunities offer. The pupils should be required to identify them by means of the chart of skulls (p. 194). If some enthusiastic students fond of anatomy should dissect small mammals, the specimens should be killed with chloroform, and the directions for dissection usual in laboratory works on this subject may be followed. 'There is a brief guide on page 223. The following outline for the study of a live mammal will apply almost as well to the rabbit or the squirrel as to the cat.

The Cat. - The house cat (Felis domestica) is probably descended from the Nubian cat (Felis maniculata, Fig. 333) found in Africa. The wild species is about half as large again as the domestic cat, grayish brown with darker stripes; the tail has dark rings. The lynx, or wild cat of America (Lynx rufus), is quite different. Compare the figures $(333,335)$ and state three obvious differences. To which American species is the house cat closer akin, the lynx (Fig. 335) or the ocelot (Fig. 334)? The domestic cat is found among all nations of the world. What is concluded, as to its nearest relatives, from the fact that the Indians had no cats when America was discovered? It was considered sacred by the ancient Egyptians, and after death its body was embalmed.

The body of the cat is very flexible. It may be divided into five 'regions, head, neck, trunk, tail, and limbs. Its 


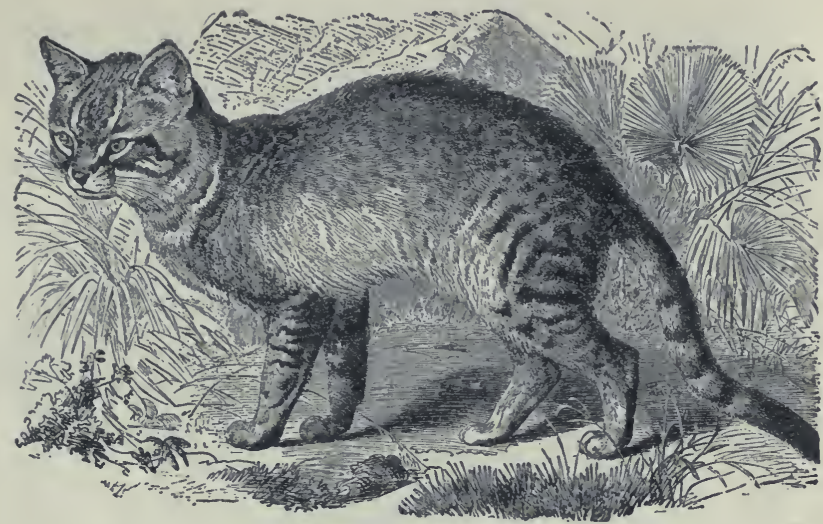

FIG. 333. - WILD CAT OF AFRICA (Felis maniculata), $\times 1 / 8$.

eyes have the same parts as the eyes of other mammals. Which part of its eye is most peculiar? (Fig. 333.) What part is lacking that is present in birds? How are the eyes especially adapted for seeing at night? Does the pupil in the light extend up or down or across the iris? Does it ever become round?

What is the shape and the position of the ears? Are they large or small compared with those of most mammals? They are fitted best for catching sound from what direction? What is thus indicated in regard to the cat's habits? (Compare with ears of rabbit.) Touch the whiskers of the cat. What result? Was it voluntary or involuntary motion? Are the nostrils relatively large or small compared with those of a cow? Of man?

Is the neck long or short? Animals that have long fore legs usually have what kind of neck? Those with short legs? Why? How many toes on a fore foot? Hind foot? Why is this arrangement better than the reverse? Some mammals are sole walkers (plantigrade), some are toe walkers (digitigrade). To which kind does the cat 


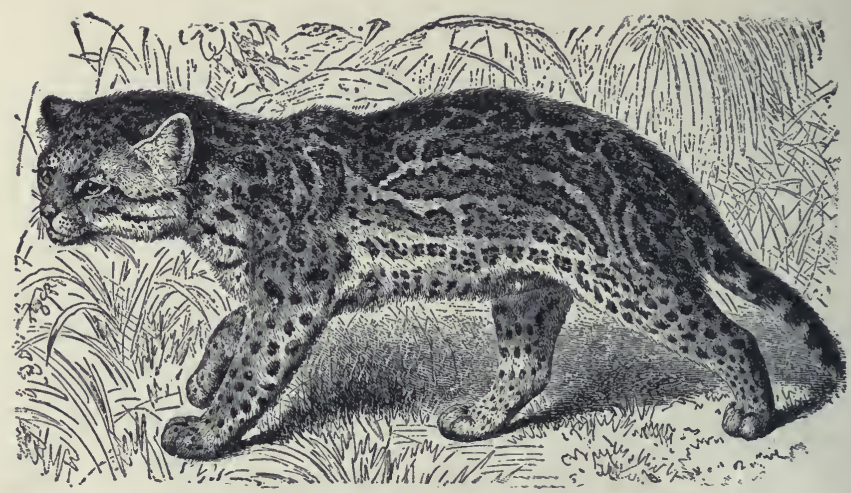

FIG. 334. - OCELOT (Felis pardalis), of Texas and Mexico. $\times \frac{1}{3}$.

belong? Does it walk on the ends of the toes? Does it walk with all the joints of the toes on the ground? Where is the heel of the cat? (Fig. 334.) The wrist? To make sure of the location of the wrist, begin above : find the shoulder blade, the upper arm (one or two bones?), the lower arm (one or two bones?), the wrist, the palm, and the fingers (Fig. 337). Is the heel bone prominent or small?

In what direction does the knee of the cat point? The heel? The elbow? The wrist? Compare the front and the hind leg in length; straightness; heaviness; number and position of toes; sharpness of the clares. What makes the dog's clawes duller than a cat's? What differences in habit go with this? Judging from the toe that has become useless on the fore foot of the cat, which toe is lacking in the hind foot? Is it the cat's thumb or little finger that does not touch the ground? (Fig. 337.) Locate on your own hand the parts corresponding to the pads on the forefoot of a cat. Of what use are soft pads on a cat's foot?

Some animals have short, soft fur and long, coarse over hair. Does the cat have both? Is the cat's fur soft or coarse? Does the fur have a colour near the skin different 
from that at the tip? Why is hair better suited as a covering for the cat than feathers would be? Scales? Where are long, stiff bristles found on the cat? Their length suggests that they would be of what use to a cat in going through narrow places? Why is it necessary for a cat to be noiseless in its movements?

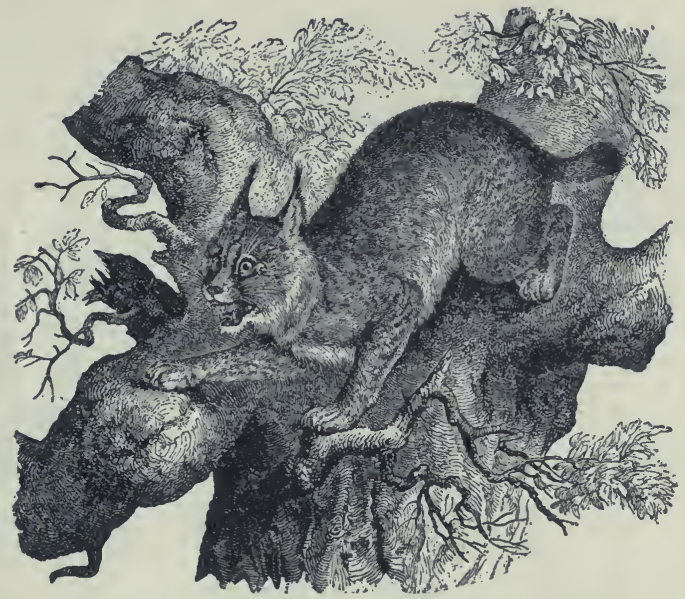

FIG. 335. - LYNX (Lynx rufus). The "Bob-tailed cat" (North America).

Observe the movements of the cat. - Why cannot a cat come down a tall tree head foremost? Did you ever see a cat catch a bird? How does a cat approach its prey? Name a jumping insect that has long hind legs; an amphibian; several mammals (Figs. 362, 374). Does a cat ever trot? Gallop? Does a cat chase its prey? When does the cat move with its heel on the ground? The claws of a cat are withdrawn by means of a tendon (see Fig. 338). Does a cat seize its prey with its mouth or with its feet?

How does a cat make the purring sound? (Do the lips move? The sides?) How does a cat drink? Do a cat 
and dog drink exactly the same way? Is the cat's tongue rough or smooth? How is the tongue used in getting the flesh off close to the bone? Can a cat clean a bone entirely of meat?

In what state of development is a newly born kitten? With what does the cat nourish its young? Name ten

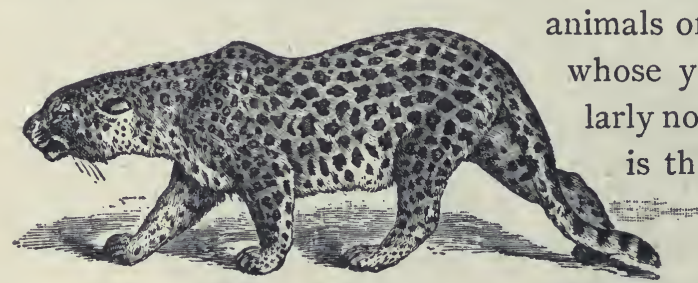
various kinds

FIG. 336. - JAGUAR, of tropical America.

cat bend its back when it is frightened or angry? Does a cat or a dog eat a greater variety of food ? Which refuses to eat an animal found dead? Will either bury food for future use? Which is sometimes troublesome on account of digging holes in the garden? Explain this instinct. Which lived a solitary life when wild? Which had a definite haunt, or home? Why are dogs more sociable than cats? A dog is more devoted to his master. Why? A cat is more devoted to its home, and will return if carried away. Why? Why does a dùg turn around before lying down? (Consider its original environment.)

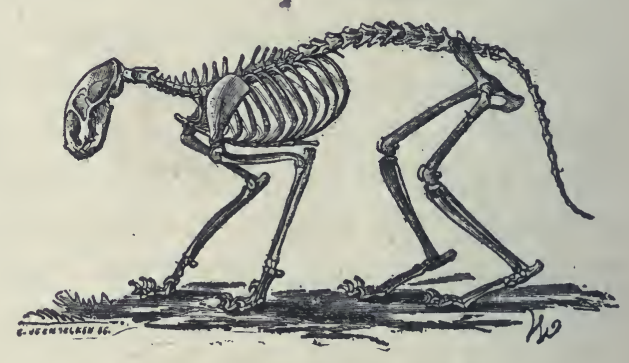

Fig: 337.-SKELETON OF CAT.

The Skeleton (Fig. 337). - Compare the spinal column of a cat in form and flexibility with the spinal column of a fish, a snake, and a bird. 
The skull is joined to the spinal column by two knobs (or condyls), which fit into sockets in the first vertebra. Compare the jaws with those of a bird and a reptile. There is a prominent ridge in the temple to which the powerful chewing muscles are attached. There is also a ridge at the back of the head where the muscles which support the head are attached (Fig. 348).

Count the ribs. Are there more or fewer than in man? The breastbone is in a number of parts, joined, like the vertebræ, by cartilages. Compare it with a bird's sternum; why the difference? The shoulder girdle, by which the front legs are attached to the trunk, is hardly to be called a girdle, as the collar bones (clavicles) are rudimentary. (They often escape notice during dissection, being hidden by muscles.) The shoulder blades, the other bones of this girdle, are large, but relatively not so broad toward the dorsal edge as human shoulder blades. The clav-

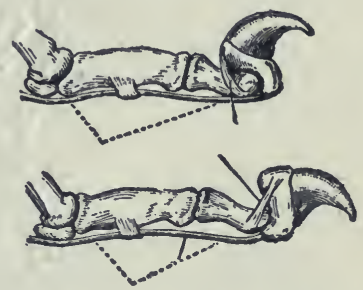
FIG. 338. - CLAW OF CAT (I) retracted by ligament, and (2) drawn down by muscle attached to lower tendon.

icles are tiny because they are useless. Why does the cat not need as movable a shoulder as a man? The pelvic, or hip girdle, to which the hind legs are attached, is a rigid girdle, completed above by the spinal column, to which it is immovably joined. Thus the powerful hind legs are joined to the most rigid portion of the trunk.

Mammals. - The cat belongs to the class Mammalia or mammals. The characteristics of the class are that the young are not hatched from eggs, but are born alive, and nourished with milk (hence have lips), and the skin is covered with hair. The milk glands are situated ventrally. The position of the class in the animal kingdom was 
shown when the cow was classified (p. 9). Their care for the young, their intelligence, and their ability to survive when in competition with other animals, causes the mammals to be considered the highest class in the animal kingdom.

According to these tests, what class of vertebrates should rank next to mammals? Compare the heart, the lungs, the blood, and the parental devotion of these two highest classes of animals.

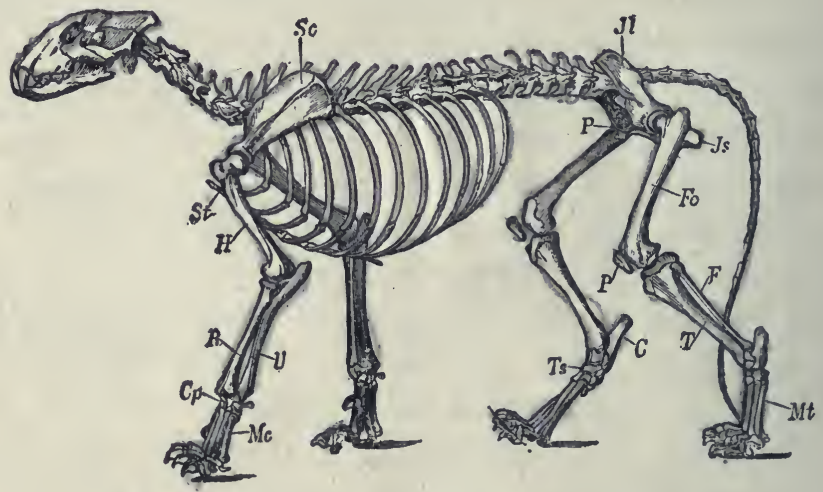

Fig. 339. - SKELETON of Lion (cat family).

The first mammals, which were somewhat like small opossums, appeared millions of years ago, when the world was inhabited by giant reptiles. These reptiles occupied the water, the land, and the air, and their great strength and ferocity would have prevented the mammals from multiplying (for at first they were small and weak), but the mammals carried their young in a pouch until able to care for themselves, while the reptiles laid eggs and left them uncared for. The first mammals used reptilian eggs for food, though they could not contend with the great reptiles. Because birds and mammals are better parents than reptiles, they have conquered the earth, and the rep- 
tiles have been forced into subordination, and have become smaller and timid.

Classification of Mammals. - Which two have the closest resemblances in the following lists: Horse, cow, deer. Why? Cat, cow, bear. Why? Monkey, man, sheep. Why? Rat, monkey, squirrel. Why? Giraffe, leopard, camel. Why? Walrus, cat, cow. Why? Check the five mammals in the following lists that form a group resembling one another most closely: Lion, bear, pig, dog, squirrel, cat, camel, tiger, man.

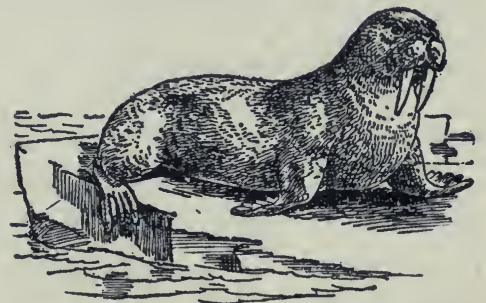
State your reasons. Gi- FIG.340.-WALRUS (Trichechus rosmarus). raffe, leopard, deer, cow, rat, camel, hyena, horse, monkey. State reasons.

Teeth and toes are the basis for subdividing the class mammalia into orders. Although the breathing, the circulation, and the internal organs and processes are similar in all mammals, the external organs vary FIG. 34r. - WEASEL, in summer; in Canada greatly because of in winter it is all white but tip of tail. the varying environments of different species. The internal structure enables us to place animals together which are essentially alike; e.g. the whale and man are both mammals, since they resemble in breathing, circulation, and multiplication of young. The external organs guide us in separating the class into orders. The teeth vary according to the food 
eaten. The feet vary according to use in obtaining food or escaping from enemies. This will explain the differ-

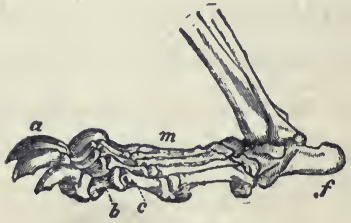

FIG. 342. - FOOT OF BEAR (Plantigrade). ence in the length of legs of lion and horse, and of the forms of the teeth in cat and cow. Make a careful study of the teeth and the limbs as shown in the figures and in all specimens accessible Write out the dental formulas as indicated at the top of page 194. The numerals above the line show the number of upper teeth, those below the line show the number of lower teeth, in one half of the jaw. They are designated as follows: $I$, incisors; $C$, canine; $M$, molars. Multiplying by two gives the total number. Which skulls in the chart have the largest canines? Why? The smallest, or none at all? Why? Compare the molars of the cow, the hog, and the dog. Explain their differences. In which skulls are some of the molars lacking? Rudimentary? Why are the teeth that do not touch usually much smaller than those that do?

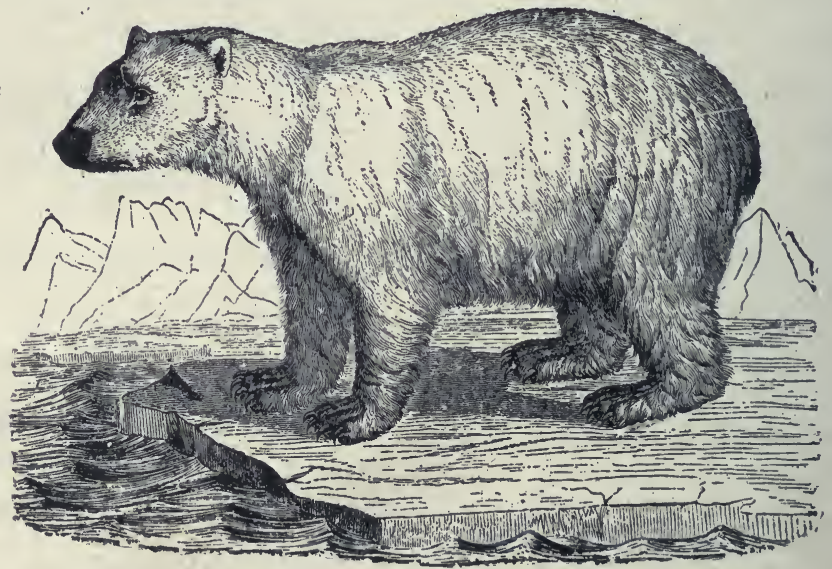

FIG. 343. - POLAR BEAR (L'rsus maritimus). 
KEY, OR TABLE, FOR CLASSIFYING MAMMALS (class Mammalia) INTO ORDERS

A Imperfect Mammals, young hatched or pre-

Orders

maturely born

$\mathrm{B}_{1}$ Jaws a birdlike beak, egg-laying

Mon'otreines

$\mathrm{B}_{2}$ Jaws not beaklike, young carried in pouch

A $_{2}$ Perfect Mammals, young not hatched, nor

Marsu'pials

prematurely born

$\mathrm{B}_{1}$
Digits
with
claws $\left\{\begin{array}{l}\mathrm{C} \text { Front part of both jaws lack teeth } \\ \mathrm{C}_{2} \text { Teeth with sharp points for piercing } \\ \text { shells of insects } \\ \mathrm{C}_{3} \text { Canines very long, molars suited for } \\ \text { tearing } \\ \mathrm{C}_{4} \text { Canines lacking, incisors very large }\end{array}\right.$

Eden tates

Insect'ivors

Car'nivors

Rodents

$\mathrm{B}_{2}$
Digits
distinct $\begin{cases}\mathrm{C}^{1} & \text { Head large; carnivorous } \\ \mathrm{C}_{2} & \text { Head small; herbivorous }\end{cases}$

Ceta'ceans

Sire'neans

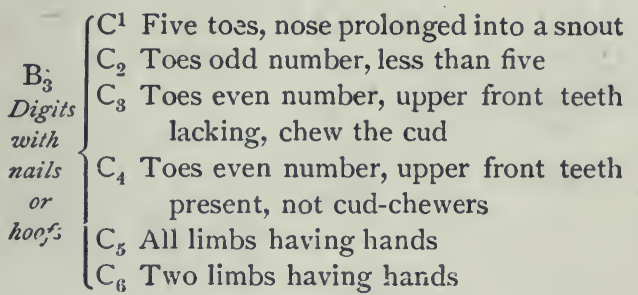

Proboscid'eans

Ru'minants $\left[\begin{array}{c}\text { E'quines } \\ \text { Swine }\end{array}\right]$

Quad'rumans

Bi'mans

Exercise in Classification. - Copy the following list, and by reference to figures write the name of its order after each mammal :-

Ape (Figs. 405, 406)

Rabbit (Fig. 345)

Dog (Figs. 356, 408)

Hog (Figs. 357, 393)

Bat (Figs. 347, 370)

Cat (Figs. 337, 348)

Armadillo

(Figs 349, 365)
Cow (Figs. 344, 386)

Walrus (Fig. 340)

-Monkey

(Figs. 352, 401)

Horse

(Figs. 355, 395)

Ant-eater

(Figs. 354, 364)
Antelope (Fig. 39I)

Mole

(Figs. 367, 368)

Beaver

(Figs. 372, 373)

Duckbill (Fig. 359)

Tapir (Fig. 384)

Dolphin $(379,397)$

Use chart of skulls and Figs. $381,382,395-400$ in working out this exercise. 
Man's dental formula is

$$
\left(M \frac{5}{5}, C \frac{1}{1}, I \frac{2}{2}\right)^{2}=32
$$

In like manner fill out formulas below:-

Cow ......... $\left(M \frac{6}{6} C-1 \frac{4}{4}\right)^{2}=3^{2}$

Rabbit ........ $\left(M \frac{6}{3} C-1 / \frac{2}{1}\right)^{2}=28$

Walrus........ $\left(M-C-I \frac{1}{-3}\right)^{2}=3+$

Bat........... $\left.\left(M \frac{4}{2} C-\frac{1}{1}\right)^{2}\right)^{2}=34$

Cat............ $\left(M-C-I^{3}\right)^{2}=30$

Armadillo .....(.M-C-I- $)^{2}=28$

Horse.......... $\left.M \frac{6}{6} C \frac{1}{1} 1 \frac{8}{3}\right)^{2}=40$ )

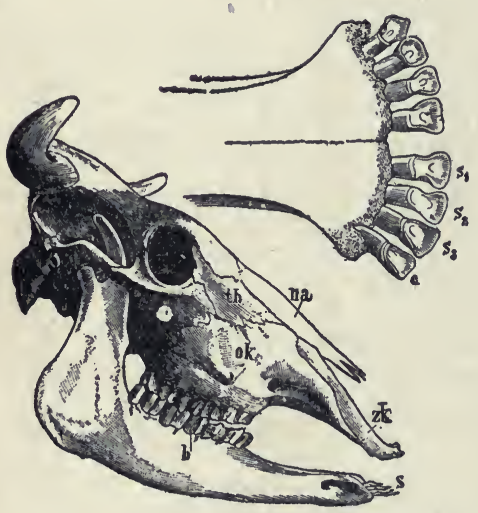

Fig. 344. - Skull and front of lower jaw of Cow.

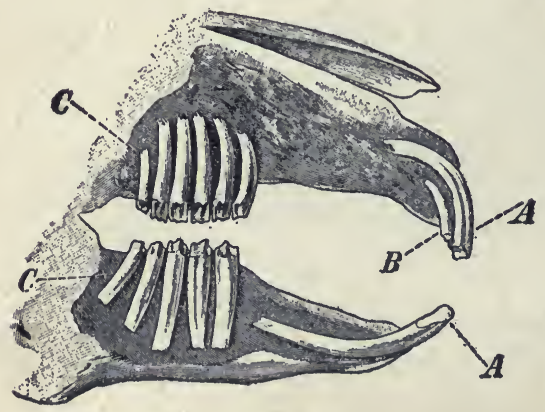

FIG. 345. - RABBIT.

$A, B$, incisors; $C$, molars
Whale........ (M-C-I- $)^{2}=0$ Am. Monkey...( $M-C-I-)^{2}=36$ Sloth.......... $(M-C-1-)^{2}=18$ Ant-eater ..... $(M-C-I-)^{2}=0$ $\operatorname{Dog} . . . \ldots \ldots(M-C-I-)^{2}=42$ $\operatorname{Hog} \ldots \ldots \ldots(M-C-I-)^{2}=44$ Sheep ......... $(M-C-I-)^{2}=3^{2}$

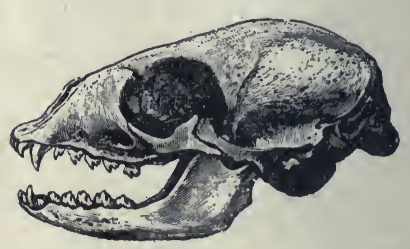

FIG. 346. - WALRUS (see Fig. 34I).

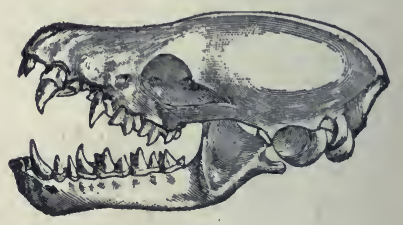

FIG. 347. - BAT.

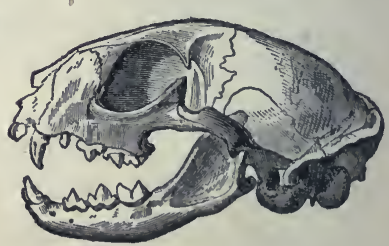

FIG. 348.-CAT, 


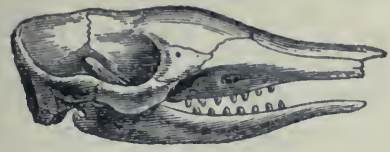

FIG. 349.-AKMADII.LO.

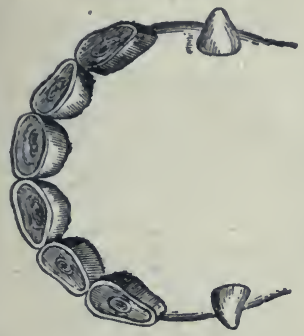

FiG. 350. - HORSE (front of jaw).

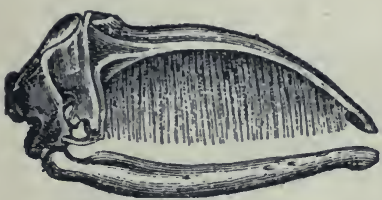

FIG. 351. - GREFNLAND WHALE.

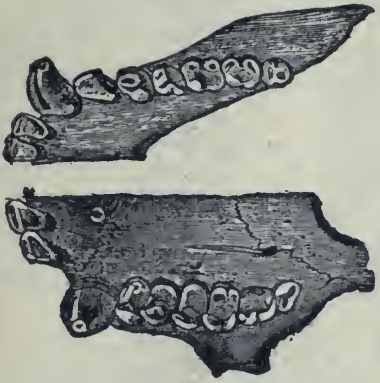

FIG. 352. - AMERICAN MONKEY.

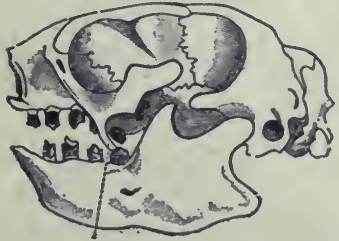

FIG. 353.-SLoth (Fig. 363).

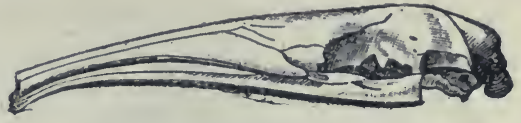

FIG. 354. - ANT-EATER (Fig. 364).
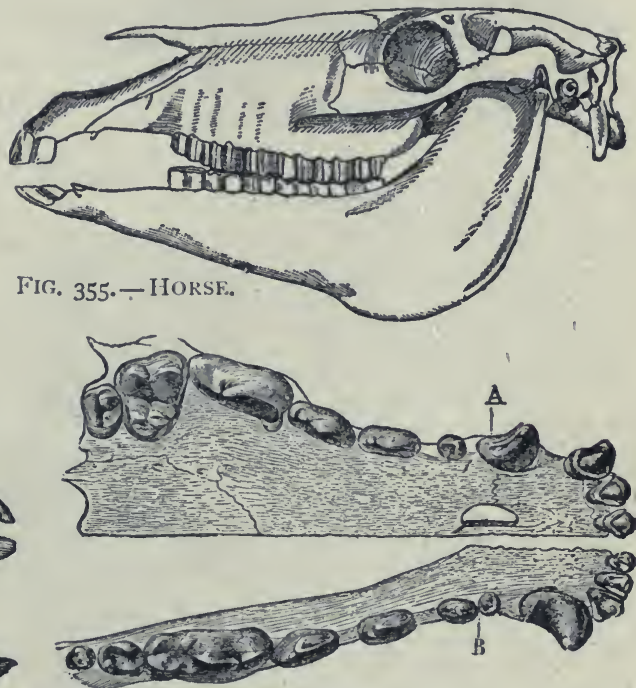

Fig. 356.-DoG. Upper $(A)$ and lower $(B)$ jaw.
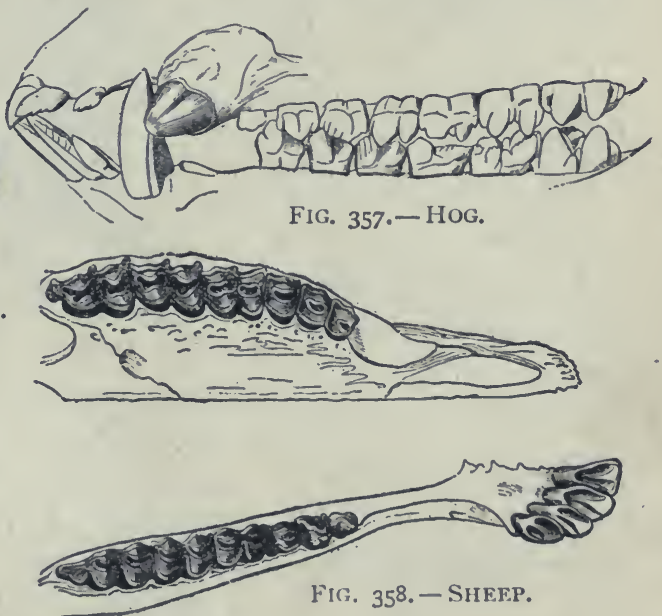
The lowest order of mammals contains only two species, the duckbill and the porcupine ant-eater, both living in

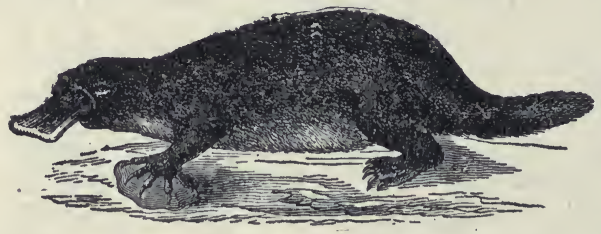

FIG. 359. - DUCKBILL (Ornithorhynchus paradoxus). the Australian region. Do you judge that the duckbill of Tasmania (Fig. 359) lives chiefly in water or on land? Why? Is it probably active or slow in movement? It dabbles in mud and slime for worms and mussels, etc. How is it fitted for doing this? Which feet are markedly webbed? How far does the web extend? The web can be folded back when not in use. It lays two eggs in a nest of grass at the end of a burrow. Trace resemblances and differences between this animal and birds.

The porcupine anteater has numerous quill-like spines (Fig. 360)interspersed with its hairs. (Use ?) Describe its claws. It has a long prehensile

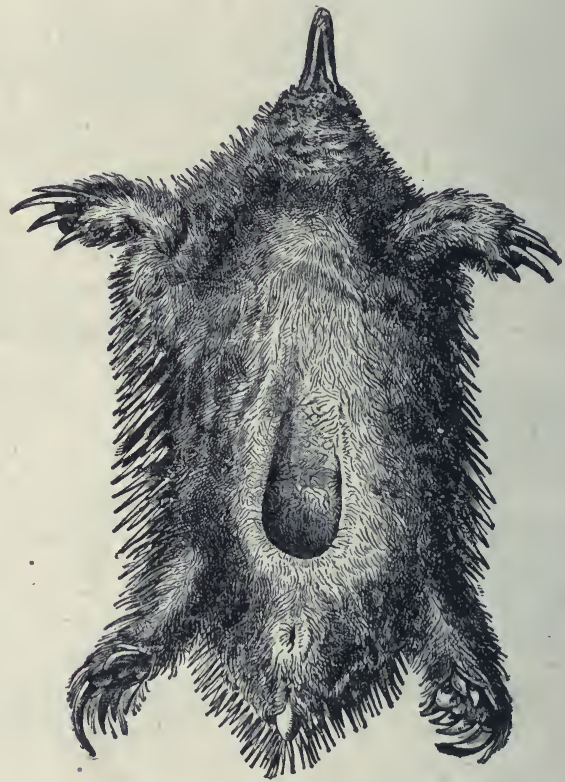

Fig. 360.- SPINY ANT-EATER (Echidna aculeata). View of under surface to show pouch. (After Haacke.) tongue. It rolls into a ball when attacked. Compare its jaws with a bird's bill. It lays one egg, which is carried 
in a fold of the skin until hatched. Since it is pouched it could be classed with the pouched mammals (next order), but it is egg-laying. Suppose the two animals in this order did not nourish their young with milk after hatching, would they most resemble mammals, birds, or reptiles?

Write the name of this order.

(See Table, p. 193.) Why do you place them in this order (__ See p. 193.) The name of the order comes from two Greek

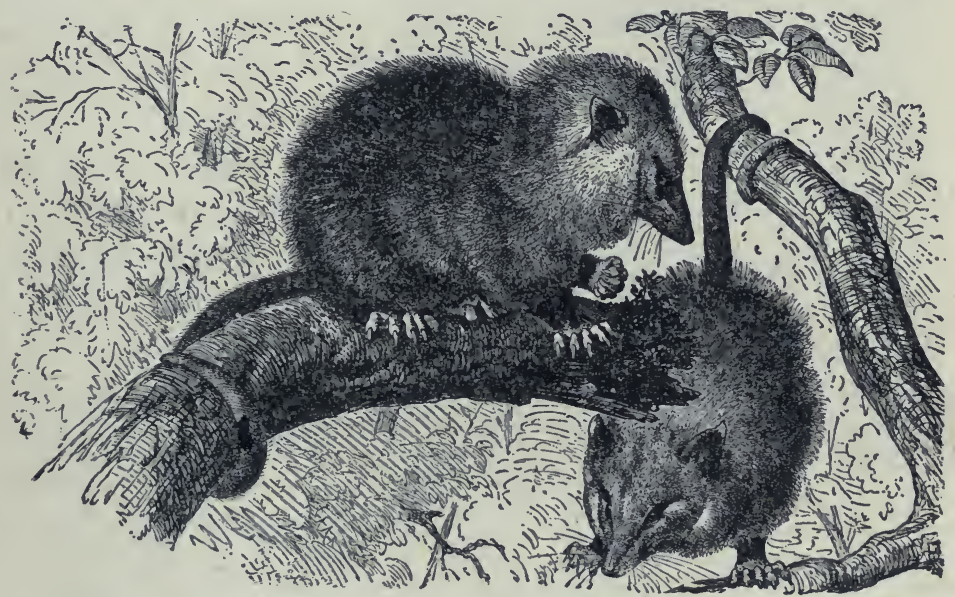

FIG. 36r. - Opossum (Didelphys Virginianus).

words meaning "one opening," because the ducts from the bladder and egg glands unite with the large intestine and form a cloaca. What other classes of vertebrates are similar in this?

Pouched Mammals. - These animals, like the last, are numerous in the Australian region, but are also found in South America, thus indicating that a bridge of land once connected the two regions. The opossum is the only species which has penetrated to North America (Fig. 36I). Are its jaws slender or short? What kinship is thus suggested? As shown by its grinning, its lips are not well de- 
veloped. Does this mean a low or a well-developed mammal? Where does it have a thumb? (Fig. 36r.) Does the thumb have a nail? Is the tail hairy or bare? Why? Do you think it prefers the ground or the trees? State two reasons for your answer. It hides in a cave or bank or hollow tree all day, and seeks food at night. Can it run fast on the ground? It feigns death when captured,

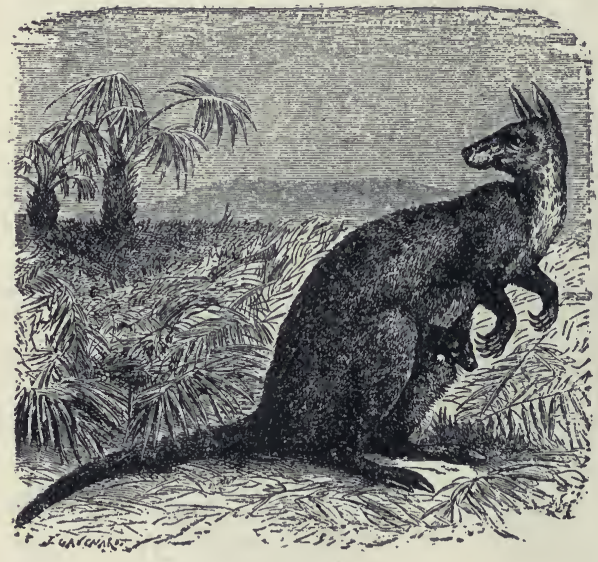

Fig. 362. - GIANT KANGAROo. and watches for a chance for stealthy escape.

The kangaroo (Fig. 362), like the opossum, gives birth to imperfectly developed young. (Kinship with what classes is thus indicated ?) After birth, the young (about threefourths of an inch long) are carried in a ventral pouch and suckled for seven or eight months. They begin to reach down and nibble grass before leaving the pouch. Compare fore legs with hind legs, front half of body with hind half. Describe tail. What is it used for when kangaroo is at rest? In jumping, would it be useful for propelling and also for balancing the body? Describe hind and fore feet. Order Why? See key, page 193.

Imperfectly Toothed Mammals. - These animals live chiefly in South America (sloth, armadillo, giant ant-eater) and Africa (pangolin). The sloth (Fig. 363) eats leaves. Its movements are remarkably slow, and a vegetable growth 
resembling moss often gives its hair a green colour. (What advantage?) How many toes has it? How are its nails suited to its manner of living? Does it save exertion by hanging from the branches of trees instead of walking upon them?

Judging from the figures $(363,364$, 365 ), are the members of this order better suited for at-

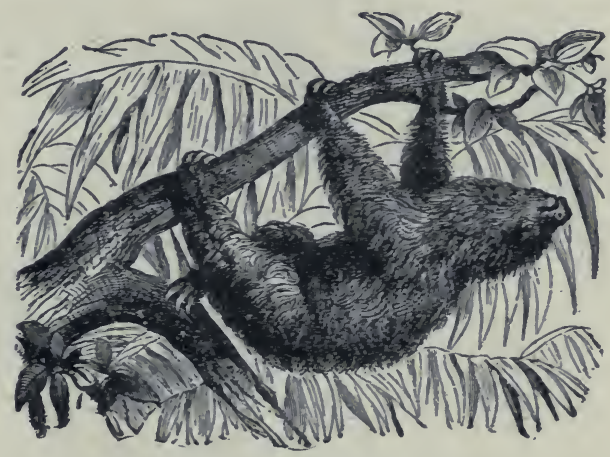

Fig. 363.-SLOTH of South America. tack, active resistance, passive resistance, or concealment

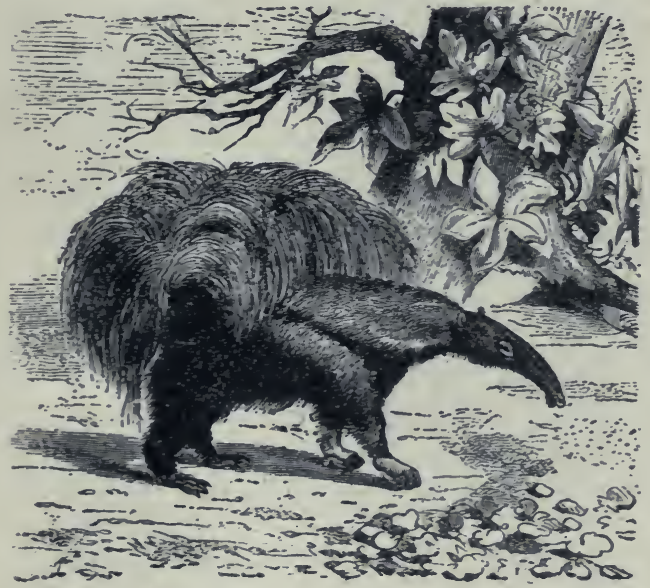

FIG. 364.-GIANT ANT-EATER of South America. (See Fig. 354.) Find evidences that the edentates are a degenerate order. Describe another ant-eater (Fig. 360). when contending with other animals? The ant-eater's claws (Fig. 364) on the fore feet seem to be a hindrance in walking; for what are they usefui? Why are its jaws so slender? What is probably the use of the enormous bushy tail? The nine-banded armadillo (Fig. 365) lives in Mexico and Texas. It is omnivorous. To escape its enemies, it burrows into 
the ground with surprising rapidity. If unable to escape when pursued, its hard, stout tail and head are turned

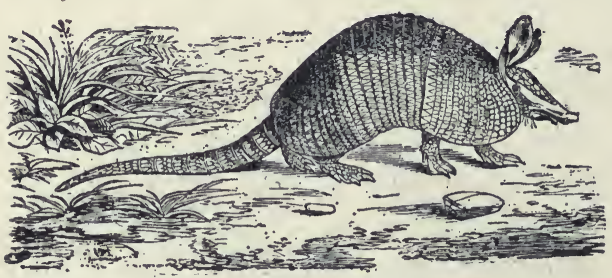

Fig. 365.- NiNE-BANDED ARMADILlo of Texas and Mexico. (Dasypus novemcinctus.) It is increasing in numbers; it is very useful, as it digs up and destroys insects. (See Fig. 347.) under to protect the lower side of the body where there are noscales. The three-banded species (Fig. 366) lives in Argentina. Compare the ears and tail of the two species; give reasons for differences. Why are the eyes so small? The claws so large? Order Why?

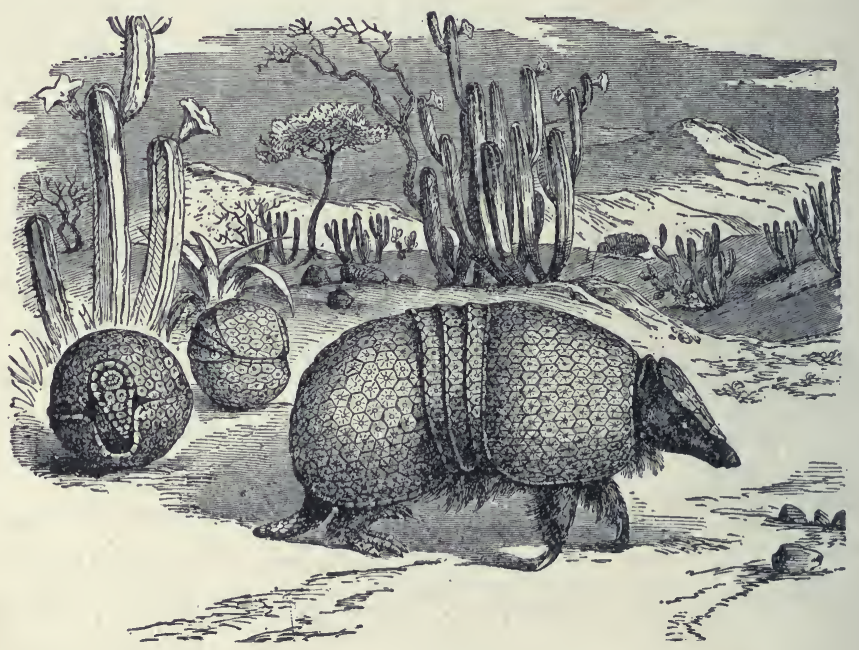

FIG. 366. - THREE-BANDED ARMADILLO (Tolypeutes tricinctus).

Insect Eaters. - The soft interior and crusty covering of insects makes it unnecessary for animals that prey upon them to have flat-topped teeth for grinding them to 
powder, or long cusps for tearing them to pieces. The teeth of insect eaters, even the molars (Fig. 368), have many sharp tubercles, or points, for holding insects and piercing the crusty outer skeleton and reducing it to bits. As most insects dig in the ground or fly in the air, we are not surprised to learn that some insect-eating mam-

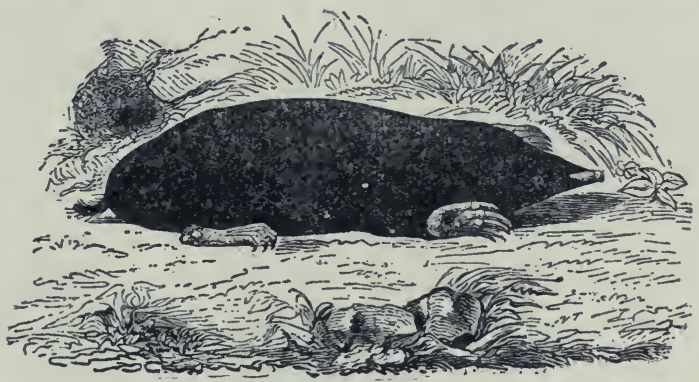

FIG. 367. - THE MOLE.

mals (the bats) fly and others (the moles) burrow. Are the members of this order friends or competitors of man?

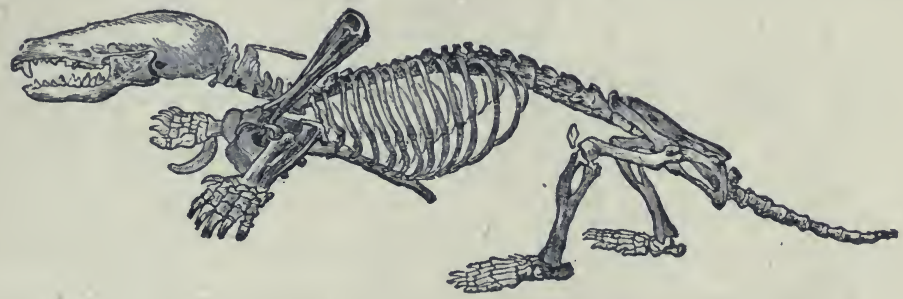

Fig. 368. - SkEleton OF MOLE. (Shoulder blade is turned upward.)

Why does the mole have very small eyes? Small ears? Compare the shape of the body of a mole and a rat. What difference? Why? Compare the front and the hind legs of a mole. Why are the hind legs so small and weak? Bearing in mind that the body must be arranged for digging and using narrow tunnels, study the skeleton 
(Fig. 368) in respect to the following: Bones of arm (length and shape), fingers, claws, shoulder bones, breastbone (why with ridge like a bird?), vertebræ (why are the first two so large?), skull (shape). There are no eye sockets, but there is a snout gristle; for the long, sensitive snout must serve in place of the small and almost useless eyes hidden deep in the fur. Is the fur sleek or rough? Why? Close or thin? It serves to keep the mole clean. The muscles of neck, breast, and shoulders are very strong. Why? The mole eats earthworms as well as insects. It injures plants by breaking and drying out their roots. Experiments show that the Western mole will eat moist grain, though it prefers insects. If a mole is caught, repeat the experiment, making a careful record of the food placed within its reach.

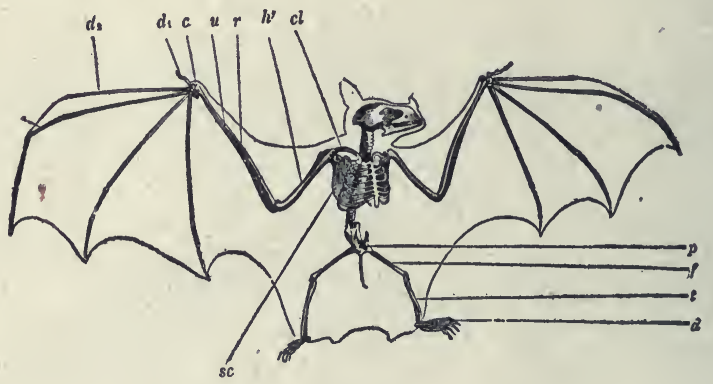

Fig. 369. - SKELETON OF BAT.

As with the mole, the skeletal adaptations of the bat are most remarkable in the hand. How many fingers? (Fig. 369.) How many nails on the hand? Use of nail when at. rest?, When creeping? (Fig. 369.) Instead of feathers, the flying organs are made of a pair of extended folds of the skin supported by elongated bones, which form a framework like the ribs of an umbrella or a fan. How many digits are prolonged? Does 


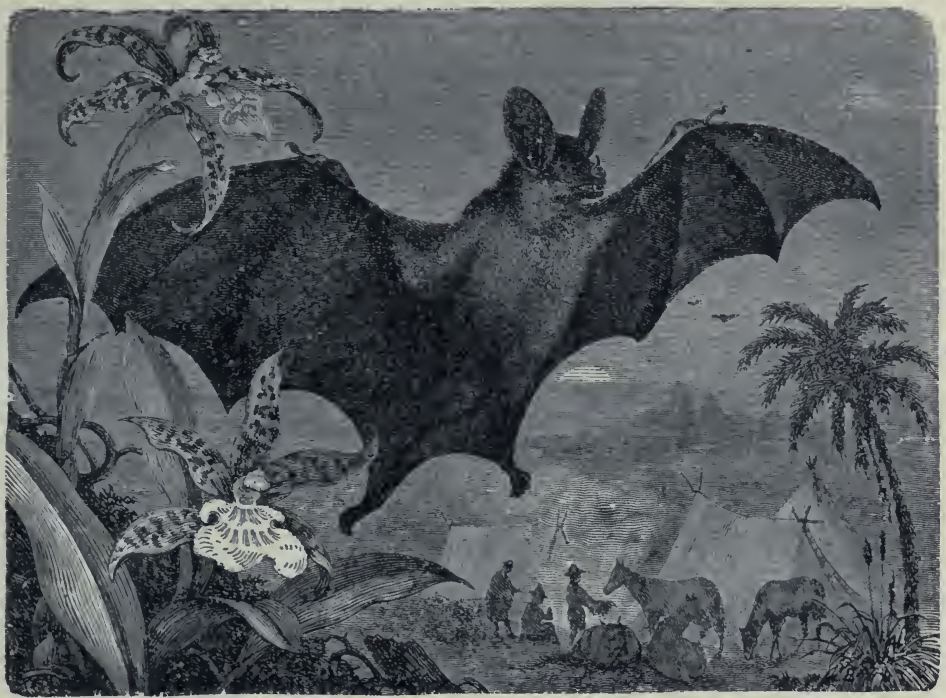

FIG. 370. - VÁMPIRE (Phyllostoma spectrum) of South America. $\times \frac{1}{6}$.

the fold of the skin extend to the hind legs? The tail? Are the finger bones or the palm bones more prolonged to form the wing skeleton?

The skin of the wing is rich in blood vessels and nerves, and serves, by its sensitiveness to the slightest current of air, to guide the bat in the thickest darkness. Would you judge that the bat has sharp sight? Acute hearing?

The moles do not hibernate; the bats do. Give the reason for the difference. If bats are aroused out of a trance-like condition in winter, they may die of starvation. Why? The mother bat carries the young about with her, since, unlike birds, she has no nest. How are the young nourished? Order

Why?

(Key, p. 193.)

The Gnawing Mammals. - These animals form the most numerous order of mammals. They lack canine teeth. Inference? The incisors are four in number in all species 
except the rabbits, which have six (see Fig. 345). They are readily recognized by their large incisors. These teeth grow throughout life, and if they are not constantly worn

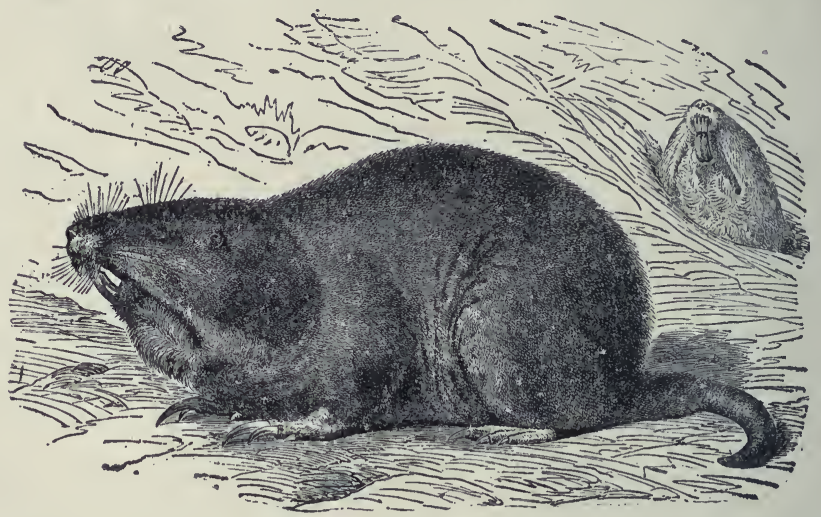

FIG. 37I. - POUCHED GoPHER (Geomys bursarius) $\times \frac{1}{4}$, a large, burrowing field rat, with cheek pouches for carrying grain.

away by gnawing upon hard food, they become incon. veniently long, and may prevent closing of the mouth and cause starvation. The hard enamel is all on the front surface, the dentine in the rear being softer; hence the incisors sharpen themselves by use to a chisel-like edge.

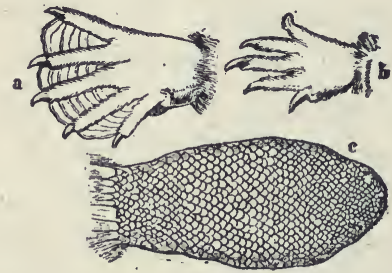

FiG. 372. - Hind foot $a$, fore foot $b$, tail $c$, of BEAVER.

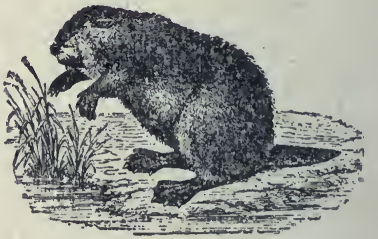

FIG. 373. - BEAVER.

The molars are set close together and have their upper surfaces level with each other. The ridges on them run crosswise so as to form a continuous filelike surface for 
reducing the food still finer after it has been gnawed off (Fig. 345). The lower jaw fits into grooves in place of sockets. This allows the jaw to work back and forth instead of sidewise. The rabbits and some squirrels have a hare lip; i.e. the upper lip is split. What advantage is this in eating? In England the species that burrow are called rabbits; those that do not are called hares.

Name six enemies of rabbits. Why does a rabbit usually sit motionless unless approached very close? Do you usually see one before it dashes off? A rabbit has from three to five litters of from three to six young each year. Squirrels have fewer and smaller litters. Why must the rabbit multiply more rapidly than the squirrel in order to survive? English rabbits have increased in Australia until they are a plague. Sheep raising is interfered with by the loss of grass.

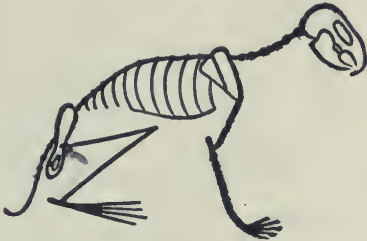

Fig. 374.- Position of LimbS IN RABBIT.

The Australians now ship them to England in cold storage for food. Rabbits and most rodents lead a watchful, timid, and alert life. An exception is the porcupine, which, because of the defence of its barbed quills, is dull and sluggish.

The common rodents are:-

squirrels beavers rabbits

rats

mice muskrats

porcupines

guinea pig pouched gopher prairie dog prairie squirrel

chipmunk

Which of th: above rodents are commercially important? Which are in urious to an important degree? Which have long tails? Why? Short tails? Why ? Long ears ? Why ? 
Short ears? Why? Which are aquatic? Which dig or burrow? Which are largely nocturnal in habits? Which are arboreal? Which are protected by coloration? Which escape by running? By seeking holes?

Economic Importance. - Rabbits and squirrels destroy the eggs and young of birds. Are rabbits useful? Do they destroy useful food? The use of beaver and muskrat skins as furs will probably soon lead to their extinction. Millions of rabbits' skins are used annually, the hair being made into

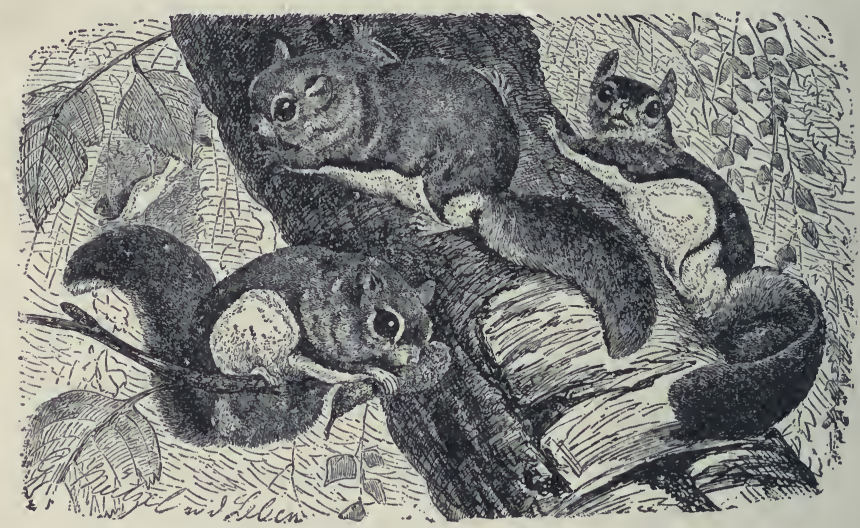

FIG. 375. - FLYING SQUIRREL (Pteromys volucella). $\times 1 / 4$.

felt hats. There are also millions of squirrel skins used in the fur trade. The hairs of the tail are made into fine paint brushes. The skins of common rats are used for the thumbs of kid gloves. Order

Elephants. - Elephants, strange to say, have several noteworthy resemblances to rodents. Like them, elephants have no canine teeth; their molar teeth are few, and marked by transverse ridges and the incisors present are prominently developed (Figs. 376, 377). Instead of four incisors, however, they have only two, the enormous tusks, for there are no incisors in the lower jaw. Elephants and rodents 
both subsist upon plant food. Both have peaceful dispositions, but one order has found safety and ability to survive by attaining enormous size and strength; the other (e.g. rats, squirrels) has found safety in small size. Explain.

Suppose you were to observe an elephant for the first time, without knowing any of its habits. How would you know that it does not eat meat? That it does eat plant food? That it can defend it-

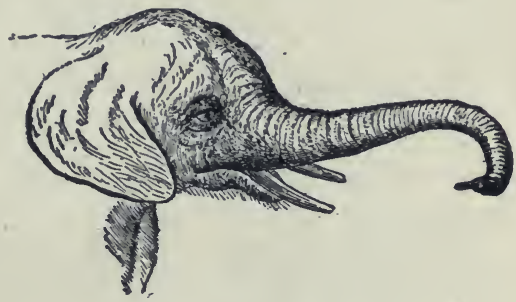

Fig. 376. - HeAd of African Elephant.

self? Why would you make the mistake of thinking that it is very clumsy and stupid? Why is its skin naked? Thick? Why must its legs be so straight? Why must it have either a very long neck or a substitute for one? (Fig. 376.) Are the eyes large or small? The ears? The brain cavity? What anatomical feature correlates with the long proboscis? Is the proboscis a new organ not found in other animals, or is it a specialization of one or more old ones? Reasons? What senses are especially active in the proboscis? How is it used in drinking? In

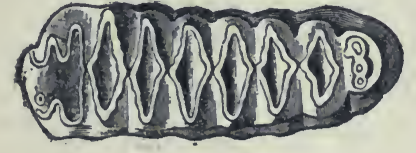

Fig. 377. - MOLAR TOOTH OF AFrican ELEPHANT. grasping? What evidence that it is a development of the nose? The upper lip?

The tusks are of use in uprooting trees for their foliage and in digging soft roots for food. Can the elephant graze? Why, or why not? There is a finger-like projection on the end of the snout which is useful in delicate manipulations. The feet have pads to prevent jarring; the nails are short and hardly touch the ground. Order

Why? Key, page 193. 
Whales, Porpoises, Dolphins. - As the absurd mistake is sometimes made of confusing whales with fish, the pupil may compare them in the following respects: eggs, nourishment of young, fins, skin, eyes, size, breathing, temperature, skeleton (Figs. 209, 379, and 397).

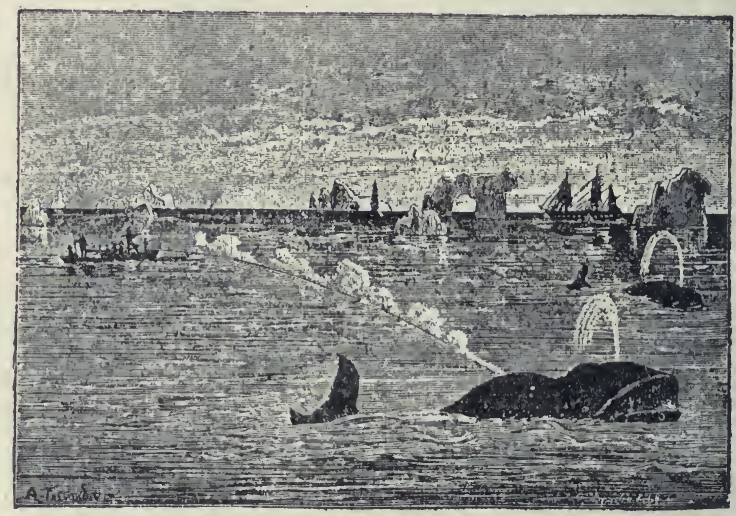

Fig. 378. - Harpooning Greenland Whale (see Fig. 35I).

Porpoises and dolphins, which are smaller species of whales, live near the shore and eat fish. Explain the expression "blow like a porpoise." They do not exceed five or eight feet in length, while the deep-sea whales are from thirty to seventy-five feet in length, being by far the largest animals in the world. The size of the elephant is limited by the weight that the bones and muscles support and move. The whale's size is not so limited.

The whale bears one young (rarely twins) at a time. The mother carefully attends the young for a long time. The blubber, or thick layer of fat beneath the skin, serves to retain heat and to keep the body up to the usual temperature of mammals in spite of the cold water. It also serves, along with the immense lungs, to give lightness to the body. 
Why does a whale need large lungs? The tail of a whale

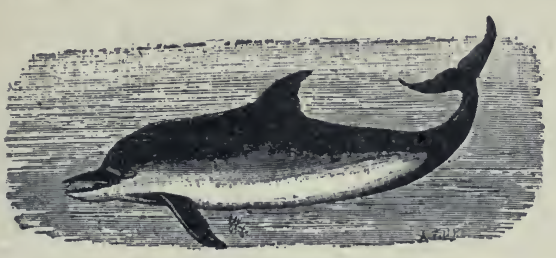

FIG. 379. - DOLPHIN. is horizontal instead of vertical, that it may steer upward rapidly from the depths when needing to breathe. The teeth of some whales do not cut the gum, but are reabsorbed and are replaced by horny plates of "whalebone," which act as strainers. Give evidence, from the flippers, lungs, and other organs, that the whale is descended from a land mammal (Fig. 397). Compare the whale with a typical land mammal, as the dog, and enumerate the specializations of the whale for living in water. What change took place in the general form of the body? It is believed that on account of scarcity of food the land ancestors of the whale, hundreds of thousands of years ago, took to living upon fish, etc., and, gradually becoming swimmers and divers, lost the power of locomotion on land. Order

Why?

Elephants are rapidly becoming extinct because of the value of their ivory tusks. Whales also furnish valuable products, but they will probably exist much longer. Why?

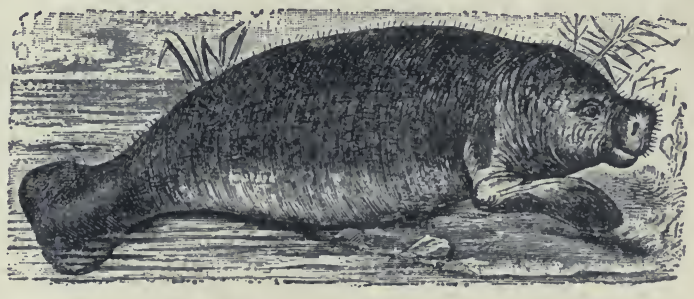

FIG. 380. - MANATEE, or sea cow; it lives near the shore and eats seaweed. (Florida to Brazil.)

The manatees and dugongs (sea cows) are a closely related order living upon water plants, and hence living close to shore and in the mouths of rivers. Order . Why? _... 
Hoofed Mammals. - All the animals in this order walk on the tips of their toes, which have been adapted to this use by the claws having developed into hoofs. The order is subdivided into the odd-toed (such as the horse with one toe and the rhinoceros with three) and the cven-toed (as the ox with two toes and the pig with four). All the eventoed forms except the pig and hippopotamus chew the cud and are given the name of ruminants.

Horse and Man Compared. - To which finger and toe on man's hand and foot does a horse's foot correspond?

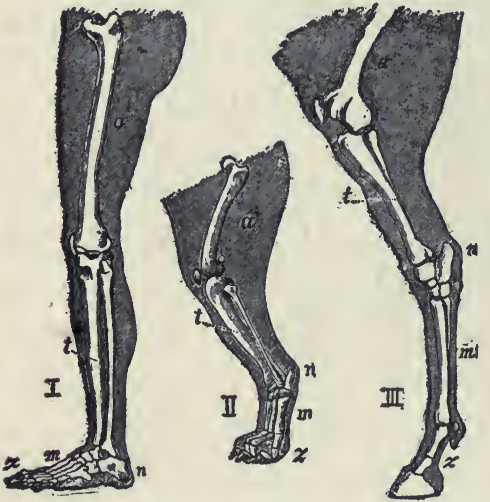

FIG. 38r. - Left leg of man, left hind leg of dog and horse; homologous parts lettered alike.

(Figs. 381, 383, 399.) Has the horse kneecaps? Is its heel bone large or small? Is the fetlock on toe, instep, or ankle? Does the part of a horse's hind leg that is most elongated correspond to the thigh, calf, or foot in man? On the fore leg, is the elongated part the upper arm, forearm, or hand? (Figs. 395, 399.) Does the most elongated part of the fore foot correspond to the finger, the palm, or the wrist? (Fig. 382.) On the hind foot is it toe, instep, or ankle? Is the fore fetlock on the finger, the palm, or the wrist? (Figs. 382, 385, 399.) Is the hock at the toe, the instep, the heel, or the knee?

Specializations of the Mammals. - The early mammals, of which the present marsupials are believed to be typical, had five toes provided with claws. They were not very rapid in motion nor dangerous in fight, and probably ate both animal and vegetable food. 


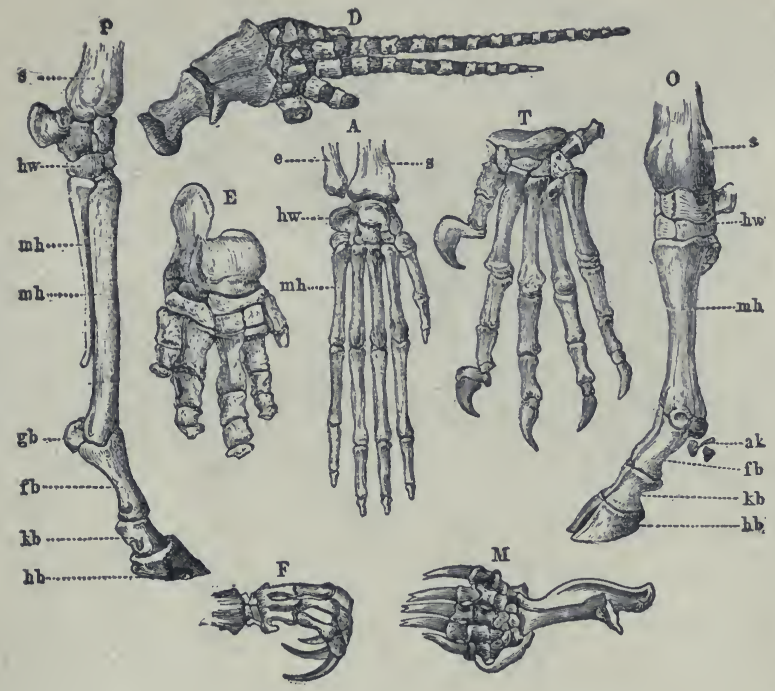

Fig. 382. - Skeletons OF FEeT OF MAMMALS.

$P$, horse; $D$, dolphin; $E$, elephant; $A$, monkey; $T$, tiger; $O$, aurochs: $F$, sloth; $M$, mole.

Question: Explain how each is adapted to its specialized function.

According to the usual rule, they tended to increase faster than the food supply, and there were continual contests for food. Those whose claws and teeth were sharper drove the others from the food, or preyed upon them. Thus the specialization into the bold flesh eating beasts of prey and the timid vegetable feeders began. Which of the flesh eaters has already been studied at length? The insectivora escaped their enemies and found food by learning to burrow

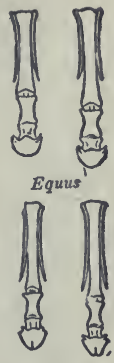

Prọtohippus]
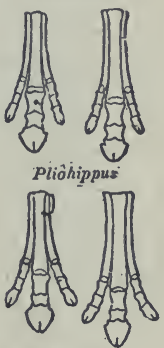

Mlohippus

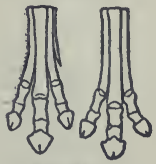

Mesohippus?

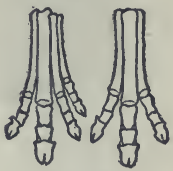

Orohippus.

Fig. 383.Feet of the ancestors of the horse. or fly. The rodents accomplished the same result either by acquiring great agility in climbing, or by living in holes, or by running. The proboscidians acquired enormous size and strength. The hoofed animals found safety in flight. 


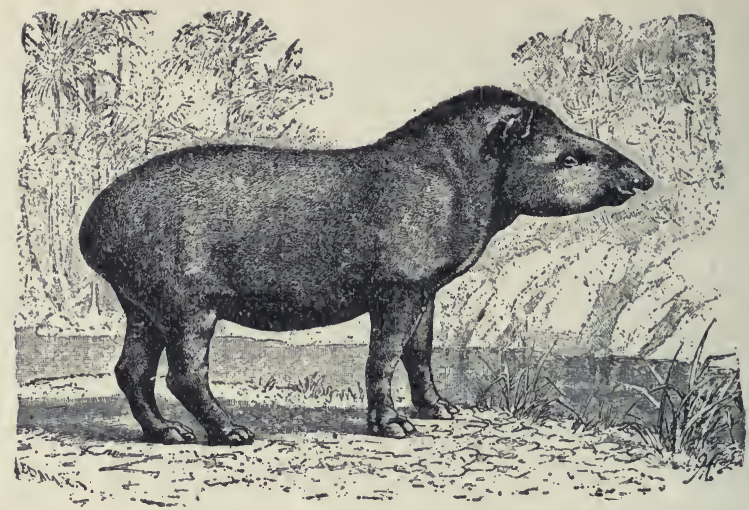

FIG. 384 - - TAPIR OF SOUTH AMERICA (Tapirus americanus). $\times$ šb. Questions: How does it resemble an elephant? (Fig. 376.) A horse? (p. 210.)

Ungulates, as the horse, need no other protection than their great speed, which is due to lengthening the bones of

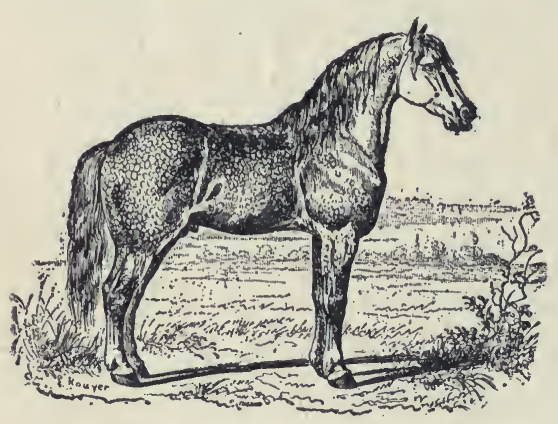

FIG. 385. - HoRSE, descended from a small wild species still found in Western Asia. the legs and rising upon the very tip of the largest toe, which, to support the weight, developed an enormous toe-nail called a hoof. The cattle, not having developed such speed as the horse, usually have horns for defence. If a calf or cow bellows with distress, all the cattle in the neighbourhood rush to the rescue. This unselfish instinct to help others was an aid to the survival of wild cattle living in regions infested with beasts of prey. Which of Æsop's fables is based upon this instinct? The habit of rapid grazing and the correlated habit of chewing the cud were also of great value, as it enabled cattle to obtain grass hur- 
riedly and to retire to a safe place to chew it. Rudiments of the upper incisors are present in the jaw of the calf, showing the descent from animals which had a complete set of teeth. The rudiments are absorbed and the upper jaw of the cow lacks incisors entirely, as they would be useless beçause of the cow's habit of seizing the grass with her rough töngue and cutting it with the lower incisors as the head is jerked forward. This is a more rapid way of eating than by biting. Which leaves the grass shorter

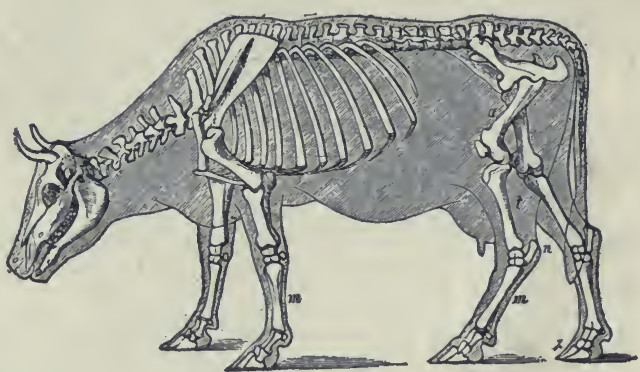

FIG. 386.-Skeleton of Cow. Compare with horse (Fig. 395) as to legs, toes, tail, mane, dewlap, ears, body.

after grazing, a cow or a horse? Why? Grass is very slow of digestion, and the ungulates have an alimentary canal twenty to thirty times the length of the body. Thorough chewing is necessary for such coarse food, and the ungulates which chew the cud (ruminants) are able, by leisurely and thorough chewing, to make the best use of the woody fibre (cellulose) which is the chief substance in their food.

Ruminants have four divisions to the stomach. Their food is first swallowed into the roomy paunch in which, as in the crop of a bird, the bulky food is temporarily stored. It is not digested at all in the paunch, but after being moistened, portions of it pass successively into the honeycomb, which forms it into balls to be belched up and ground by the large molars as the animal lies with eyes half closed under the shade of a tree. It is then swal- 
lowed a second time and is acted upon in the third division (or manyplies) and the fourth division (or reed). Next

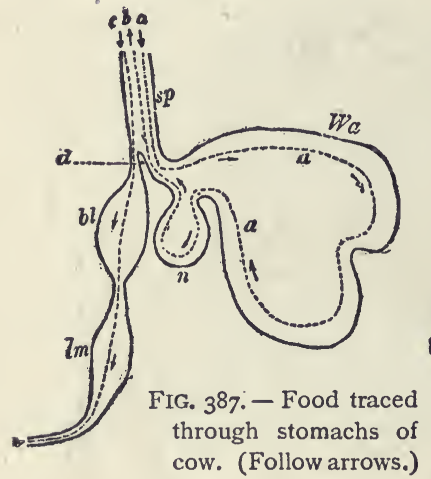

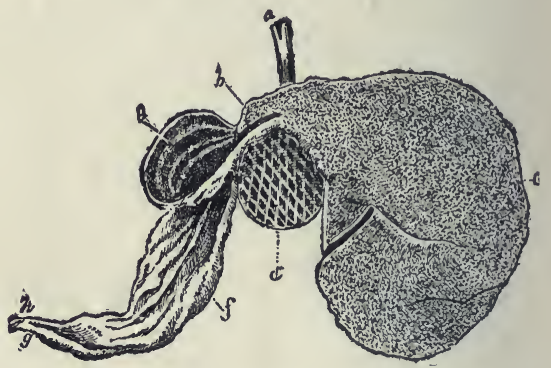

FIG. 388. - Section of cow's stomachs. Identify each. (See text.)

it passes into the intestine. Why is the paunch the largest compartment? In the figure do you recognize the paunch by its size? The honeycomb by its lining? Why is it

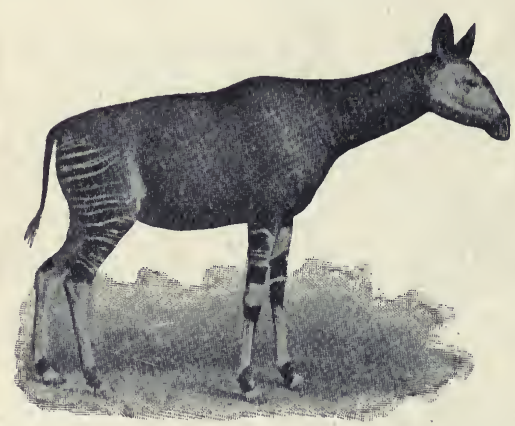

FIG. 389. - OKAPI. This will probably prove to be the last large mammal to be discovered by civilized man. It was found in the forests of the Kongo in Igoo. giraffe, deer, and zebra. It is a ruminant ungulate (explain meaning - see text).
Questions: It shows affinities (find them) with

round? The last two of the four divisions may be known by their direct connection with the intestine.

The true gastric juice is secreted only in the fourth stomach. Since the cud or unchewed food is belched up in balls from the round "honeycomb," and since a ball of hair is sometimes found in the stomach of ruminants, some ignorant people make the absurd mistake of calling the ball of hair the cud. This ball accumulates in the paunch 
because of the friendly custom cows have of combing each other's hair with their rough tongues, the hair sometimes

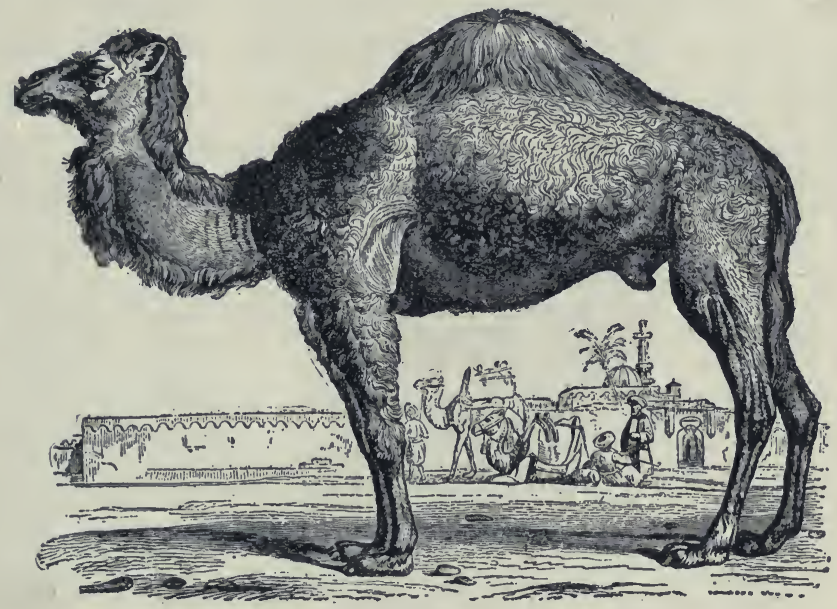

FIG. 390. - AFRICAN CAMEL (Camelus dromedarius).

being swallowed. Explain the saying that if a cow stops chewing the cud she will die.

Does a cow's lower jaw move sidewise or back and forth? Do the ridges on the molars run sidewise or lengthwise? Is a cow's horn hollow? Does it have a bony core? (Fig. 344.)

The permanent hollow horns of the cow and the solid deciduous horns of the deer are typical of the two kinds of horns possessed by ruminants. The prong-horned antelope (Fig. 39I) of

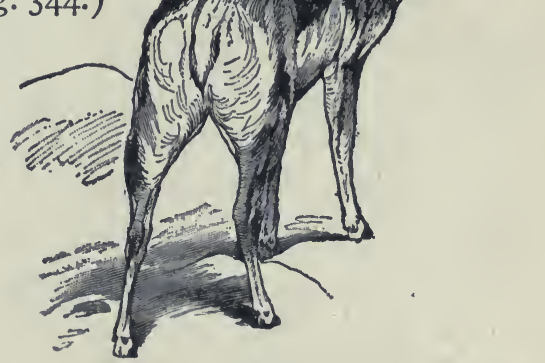

FIG. 391. - PRONG-HORNED ANTELOPE (Antelocarpa Americana). 
the United States, however, is an intermediate form, as its horns are hollow, but are shed each year. The hollow horns are a modification of hair. Do solid or hollow horns branch? Which are possessed by both sexes? Which are pointed? Which are better suited for fighting? Why would the deer have less need to fight than the cattle? Deer are polygamous, and the males use their

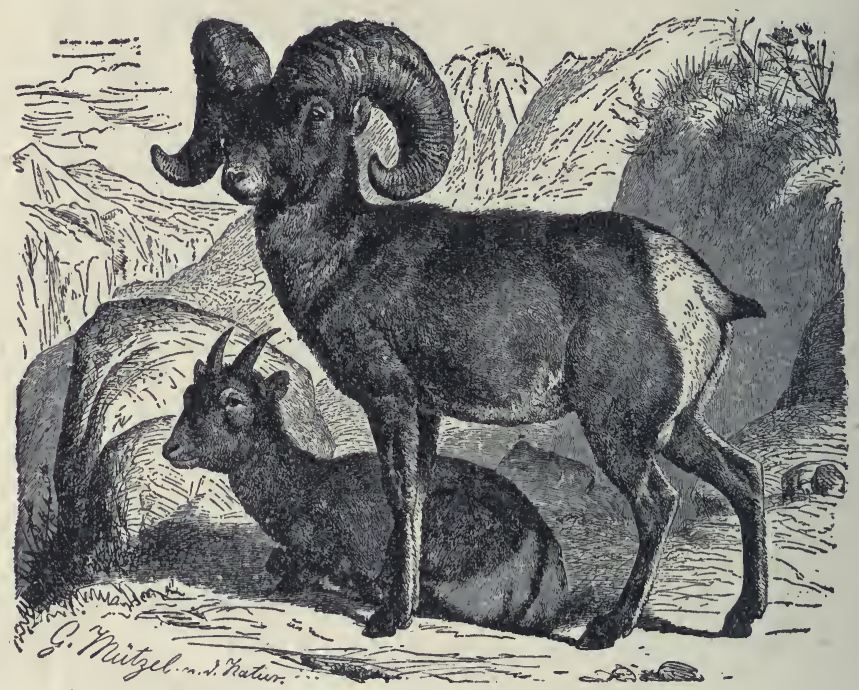

FIG. 392. - Rocky MOUNTAIN SheEP (Ovis montana). $\times \frac{2}{24}$.

horns mostly for fighting one another. The sharp hoofs of deer are also dangerous weapons. The white-tail deer (probably the same species as the Virginian red deer) is the most widely distributed of the American deer. It keeps to the lowlands, while the black-tailed deer prefers a hilly country. The moose, like the deer, browses on twigs and leaves. The elk, like cattle, eats grass.

The native sheep of America is the big horn, or Rocky Mountain sheep (Fig. 392). The belief is false that they 
alight upon their horns when jumping down precipices. They post sentinels and are very wary. There is also a native goat, a white species, living high on the Rocky Mountains near the snow. They are rather stupid animals. The bison once roamed in herds of countless thousands, but, with the exception of a few protected in parks, it is now extinct. Its shaggy hide was useful to man in winter, so it has been well-nigh destroyed. For gain man is led to exterminate elephants, seals, rodents, armadillos, whales, birds, deer, mussels, lobsters, forests, etc.

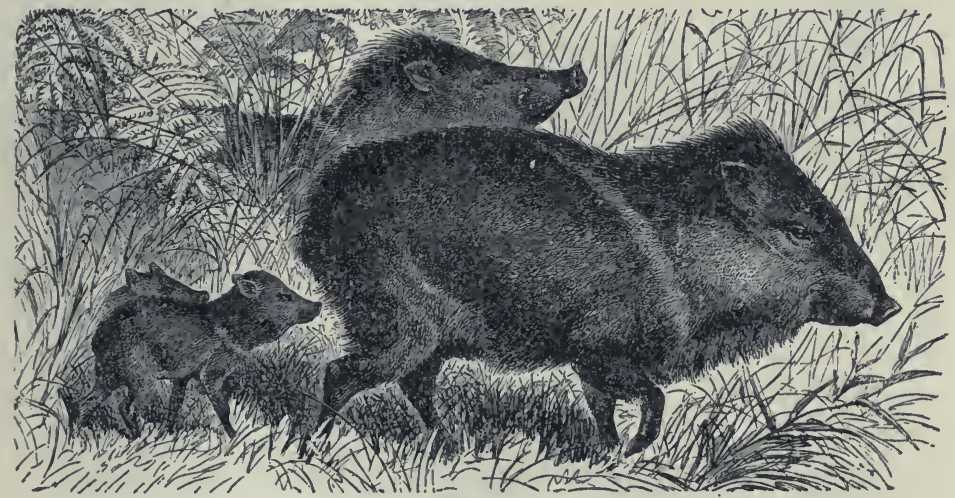

Fig. 393. - PECCARy (Dicotyles torquatus) of Texas and Mexico. $\times \frac{1}{12}$

Our only native hog is the peccary, found in Texas (Fig. 393). In contrast with the heavy domestic hog, it is slender and active. It is fearless, and its great tusks are dangerous weapons. The swine are the only ungulates that are not strictly vegetable feeders. The habit of fattening in summer was useful to wild hogs, since snow hid most of their food in winter. The habit has been preserved under domestication. Are the small toes of the hog useless? Are the "dew claws" of cattle useless? Will they probably become larger or smaller? Order? 


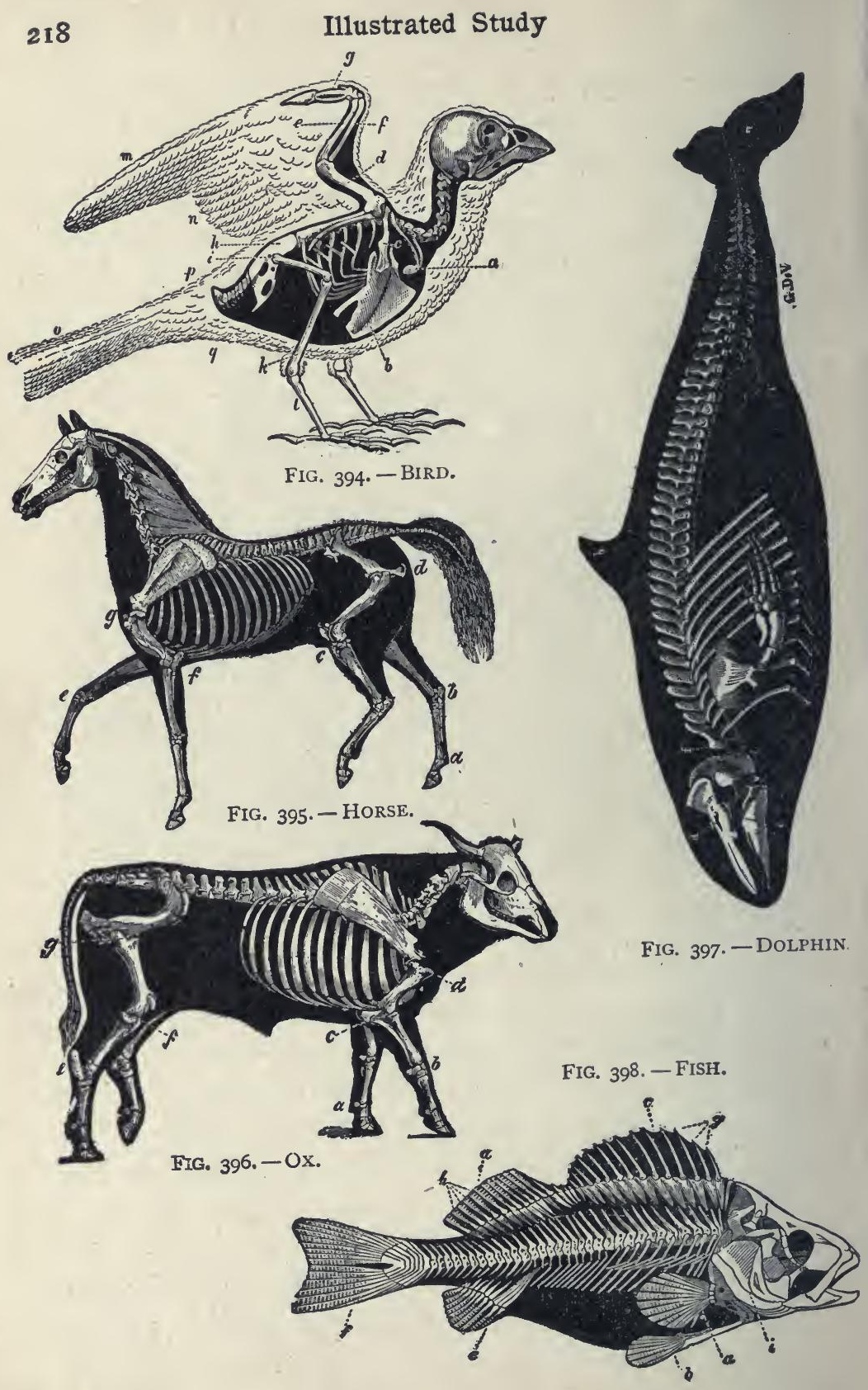




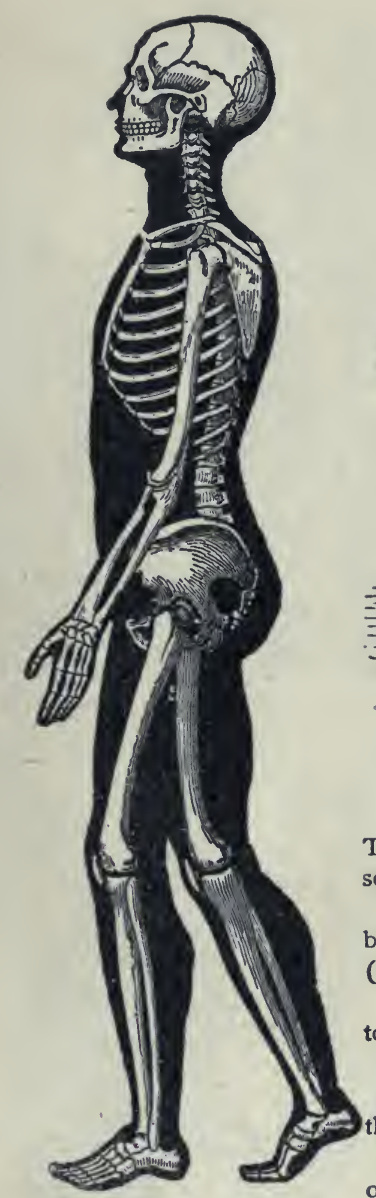

FIG. 399. - MAN.

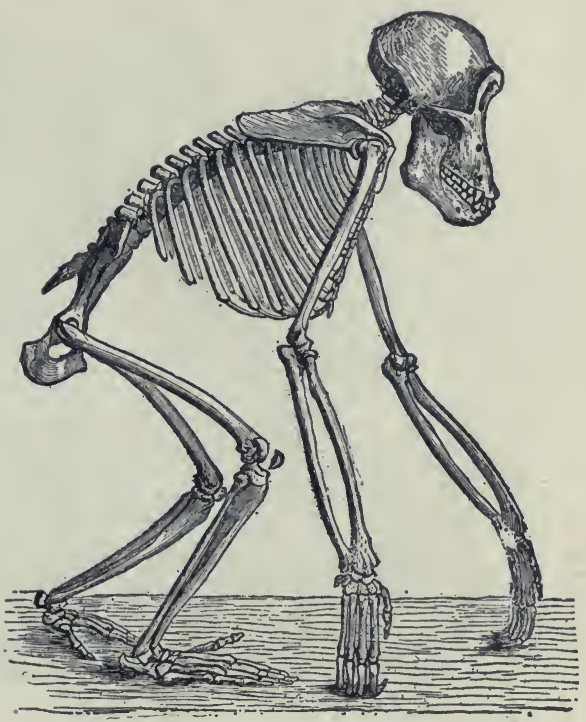

Fig. 400.-ChimpanzeE. (See Fig. 406.)

Illustrated Study of Vertebrate Skeletons: Taking man's skeleton as complete, which of these seven skeletons is most incomplete?

Regarding the fish skeleton as the original vertebrate skeleton, how has it been modified for (I) walking, (2) walking on two legs, (3) flying ?

Which skeleton is probably a degenerate reversion to original type? (p. 209.)

How is the horse specialized for speed?

Do all have tail vertebræ, or vertebræ beyond the hip bones? Does each have shoulder blades?

Compare ( $\mathrm{r}$ ) fore limbs, (2) hind limbs, (3) jaws of the seven skeletons. Which has relatively the shortest jaws? Why? What seems to be the typical number of ribs? limbs? digits?

Does flipper of a dolphin have same bones as arm of a man ?

How many thumbs has a chimpanzee.? Which is more specialized, the foot of a man or that of a chimpanzee? Is the foot of a man or that of a chimpanzee better suited for supporting weight? How does its construction fit it for this?

Which has a better hand, a man or a chimpanzee? What is the difference in their arms? Does difference in structure correspond to difference in use ?

Which of the seven skeletons bears the most complex breastbone?

Which skeleton bears no neck (or cervical) vertebræ? Which bears only one? Are all the classes of vertebrates represented in this chart? (p. 125.) 


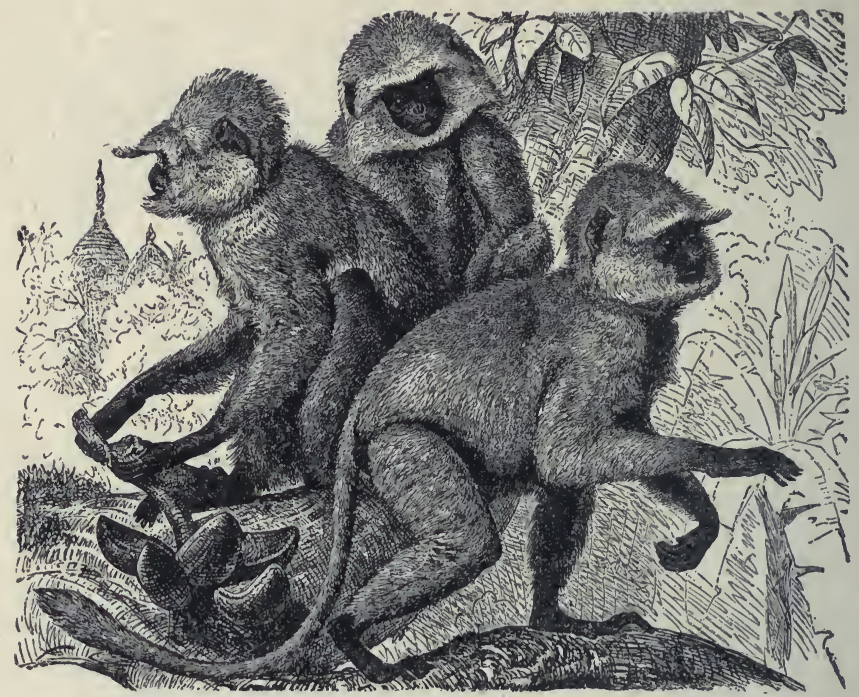

Fig. 40I. - SACRED MONKEY OF INDIA (Semnopithecus entellus). $\times \frac{1}{12}$.

Monkeys, Apes, and Man. Study the figures $(399,400)$; compare apes and man and explain each of the differences in the following list : ( $\mathrm{I}$ ) feet, three differences; (2)arms; (3) brain case; (4) jaws ; (5) canine teeth ; (6) backbone ; (7) distance between the eyes.

$A$ hand, unlike a foot, has one of the digits, called a thumb, placed opposite the other four digits that it may be used in grasping. Two-handed man and four-handed apes and monkeys are usually placed in one order, the Primates, or

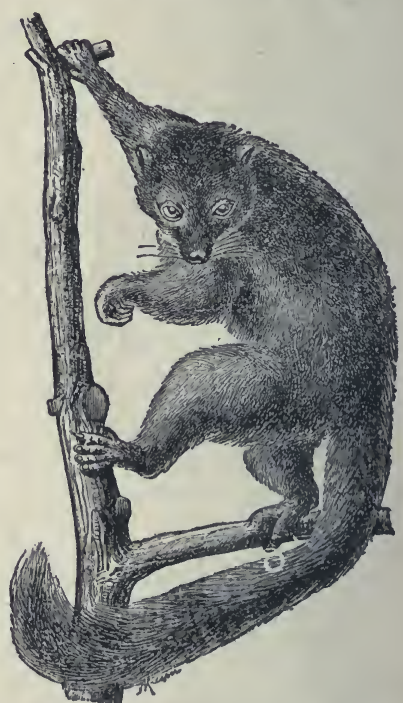

FIG. 402. - Lemur (Lemur Mono goz). $\times \frac{1}{y}$. Which digit bears a claw? 
in two orders (see table, page 193). The lowest members of this order are the lemurs of the old world. Because of

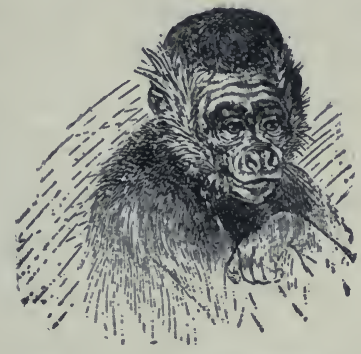

FIG. 4O3. - BROAD-NOSED

MONKEY. $\times \frac{\text { ro }}{10}$. America.

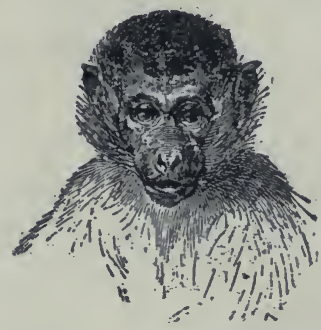

FIG. 404. - NARROW-NOSED

MONKEY. $\times \frac{1}{12}$. Old World.

their hands and feet being true grasping organs, they are placed among the primates, notwithstanding the long muzzle and expressionless, foxlike face. (Fig. 402.) Next in order are the tailed monkeys, while the tailless apes are the highest next to man.

The primates of the Nere World are all monkeys with long tails and broad noses. They are found from Paraguay to Mexico. The monkeys and apes of the Old World have a thin partition between the nostrils, and are thus distinguished from the

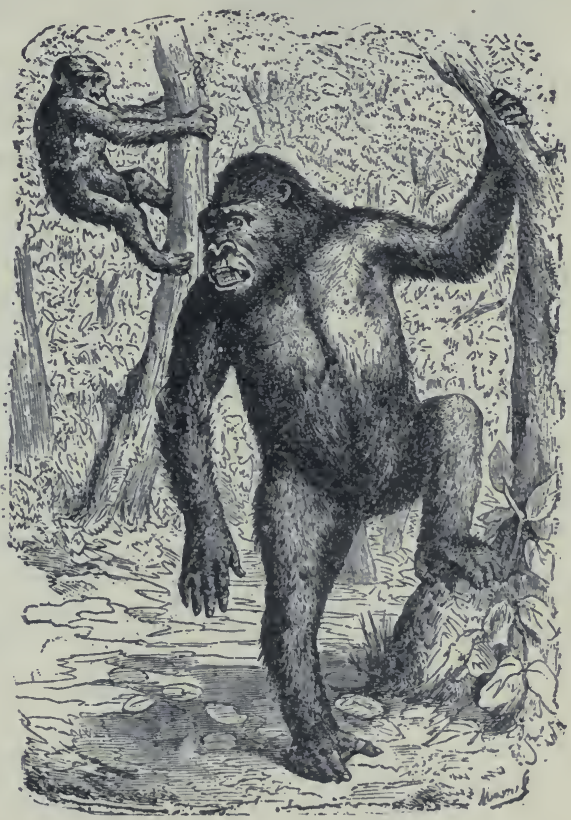

Fig. 405. - GoRILla. (Size of a man.) 
monkeys of the New World, which have a thicker partition and have a broader nose. (Figs. 403, 404.) The monkeys of America all have six molar teeth in each half jaw (Fig. 352); the monkeys and apes of the Old World have thirty-two teeth, which agree both in number and arrangement with those of man.

Which of the primates figured in this book appear to have the arm longer than the leg? Which have the

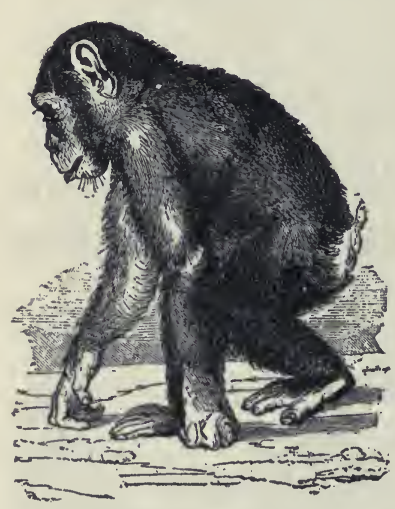

FIG. 406. - CHIMPANZEE. eyes directed forward instead of sideways, as with cats or dogs? Nearly all the primates are forest dwellers, and inhabit warm countries, where the boughs of trees are never covered with ice or snow. Their ability in climbing serves greatly to protect them from beasts of prey. Many apes and monkeys are able to assume the upright position in walking, but they touch the ground with their knuckles every few steps to aid in preserving the balance.

The Simians are the highest family of primates below man, and include the gorilla, chimpanzee, orang, and gibbon. Some of the simians weave together branches in the treetops to form a rude nest, and all are very affectionate and devoted to their young. How are apes most readily distinguished from monkeys? (Figs. 40I, 406.) 
Fig. 407.-ANATOMY OF RABbit.

$a$, incisor teeth;

$b, b^{\prime}, b^{\prime \prime}$, salivary glands:

$k$, larynx:

l, windpipe;

$c$, gullet;

d, diaphragm (possessed only by mammals);

e, stomach;

$g$, small intestine;

$h, h^{\prime}$, large intestine;

$f$, junction of small and large intestine;

$g, g^{\prime}$, cæcum, or blind sac from $f \quad b$, cerebrum: (corresponds to the shrunken rudimentary vermiform appendix in man); $m$, carotid arteries:

$n$, heart;

0 , aorta;

$p$, lungs:

$q$, end of sternum; $r$, spleen;

$s$, kidney:

$t$, ureters (from kidney to bladder $v$ ).

2. brain of rabbit: $a$, olfactory nerves;

$c$, midbrain; $d$, cerebellum.

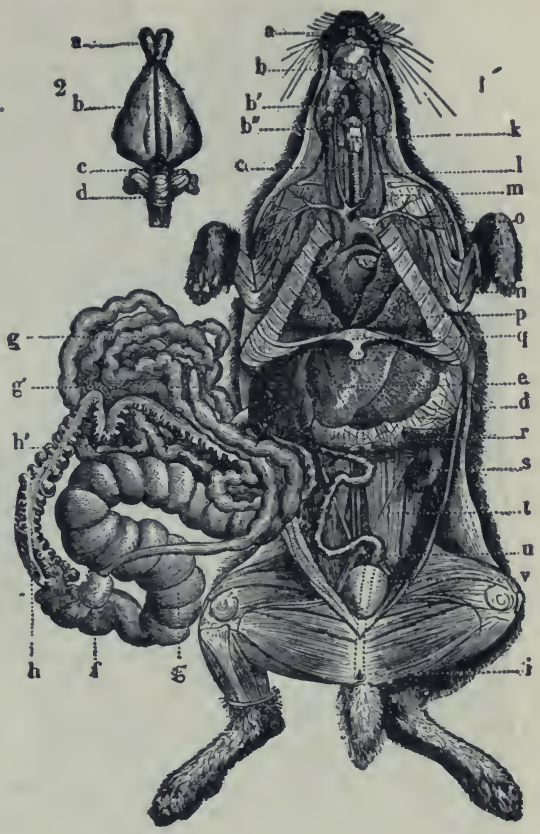

Table for Review

\begin{tabular}{|c|c|c|c|c|c|c|c|}
\hline$x_{1}$ & FISH & FroG & TýRTLI: & Dird & $\mathrm{CAT}_{\mathrm{AT}}$ & Horse & MAN \\
\hline \multicolumn{8}{|l|}{ Names of limbs } \\
\hline Acutest sense & & & & & & & 11 \\
\hline \multicolumn{8}{|c|}{$\begin{array}{l}\text { Digits on fore } \\
\text { and hind limb }\end{array}$} \\
\hline \multicolumn{8}{|l|}{ Locomotion } \\
\hline \multicolumn{8}{|l|}{ Kind of food } \\
\hline Care of young & & & & & & & \\
\hline
\end{tabular}




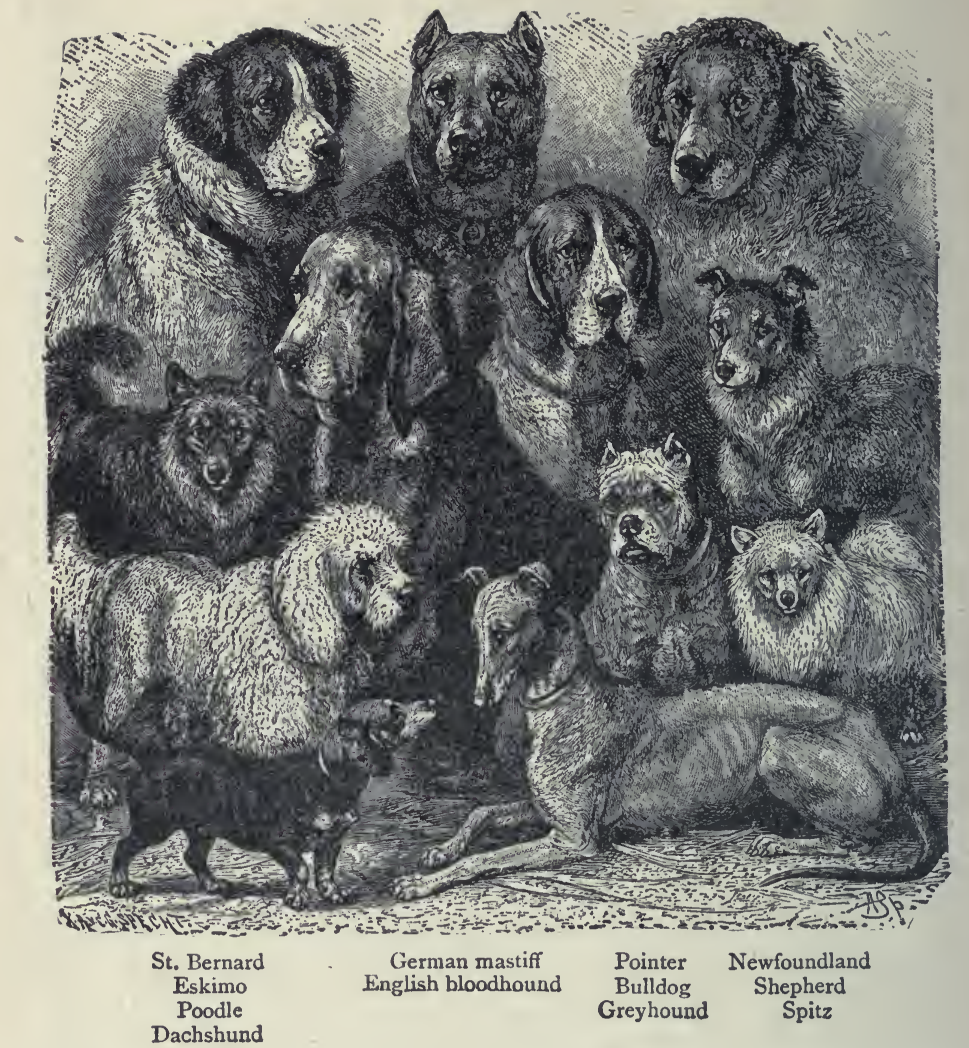

Fig. 408. - ARtificial Selection. Its effects in causing varieties in one species. Which of the dogs is specialized for speed? Driving cattle ? Stopping cattle ? Trailing by scent? Finding game? Drawing vehicles? Going into holes? House pet? Cold weather? In Mexico there is a hairless dog specialized for hot climates. The widely differing environments under various forms of domestication cause "sports" which breeders are quick to take advantage of when wishing to develop new varieties. Professor De Vries by cultivating American evening primroses in Europe has shown that a sudden change of environ:ment may cause not only varieties but new species to arise. 


\section{INDEX}

Aboral surface, 35 .

Acephala, 107.

Breathing, of bird, 161; of in sect, 76.

Adaptation to environment, 148, Bureau of entomology, 95 .

185, 201, 205, 207.

Ambulacral, 36.

Amœba, 10.

Anadon, 98.

Antelope, 215.

Antennæ, 68, 87.

Ant-eater, giant, 199; spiny, 196.

Ant-lion, 91.

Ape, 220.

Aptera, 82.

Apteryx, 174.

Aquarium, 17.

Argonaut, paper, 107.

Armadillo, 200.

Arthropoda, 9, 125.

Bat, 202.

Batrachia, 126.

Beaver, 204.

Bedbug, 92, 93.

Bee, bumble, 89; honey, 88.

Beetle, 90, 91.

Big-headed turtle, 149.

Bilateral, 34, 49, 98.

Bill of bird, 151.

Biology defined, 1.

Birds, 150.

Blood, of insects, 78.

Boll weevil, 95, 96.

Boll worm, 95, 96.

Brain, of fish, 118 .

Butterfly, 83.

Cabbage butterfly, 84, 86, 87.

Camel, 214.

Candle, 5.

Carbon, dioxide, 24.

Carp, 112, 117, 123.

Cat, 184.

Caterpillar, tent, 84.

Cell, 6, 7.

Celom, 46.

Cephalopod, 106.

Chelonia, 143.

Chimpanzee, 219, 221.

Chirping, 66.

Chitin, 77.

Cilia, 14, 20, 101, 103.

Ciliated chamber, 17.

Circulation, in aınœba, 12; in insect, 77; in fish, 117.

Clam, hardshell, 104; softshell, 104.

Class, 9.

Classification, of animals, 8, 125; of birds, 177; insects, 82; mammals, 193.

Click-beetle, 91 .

Clitellum, 43, 47.

Cloaca, 18.

Clothes moth, 84, 92, 93.

Cockroach, 71. 
Cocoon, 84.

Codling moth, 84, 86, 87, 95.

Cœlenterata, 28.

Coleoptera, 82.

Collecting insects, 72 .

Colorado beetle, 90,91 .

Coloration, warning, 84, 146; pro. tective, 34, 37, 49.

Colours of flowers, 85.

Comparative study, $85,108,122$, 223 ; moth and butterfly, 85 .

Copper head, 145.

- Coral, 31.

Coralline, 31.

Coral snake, 145, 146.

Cricket, 71.

Cross-fertilization, 25.

Cuckoo, 179.

Cuttlefish, 107.

Cypræa, 104.

Cysts, 13.

Darwin, 48, 148.

Devil's horse, 71.

De Vries, 148, 224.

Digits, 222.

Diptera, 82.

Division of labour, 27, 29.

Dog, 224.

Dolphin, 209.

Doodle bug, 91.

Dorsal, 43.

Dove, 179.

Dragon fly, 93.

Duckbill, 196.

Ear, of bird, 151; of frog, 131; of fish, 112.

Earthworm, 42.

Echinoderms, 9, 34, 125.

Economic importance of birds, 167 ; insects, 9.3; molluscs, 105; rodents, 206.

Ectoderm, 26, 87.

Ectoplasm, 11, 14.

Egg, of insect, 81.

Endolerm, 26, 27, 37.

Endoplasm, 11, 14.

Energy, in amœba, 12; organic, 2,3 ; plant, $2,3,5$.

Environment, 148.

Epidermis, of mussel, 98.

Excretion, 12.

Eye, of bird, 150; of frog, 30 ; of grasshopper, 67, 79; of fish, 111.

Family, 8.

Fangs, venomous, 145.

Farmers' bulletins, 95 .

Feather, 155.

Fertilization, cross, 85 .

Field study, 10, 22, 42, 71, 72, 97, 127, 165, 166, 167, 184.

Fins, 110, 113.

Flagellum, 21, 27.

Flatworm, 49.

Flea, 92, 93.

Flight, of bird, 157, 175; of moth, 84.

Fly, horse, 81 ; house, 92, 93.

Food, of birds, 177.

Food tube, of bird, 163; of fish, 116; of insect, 76; of mussel, 102.

Foraminifera, 15, 18.

Frog, 128.

Function, 1.

Ganglion, 45.

Gasteropod, 108.

Gastrula, 7.

Genus, 8.

Geographical barriers, 148.

Gila monster, 147. 
Gills, of mussel, 100; of fish, 115. Lady bug, 91.

Gnawing mammals, 203.

Gopher, pouched, 204.

Gorilla, 221.

Grantia, 18.

Grasshopper, 70.

Gypsy moth, 95.

Hands, defined, 220.

Heart, insect, 77.

Hemiptera, 82.

Heredity, 147, 153.

Hessian fly, 95.

Horned toad, 140.

House fly, 92, 93.

Human species, 220.

Hydra, 22.

Hydranth, 29.

Hydroid, 28, 29, 30.

Hymenoptera, 82.

Hypostome, 23.

Ichneumon fly, 89.

Imago, 81.

Infusoria, 16.

Inorganic, 1.

Insecticides, 95.

Insects, 73, 75; biting, 82 ; classified, 82 ; sucking, 82 .

lnstinct, 80, 121.

Jacana, Mexican, 178.

Jay, blue, 181.

Jelly fish, 29, 30.

Kangaroo, 198.

Kidneys, of fish, 117; of insects, 76 ; of mussel, 102 ; of worm, 45.

Labial palpi, 68, 74, 101.

Labium, 68, 74.

Labrum, 68, 74.

Lamellibranch, 107 .

Lark, meadow, 182 ; sky, 179.

Larva, 81.

Lasso cell, 34.

Leg, of bird, 152; of horse, 210 ; of insect, 74.

Lemur, 220.

Lepidoptera, 82, 87.

Louse, 92, 93.

Lungs, of bird, 165.

Madreporite, 35.

Mammal, 184; classified, 193; defined, 189.

Manatee, 209.

Mandibles, 68, 74.

Mantis, praying, 3 .

Mantle, 99.

Maxillæ, 68, 74.

Maxillary palpi, 68, 74.

May beetle, 90, 91.

May fly, 83.

Measuring worm, 81,84 .

Medusa, 31.

Mesoglea, 26.

Metamorphosis of insect, 80,81 , 82.

Metazoan, 1.

Migration of birds, 171, 173.

Mimicry, 146.

Moccasin, 145.

Mole, 201.

Mollusc, 9, 97, 125.

Moulting, 69, 174.

Monkey, 220.

Morula, 7.

Mosquito, 92, 93, 96.

Moth, 83.

Mother-of-pearl, 99.

Mussel, 96, 103. 
Nautilus, chambered, 107.

Nectar, 8.

Nephridium, 45.

Nervous system, of $\cdot$ bee, 78 ; of mussel, 102.

Nest building, 166, 182.

Neuroptera, 82.

Nostril, of bird, 151; of fish, 112.

Nucleolus, 6.

Nucleus, 6, 11, 14.

Octopus, 106.

Okapi, 214.

Omnivorous, 47.

One-celled animals, 7.

Opossum, 197.

Oral surface, 35.

Orang, 227.

Order, 9.

Organ, 1.

Organism, 1.

Orthoptera, 82.

Osculum, 18.

Ovary, 25, 37, 117.

Oviduct, 46.

Oxidation, 3, 4, 5 .

Oxygen, 4, 5.

Oyster, 104.

Paramecium, 13.

Parasites, 49, 93.

Partridge, 178.

Pearls, 105.

Peccary, 217.

Perch, 109, 110, 123.

Pests, insect, 93.

Pheasant, 174.

Plastron, 141.

Pollen, 85.

Pollen basket, 88 .

Polyp, 9; 22, 125.

Portuguese man-o'-war, 28.
Potato bug, 90.

Primates, 220.

Proboscis, of butterfly, 83, 87;

elephant, 207.

Prolegs, 84, 87.

Protection of birds, 171.

Protective resemblance, 34, 146.

Protoplasm, 6, 11.

Protozoa, 7, 9, 11, 125.

Pseudoneuroptera, 82.

Pseudopod, 11.

Quill, 156.

Rabbit, 205, 223.

Radial symmetry, 34, 125.

Rattlesnake, 145.

Rectum, 134.

Regeneration of lost parts, 37 .

Reproduction, 12, 15, 20, 25, 37, 46, 120.

Reptiles, 139.

Rhizopoda, 16.

Road runner, 169.

Robin, 183.

Rotifer, 49.

Round worm, 49.

Ruminant, 213.

Salamander, 134, 138, 139.

Sandworm, 49.

San José scale, 95.

$\mathrm{Scab}$ in sheep, 95.

Scales, of bird, 161; fish, 110; moth, 89.

Scallops, 104.

Scarab, 90, 91.

Sea anemone, 33.

Sea fan, 32.

Sea horse, 124.

Sea urchin, 38.

Senses of insects, 76. 
Setæ, 43, 48.

Sexual selection, 174.

Shark, 121.

Silkworm, 84, 86, 95.

Silver scale, 83.

Siphon, 101.

Siphonoptera, 82.

Skeleton, of bird, 152; cat, 188 ; frog, 131 ; of fish, 113 ; chart of, 218.

Skull, mammalian, 194.

Slipper animalcule, 13.

Sloth, 199.

Slug, 105.

Snail, 105.

Soil, 48.

Sparrow, 182; English, 170.

Specialization, 20, 27, 66, 210.

Species, 8.

Spermary, 25, 27.

Spicule, 18.

Spider, 94.

Spiracle, 77, 87.

Sponges, 17, 125; glass, 19 ; horny, 19; limy, 19.

Sports, 148, 224.

Squash bug, 93, 95.

Squid, 106.

Stickleback, 119.

Struggle to live, 147.

Study, comparative, 82, 149, 223.

Sun energy, 2.

Sunlight, 2.

Survival of fittest, 147.

Tadpole, 126, 134.
Tapeworm, 49.

Tarantula, 94.

Teeth, of frog, 130.

Terrapin, 143, 144.

Toad, 137.

Tortoise, 140, 143, 144.

Trap-door spider, 94.

Tube feet, 35 .

Tumble bug, 90, 91.

Turtle, 140, 143, 144.

Umbo, 98.

Ungulate, 212.

Vacuole, 11, 12, 14.

Vampire, 203.

Variation, 147.

Variety, 8.

Venomous snakes, 143.

Vent, 42.

Ventral, 43.

Vernies, 9, 125.

Vertebrates, 9, 125.

Vertebrate skeletons, 218.

Viscera, of bird, 163.

Warning sound, 147.

Wasps, digging, 89.

Weevil, 90, 91, 96.

Whale, 208.

Wings, of grasshopper, 67; of bird, 153, 158.

Woodpecker, 180.

Worms, 42.

Zoology defined, 1.

Zoophytes, 33. 


Geo Lock hart

$$
\text { are.d }
$$

dip * jat wordalock Goncession 2 .

blandford

Axpond

Ontanio

Gomada

Main Comenca

Hew yarlid.

Hedem teinisp.

OH: impre

carla

flar ifytem 


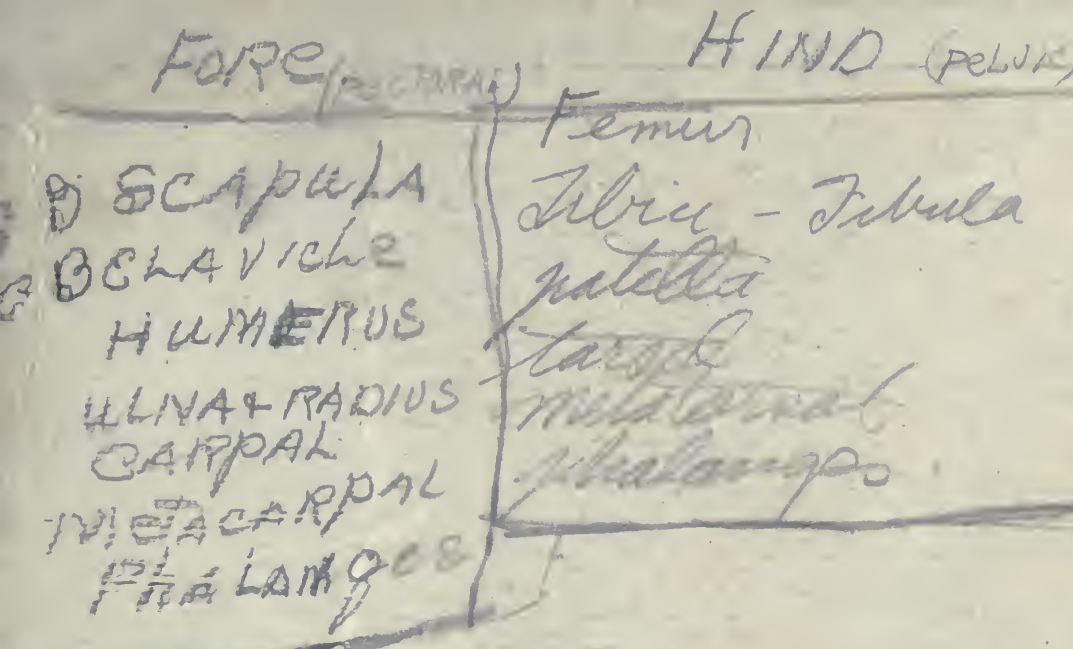


